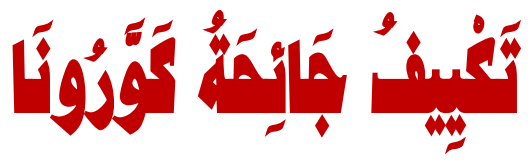

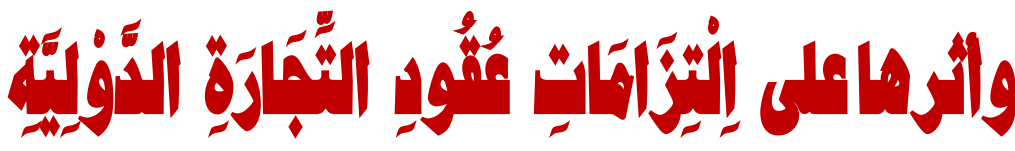

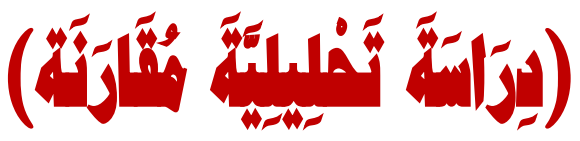 \\ كلية الحقوق - جامعة القاهرة
}

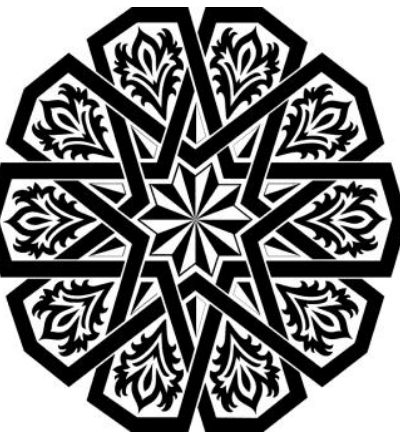

\section{موجز البحث}

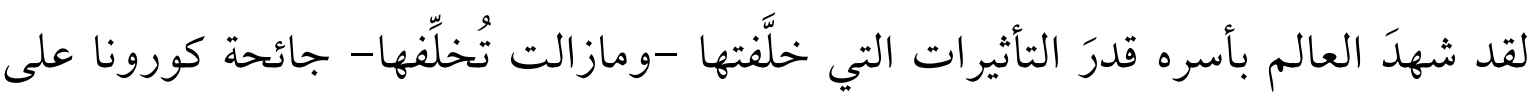
مختلف الأصعدة الصحيَّة والقانونيَّة والاقتصاديَّة العالميَّة، تلك التبعات التي سُطرّت في تاريخ

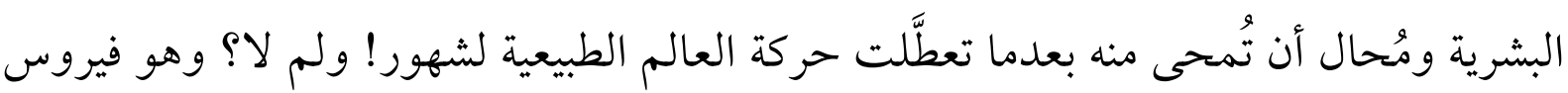
فتّاك، ولم يشهد العالم له نظير في ضراوته وشدة إبادته وسرعة انتشاره، وعدم وجود لقاح للوقاية منه. وفي خضم ملابسات جائحة هذه معطياتها كان مهمًّا الخوض في تبعات هذه الجائحة على هرئ مسألةٍ ذات بُعد دولي؛ ألا وهي عقود التجارة الدولية في محاولة لتكييف الجائحة بحذرٍ ودقة، نلوذ فيها بما لدينا من موروث علمي لنبحث فيه عن مسوغات تأييد الرؤى في موضوعيةٍ ورويَّةٍ

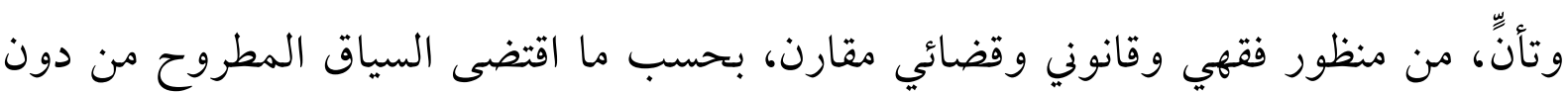

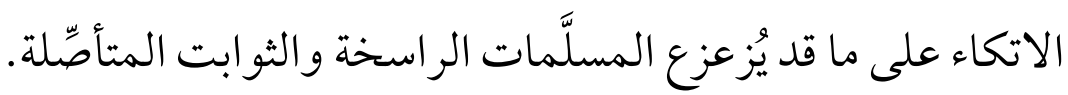

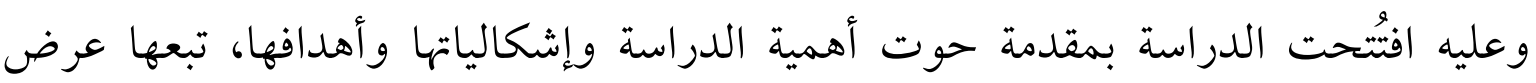
لمنهجية الدراسة وبيان حدودها ومنهجها الأنسب، وكذا خطتها، ثم انقسمت الدراسة إلى:

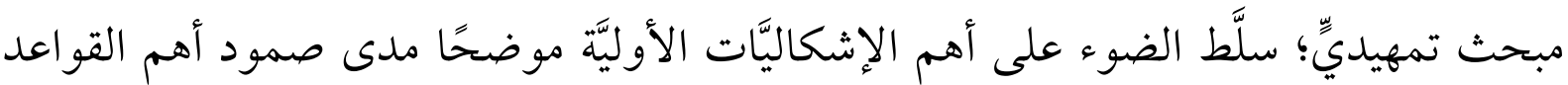
القانونية المستقرة المتعلقة بعقود التجارة الدولية أمام رياح الجائحة، ومدى خضوع جائحة كورونا للمقتضيات التقليدية لإنهاء عقود التجارة الدولية، ومدى سلطة القاضي، والتفرقة بين فرضي وجود نصِّ عقدي يبيّن موقف الأطراف من الأوبئة من عدمه، بالإضافة لإبراز بعض 
المفردات الموضوعية والزمنية لوضع عقود التجارة الدولية في ميزان الجائحة.

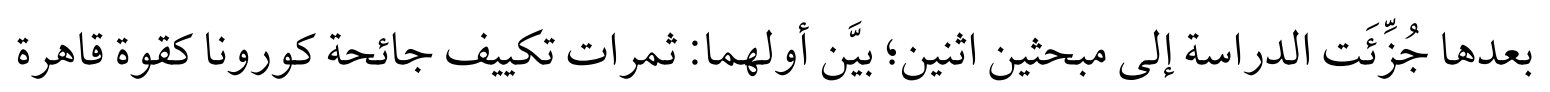
أو حادث فجائي، مما استوجب النظر في أمهات الكتب لاستخلاص مدى انطباق شروطها وآثارها، وماهية القانون الواجب التطبيق ولماذا، ونطاق تطبيقه، وتأصيل الحلول المنصفة التي يقدمها قانون العقد لأطرافه، ووازى ذلك إبراز مواقف القضاء المقارن؛ كالقضاء الفرنسي و المصري والأمريكي، وكذا القوانين المقارنة؛ كقانون العقود الإنجليزي والصيني، من دون إغفال بيان مو اقف الاتفاقيات الدولية والكيانات ذات الصلة، ثم الكشف عما أحيط بـ "شهادات القوة القاهرة" كقرينة قد تُعف المدين المتعاقد الذي تأثر وفائه بالتزاماته، ببيان طبيعتها القانونية،

و الدول التي طبقتها، ومدى إمكانية الاعتداد بها خارج محاكم الدولة التي أصدرتها. ووضَّح المبحث الثاني مسألة وضع جائحة كورونا في سياق نظرية الظروف الطارئة وإعادة التفاوض، لذا وضح آثار تكييف جائحة كورونا كظرف طارئ، وبيان مضمون إنزال شروط النظرية وآثارها، وإبراز دور قانون العقد، والرأي المقترح في شأن تكييف الجائحة كورونا، رافقه

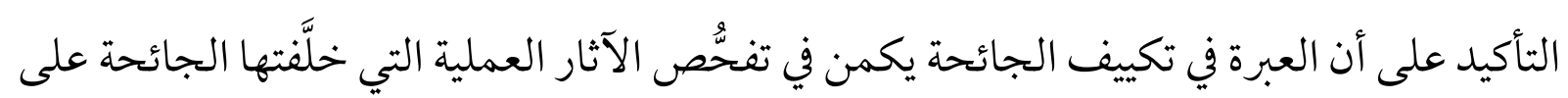

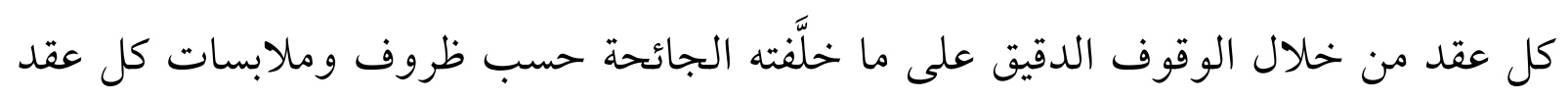
دولي على حدة، وكذا بيان آثار دور شرط إعادة التفاوض في طرح حلول لتأثير الجائحة، وتوضيح

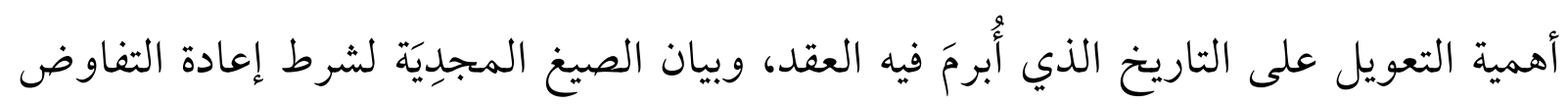

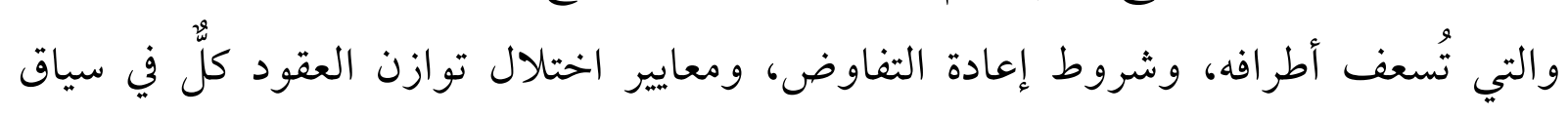
الجائحة، وفي سبيل ذلك بُنيت الدراسة على أربعة مناهج؛ هي: المنهج المقارن، والمنهج التحليلي، والمنهج التأصيلي، وكذا المنهج التاريخي. الكلمات المفتاحية : العقود التجارية الدولية ، التوصيف ، كوفيد9 1 ، القوة الجبرية ، المشقة ، القانون المعمول به ، إعادة التفاوض ، الحلول القانونية ، التحكيم التجاري الدولي الافتراضي ، الوساطة ، تسويات قانونية . 


\section{.Characterization Of COVID-19 Pandemic And Its Effects On International Commercial Contract Obligations An Analytical Comparative Study}

Haidy Eissa Hassan Ali Hassan

Department of Private International Law, Faculty of Law, Cairo University

E-mail : Haidy_eissa@cu.edu.eg

\section{Abstract :}

The entire world has witnessed, and is still witnessing, the effects of COVID-19 pandemic on various levels. It is impossible to erase its effects from human history because it disrupted the natural movement of the world for months! Why? Because it is a ferocious, deadly virus that has no match due to its rapid spread and the lack of vaccine for it.

Accordingly, the study starts with an introduction that provides an overview of the topic: its importance, problems, objectives, methodology, limits, and plan. The introduction also explains issues such as the stability of the relevant legal confirmed rules, the authority of a judge, and the difference between the existence and non-existence of a contract that shows the parties situation from epidemics.

The study is divided into two parts: the first part describes the effects of characterization of the COVID-19 pandemic as a force majeure, which requires consideration of the extent of its applicability as well as the effects of COVID-19. This part also discusses the applicable law, its scope of application, and the role of the contract law. This is further to an explanation of the positions of comparative judiciary such as the French, Egyptian and American judiciary as well as comparative English and Chinese contract law. The part also clarifies the role of the "certificates of force majeure", their legal nature, the countries that adopted them, and the extent of their applicability outside the courts of the State that issue them.

The second part puts the pandemic in the context of the hardship theory and renegotiation. This part discusses the applicability of the hardship theory condition to the COVID-19 pandemic and its effects, the role of the contract law, and the proposed opinion by affirming the importance of considering the circumstances of each international contract separately.

The second part also shows the dimensions of the role of the re-negotiation clause in resolving the effects of the pandemic on international trade contracts. It also highlights the importance of feasible formulas of the re-negotiation clause and the criteria for dealing with contract imbalance. The part concludes with the role of alternative means of resolving disputes, such as the role of virtual international commercial arbitration and mediation, along with a series of findings and recommendations.

Keywords : International commercial contracts, Characterization, COVID-19, Force majeure , Hardship, Applicable law, Re-negotiation, Legal Solutions, Virtual International Commercial Arbitration, Mediation, Amiable composition.

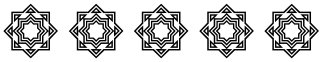




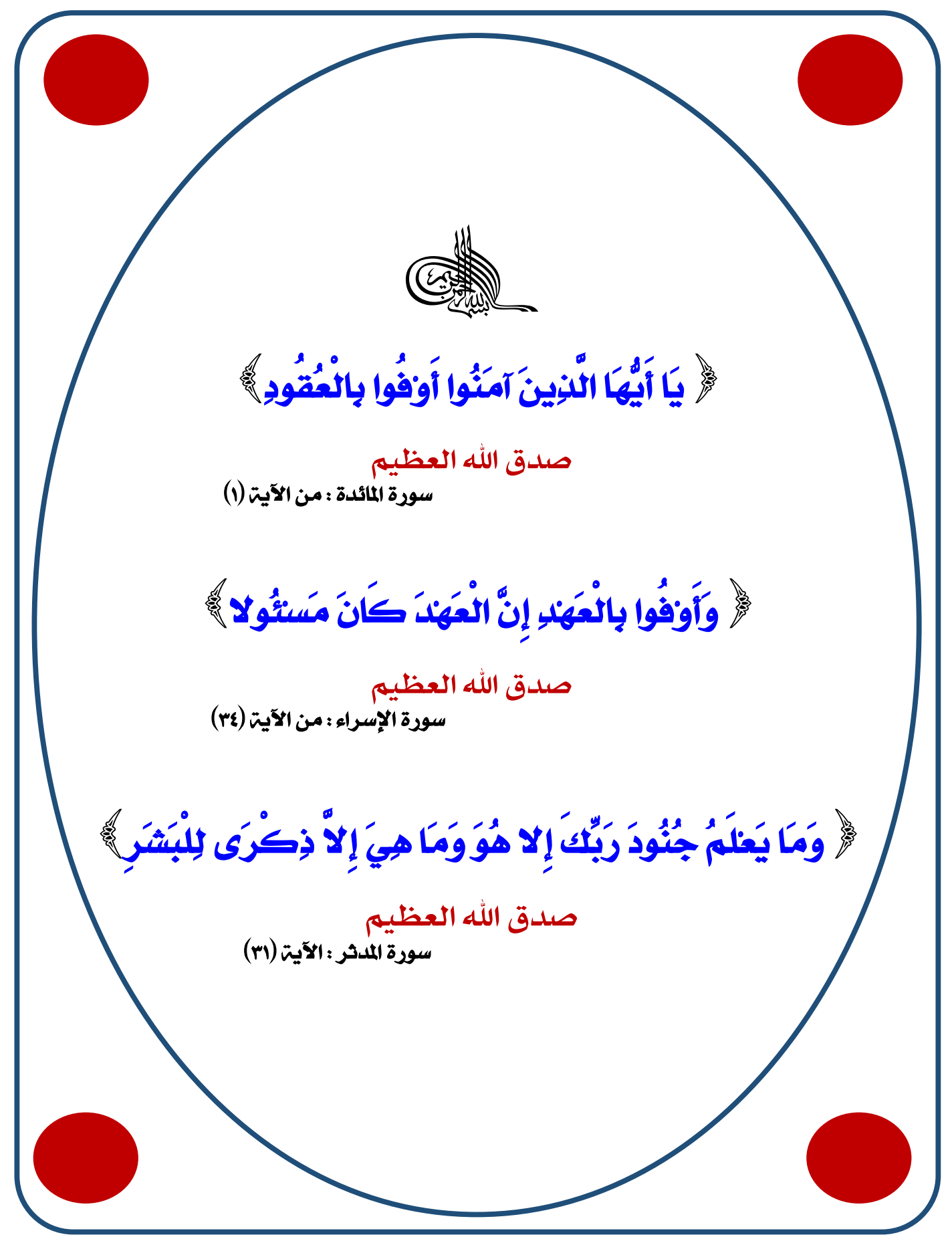




\section{تصدمبر}

لقد دارت حجج عديد من الآراء المؤيّدة لفكرة مقاضاة الصين عن الأضرار الناتجة عن فيروس كورونا في عدم اتخاذها للاحتياطات اللازمة الكفيلة باحتو اء تفشّي الفيروس في بدايته(1)، متفاديةً استفحاله ووصوله للنحو الذي آل إليه حال العالم، وجليُّ ما لهذه الرؤى والحجج من ارتداد لاتباع هدي خير البرية الذي لا ينطق عن الهوى في

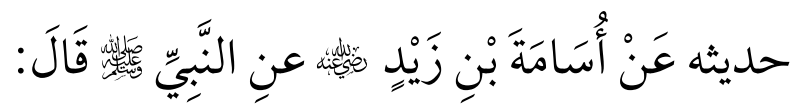

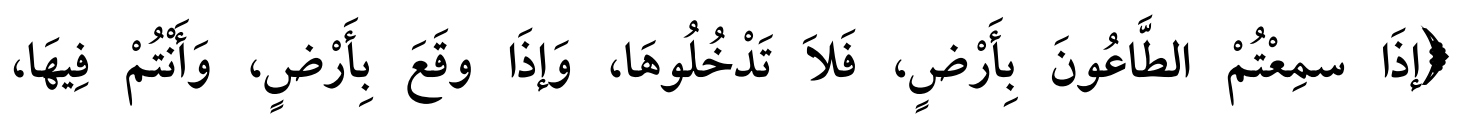
فَالكَتَخْرُجوُو امِنْهَا متفقِ عليهِ

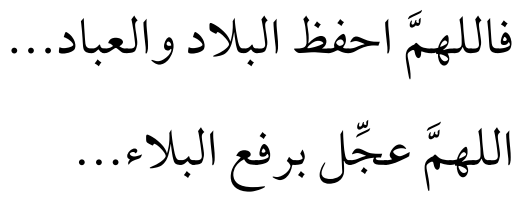
اللهُمَّ أهلَّ علينا العام الهجري الجديد بالعافية المجلَّلة ودفع الأسقام.

(1) سيقف متن الدراسة عند أنصار هذا الر أي بمزيد من البيان والتأصيل في مواضع عدَّة لاحقة كلّ في حينه حسبما

$$
\text { اقتضى السياق، وبخاصة في الفرع الثالث من المبحث الثاني؛ ومن هذه الآراء: }
$$

Zheng Sophia Tang, Zhengxin Huo, State immunity in global COVID-19 pandemic: Alters, et. al. v People's Republic of China, et. al., Issued by Conflict of Laws.Net official website, published on 21/03/2020.

Available online at, https://conflictoflaws.net/2020/state-immunity-in-global-covid-19-pandemic/ Last visit on $2 / 7 / 2020$.

$$
\text { (Y) طالع الرابط الإلكتروني الرسمي للشيخ ابن باز رحمه الله: }
$$

See at, https://binbaz.org.sa/audios/2476/561 , Last visit on 3/7/2020. 


\section{المقدمة}

الحمد لله أقصى مبلغ الحمد، الحمد لله حتى يرضى، الحمد لله على المعافاة، الحمد لله على بلائك، الحمد لله على جميع آلائك وألطافك الخفية، وصلاةً وسلامًا

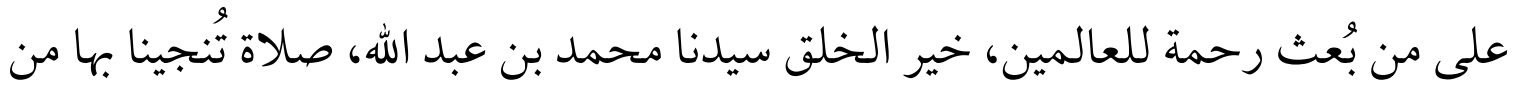

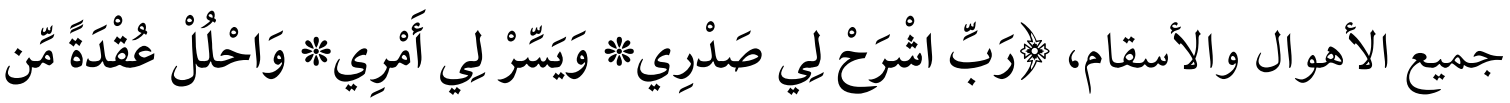

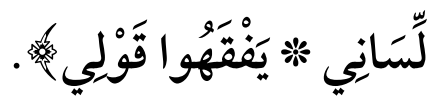

لقد اخترقت تداعيات جائحة كورونا الحدود الوطنية والدولية على حدِّ سو اء جرَّاء

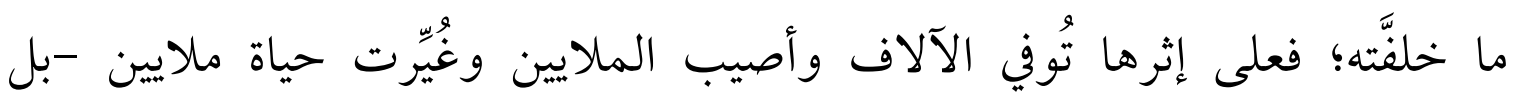
مليارات- غيرهم (1)! حتى أسفر تفشّي فيروس كورونا المستجد المسبب لمرض

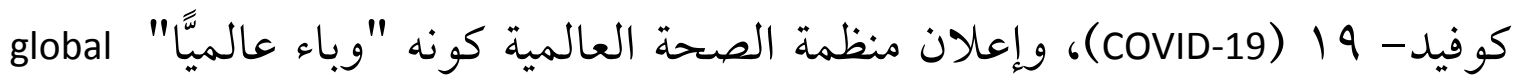
أن هرولت دول العالم واحدة تلو الأخرى في اتخاذ العديد من الإجراءات

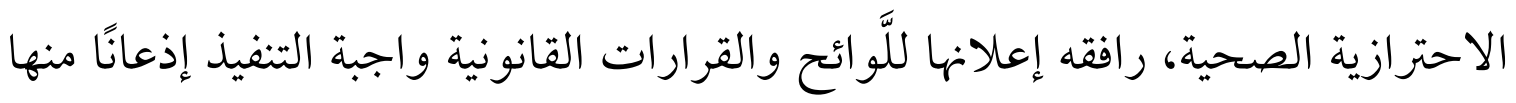
لجائحة صحية لم يسبق لها نظير ضربت الكرة الأرضية بأسرها وأصابتها في مقتل؛ رغبة ونس من هذه الدول في أن تَعبرُ مع شعوبها بسلام من هذه المرحلة الدقيقة من عمر البشرية، التي غيَّرت مجرى خطط الجميع. والشاهد أن الحياة قد تعطَّت في العديد من دول العالم، وهو ما خلَّفَ وراءه خسائر

(1) للاطلاع على التحديثات الرسمية لعدد الوفيات والحالات المؤكدة للإصابات، يمكن زيارة الموقع الرسمي

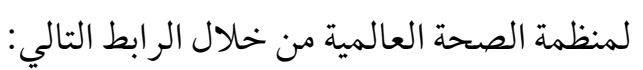

See at, https://covid19.who.int/?gclid=EAlalQobChMI1dHIvpmC6wIVFrTVCh37pQTGEAAYASABEgLCwfD_BwE, Last visit on 4/8/2020. 
جمَّة، امتدَّت لتشمل كافة الأصعدة؛ من بينها إحداث تأثير عظيم على الاقتصاد العالمي في ظل الآثار غير المسبوقة للجائحة، بعدما تأثَّ أو دُّرّ -بحسب تقرير جمعية هنري جاكسون- الاقتصاد العالمي"(1)! ولِمَ لا؟ وهي الجائحة -حسب وصف منظمة الصحة العالمية(()- التي قيل عنها إنها من أحلك ما مرَّت به الإنسانية جمعاء على الأقل من بعد

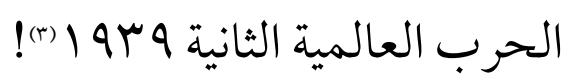

\section{أولاً: أهمية الدراسة}

في خضم التداعيات المذكورة كان طبيعيّا -حدَّ المنطقية- أن يصبح الوفاء بالالتزامات التعاقدية تحت وطأة هذه الظروف مستحيلًا، أو صعبًا ومرهقًا وأكثر كلفة على المدين، وهو ما دفع الفقه والكيانات الدولية إلى البحث عن أسانيد ومسوغات

(1) Matthew Hendreson, Alam Mendoza, et al, Coronavirus compensation? Assessing China's Potential Culpability and Avenues of Legal Response, Issued by Henry Jackson Society, April 2020.

Available online at, https://henryjacksonsociety.org/wp-content/uploads/2020/04/Coronavirus-Compensation.pdf , Last visit on 3/7/2020.

(r) ولقد قسَّمت منظمة الصحة العالمية انتشار الأمراض الوبائية إلى عدة أقسام؛ أولها: المستوطنة، وهي

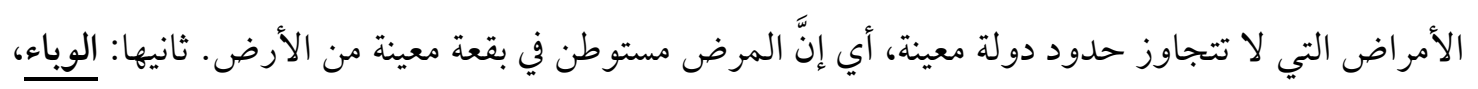

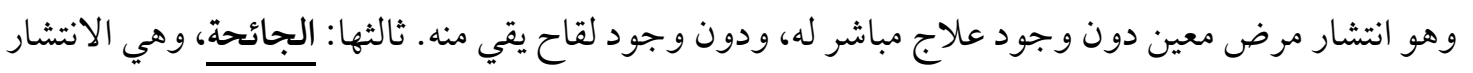
السريع في العديد من الدول بمختلف القارات والأقطار مع عدم وجود علاج مباشر له أو لقاح يقي منه، للمزيد انظر : د. أنس فيصل التورة، تأثيرات فيروس كورونا على عقد العمل بين الظروف الطارئة والقوة القاهرة، مجلة

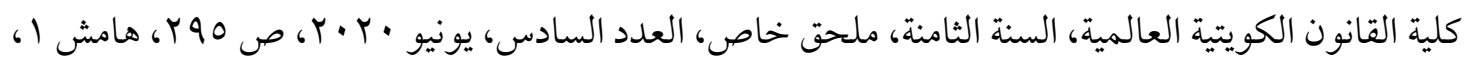

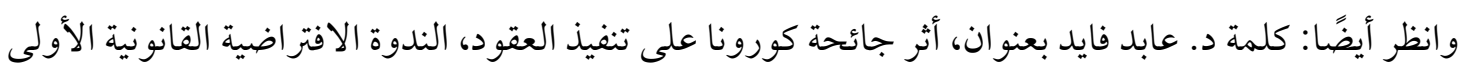

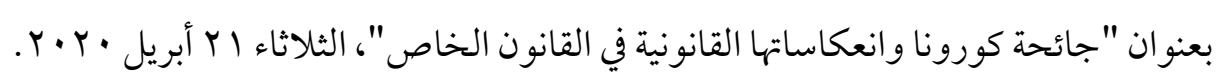

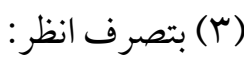

Klaus Peter Berger, Daniel Behn, Force Majeure and Hardship in the Age of Corona: A Historical and Comparative Study, McGill Journal of Dispute Resolution, Forthcoming, published also by SSRN, 14/4/2020, p. 2. 
قانونية ترفع الحيف الواقع حتمًا، أو حتى تبرِّر فسخ العقود -متى كان التنفيذ مستحيلًاأو إنهاءها، أو على الأقل تطلب إعادة التوازن المالي للعقد بعدما صار تنفيذه مرهقًا لأحد الأطراف، إلى غير ذلك من الحلول التي برُزت على الى الساحة.

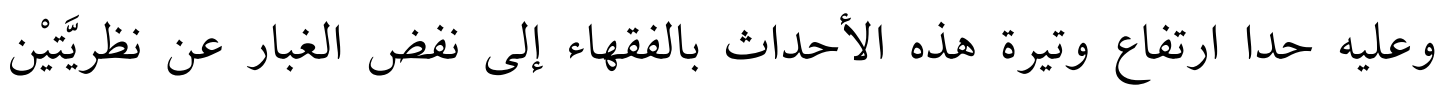

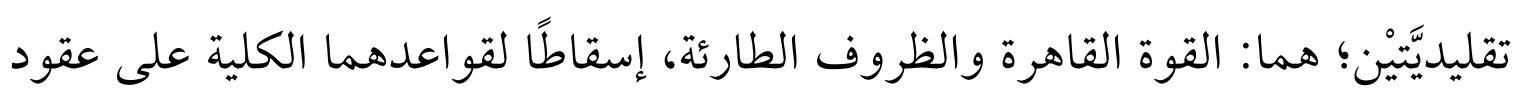

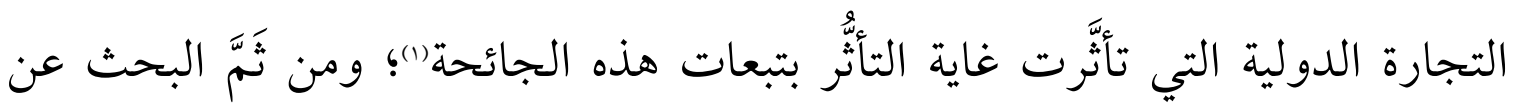

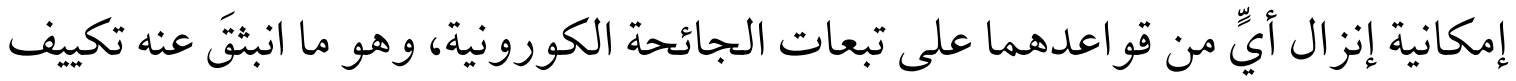
البعض الصريح للجائحة كقوة القاهرة FM تارة، أو كظرف طارئ تارة أخرى، وبطبيعة

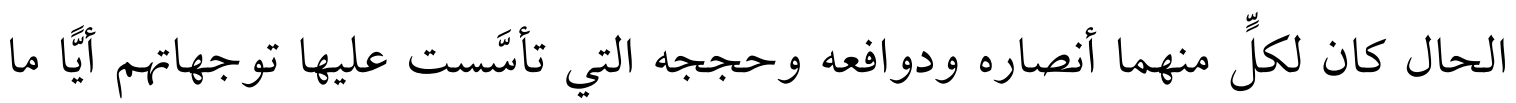
كانت، وما بين هذا وذاك وغيرهما درات رحى حلول قانونية أخرى كشفت عنها الدراسة، وسيُكشف عنها الستار لاحقًا. كما صاحب اجتهادات الفقه المذكورة في البحث عن حلول قانونية تتلاءم مع معطيات الجائحة، هرولة شركات المحاماة هي الأخرى لعرض خدماتها؛ هادفة إلى دعم أطراف العقود الدولية في وضع استراتيجيات سليمة بشأن مستقبل عقودهم ومساعدتهم في اختيار الحالّ الأنسب. ولنا في عقود المقاولات الدولية (فردية كانت أو شركات) مثالْ؛ فقد كان من آثار الجائحة عليها إحداث تأخير في مواعيد التسليم المتفَق عليها، مرورًا باحتمالات زيادة الأعباء المالية، ووصو لا إلى الإخلال بالتوازن المالي للعقد، بل استحالة تنفيذ العقد في

(1) Ibid, 2 
بعض الأحو ال، وهو ما انتفض بسببه كلُّ طرف متعاقد لَحِقِ به الضرر كي يدفع بالقوة القاهرة أو بالظروف الطارئة بغية الدفاع عن مصالحه لعدم قدرته على الوفاء.

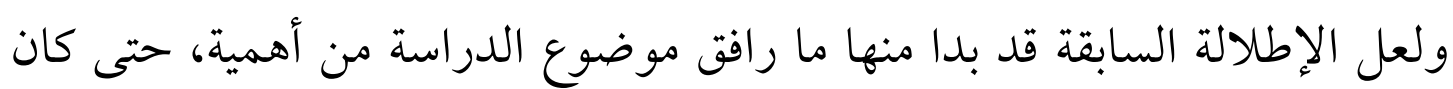
طبيعيًّ بعدها التساؤل المتشعب عن آثار تكييف جائحة كورونا على سياق التزامات عقود التجارة الدولية، مُعرِّين في ذلك على تأصيل القواعد القانونية الكلية ذات الصلة في محاولة لاستخلاص تبعات إنزال مقتضيات هذه القواعد على هذه الجائحة، ومن ثَمَّم السعي للخروج منها بحلول محددة تقليدية وحديثة في إطار نظري ممزوج بعملية التطبيقات القضائية والو اقعية المقارنة، ونقاشات الآراء الفقهية.

\section{ثانيًا- إشكاليات الدراسة}

إنَّ النظر في التبعات الدولية النيات لدائحة كورونا في سياق عقود التجارة الدولية يُنبئ عن

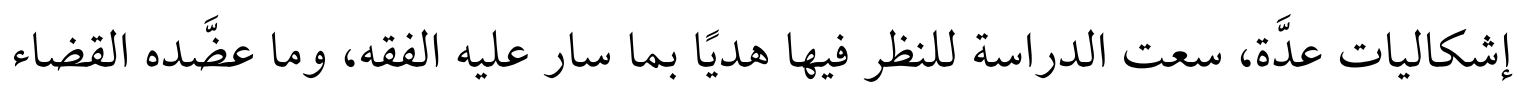
والقانون المقارن إثراءً للدراسة؛ فللدراسة إشكاليات عدَّة تتمثل في أن: - يُبحث عن مآل الالتزامات التعاقدية المتأثثّرة بتبعات جائحة كورونا، فالأمر لا يتعلق بالتزامات تعاقدية أبرمت قبل أن تستشري الجائحة فحسب، بل البحث -أيضًا - عن

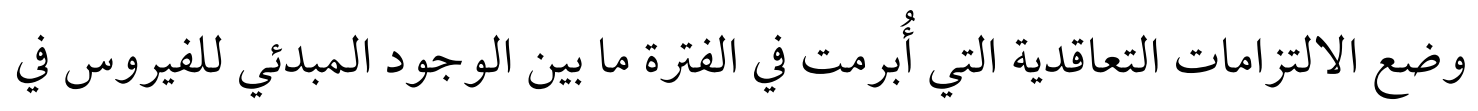

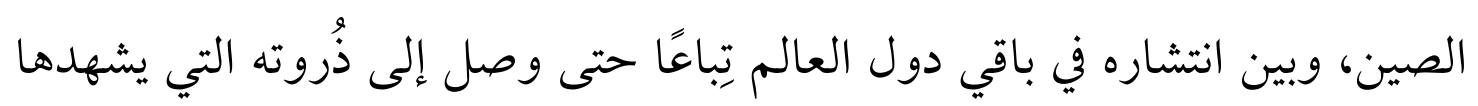
الكافة، وكذا التاريخ الواجب اعتماده لإعلان ظهور فيروس كورونا، موقف العقود المُجدَّدة؛؛

- يُبين مدى تأثير جائحة كورونا على ما استُقََّّ عليه من مبادئ قانونية ثابتة، والمفردات الزمنية والموضوعية لعقود التجارة الدولية في زمن الكورونا؛ 
- يُوضح آليات الدور الذي تؤديه النظريات القانونية الكلاسيكية المستقرة ذات الصلة في تكييف الجائحة، والموقف القانوني الفقهي والقضائي المقارن إزاء تتابُع النتائج

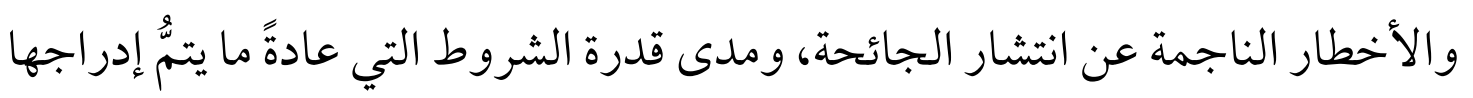

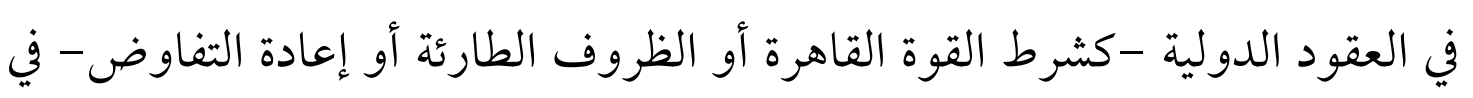
الحفاظ على التوازن المالي للعقد الدولي؛ - يُحدد الثمرات العملية التي أظهرها الواقع العملي لوضع جائحة كورونا في سياق مقتضيات نظريتي القوة القاهرة والظروف الطارئة، وييان أيٌّ من النظريَّيْنْ أولى بالاتباع دون غيرها، أو حتى حال وجود حلول أولى غيرهما مع طرح الحجج الداعمة، وإلَّا فما

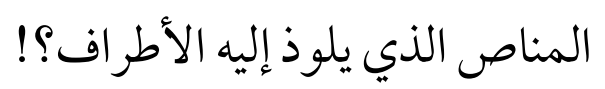

- يطرح مواقف الاتفاقيات الدولية ذات الصلة التي قد تُسعف في هذا المقام، وبيان

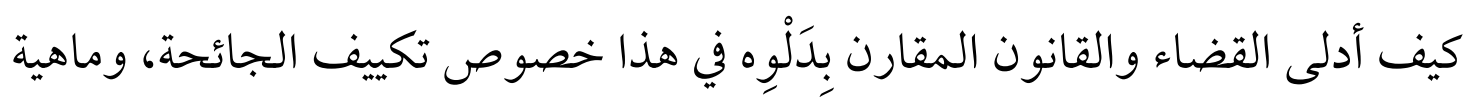
الثمرات ملموسة لهزا وذاك؛

- يُبين القانون الواجب التطبيق على العقود الدولية في خضم جائحة كورونا إذا جاز

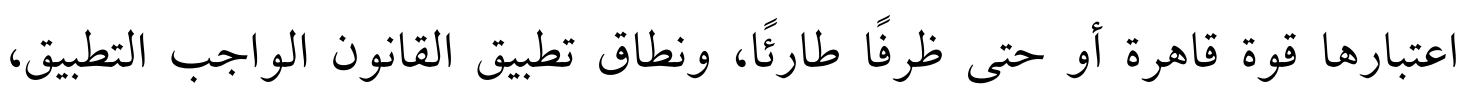

$$
\text { وتحديد أيّ قانون هو الأولى بتكييف الجائحة؛ قاهرة }
$$

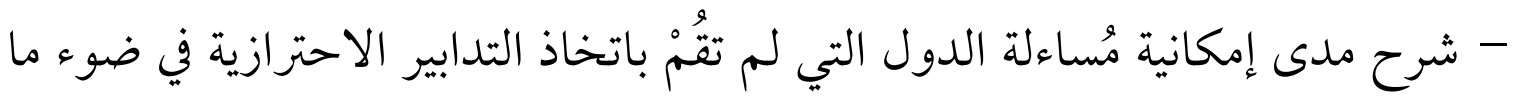

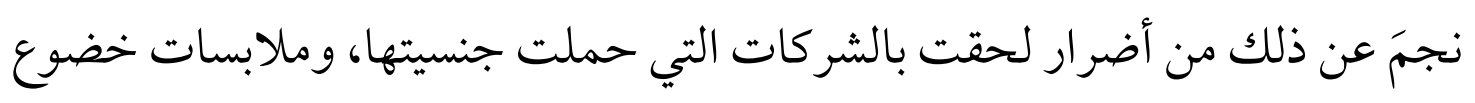
عقود التجارة الدولية للفسخ القضائي جرَّاء ما خلفته الجائحة، ومدى اختلاف الحال

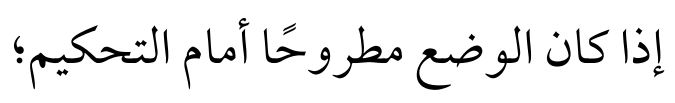

- يبحث عن جدوى الشروط التعاقدية التي يتمّ إدراجها في العقود الدولية في الحفاظ 
على التوازن العقدي كشرط إعادة التفاوض، ومن قبلها ما هي آليات الإدراج

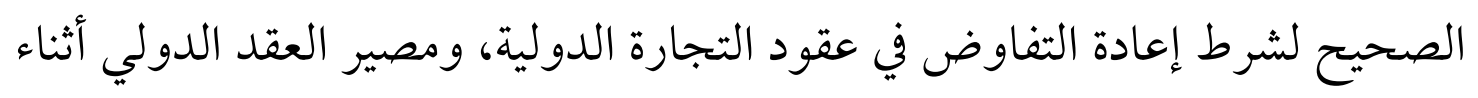

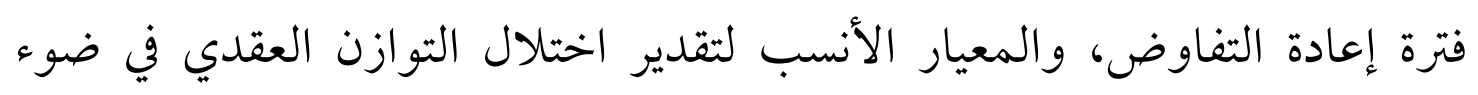

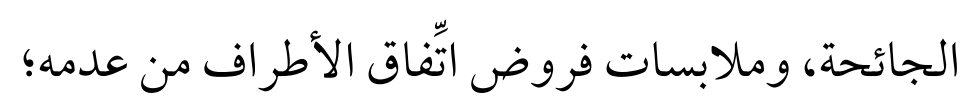

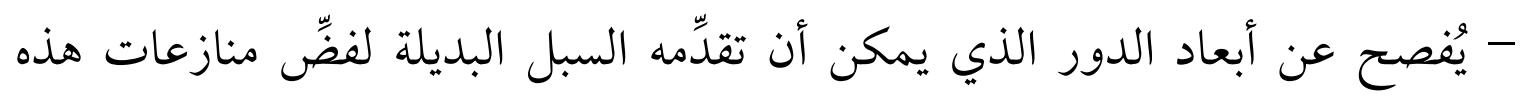

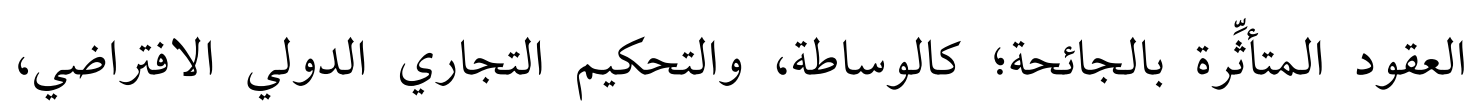

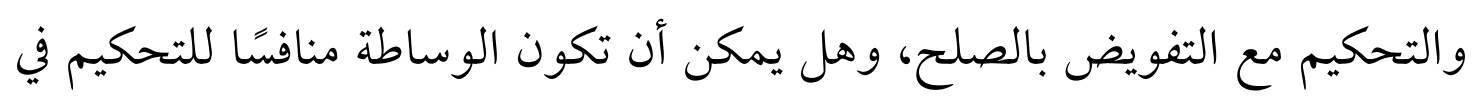
هذا الخصوص؟ وفي هذا المقام يتعيَّن التأكيد على أن ما ذُكر -أو بالأحرى ما تناولته الدراسة- يكمن

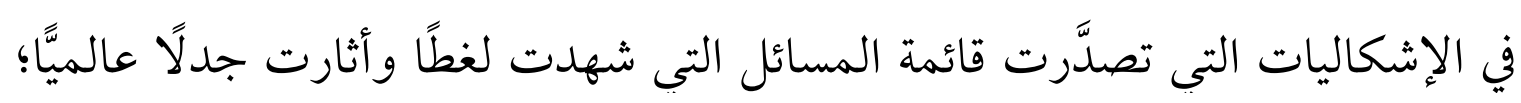

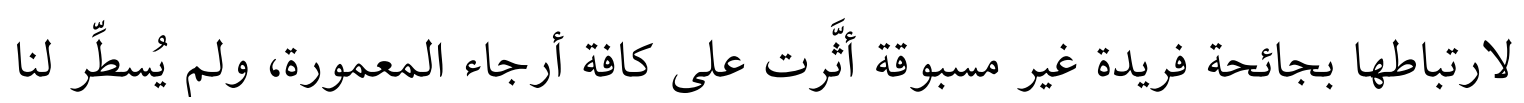
التاريخ مثلها في خطر العدوى منها، وعدم وجود لقاح لها؛ فحتى إن مرَّت البشرية بأوبئة البهاء

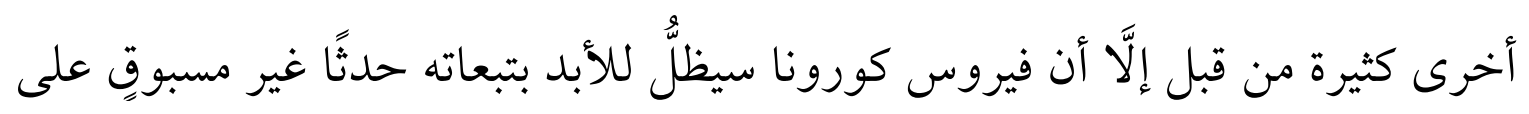
كافة الأصعدة الصحية والقانونية والاقتصادية والاجتماعية وغيرها.

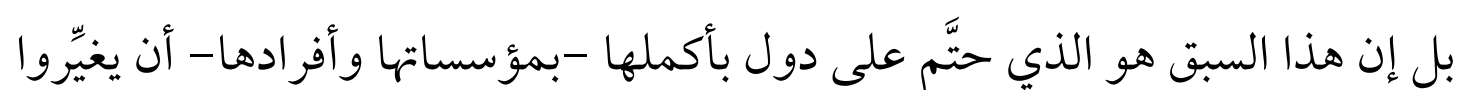

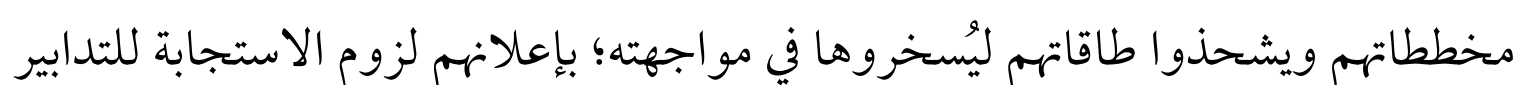

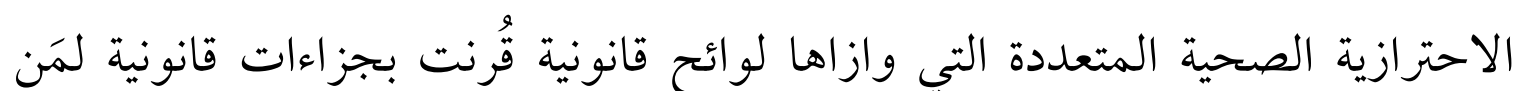
يخالفها أَذعن لها الجميع؛ كغلق الحدود بين الدول والمطارات، وتعطُّل وسائل النقل

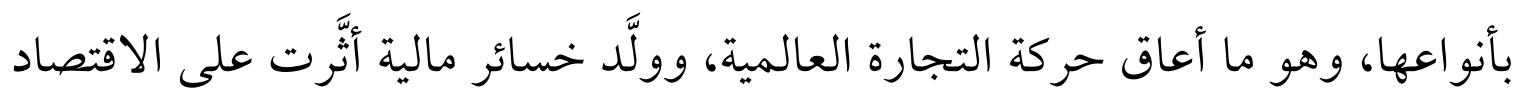
العالمي. 


\section{ثالثأ- أهداف الدراسة}

بالنظر لما رافق فكرة البحث من غموض نسبي تجلَّت بعض ملامحه من عرض ألدراف إشكالياته، شقَّ البحث طريقه للنور؛ بغرض أن:

- يُبيِن ماهية وضع الالتزامات التعاقديَّة التي تمَّ إبر امها قبل الجائحة وبعدها؛

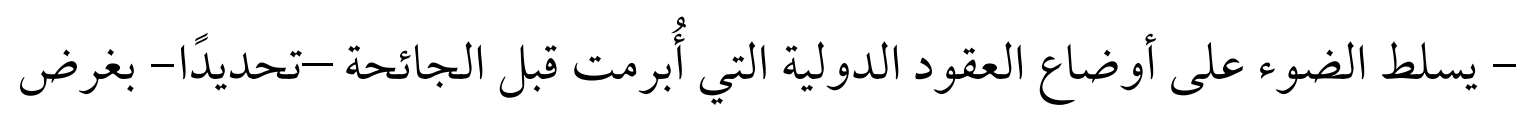
إعلام الأطراف المتعاقدة بالحلول القانونية للخروج من هذه الجائحة بأقل الخسائر، بعدما أضحت واقعًا ملموسًا يُراودنا مهما حاولنا غضَّى الطرف عنه، وبات من المستحيل التغاضي عن آثارها لعدم قدرة الأطر اف التعاقدية على الوفاء بالتز اماتهم؛ - يُبرز الآليات القانونية للتصدِي للآثار الجليَّة لهذه الجائحة على الالتزامات التعاقدية الدولية التي تكفل للأطر اف الخروج من هذا النفق المظلم؟ - يكشف عن الحلول القانونية الأبرز المتاحة، من خلال التأكيد على مسوِّات وحجج الآراء الأَّلى بالاعتداد من خلال النظر في التداعيات والمستجدات بطريقة

$$
\text { موضوعية محايدة؛ }
$$

- يتصدى تصديًا مباشرًا للمسائل محلّ التناول بالبحث و التأصيل؛ وذلك بغرض

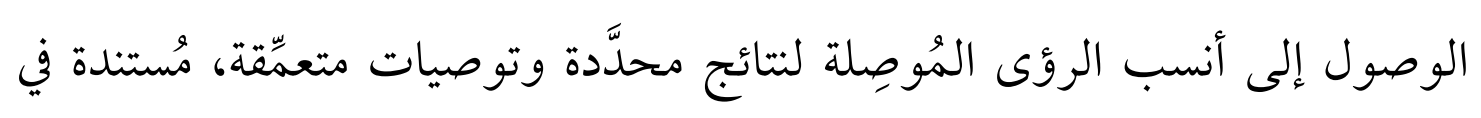
ذلك إلى أسس قانونية وعلمية وواقعية رصينة.

\section{رابعًا- منهفج الدراسة}

امتثلت الدراسة -وهي في سبيل معالجة الموضوع- على أربعة مناهج، حسب ما كان منها مُعينًا ومناسبًا لموضوع البحث؛ أوَّلها: المنهج المقارن؛ إذ أثرى الدراسة إجراء المقارنة بين مواقف الفقه والقضاء المقارن من تكييف جائحة كورونا، وغيرها من 
المسائل التي اعترضت سبيل الدراسة، حسب ما ارتأيته مُثيرًا للأهمية، وداعيًا للذّّكر. وثانيها: المنهج التحليلي؛ إذ سعت الدراسة إلى إجراء تحليل مناسب للمسائل ذات الصلة التي كانت محلَّا لذلك، مع عرض الآراء التي خدمت البحث، وبيَّنت ما أقيمت عليه من حجج وأوجه نقد أينما وجدت. وثالثها: المنهج التأصيلي؛ وذلك عبر إجراء التدقيق والملاحظة لبعض التطبيقات من خلال در استها وتحليلها، ثم محاولة الوصول إلى قو اعد عامة تحكمها. ورابعها المنهج التاريخي؛ وذلك في خصوص بعض زوايا البحث التي سُلِّط فيها الضوء على مسألة معينة في زمن سابق عن الزمن الذي يُعاصره البحث، وبما أنَّه عادة ما يُستخدم هذا المنهج في التقديم؛ فقد استَّعى الأمر وجوده في بعض مواضع البحث، وبخاصة عند البيان الموجز لتاريخ الأوبئة التي مرَّت بها البشرية").

\section{خامسئا- خطة الدراسة}

لقد ارتأيت بعد الخوض في صميم المراجع الورقية والافتراضية لهذه الدراسة أنَّه من الأنسب أن تأتي خطتها على: مبحث تمهيدي يعقبه مبحثين رئيسيين يُفِّلان مضمون ما حملته الدراسة؛ وذلك على النحو الآتي: مبحث تمهيدي: إشكاليات أوليَّة تتصل بعقود التجارة الدولية في زمن الكورونا. المبحث الأول: آثار تكييف جائحة كورونا كقوة قاهرة أو حادث فجائي. المبحث الثاني: جائحة كورونا بين الظروف الطارئة وإعادة التفاوض.

(1) لمزيد من التفاصيل عن مناهج إعداد البحوث العلمية انظر : د. أحمد عبد الكريم سلامة، الأصول المنهجية

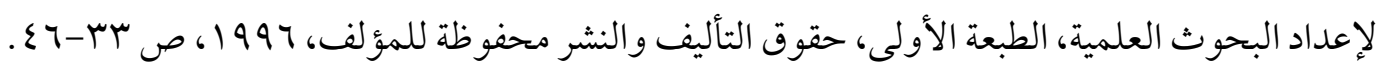




\section{مبحسث ثمهريد \\ إشكاليات أوليَّة ثتصل بعقود التبارة الثدولية في زمن الكورونا تمهيدٌ وتقسيمٌ:}

إنَّ الخوض في سياق تأثير ات الجائحة الكورونية على عقود التجارة الدولية أمرّ جدُّ متشعِبِ، ليس فقط بالنظر إلى عموم هذه التأثيرات، بل -أيضًاـ- امتثالًا لما تقتضيه التجارة عمومًا -بما فيها عقودها- من سرعة ومرونة وإعلاء لإرادة الأطراف، وعليه كان مهمًّا الوقوف عند هذا المبحث التمهيدي لِيْمَِّد ما ستتناوله الدراسة. لذا قُسم المبحث إلى مطلبَين اثنين؛ تناول أولهما ماهية التأثيرات التي فرضتها الجائحة على ما هو مستقَّرّ عليه من مبادئ قانونية ذات صلة بعقود التجارة الدولية في عموم القول؛ من زاوية مبدأ العقد شريعة المتعاقدين، وموقف نظرية تبديل الأحكام أو النصوص العقدية بتبدُّل الظروف، ومدى امتثال جائحة كورونا لآليات انقضاء العقد الدولي كفكرة مجملة من ناحية أخرى، ثم سلَّط ثانيهما الضوء على المفردات الواقعية الناجمة عن جائحة كورونا في سياق عقود التجارة الدولية من الناحيَّيْن الموضوعية والزمانية.

\section{المطلب الأول \\ علاقة جائحة كورونا بالمبادئ القانونية المستقرة المسارة في عقود التجارة الدولية}

تمهيدٌ وتقسيمٌ:

لقد تخطَّت الأزمة الكورونية في تداعياتها حو اجز الحدود الوطنية، وأثرت بمفاعيلها القانونية على كافة الأنظمة القانونية حول العالم، وشكَّلت -بلا ريب- "أزمة قانونية" واختبارًا حقيقيًّا مباشرًا لمدى كفاية النصوص ونجاعة التحليل في إيجاد تكييف قانوني 
لها، من خلال الثابت من المفاهيم والمبادئ التي دأبت النظم القانونية قاطبة على ترسيخها و العمل بهَذِيهِا منذ عقود مَضَتِ (1).

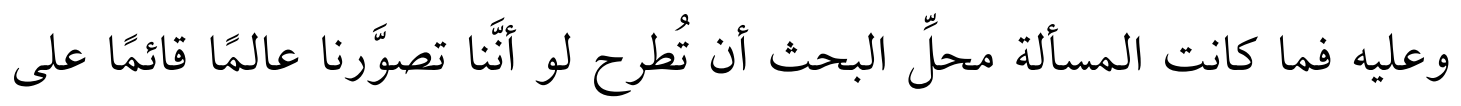

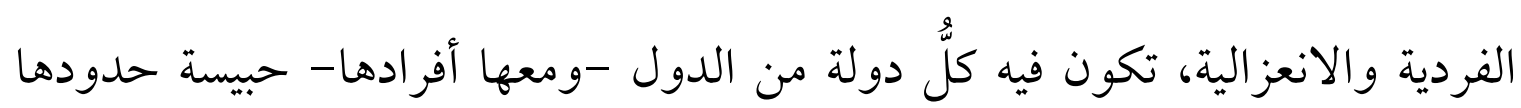
منكفئة على نفسها لا تتعامل مع أحد، ففي مثل هذه الأحوال ستكون العلاقات وطنية بحتة يحكمها في كافة مراحلها -من النشأة إلى الانقضاء- قانون واحد هو القانون

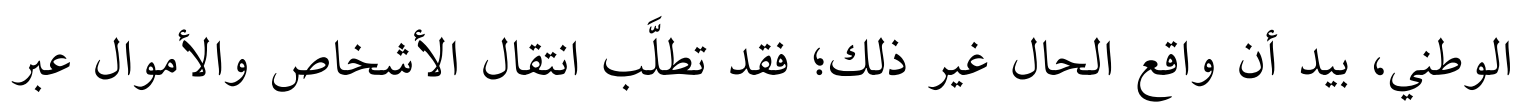

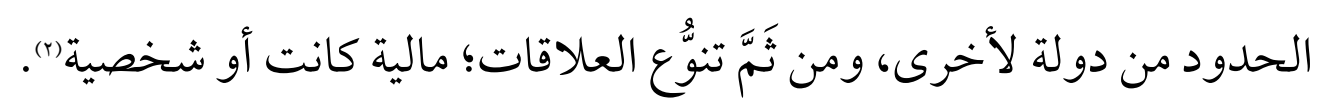
ولمَّا كانت تأثيرات فيروس كورونا على العقود الدولية قد اتَّصلت بما هو مستقَّرّ

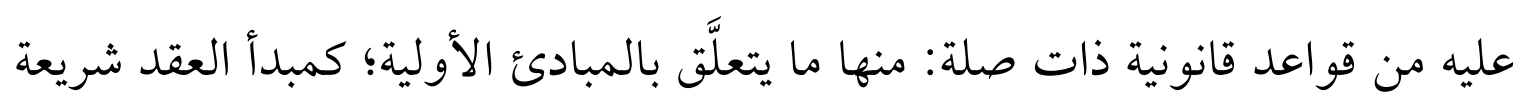

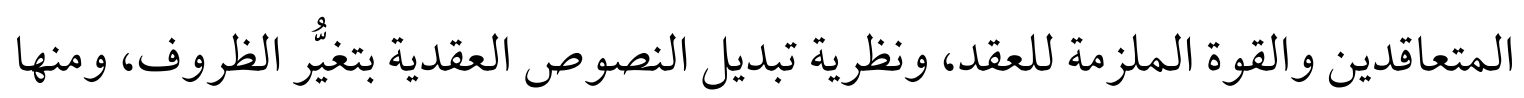

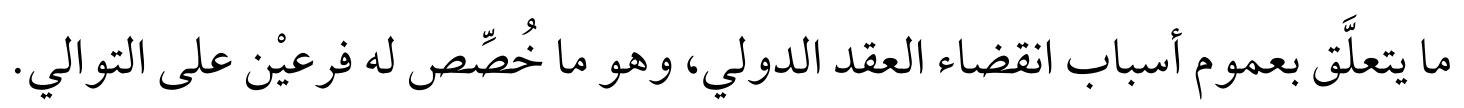

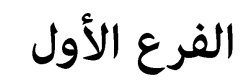

\section{أثر جائحة كورونا على مبدأ القوة الملزمة للعقد}

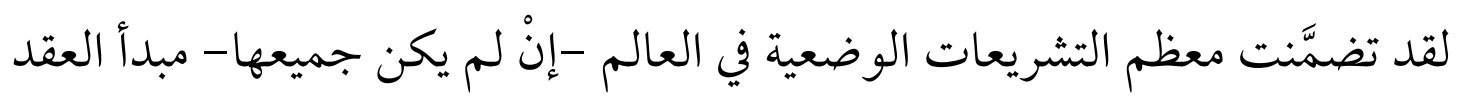

(1) بتصرف، د. محمود المغربي، د. بلال صنديد، التكييف القانوني للجائحة "الكورونية" على ضوء الثوابت التباتي

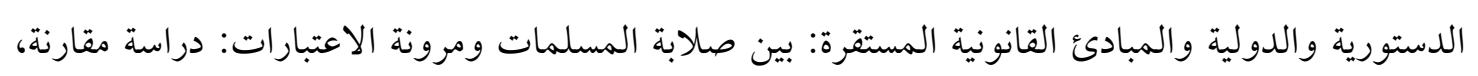

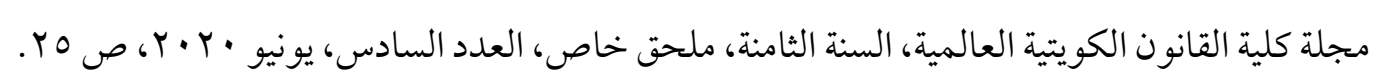

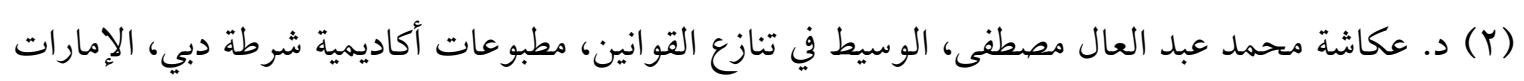

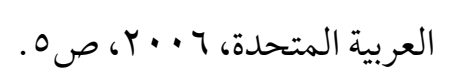


شريعة المتعاقدين Pacta sunt servanda، المرادف للقوة الملزمة للعقد")، فهو مبدأ تاريخيُّ عريق؛ وُجِد منذ العصور الوسطى (()، ومبدأ جوهريٌّ ظلَّ منذ ظهوره له قدسية لارتباطه بالدين و الأخلاق (r).

ولمَّا كان المآل الأساسي للالتزامات التعاقدية هو الوفاء بها وتنفيذها تنفيذًا عينيّا مادام هذا التنفيذ ممكنًا، فماذا لو استحال هذا التنفيذ لقيام عذر يَحول بين المدين و الوفاء بالتزامه، هنا يمكن للمدين أن يستعفي من تنفيذ التزامه()؛ لأنَّ الأصل أنَّ العقد إذا انعقد صحيحًا مستوفيًا أركانه وشروطه صار ملزمًا لطرفَهْ وأنتج بالتالي آثاره الموضوعية، وتعيَّن على كلٍ منهما أن يقوم بتنفيذ الالنزامات الناشئة عنه، وهذا هو صميم القوة الملزمة للعقد؛ فآثاره من حيث الموضوع يُعبَّر عنها بأن العقد شريعة المتعاقدين، لا يجوز نقضه أو تعديله إلا باتفاق المتعاقدين، أو للأسباب التي يقرِّرها

(1) المادة (I I / I ) من القانون المدني المصري، في تفصيل هذه القاعدة، انظر: د. عبد الرزاق السنهوري، الوسيط في شرح القانون المدني الجديد، الجزء الأول، نظرية الالتزام بوجه عام، مصادر الالتزام، الطبعة الثالثة،

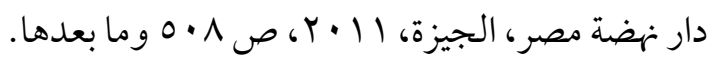

$$
\begin{aligned}
& \text { (r) وفي الأمر تفصيلات عدَّة لا يتسع المقام للوقوف عندها، راجع: }
\end{aligned}
$$

Marcel Fontaine, The evaluation of the Rules on Hardship from the First Study on Hardship Clauses to the Enactment of specific Rules, Published in Hardship and Force Majeure in International Commercial Contracts: Dealing with unforeseen events in changing world, Edited by Fabio Bortolotti, Dorothy Ufot, Issued by ICC, 2018, Ch. 1, para II.A, para 65.

(r) د. خالد منصور إسماعيل، إشكاليات التحكيم في منازعات عقود النفط: در اسة معمقة وفقًا للتشريعات الوطنية والاتفاقيات الدولية وأحكام التحكيم الدولية المتعلقة بمنازعات النفط، مكتبة القانون والاقتصاد، الرياض،

$$
.279=6 \cdot 10
$$

(ع) راجع: كلمة د. جابر محجوب، أثر جائحة كورونا على تنفيذ العقود، الندوة الافتراضية القانونية الأولى بعنوان

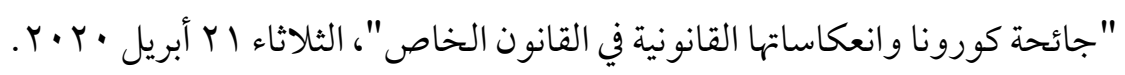


القانون(1)، تأكيدًا على مبدأ الرضائية في العقود، وأنه مصدر القوة الملزمة للعقد، لكنَّ

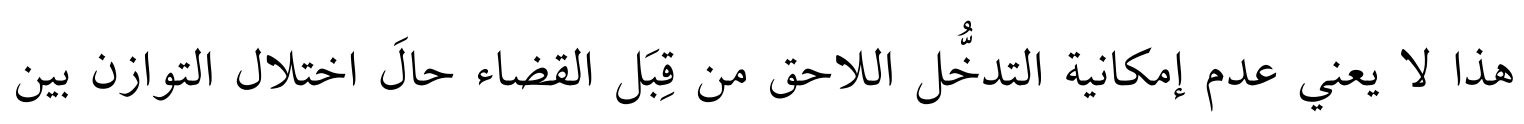
الأطراف لأيٍّ من العوارض؛ كحصول الجائحة").

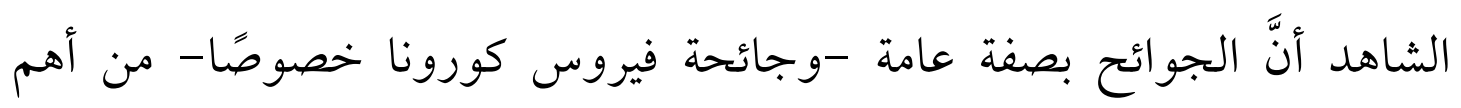

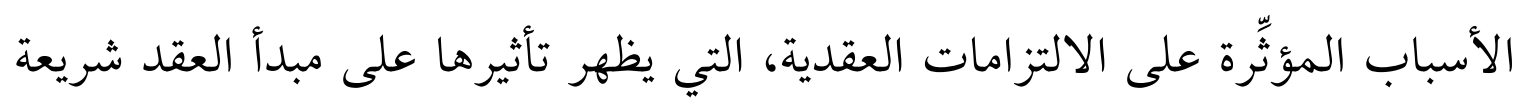

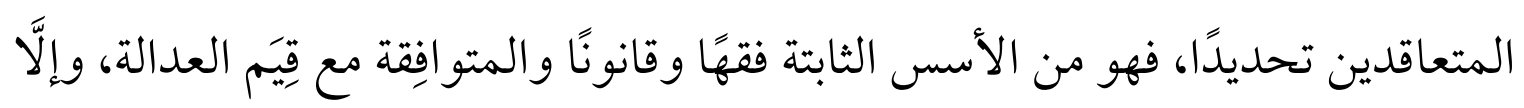

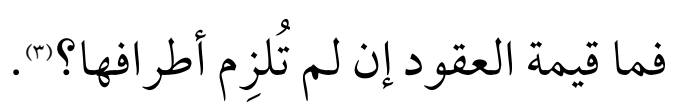

وعليه فقوة الإلزام التي منحتها هذه القاعدة للعقد ليست مطلقة، فالعدالة في منحها قوة الإلزام هي التي تسمح باستثناءات عليها، لكن يَلَزم أن تكون الاستثناءات واضحة،

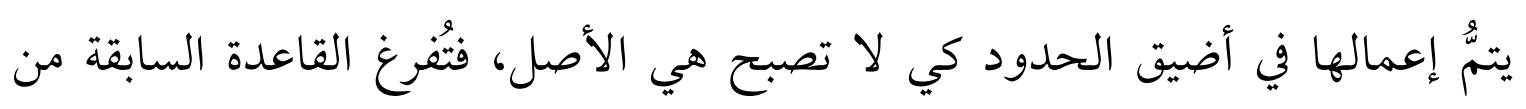

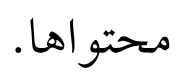
وبالنظر إلى جائحة كورونا فقد سبَّت خسائر اقتصادية جمَّة للعديد من الشركات التجارية، وهو ما حاولَتْ على إثره تعديل عقودها أو حتى فسخها إلى غير ذلك إنى إنى لذا

\section{(1) لمزيد من التفاصيل حول تاريخ المبدأ، انظر:}

Klaus Peter Berger, Daniel Behn, Force Majeure and Hardship in the Age of Corona: A Historical and Comparative Study, op, cit., pp. 6-8.

(Y) د. ياسر عبد الحميد الإفتيحات، جائحة فيروس كورونا وأثرها على تنفيذ الالتزامات العقدية، مجلة كلية

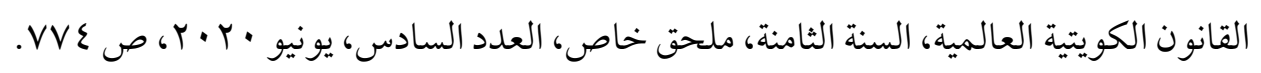

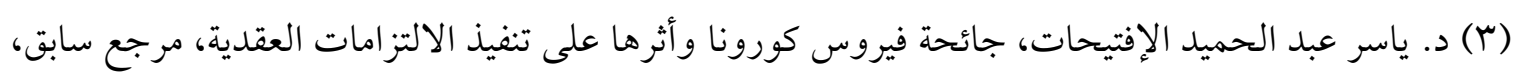

$$
\text { ص (ع ) الموضع السابق ذاته. }
$$


قيل بأن الإقرار بمبدأ القوة الملزمة للعقد بصفة مطلقة يتنافى في كثير من الحالات مع اعتبارات العدالة، وعليه نُودي في أعقاب جائحة كورونا بـ "نسبية مبدأ القوة الملزمة للعقد" كي لا يطبَّق المبدأ على إطلاقه على كافة العقود".. وثمَّة نظرية أخرى ترتبط بالعقود الدولية قد تأثَّرَت هي الأخرى بالجائحة، ورغم ذلك أغفلت العديد من المراجع -التي تناولت المسألة محلَّ البحث- الوقوف عندها؛ ألا وهي نظرية تبديل الأحكام أو النصوص بتبدُّل الظروف، وستقف الدراسة عند مدى امتثال مقتضيات النظرية لآثار جائحة كورونا، وإبراز ما بينهما من علاقة فيما يلي. بين مبدأ العقد شريعة المتعاقدين ونظرية تبديل الأحكام أو النصوص بتبدّل الظروف: لعلَّ من الأَّْلى قبل الخوض في تبعات تأثير فيروس كورونا على عقود التجارة الدولية أن نقف عند العلاقة بين مبدأ العقد شريعة المتعاقدين -كمبدأ أصيل - ونظرية تبديل الأحكام بتبدُّل الظروف، تلك العلاقة بين الفكرتيْن الأساسيتْن التي وُصِفت بأنَّها صراع أبديّيّ بين الاستقرار ومرونة العلاقات (r). فلقد أظهر الواقع العملي -بشكل عام- أنَّ هناك أعدادًا هائلة يصعُب حصرها من الظروف المتغيِّة في مُجمَل مجتمع التجارة الدولية -بصرف النظر عن جائحة كورونا-؛؛ تكون فيها مثل هذه التغيّر ات في الظروف متعلقة بأيِّ مسألة تجارية كانت، أو فنية، أو

(1) د. إبراهيم أحاطب، فيروس كورونا "كوفيد 19 " بين القوة القاهرة ونظرية الظروف الطارئة، مقالة منشورة

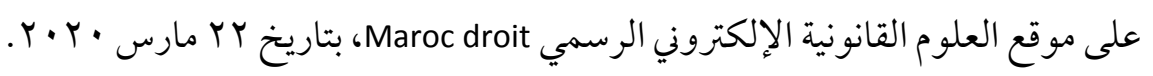
See at, https://www.marocdroit.com, Last visit on 16/6/2020.

(2) "The eternal conflict between stability and flexibility of contractual relations"; Klaus Peter Berger, Daniel Behn, Force Majeure and Hardship in the Age of Corona: A Historical and Comparative Study, op, cit., p. 4. 


$$
\text { سياسية، أو حتى بيئية إلى غير ذلك"(1). }
$$

وبناءً على طبيعة هذه النظرية فالحاجة إلى إقامة توازن بين الفكرتين هي حاجة

ملحَّة، وتحديد أيِّ من هذيْن المبدأين هو الذي يسود في كلّ قضية بعينها طالما تغيَّرت

ظروفها، هو شأن يعتمد على مدى القوة التي يوليها الاختصاص القضائي المَعني لمبدأ العقد شريعة المتعاقدين، بل وعلى استعداد المحاكم والفقه ومعها الأطر اف على حدٍ سواء لقبول استثناءات عادلة على مبدأ العقد شريعة المتعاقدين؛ كتلك التي تسبَّبت فيها جائحة كورونا.

وبالنظر لقانون العقود الدولي؛ فقد قُبَلت -ومنذ فترة طويلة- استثناءات "منصفة" على مبدأ العقد شريعة المتعاقدين في أوجه مختلفة لمبدأي القوة القاهرة والظروف الطارئة بدرجات متفاوتة) وإجمالًا: فما ظهر من ظروف متغيِّة لاحقت مجتمع التجارة الدولية -من قبل جائحة فيروس كورونا- حيث تكون الظروف المحيطة في العقود طويلة الأجل مدعاة لإعمال مقتضيات نظرية تبديل النصوص أو الأحكام الخاصة بالعقد بتغيٌّ الظروفclausula rebus sic stantibus كردّ لمثل هذه الظروف التي من بينها ما فرضته جائحة كورونا، وإلَّا فلربما تتحوَّل القوة الملزمة للعقد إلى قيود. وعليه تسمح النظرية محلَّ التناول للأطراف بتحرير أنفسهم من التطبيق الصارم لمبدأ العقد شريعة المتعاقدين، وتفاديًا للاستمرار في تنفيذ العقد رغم تلك الظروف Ibid. 4-6, ft. 16.

(2) Ibid. 10, ft. 52. 
تعويلًا على فكرتئي الإنصاف وحسن النية؛ فنظرية تبديل النصوص العقدية بتغيُّ الظروف هي المبدأ القانوني الذي يسمح لعقد أو معاهدة أن تصبح غير قابلة للتطبيق

$$
\text { بسبب تغيير جوهري في الظروف (1). }
$$

وثمَّة شروط أربعة أبنأت عنها السوابت القضائية يتعيَّن توافرها لكي يتمّ تطبيق فكرة

نظرية تبديل النصوص أو الأحكام الخاصة بالعقد بتغيُّ الظروف؛ وهي كالآتي: (1) تغيير في الظروف التي وقَّ فيها الطرفان على العقد.

(r) عدم التناسب غير المتوقَّع أو المفرِطِ بين مصالح الأطراف المتعاقدة على نحِِ يهدم التوازن بين هذه المصالح.

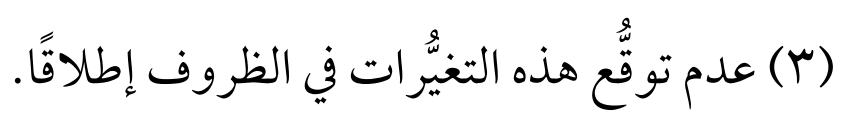
(ع) افتقار العلاقة التعاقدية إلى آليات أخرى لإعادة التوازن(().

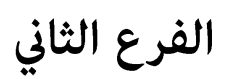

\section{أثر جائحة كورونا على انقضاء عقود التجارة الدولية الفية}

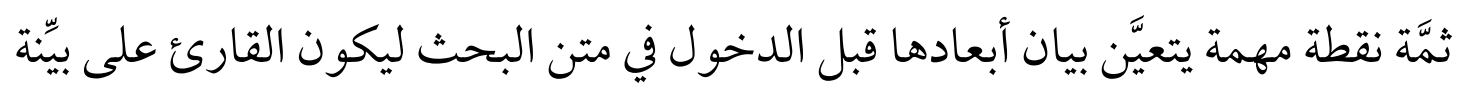

منها في البداية؛ ألا وهي آليات انقضاء العقد الدولي بشكل عام، كي تُعبّد سبيل إدراك كيف أثَّرت جائحة كورونا على الوضع العام الذي كانت تسير في فَلَكه عقود التجارة الدولية منذ نشأتها، ومعرفة هل سنجد في الحلول التقليدية خروجًا من الأزمة الاقتصادية

: (1) (1) في هذا التأصيل، انظر: Ibid. p. 4, 8 .

$$
\text { ولمن أراد الاستز ادة انظر: }
$$

The coronavirus crisis and the application of the rebus sic stantibus clause in leases for use other than housing, issued by osborne Clarke Law Firm the official website, published on 22 Jun 2020.

See at, https://www.osborneclarke.com/insights/coronavirus-crisis-application-rebus-sic-stantibusclause-leases-use-housing/, Last visit on 12/7/2020.

(2) Ibid. 
الدولية التي خلَّفتها الجائحة، وإجمالًا فعقود التجارة الدولية تنقضي لأيٍّ من الأسباب الآتية (1): - 20 - 20

السبب الأول: الانقضاء بالوفاء؛ إما بالتنفيذ العيني أو بالتنفيذ بمقابل، ويالنسبة للتنفيذ العيني -وهو الأصل - نجد اختصاص قانون العقد بتحديد شروط التنفيذ العيني وبيان أشخاص التنفيذ العيني، وتحديد زمانه ومكان التنفيذ، غير أنه يخرج من نطاق قانون العقد التهديدات المالية التي يقصد بها حمل المدين على التنفيذ العيني؛ فهي من مسائل الإجراءات أو مقدمات التنفيذ الجبري والتي تخضع بتلك المثابة لقانون القاضي، وبصفة عامة تخضع طرق التنفيذ لقانون محل التنفيذ دون قانون العقد (r). وبالنسبة للتنفيذ بمقابل فيختص قانون العقد بيان شروط استحقاق الدائن للتعويض، أو التنفيذ بمقابل وإذا كان التعويض عن عدم التنفيذ لا يستحق إلا بعد إعذار

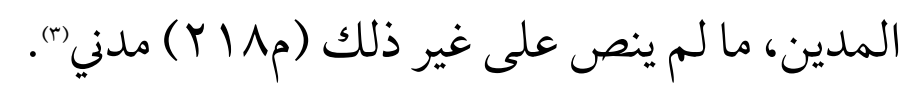
والشاهد أن حالتي انقضاء العقد بالوفاء سواء بالتنفيذ العيني أو بالتنفيذ بمقابل تبتعدان عن الموضوع الذي من أجله أُفرد البحث؛ فما المشكلة في إمكانية الوفاء بالتزامات عقدية، ولو كان العقد قد تأثَّ بالجائحة، مادام الوفاء قد تمَّ على النحو الذي انقضى معه العقد. السبب الثاني: الانقضاء بما يعادل الوفاء؛ إما بالتجديد، أو حو الة الحقِّ، أو الحلول،

(1) في عموم هذه الأسباب، راجع: د. أحمد عبد الكريم سلامة، الأصول في الثنازع الدولي للقوانين، دار النهضة

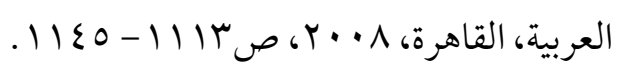

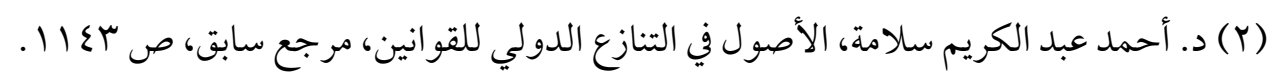
(r) - (ب) لمزيد من التفاصيل، المرجع السابق ذاته. 
أو المقاصة، وأسباب الانقضاء هذه هي الأخرى تبتعد عن مجال الدراسة، اللهمَّ إلَّا في شقّ التجديد من منطلق التفرقة بين أبعاد وضع إبرام العقد أو تجديده؛ فقد يبرم العقد قبل الجائحة وهو ينطبق عليه وصف الشرط ويرتِّ أمورًا تختلف عن تلك المتعلقة بتجديد العقد بعد ظهور الجائحة؛ سواء أكان التجديد ضمنيّا أم ظاهرًا، بحسب ما ستفصِّله الدراسة في موضع لاحق "(1) السبب الثالث: الانقضاء دون وفاء؛ إما بانفساخ العقد لاستحالة التنفيذ، أو الإبراء، أو التقادم المسقط ()، وهذا السبب الثالث يتَّصل جزئيَّا بموضوع الدراسة حلَّ ما سيظهر. وسنقف بقليل من البيان عند هذه الجزئية -تحديدًا - بييان الآليات التقليدية لانقضاء العقد الدولي دون وفاء على النحو الآتي(r): الفرض الأول: انفساخ العقد لاستحالة التنفيذ، فبمقتضاه تنقضي الالتزامات التعاقدية إذا استحال تنفيذها لسبب أجنبي لا يدَّ للطرفين أو لأحدهما فيه؛ فالعقد هنا ينفسخ بقوة القانون ومن تلقاء نفسه(s)، دون حاجة إلى حكم قضائي؛ فالأمر هنا خاضع للقانون الواجب التطبيق على العقد في ظلّ ارتباط الأمر بأحد أوجه انقضائه، وفي ذلك تطبيق لنص المادة

(1) راجع: كلمة د. جابر محجوب، أثر جائحة كورونا على تنفيذ العقود، الندوة القانونية الأولى بعنو ان "جائحة

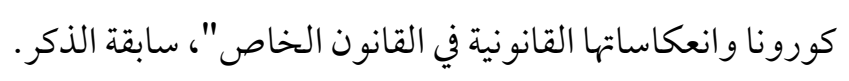

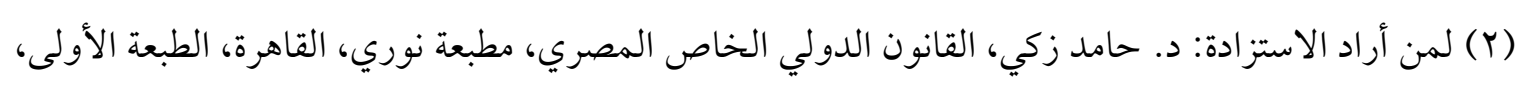

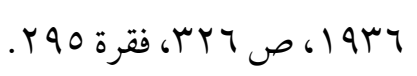

(r) في هذه الفروض الثلاثة انظر: د. أحمد عبد الكريم سلامة، الأصول في الثنازع الدولي للقوانين، الموضع السابق ذاته.

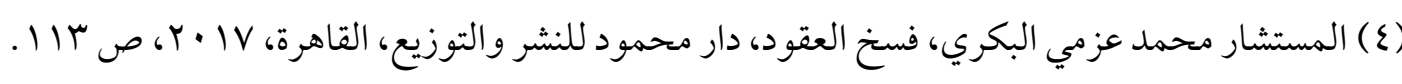




$$
\text { (109 ) من القانون المدني المصري التي نصَّت على أنه: }
$$

"في العقود الملزمة للجانبين إذا انقضى التزام بسبب استحالة تنفيذه انقضت معه

$$
\text { الالتزامات المقابلة له، وينفسخ العقد من تلقاء نفسه". }
$$

الفرض الثاني: الفسخ القضائي للعقد الدولي، وهنا يتعيَّن أولًا أن نؤكِّد أنَّ الفرض السابق يتعلَّق بانقضاء العقد بقوة القانون دون الحاجة لحكم قضائي، وهو على ذلك يختلف عن الفرض المتعلّّق بفسخ العقد بحكم من المحكمة، الذي دارت الآراء ما بين خضوعه إما لقانون العقد أو لقانون القاضي بحسبان أن الفسخ في هذا الفرض لا يتقَّر

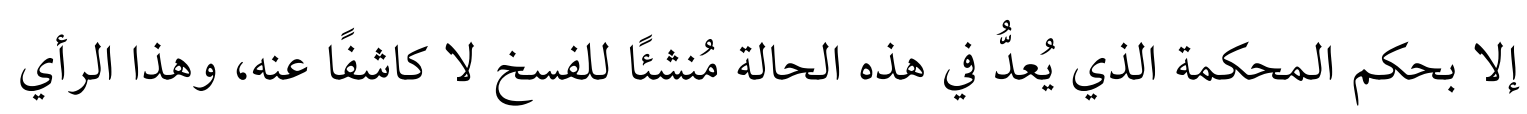

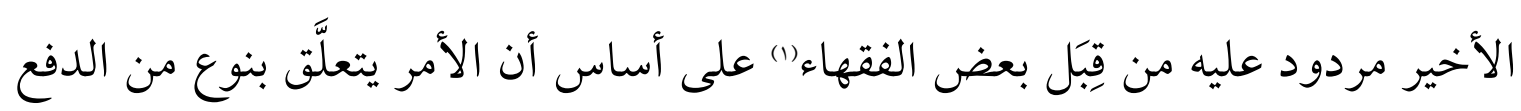
بعدم التنفيذ في العقود الملزمة للجانبين؛ وعليه: يُفترض أن أحد المتعاقدين قد أخلَّ بالتز امه. وبشكل عام يستند التوجُه في حدِّ ذاته، وبعيدًا عن القانون الأولى بالاتباع، لما ورد

$$
\text { بنصِّ المادة (1 / / V ) من القانون المدني المصري من أنه: }
$$

"في العقود الملزمة للجانبين إذا لم يوفِ أحد المتعاقدين بالتزامه جاز للمتعاقد الآخر بعد إعذاره المدين أن يطالب بتنفيذ العقد أو بفسخه، مع التعويض في الحالتين إن

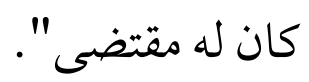
الفرض الثالث: الفسخ الاتفاقي، وهو الفرض الأخير هنا لانفساخ العقد لاستحالة

(1) لمزيد من التفاصيل، انظر : د. أحمد عبد الكريم سلامة، الأصول في التنازع الدولي للقوانين، مرجع سابق، ص ص 
التنفيذ؛ كمسوِّغ لانقضاء العقد الدولي دون وفاء فسخًا اتفاقيَّا، وبما أنَّهَ اتفاقي فهو

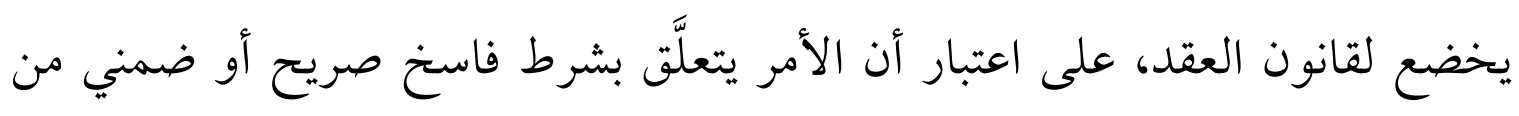
شروط العقد وبنوده. وفي خصوص هذا الفرض الأخير نصَّت المادة (101) من القانون المدني المصري

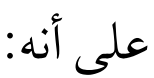
"يجوز الاتفاق على أن يعتبر العقد مفسوخًا من تلقاء نفسه دون حاجة إلى حكم قضائي عند عدم الوفاء بالالتزامات الناشئة عنه، وهذا الاتفاق لا يعفي من الإعذار، إلا إذا اتفق المتعاقدان صراحة على الإعفاء منه". هذا، ولا يختصُّ قانون العقد ذاته بتحديد انفساخ العقد لاستحالة منها تنفيذه فقط، بل

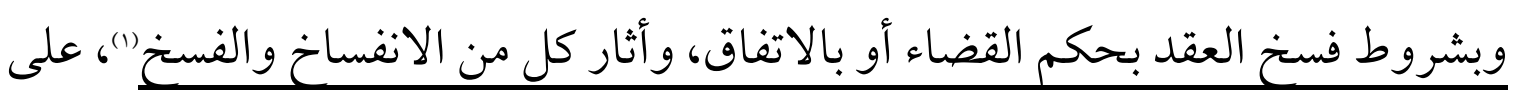
اعتبار أن قانون العقد لا يحكم سوى آثاره وكذلك انقضائه(")، وإن كان يترتب على الانفساخ ما يترتب على الفسخ من عودة المتعاقدين للحالة التي كانا عليها قبل العقد")؛ وإجمالًا يلزم التأكيد على أنَّ: - القانون الواجب التطبيق يختلف بحسب المرحلة التي يمرُّ بها العقد الدولي، بل وفي

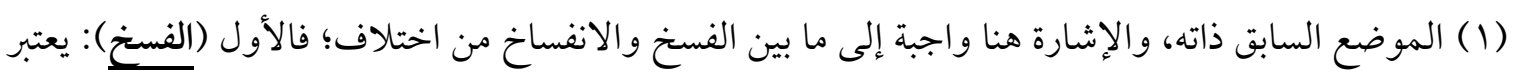

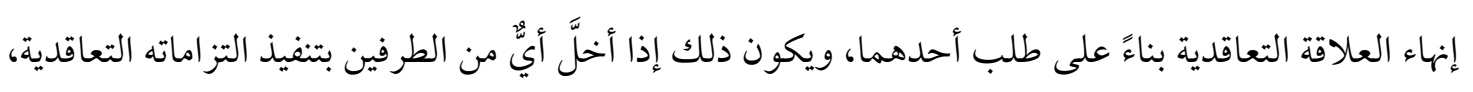

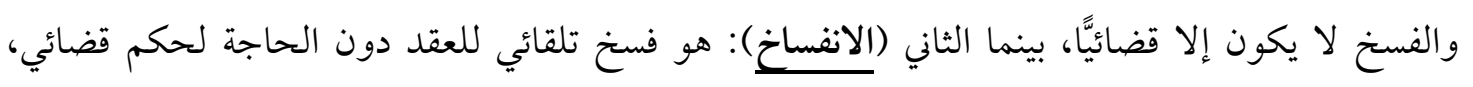

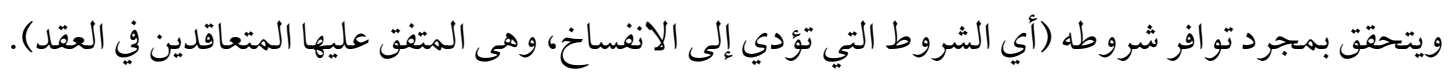

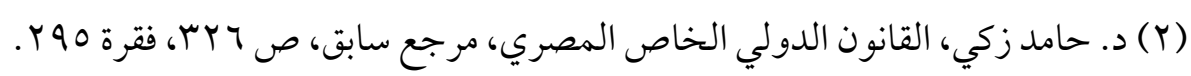

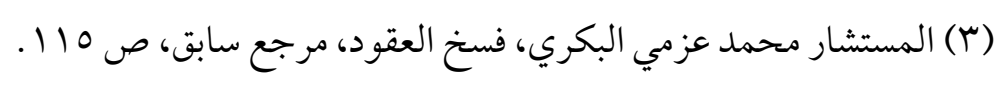


المرحلة ذاتها قد يختلف الفقه في القانون الو اجب التطبيق؛ بيد أنه على الرغم من هذا الاختلاف فالثابت أن ازدهار نظريات تنازع القوانين مقرون بانتشار التجارة والتعارف بين الناس(1).

- مشكلة تنازع القوانين ليست مشكلة تناضل بين عدَّة قوانين، وإنما هي مشكلة اختيار أو مفاضلة بين القو انين المتصلة بالعلاقة القانونية)."

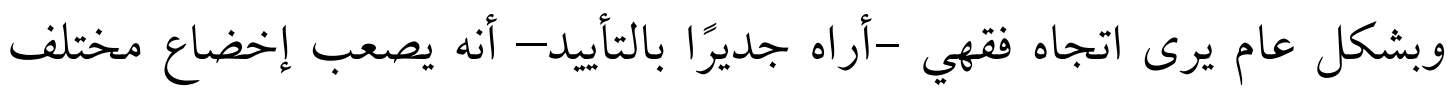

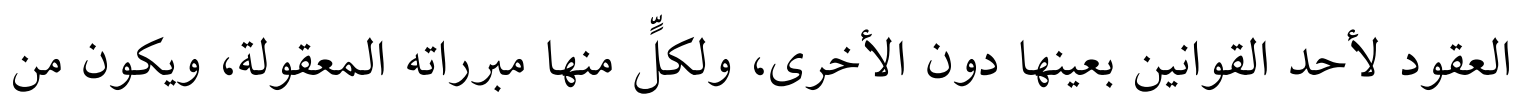

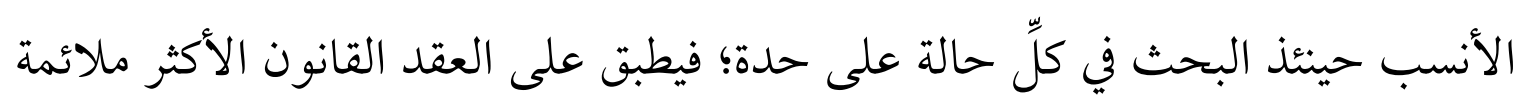
مادام المقصود هو تحقيق أغراض عملية اقتصادية). ورُبَّ متسائل.. ماذا عن سلطة القاضي في فسخ العقد بالنظر لمعطيات جائحة

كورونا؟ إنَّ من حقِّ القاضي أن يقوم بإعفاء المدين من تنفيذ التزامه عند وجود سبب أجنبي

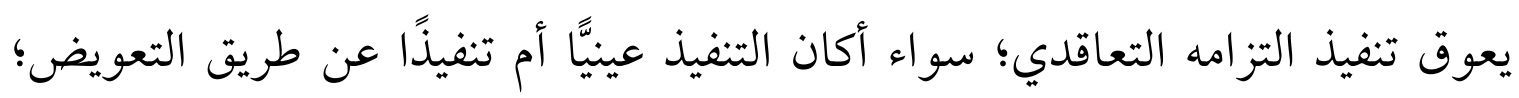
فالعقد سينفسخ لوجود سبب أجنبي يحول دون التنفيذ (s).

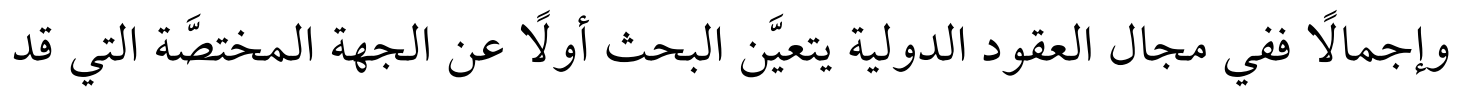

$$
\begin{aligned}
& \text { (1) د. حامد زكي، القانون الدولي الخاص المصري، مرجع سابق، ص •9، فقرة V9. }
\end{aligned}
$$

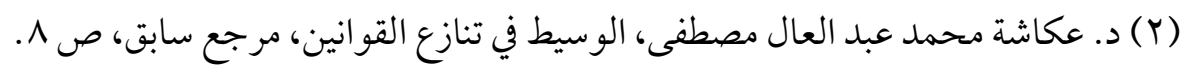

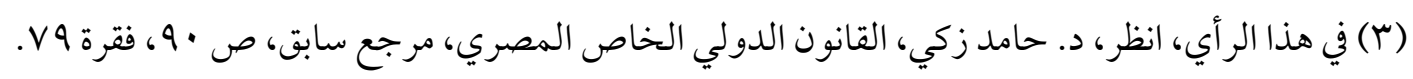

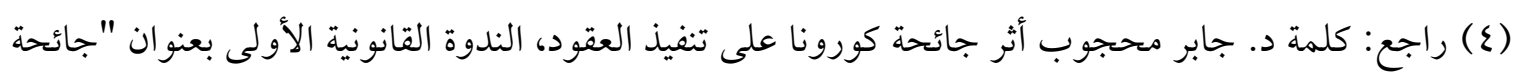

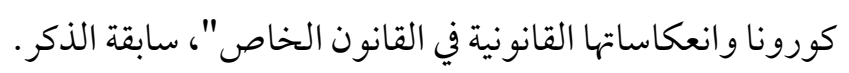


تكون جهة قضاء وطني أو تحيكم، فإذا كانت المحكمة تحكيمية فمعلوم تمثّعها بقدر كبير من الحرية، وإن كان في حدود ما اتفق عليه الأطراف، وعليه يبقى السؤال هل حدَّد العقد للمحكمة القانون الواجب التطبيق من عدمه؟ فبالنسبة للقاضي الوطني فهو مرتبط بقانونه الوطني؛ فالقاضي لا يتدخّل في نصوص مص العقد إلا في حالات استثنائية كأن تكون ألفاظ العقد مُبهَمة مثلًا، أو وجود تناقض في

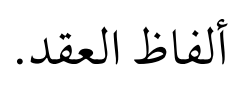

وثمَّة فارق بين تأويل العقد أو تفسيره، وبين ربط البنود التعاقدية بالو اقع؛ فربطُ بنود العقد بالواقع عملية يُيد منها القاضي البحث عن توصيف لوقائع القضية المطروحة أمامه؛ فمثلًا يقوم القاضي بقر اءة الشروط الواردة في العقد ببند القوة القاهرة -على سبيل المثال- ثم يقارن هل هذه الوقائع تستجمع الشروط التي نصَّ عليها القانون، وهذا لا

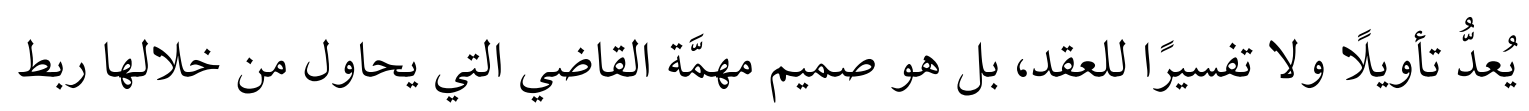
البنود التعاقدية بالو اقع، وهو إعطاء حكم معلل ، و التعليل يكون انطلاقًا من در استه لهذا العقد، و كذا السعي لتوصيف الفعل.

بينما التأويل أو التفسير يقوم فيه القاضي بالبحث -مثلًا- فيما قصده الأطراف؛ فالقاضي هنا لا يسعى لاستبدال جوهر العقد، بل استنتاج ما أرادته الأطر اف المتعاقدة

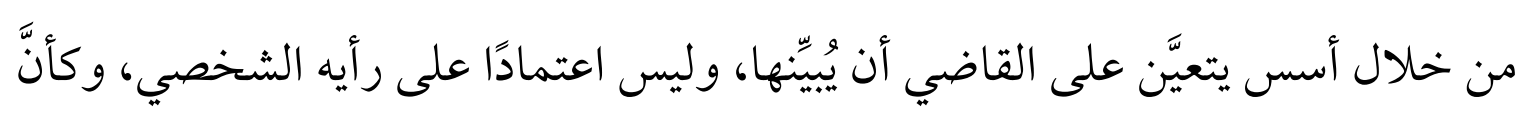
دور القاضي تفسير للإبهام، والشيء بالشيء يُذكر فهنا تتجلَّى أهمية الاهتمام بصياغة ديباجات العقود الدولية لتكون مُعينًا للقاضي أثناء قيامه بتفسير العقدل').

(1) في تفصيل ذلك وفي هذا التأصيل، راجع، كلمة الدكتور سمير أوخليفا، في الندوة افتراضية بعنوان الآثار 


\section{المطلب الثاني

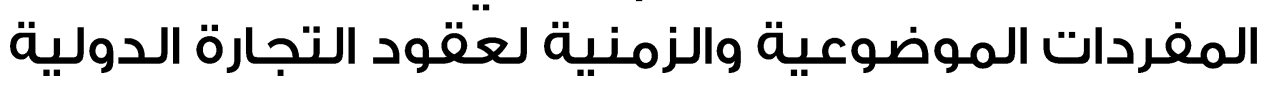 في زمن الكورونا}

\section{تمهيدٌ وتقسيمٌٌ:}

إن الحديث عن جائحة كورونا في خِضَم الالتزامات التعاقدية الدولية يرتِّب فروضًا عدَّة سيقف عندها البحث بمزيد من التأصيل والبيان في مواضع لاحقة، وفي ظلّ هذا التعلُّد فإنَّ حسن عرض الفكرة المر ادة يقتضي تقسيمها إلى مفردات موضوعية وأخرى زمنية، وهو ما انشطرت إليه فروع هذا المطلب.

الفرع الأول

\section{المفردات الموضوعية لعقود التجارة الدولية في زمن الكورونا الاول}

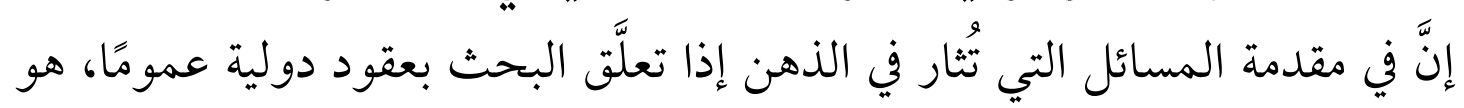

التساؤل عن مضمون ما حوته هذه العقود، وما إذا كان هناك نصٌّ بالعقد يحكم المسألة

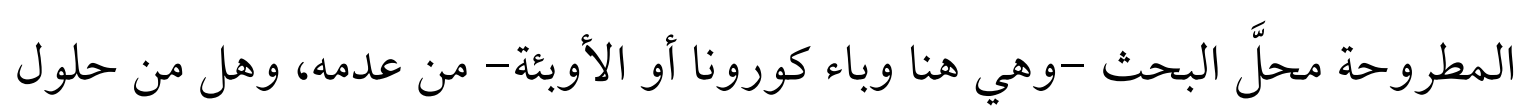
وردت بهذه العقود تتعلَّق بالمسألة من عدمه، والأمر هنا على فرضين اثنين: الفرض الأول: وجود اتفاق عقدي يُفيد اتفاق الأطراف على إضفاء وصف معين يرتب نتيجة بعينها على الأوبئة؛ مثل: أن يَنََّ الأطراف بالعقد على اعتبار الأوبئة قوة

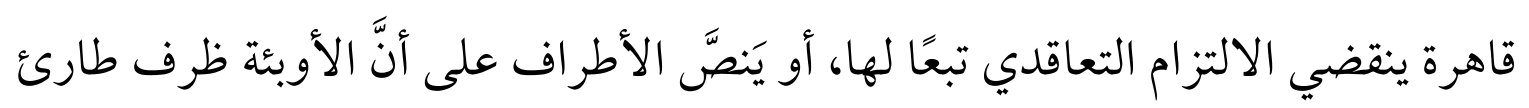
يؤدي وجوده إلى إعادة التوازن المالي للعقد في ظلّ ما بينهما من اختلاف، أو يَنصَّ الأطراف على اعتبار الأوبئة مسوِغًا لإعادة التفاوض ضبطًا للتوازن العقدي، إلى غير

القانونية لفيروس كورونا المستجد على العقود الدولية للأعمال التي نظمتها كلية القانون، جامعة أبو ظبي،

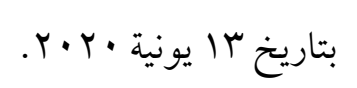


ذلك من صور هذه النصوص؛ فالمهُم هو وجود اتفاق تعاقدي مُسبِق من قِبَل الأطراف، فحو اه تكييف الأوبئة تكييفًا معينًا من منظور أطراف هذا العقد الدولي تحديدًا، ومثل هذه النصوص واجبة التطبيق احترامًا لما ارتضته إرادة الأطراف. هذا ويندرج تحت شرط الاتفاق العقدي محلّ الحديث وجود نصِّ بالعقد مثلً ينصُّ على اعتبار الأوبئة قوة قاهرة، ولكن الأطر اف يستثنون ضرورة تحقّق شيءٍ من شروط القوة القاهرة؛ كاشتراط عدم التوقُع دون استحالة الدفع أو العكس، وأيَّا ما كانت

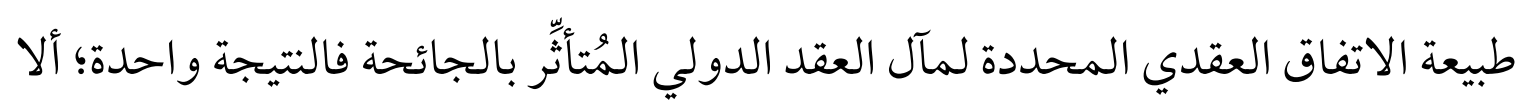
وهي ضرورة احترام ما اتفقت عليه إرادة الأطراف. وتجدر الإشارة إلى أنَّ هناك تشريعات قد نصَّت صر احة على اعتبار الأوبئة من قبيل الظروف الطارئة؛ من ذلك ما ورد بقانون الالتزامات البولوني، باعتباره أول تقنين حديث اشتمل على نصِّ عامِّ في نظرية الحوادث الطارئة؛ فقد نصَّت المادة 79 ب على ما يأتي: "إذا جلَّت حو ادث استثنائية؛ كحرب أو وباء أو هلاك المحصول هلاكًا كليَّا أو غير ذلك من النوازل الطبيعية، فأصبح تنفيذ الالتزام محاطًا بصعوبات شديدة، أو صار يهدِّد

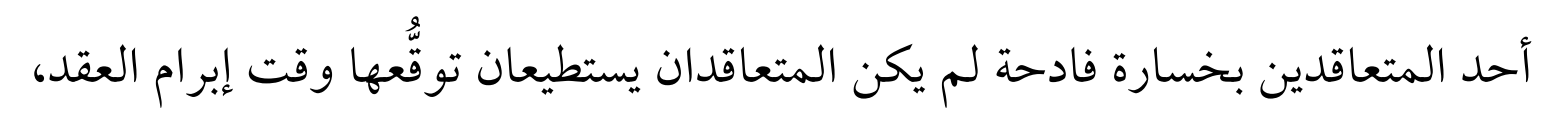
جاز للمحكمة إذا رأت ضرورة لذلك، تطبيقًا لمبادئ حسن النية، وبعد الموازنة بين مصلحة الطرفين، أن تعيِّن طريقة تنفيذ الالتزام، أو أن تحدِّد مقداره، بل وأن تقضي بفسخ العقد")

ثمة نقطة أخرى ستتم الإشارة إليها؛ وهي مدى جواز التعديل بالتخفيف أو التسديد

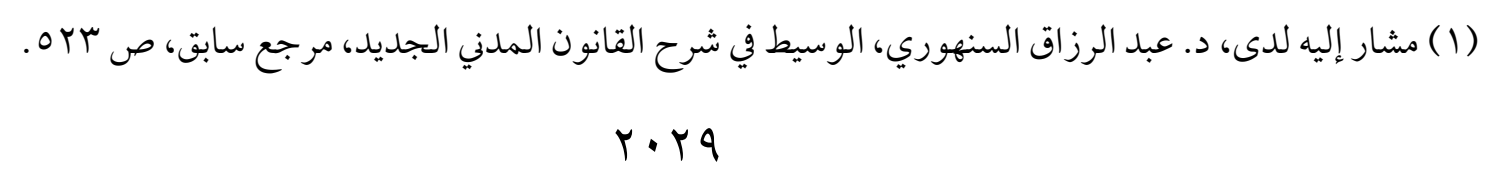


أو الإلغاء في قواعد المسؤولية العقدية، والشاهد إجمالاً مما مضى: أنه يجوز الاتفاق على تكييف محدد للوقائع في الحدود التي يجوز فيها شرط الإعفاء من المسؤولية، وبحسب القانون الذي يتم الرجوع إليه مدى إباحته لفكرة التعديل بالتخفيف أو التسديد

$$
\text { أو حتى الإلغاء. }
$$

الفرض الثاني: عدم وجود اتفاق عقدي يفيد اتفاق الأطر اف على إضفاء وصف معيَّن

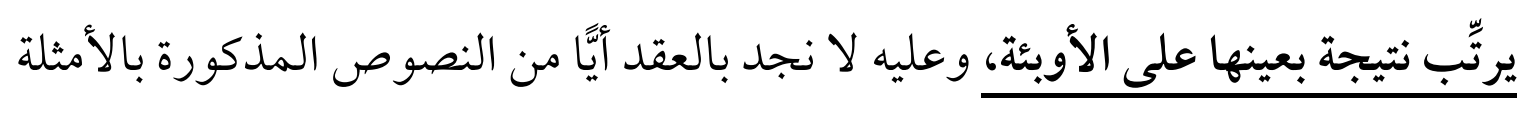

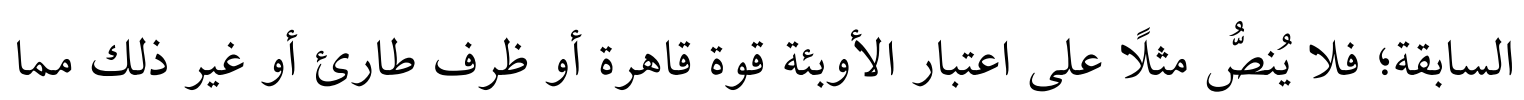
يُّتصور الاتفاق عليه، وفحوى هذا الفرض هو محلُّ متن هذه الدراسة.

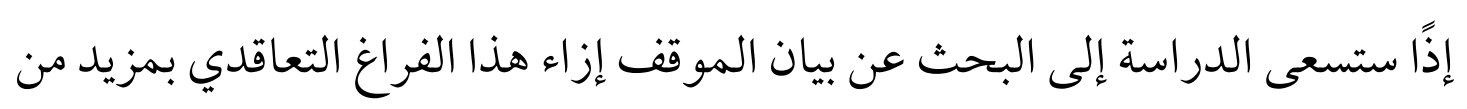
التأصيل والبيان. وحريٌّ بالذّّكر أنَّ من بين ما يندرج في صميم فكرة هذا الفرض الثاني -بطبيعة

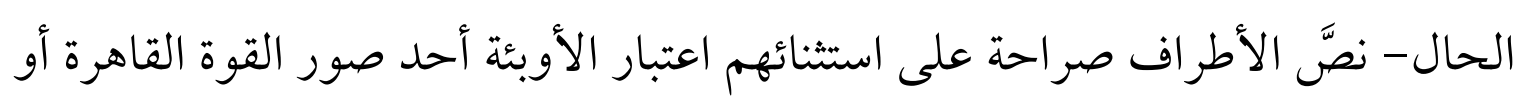

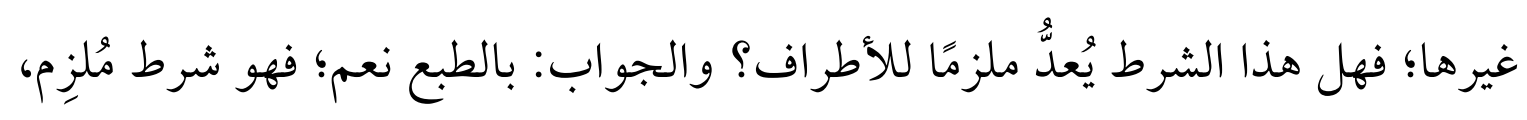

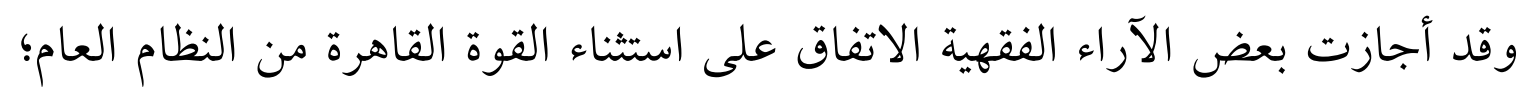

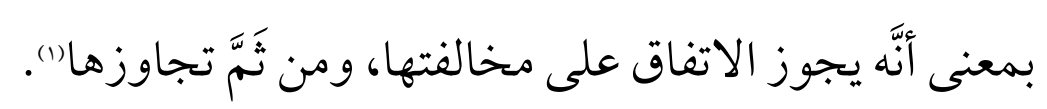
وما دام الطرح السابق قد كشف عن أبعاد الفرضَيْن السابقين وما يتصل بهما، فثمة فهمان

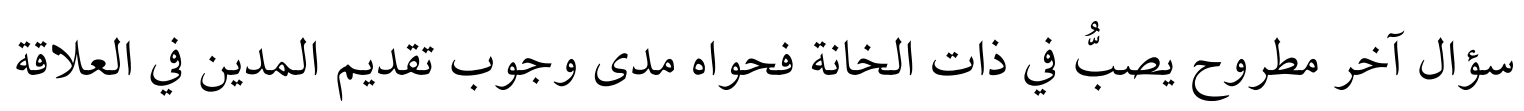

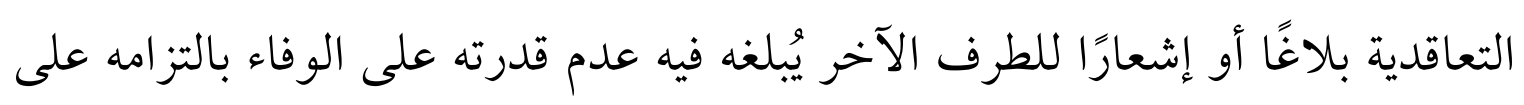


خلفية تبعات فيروس كورونا، وهو تساؤل أُفردت له صفحات البحث القادمة.

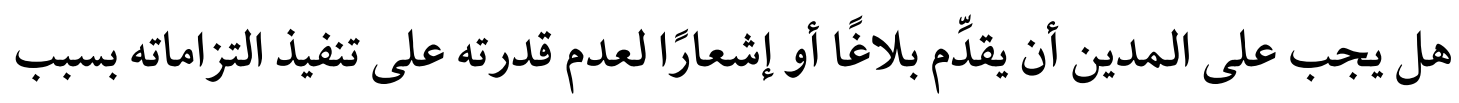

القوة القاهرة أو الظروف الطارئة؟

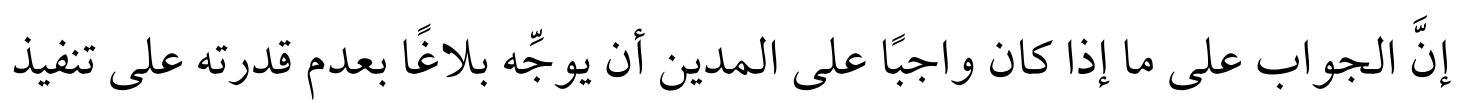

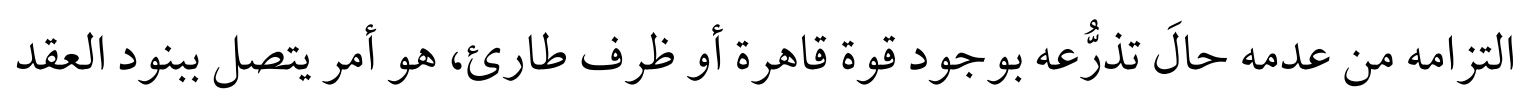

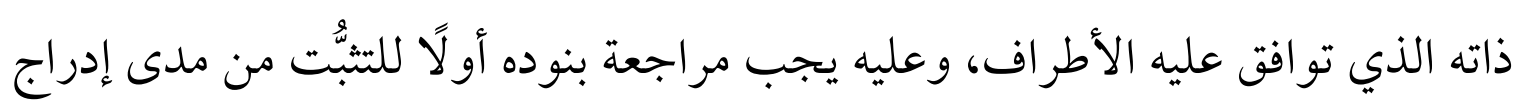
بند في العقد ذي الصلة من عدمه، ومن ثَمَّم معرفة ما إذا كانت بنوده تتطلب هذا الإشعار

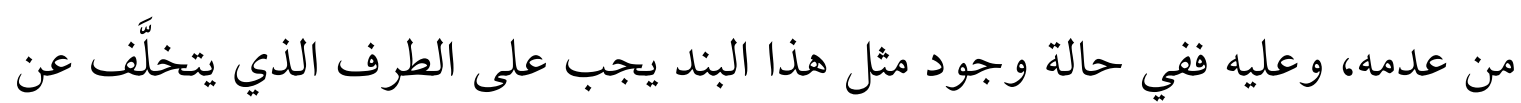
السداد أن يُسلم هذا الإشعار.

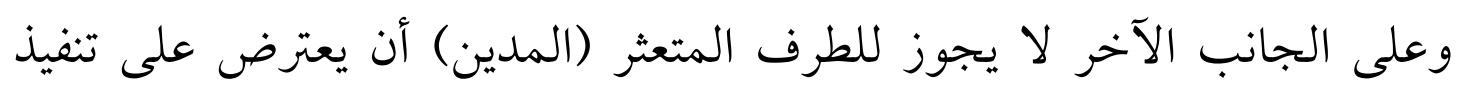
التزامه على أساس القوة القاهرة أو الظروف الطارئة حال عدم وجود مثل هذا البند

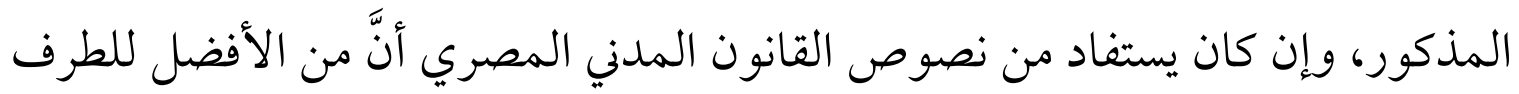

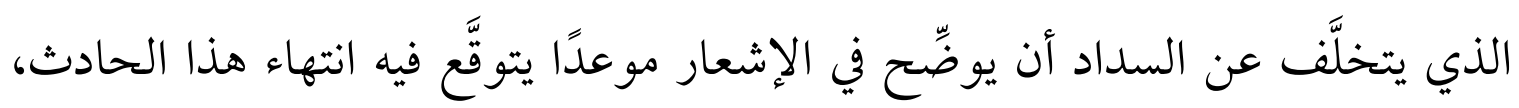
ويثبت فيه العلاقة بين القوة القاهرة أو الظروف الطارئة وبين عدم قدرته على الوفاء بالتزاماته التعاقدية. ولقد اشترطت غرفة التجارة الدولية بباريس لإعفاء الطرف المتضرّر من أداء

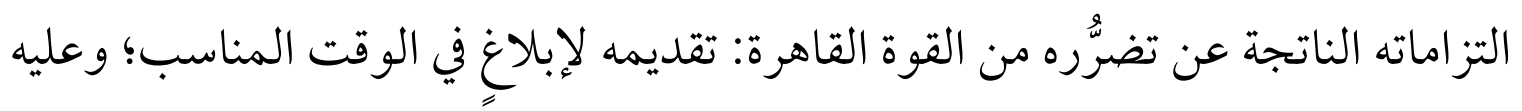

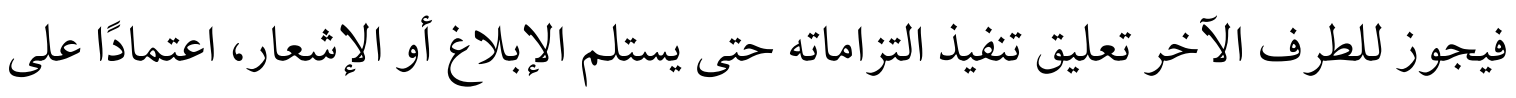




\section{الالتزامات التي أعاقتها القوة القاهرة نفسها").

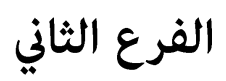

\section{المفردات الزمنية لعقود التجارة الدولية في زمن الكورونا}

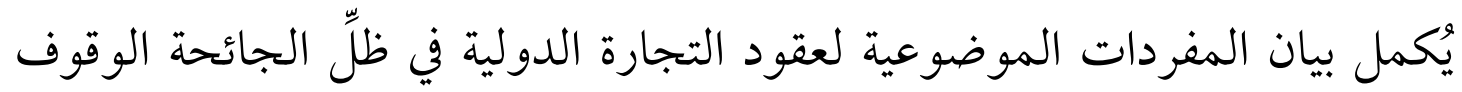
عند نظيرتها الزمنية، وهذه الأخيرة تثير ثلاثة فروض على النحو الآتي (r):

الفرض الأول: العقود الدولية التي تمَّ إبرامها خلال فترة الجائحة، ويعلم الأطراف

بوجودها؛ فهذه العقود لا يُثار الحديث بشأنها عن القوة القاهرة؛ فهي مُستثناة بحكم طبيعتها من مجال الدراسة، وإلَّا فغير منطقي الدفع بعدم القدرة على الوفاء بالالتزامات التعاقدية تذرُّعًا بجائحةٍ كان أطرافها على علمٍ بها وبتبعاتها قبل إبرام العقد، وباتت حديثَ منصَّات الإعلام في جلّ العالم ووسائل التواصل الاجتماعي وغيرها من المصادر.

الفرض الثاني: العقود التي أُبرمت بعد ظهور فيروس كورونا في الصين، وصيرورته وباءً منتشرًا -في الصين على الأقل - ولنكن صادقين مع أنفسنا فقي هذه الأثناء توقَّعت الَّت بعض الدول عدم إمكانية وصول الفيروس إليهم في ظلّ ارتفاع درجة حرارة الجو لديهم، ولاعتقادهم أنَّ هذه الحرارة لا تتناسب مع دورة حياة فيروس كورونا، ولكن - لئن كما هو معروف- عندما بدأ الفيروس يظهر في الدول الأخرى ذات الحرارة المرتفعة

(1) ICC FORCE MAJEURE CLAUSE (“Clause”), Issued by International Chamber of Commerce, March 2020, p. 3.

Available online at, https://iccwbo.org/content/uploads/sites/3/2020/03/icc-forcemajeure-hardshipclauses-march2020.pdf, Last visit on 25/6/2020.

(r) في هذه الفروض، راجع: الندوة افتراضية بعنوان الآثار القانونية لفيروس كورونا المستجد على العقود الدولية للأعمال التي نظمتها كلية القانون، جامعة أبو ظبي، كلمة الدكتور سمير أوخليفا، سابقة الإشارة. 
بات متوقًَّا أن يتتقل لباقي دول العالم الخاضعة لذات الظروف المناخية. ولمَّما انتشر الفيروس في باقي دول العالم وبات حديث منصات الإعلام الدولي، فمن المتوقَّع أن ينمو لعلم المتعاقد -في هذا الخصوص - إمكانية تفشي هذا الوباء ليصبح وباءً عالميَّا أو بالأحرى جائحة، وربما في هذه الاثناء جاء إعلان منظمة الصحة العالمية

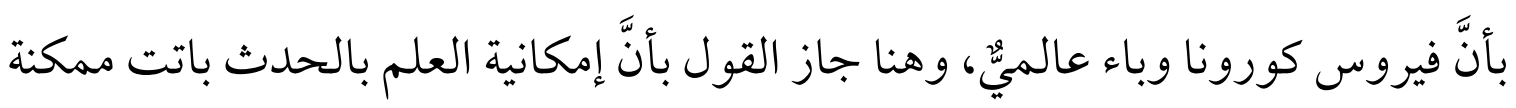

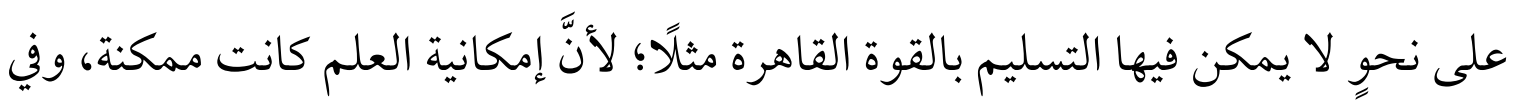
هذا الأمر تأصيلّ ستقف عنده الدراسة لاحقًا. الفرض الثالث: العقود التي أُبرمت في زمن سابق لظهور فيروس كورونا في الصين،

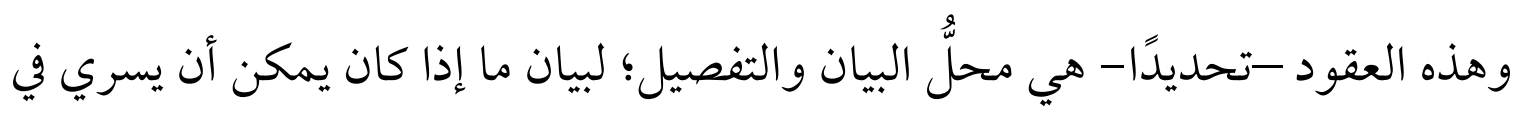
حقِّها أيٌّ من مسوِّغات تطبيق نظريتي القوة القاهرة أو الظروف الطارئة من عدمه و آثارهما، أو غيرهما، إلى غير ذلك من المسائل ذات الصلة حسب ما ستتطلَّهَ الدراسة.

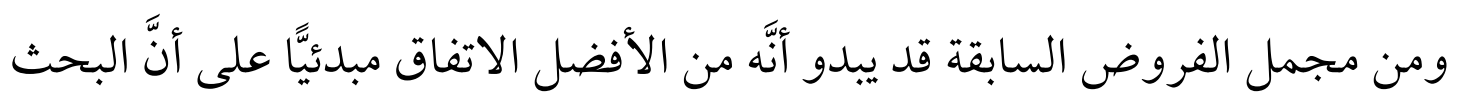

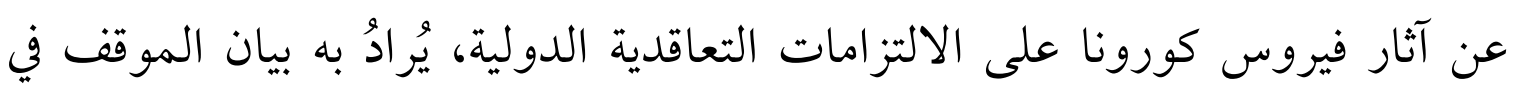

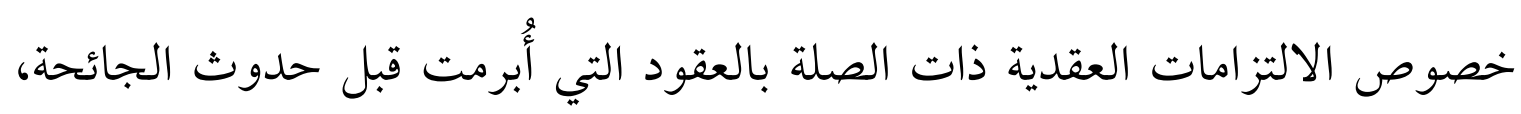

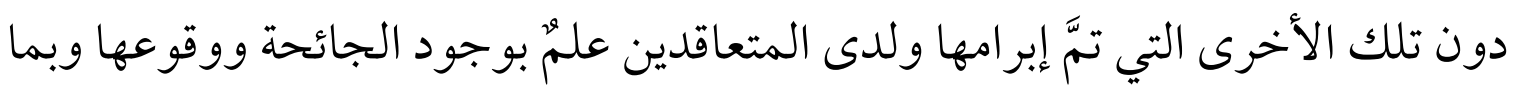

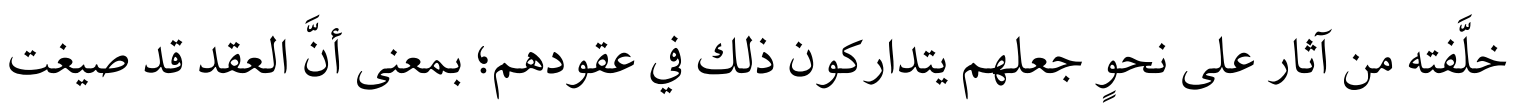

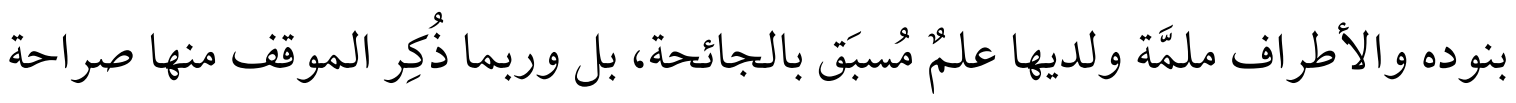

بالعقد!

وعليه، فما يعنينا في هذا المقام البحثي تلك العقود المُبرَمة قبل وقوع الجائحة،

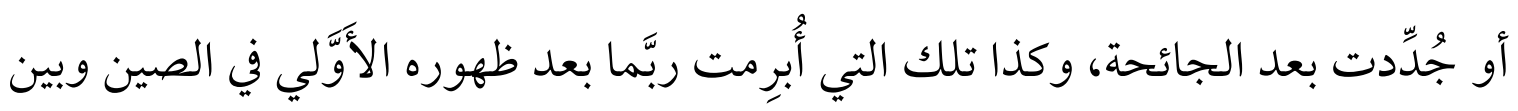


انتشاره في كافة دول العالم؛ فالفترة الزمنية بين هذا وذاك ليست باليسيرة في مجتمع

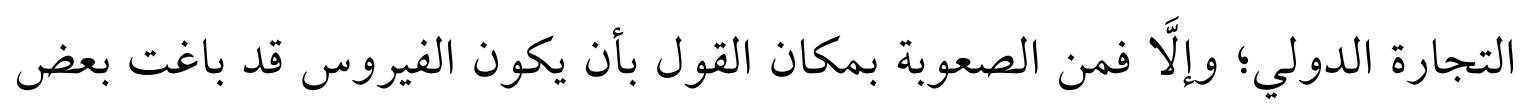
الدول فجأة من دون سابق إنذار.

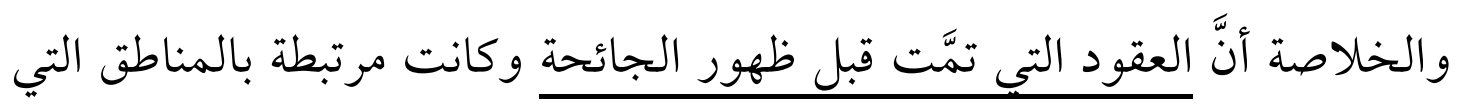

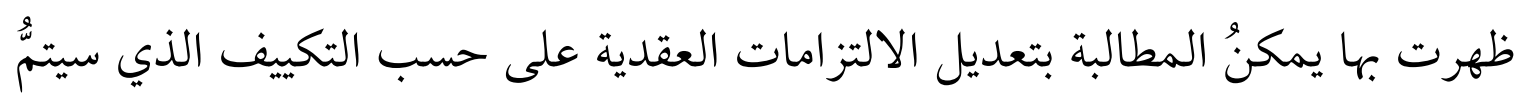

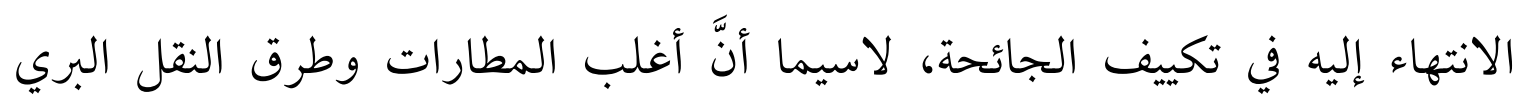

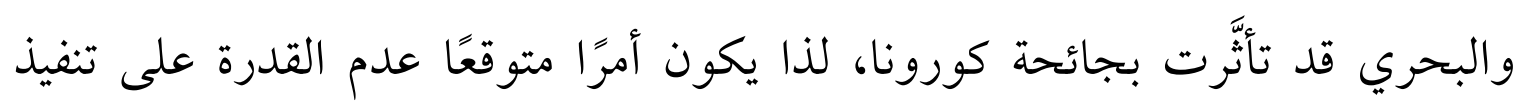

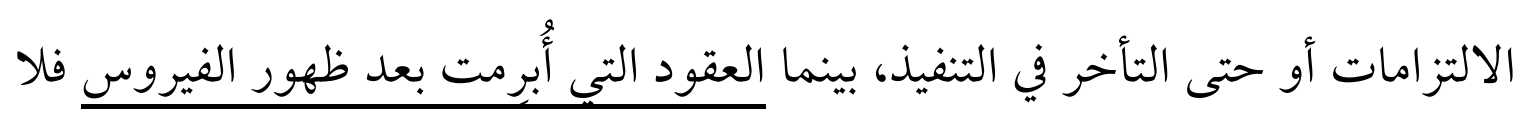

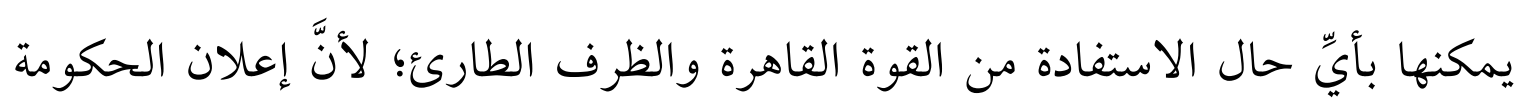

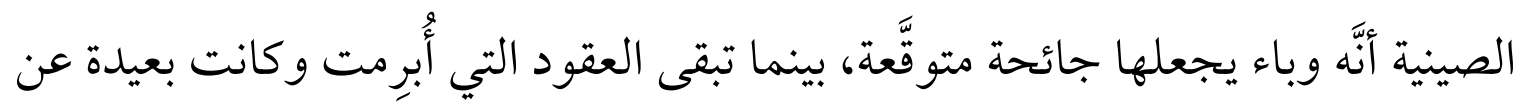

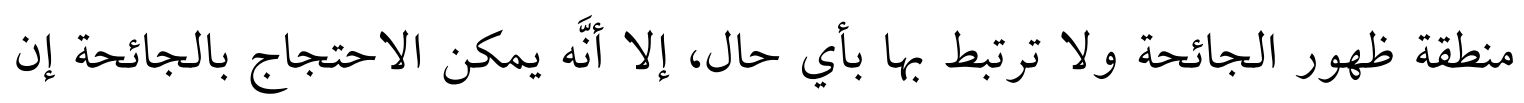

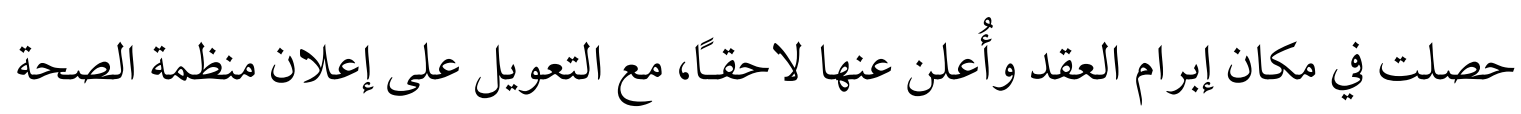
العالمية أنَّ فيروس كورونا وباء عالميُّ، يُهِّدّد دول العالم جميعًا ل). وفي هذا المقام فالتساؤل واجب: ما الذي قام به الطرف المتعاقد حتى يتفادى

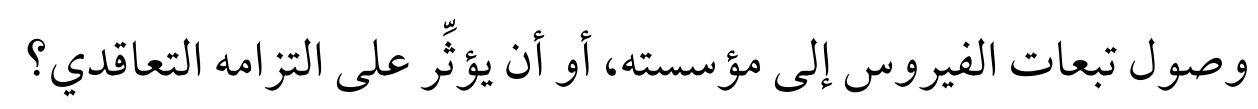

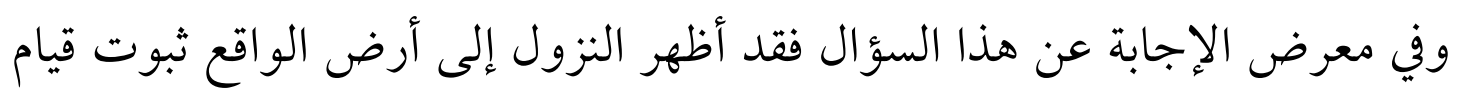

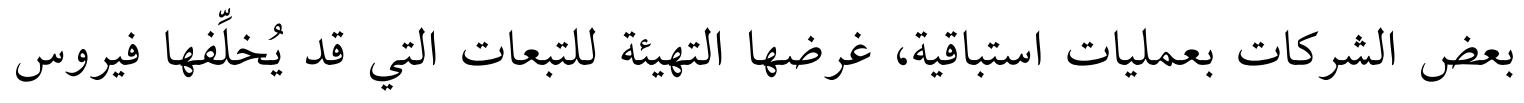

(1) د. ياسر عبد الحميد الإفتحات، جائحة فيروس كورونا وأثرها على تنفيذ الالتزامات العقدية، مرجع سابق، ص ص (1) 
كورونا إذا وصل إلى دولهم، فلما وصل الفيروس بالفعل إلى دولهم وبدأت الحكومة في اتخاذ بعض الإجراءات على خلاف غيرها كانت هذه الشركات لديها القدرة على التكيُّف والعمل في هذه الظروف الجديدة، وإن لم نُنكر أنَّها واجهت بعض الصعوبات، ولكن في النهاية كان موقفها أفضل من نظيرتها التي ظلَّت في سُبات عميق وتنَكُّ للفيروس، وفوجئت بما وقع، وحينها بدأت تستغيث بالحكومات، وبالتالي تتمسَّك بالأعذار -على اختلافها- هادفةً من ورائها التخلّي عن التزاماتها التعاقدية. وبناءً عليه: سيكون الأمر محلًّا للمناقشة -حتى مع إمكانية دفع المتعاقد باستحالة تنفيذ الالنزام- من زاوية: ما الذي تمَّ القيام به؟ ومن زاوية: الفترة الزمنية الفاصلة بين انتشار الخبر على منصات الإعلام العالمية ووصوله للدولة المعنية؟ فهناك زمن عقدي ينبغي تقيمه و أخذه في الاعتبار، وهو أمر ستظهره التكييف اللاحق للجائحة. وما دُمنا في هذا السياق الزمني، فثمَّة تساؤل آخر وهو البحث عن أيِّ التواريخ أَوْلى لِي بالاعتداد به لاعتماد تاريخ ظهور فيروس كورونا، وما ينجم عن ذلك من تساؤلات. التاريخ الواجب اعتماده لإعلان ظهور فيروس كورونا:

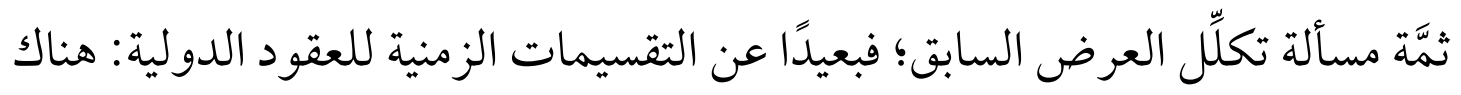
تساؤل آخر مبعثه آليات تحديد التاريخ الواجب اعتماده لتحديد تاريخ ظهور فيروس كورونا، وثمَّة اقتراحات فقهية وشخصية مُنبثقة عن هذا التساؤل (1): فهل الأَوْلى الاعتداد بتاريخ وجوده بالصين؟ أم بتاريخ وجوده بالشركة أو الجهة المتمسكة بعدم القدرة على الوفاء بالتزاماتها

(1) في بعض هذه الاقتراحات، انظر الندوة الافتراضية بعنوان الآثار القانونية لفيروس كورونا المستجد على العقود الدولية للأعمال التي نظمتها كلية القانون، جامعة أبو ظبي، د. سمير أوخليفا، سابقة الإشارة. 


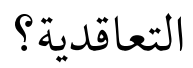

أم بالتاريخ الذي أعلنت فيه منظمة الصحة العالمية أنَّ فيروس كورونا وباء عالميٌّ؟ أم الأولى الاعتداد بتاريخ إعلان وجوده الأوَّلي في الدولة ذات الصلة؟ أم الاكتفاء بتاريخ علم المتعاقد الشخصي بتفشي المرض في الصين؟ إنَّ البحث في أيّّ التواريخ أَوْلى الاعتداد به لإعلان ظهور الفيروس يُظهِرِ ما للمسألة من أبعاد تقنيَّة وصحية تَغْبُ على نظيرتها القانونية؛ كونها ترتبط بمعطيات تقنية وصحية تبتعد قليًاً عن الجانب القانوني؛ وعليه فالأمر في مجمله وإن كان يُخلِّف آثارًا قانونية، إلا أنَّ السعي لتحديد أيّّ القوانين هو الأولى بالاعتداد مرجعُ أهميته تكمُن في البحث

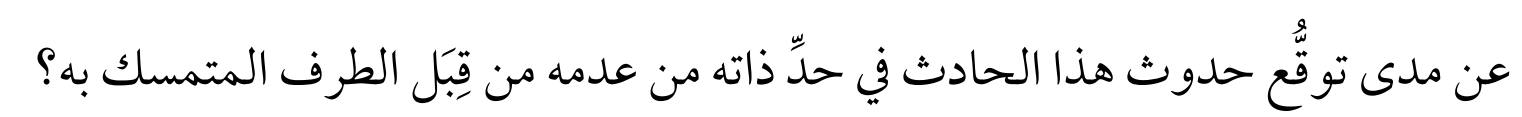
فلو أخذنا مثلً بميعاد ظهوره في الصين، فهناك فاصل زمني بين تاريخ ظهور الفيروس في الصين وبين تاريخ ظهوره في باقي دول العالم بعضها البعض، وهذا

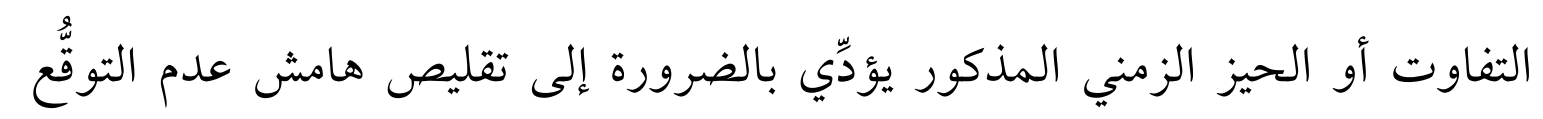

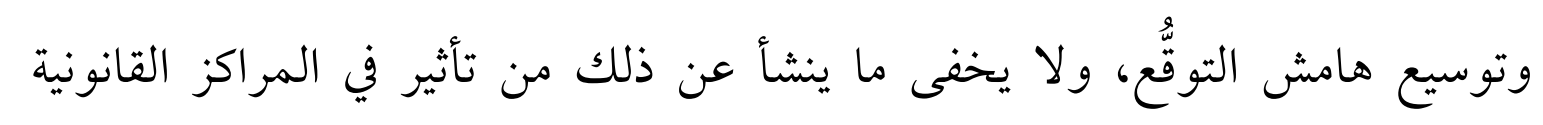
للأطراف المتعاقدة، ومن ثََّّ على قدرتها في تنفيذ التزاماتها التعاقدية، وبالتالي فما سيُعرض حينئذ في ظلّ هذه الملابسات؛ سو اء أمام التحكيم أو القضاء، هي المعايير التي سيتمّ اعتمادها بغرض تحديد زمن وقوع هذا الحدث في حدِّ ذاته.

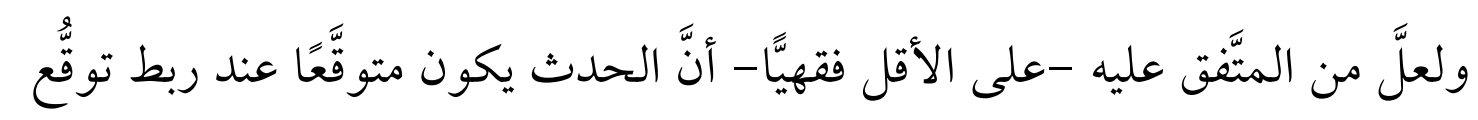
المتعاقد بتاريخ حدوث الوباء؛ فلو اعتمدنا مثلاً تاريخ إعلان منظمة الصحة العالمية فيروس كورونا وباء عالميًّا، فسيؤدِي ذلك إلى نتيجة مختلفة عمَّا إذا اعتمدنا مثلاً تاريخ

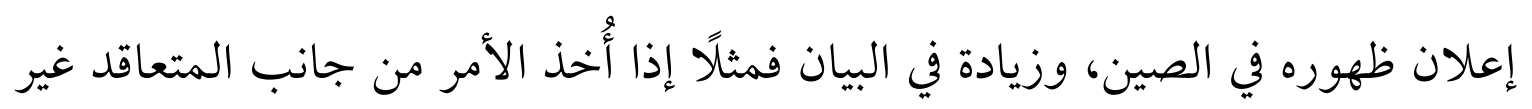


القادر على الوفاء؛ فقد يحتجُّ بعدم إلمامه بتفاصيل الأمر تذرُّعًا بعدم خبرته التقنية في المسألة، أو عدم توقُّه امتداد ما حدث في الصين لباقي الدول أو لدولة بعينها ذات صلة بالعقد، ولا يقف الوضع بطبيعة الحال على هذا الأمر؛ فقد يردُّ المتعاقد الآخر على ما ادَّعاه خصمه بأنَّ عِلمَ المتعاقد الأول بوقوع المرض وانتشاره في الصين -في حدَّ ذاتهـأمرٌ كافٍ في ظلِّ ما يُعرف عن الصين من معاملات اقتصادية متنوعة بحكم تعاملها مع

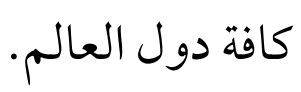

وبمعنى آخر فإنَّ من الأَّلى الاكتفاء بعلم المتعاقد بتفشّي المرض في الصين، ولا

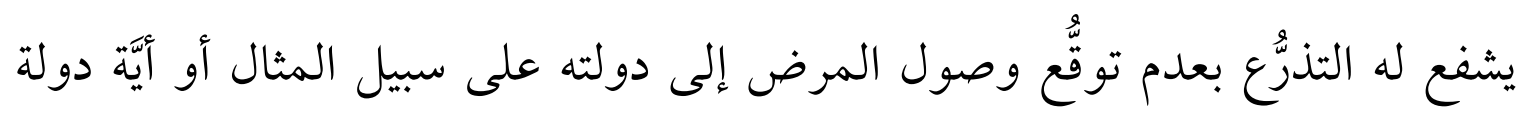
أخرى ذات صلة بالعقد، و كأنَّ المتعاقد يردُّ على ما أسس عليه الطرف الآخر دعواه (1). وما دُمنا قد انتهينا لهذا التأصيل، وما قد يدور من سجال بين الأطراف المتعاقدة يسعى معها كلّ طرف كي يعضّد وجهة نظره بالحجج المؤيدة، فمن المهمِّ الحذر من أن يعوّل القضاء في تحديده لتاريخ وجود فيروس كورونا على إعلان أيِّ من المؤسسات أو الدول الأخرى، على اعتبار أن عقود التجارة الدولية ترتبط ارتباطًا وثيقًا بإرادة أطر افها، وتنسلخ

$$
\text { كليَّة عن الإجر اءات الحكومية أو المؤسسية أو حتى الدولية ((). }
$$

وبالتالي فإنَّ تفسير أو تأويل العقود الدولية يكون في نطاق حرية أطرافها التعاقدية وإرادتهم؛ فالجائحة قد يُعتدُ بوصفها كذلك بمجرد استجماع علم الشخص وتوقُّهـ

(1) في تفصيل هذا الرأي، راجع الندوة افتراضية بعنوان الآثار القانونية لفيروس كورونا المستجد على العقود الدولية للأعمال التي نظمتها كلية القانون، جامعة أبو ظبي، د. سمير أوخليفا، سابقة الإشارة.

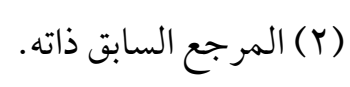


بإمكانية وقوع الحدث، بصرف النظر عن إمكانية علمه بقرار منظمة الصحة العالمية بأنَّ فيروس كورونا وباء عالميّيّ من عدمه، أو علمه بالأخبار المنتشرة في المواقع الإخبارية العالمية، أو حتى على شبكات التواصل الاجتماعي، مع الاعتراف بأنَّ لثلاثتهم تأثيرًا على تنفيذ الالتزام التعاقدي. وخلاصة القول: إنَّه من الأهمية بمكان الربط بين علم الشخص بالحدث وبين حدوثه بغض النظر عن إعلانات المؤسسات الدولية أو الجهات الحكومية').

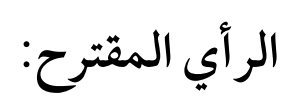

إنَّ الطرح السابق على أهميته وواقعيته يعضِّده التأكيد على أنَّهَ من المهمّ إيلاء

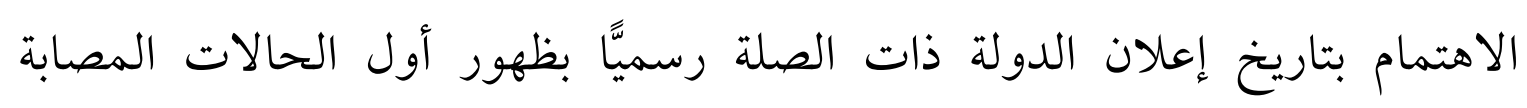

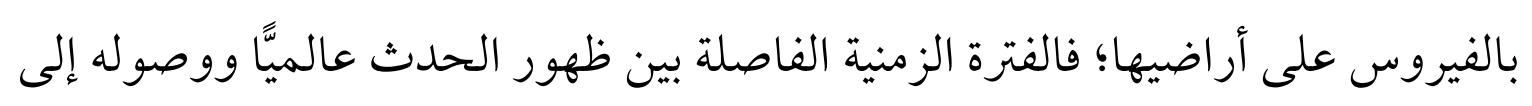

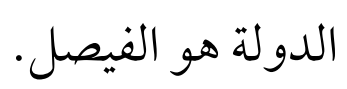
وبطبيعة الحال فإن التاريخ المذكور بهذا الوصف سيَلي تاريخ إعلان الصين وجود الصيا

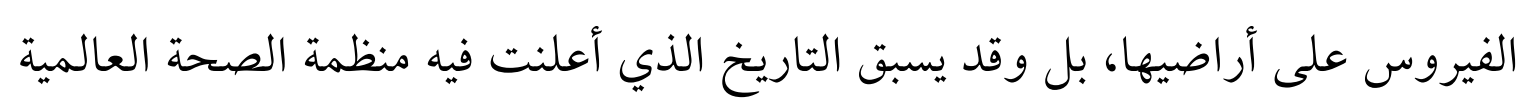

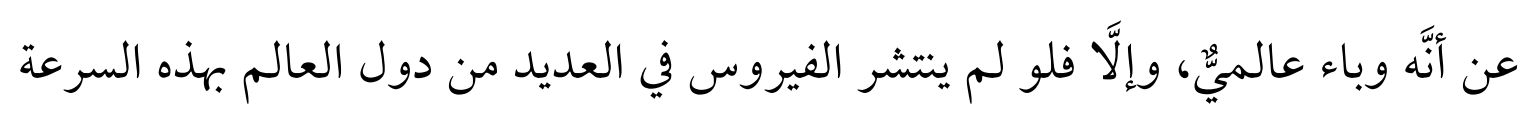

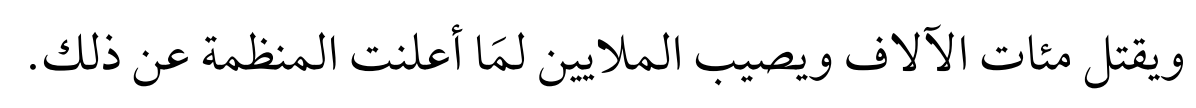

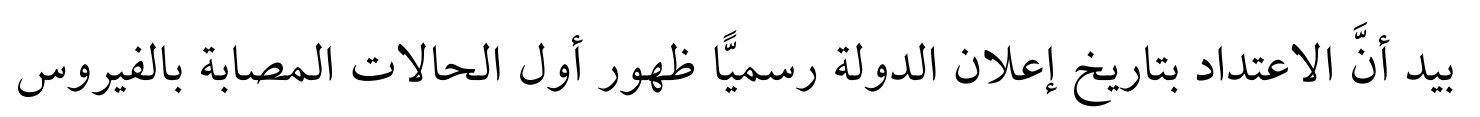

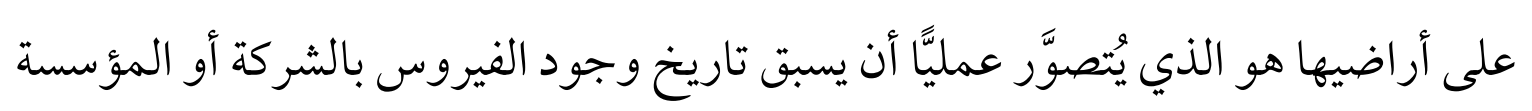

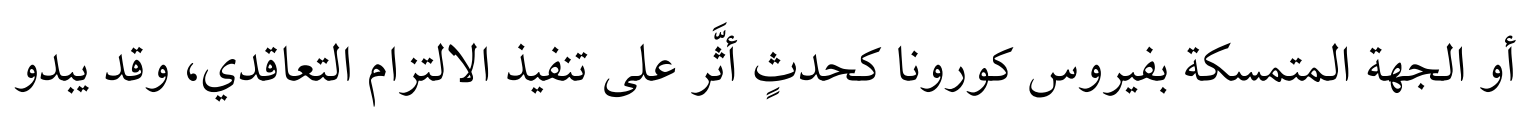

(1) (1) في تنصيل هذا الرأي والتحليل، انظر المرجع السابق ذاته. 
أنَّ هذا الحلَّ المقترح هو أقرب الآراء إلى الواقعية من خلال استقراء المعطيات المتاحة وأخذها في الاعتبار هذا من ناحية، ومن ناحية أخرى يتعيَّن النظر في الشُّبل التي اتَّخذها

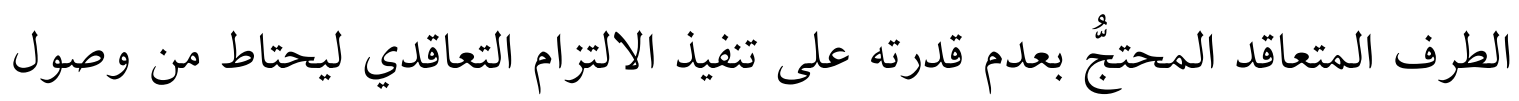

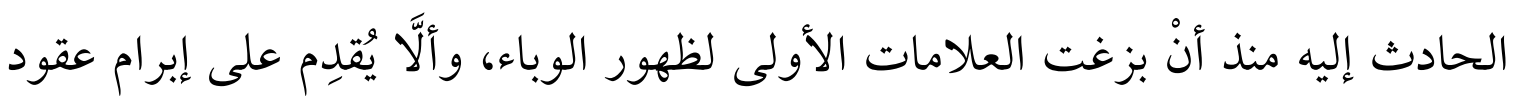

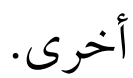

ولمَّا كان التكييف القانوني لجائحة كورونا يحتلّل حيزًا كبيرًا من التفكير والتحليل، التهل بالنظر لتأثيراته القانونية المترتبة على ذاك التوصيف على مستوى القواعد والتدابير

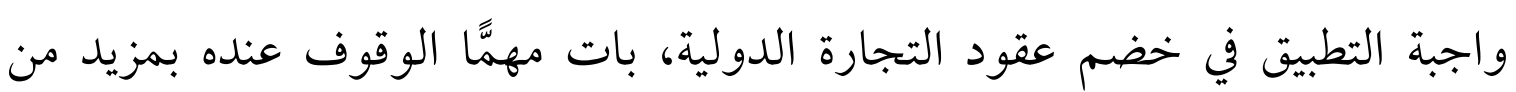
البيان(')، وهو ما جاءت بقية أجزاء الدراسة حاملة له.

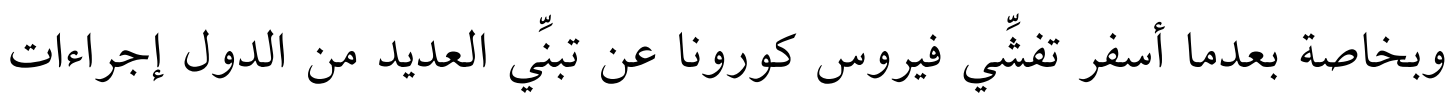

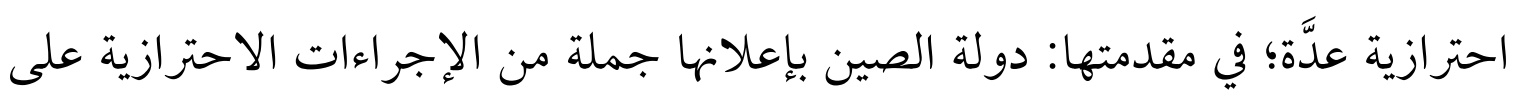

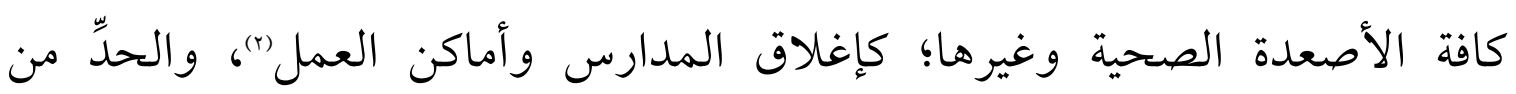

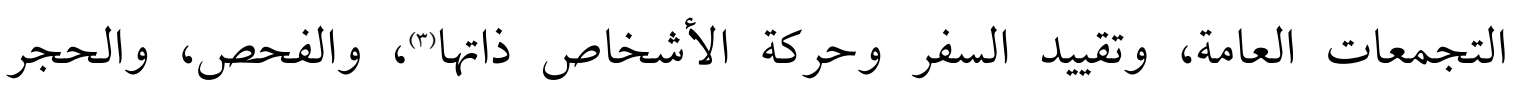

(1) بتصرف: د. محمود المغربي، د. بلال صنديد، التكييف القانوني للجائحة "الكورونية" على ضوء الثوابت

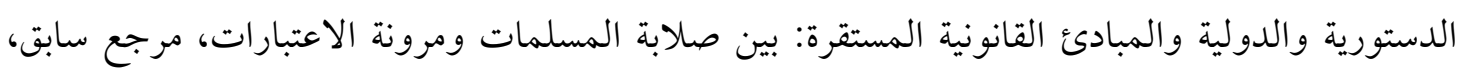
صזr.

(r) ولمزيد من التفاصيل عن أهمية ضمان الصحة والسلامة أثناء العمل في ضوء جائحة كورونا، انظر تقرير منظمة

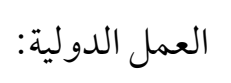

Face à une pandémie: Assurer la sécurité et la santé au travail, Organisation internationale du Travail, Première edition, 2020, pp. 10-12.

(r) بعد ما ثبت أن بعض الظروف -كالسفر والعمل في أوضاع معينة وغيرهما - مدعاة لانتشار الفيروس، لمزيد من

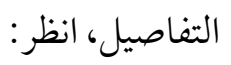




$$
\begin{aligned}
& \text { الصحي، و التباعد الاجتماعي، والعزل، كما تمَّ إغلاق م ع مدينة على الأقل بحلول ع }
\end{aligned}
$$

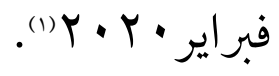

$$
\begin{aligned}
& \text { ونتيجة للإجراءات المذكورة لم يتمكَّن أكثر من ثلثي العمال المهاجرين الصينين } \\
& \text { من العودة إلى عملهُم (r)، تاركين من خلفهم هذه الشركات التي أععيد تشغيلها تعمل دون }
\end{aligned}
$$

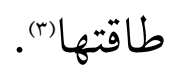

$$
\begin{aligned}
& \text { ولم تكن -بالطبع - غالبية دول العالم بعيدة عن اتخاذ مثل هذه التدابير الاحترازية } \\
& \text { المتعدِّدة، ولا عن هذه الأضرار الجسيمة التي لحقت بالعمال الصينين؛ فهذه دولة } \\
& \text { إيطاليا قد سنَّت العديد من المراسيم بقوانين لحماية العمال ()، ودولة الهند بعدما أُجبر } \\
& \text { ملايين الأشخاص على ترك عملهم بما في ذلك أصحاب الأجور اليومية والعمال }
\end{aligned}
$$

Coronavirus: A Guide to Understanding the Virus and What is Known So Far, issued by The Centers for Disease Control's Website, Start publishing company, USA, e-book, 2020, Section 3, " Travel Information".

(1) Under China's lockdown, millions have nowhere to go, issued by Reuters Graphics official website, published on $14 / 2 / 2020$.

Available online at, https://graphics.reuters.com/CHINA-HEALTH-LOCKDOWN/0100B5EF3LJ/index.html , Last visit on $3 / 7 / 2020$.

(2) Orange Wang, Coronavirus: more than two thirds of China's migrant labourers not yet back at work, issued by south china morning post Newspaper official website, published on 18/2/2020.

Available online at,

https://www.scmp.com/economy/china-economy/article/3051175/coronavirus-more-two-thirds-chinasmigrant-labourers-not-yet , Last visit on 3/7/2020.

$$
\text { : (r) }
$$

Sophia Tang, Coronavirus, force majeure certificate and private international law, Issued by Conflict of Laws. Net official website, published on $1 / 3 / 2020$.

Available online at, https://conflictoflaws.net/2020/coronavirus-force-majeure-certificate-and-privateinternational-law/, Last visit on 3/7/2020.

(4) Caterina Benini, The COVID-19 Crisis and Employment Contracts: the Italian Emergency Legislation on Dismissals, Published in The European Association of Private International Law (EAPIL), published on $11 / 5 / 2020$.

See at, https://eapil.org/2020/05/11/the-covid-19-crisis-and-employment-contracts-the-italianemergency-legislation-on-dismissals/, Last visit on 11/7/2020.

$$
r \cdot \varepsilon \text {. }
$$




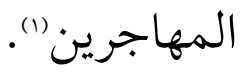

ولأنّ عقود العمل الدولية هي جزء من سلسة عقود تأتّّتَّك فو اجب التأكيد على أنَّ

جلَّ عقود التجارة الدولية المشتمِلة على عنصر أجنبي واحد أو أكثر متوقع تأثّر ها، وإن تفاوت مقدار هذا التأثّر بطبيعة الحال.

(1) Kashish Jaitley, Niharika Kuchhal et al, The COVID pandemic: Time to 'ramp-up' India's conflict of law rules in matters of tort?, Issued by Conflict of Laws.Net official website, published on 14/4/2020.

See at, https://conflictoflaws.net/2020/the-covid-pandemic-time-to-ramp-up-indias-conflict-of-lawrules-in-matters-of-tort-by-kashish-jaitley-niharika-kuchhal-and-saloni-khanderia/ , Last visit on $12 / 7 / 2020$.

ولمن أراد الاستزادة، راجع: كلمة د. مصطفى عبد الجواد حجازي، أثر جائحة فيروس كورونا على عقد

العمل، الندوة القانونية الأولى بعنوان "جائحة كورونا وانعكاساتها القانونية في القانون الخاص"، الثلاثاء إب أبريل 


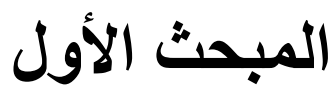 \\ آثار تكين جائحة كورونا كقوة قاهرة أو هادث فوائي تمهيدٌ وتقسيهُ:}

إن التأثير الفعلي للجائحة على عقود التجارة الدولية قد يؤول بالأطراف إلى عدم القدرة على تنفيذ التزاماتهم التعاقدية، وهو ما يدفعهم صوب البحث عن ملاذ يُمكِنهم من التصدِّي للموقف الجديد الذي تعرَّضوا له؛ فدفع أحدهم بالقوة القاهرة، وآخرين بالظروف الطارئة وغيرها على نحو ما ستقف الدراسة.

فلمَّا كان التكييف يَعدُّ تحليل الوقائع أو التصرُّفات القانونية تمهيدًا لإعطائها وصفها الحق ووضعها في المكان الملائم من بين التقسيمات السائدة في فرع معين من فروع القانون(1)، فالتكييف ليست قصرًا على القانون الدولي الخاص، فهو مشكلة ملحَّة()، يمكن أن تعرض بالنسبة لسائر الفروع القانونية الأخرى، وحينئ يلتزم القاضي بأن يخلع على الفعل أو التصرّف الوصفَ القانوني السليمج)؛ فقد خُصِّص هذا المبحث للوقوف عند أحد هذه التكييفات التي قيل بها، والتي قد تُسعف الطرف المدين المتخلِّف عن تنفيذ التزامه على وقع أحداث الجائحة. وبناء عليه قُسم المبحث إلى ثلاثة مطالب؛ عرض أوَّلها شقَّين: أحدهما نظري والآخر علمي بتمهيده للفكرة، وبيان مرتبات إنزال القواعد الكلية للقوة القاهرة أو

( (1) د. هشام صادق، د. عكاشة عبد العال، القانون الدولي الخاص: تنازع القوانين والاختصاص القضائي الدولي،

$$
\begin{aligned}
& \text { مرجع سابق، صV \& ع. } \\
& \text { (r) الموضع السابق ذاته. }
\end{aligned}
$$

(T) د. عكاشة محمد عبد العال مصطفى، الوسيط في تنازع القو انين، مرجع سابق، صیش؟. 
الحادث الفجائي على جائحة كورونا؛ وذلك بييان ماهيتها، ومدى انطباق شروطها التقليدية، ثم الآثار المترتبة على ذلك، من دون إغفال الوقوف عند القانون الواجب التطبيق على العقود الدولية في خضم جائحة كورونا كقوة قاهرة، وما اتصل به من فروض وإشكاليات، ثم عرج ثاني هذه المطالب إلى شرح بعض المسائل الجوهرية ذات الصلة التي لا يتأتى لبناء كان هذا مضمونه أن يكون دون الوقوف عندها؛ كشهادات القوة القاهرة التي أصدرتها بعض الدول على خلفية جائحة كورونا، ومدى حُجيَّة هذه الشهادات وبخاصة أمام محاكم الدول الأخرى، وكذا موقف اتفاقية الأمم المتحدة للبيع الدولي للبضائع، ثم كُلِّلت هذه المطالب بمطلبٍ ثالث فصَّلَ شرح موقفي القانون والقضاء المقارن من اعتبار جائحة كورونا قوة قاهرة، ووضَّحَ مو اقف العديد من الأنظمة القضائية؛ كفرنسا ومصر والو لايات المتحدة الأمريكية، ومواقف بعض القوانين المقارنة؛ كقانون

$$
\text { العقود الفرنسي ونظيره الصيني، كلٌّ في مقامه المناسب. }
$$

تمهيدٌ وتقسيهم::

يقتضي القول باعتبار فيروس كورونا قوة قاهرة حتميَّة الرجوع الأوَّلي لأبعاد

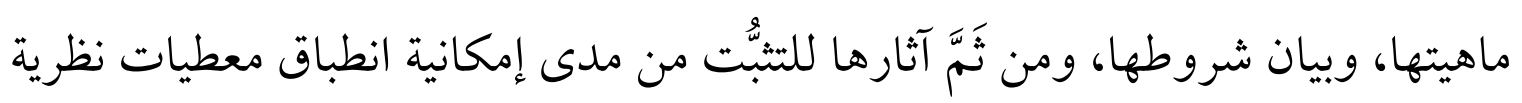
القوة القاهرة مع ما جاءت به جائحة كورونا، يعقبه شرح لفكرة القانون الو اجب التطبيق

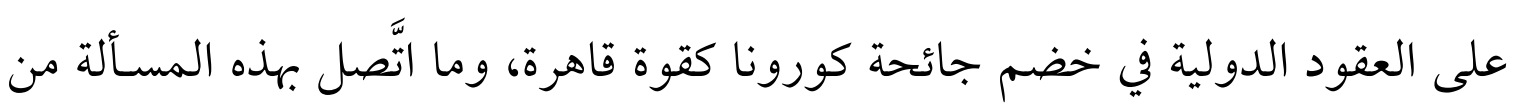
أمور ذات صلة؛ كماهية هذا القانون ونطاقه وغير ذلك. 


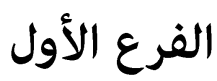

\section{آثار ماهية القوة القاهرة في ضوء جائحة كورونا}

تنصٌّ غالبية التشريعات اللاتينية -التي من بينها مصر - على نصوص تنظّمّم ما يتعلَّق

بالقوة القاهرة Force Majeure؛ فمفهوم القوة القاهرة معروف من قِبَّل معظم النظم

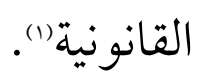

مع الاعتراف بعدم وجود نصوص قانونية متخصصة تتعلَّق بالقوة القاهرة بعينها لدى بعض الأنظمة القانونية في سياق مختلف -كما هو الحال في إيطاليا؛ فلا يوجد لديهم نص قانوني دقيق متخصص يتعلَّق بالقوة القاهرة من شأنه السماح لأطراف العقد التجاري بتجنُبّ أداء التزاماتهم التعاقدية في حالة وقوع حدث يستوجب ذلك (r)، بيد أنَّ هناك أدوات قانونية أخرى لمعالجة مثل هذه الحالات؛ كالاعتماد على بعض الأدوات التشريعية الأخرى التي تفيد في هذا المقام؛ على اعتبار أن من حق الأطراف النص في عقودهم على تنظيم معين للقوة القاهرة، وهنا تلجأ المحاكم في تفسير مثل هذه النصوص وتحديد نطاقها بما ورد في بعض مواد القوانين ذات الصلة كبعض القانون المدني (كالمواد

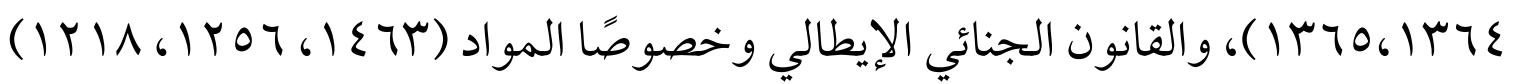

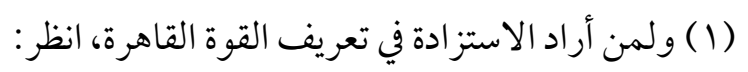

Ewan McKendrick, Force Majeure and Frustration of Contract, Second Edition, Informa Law from Routledge, USA, 2013, Ch. 1.

$$
\text { ولمن أر اد الوقوف على موقف القانون الإنجليزي من القوة القاهرة المثير للجدل، انظر، ذات الموضع السابق. }
$$

(2) " Italy does not have any general statutory provisions relating to force majeure which would allow parties to a commercial contract to avoid the performance of their contractual obligations in case of a supervening event", Alessandro Villani, Francesco Amatori, Covid-19: Impact on commercial contracts, Italy, Issued by linklaters Law Firm, 12 March 2020.

See at, https://www.linklaters.com/en/insights/publications/2020/march/novel-coronaviruscommercial-contracts/novel-coronavirus-impact-on-commercial-contracts/italy , Last visit on $12 / 8 / 2020$ 


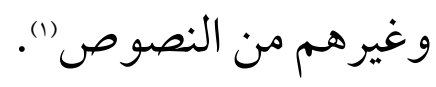

وفحوى القوة القاهرة يكمُن في حدوث أمر طارئ غير متوقَّع يجعل من تنفيذ أحد

الأطراف لالتزاماته أمرًا مستحيلً، فهنا تتدخل التشريعات ومعها الفقه لوضع الآليات

القانونية التي تساعد على إعادة تحقيق التوازن الاقتصادي للعقد، ولقد آثرت ذِكر القوة القاهرة في موضع ترادف مع الحادث الفجائي اتفاقًا مع ما أيَّده الفقيه السنهوري من أنهما شيء واحد، مخالفًا في ذلك لما سار عليه جانب فقهي عريض ومعه القضاء (r). فالقوة القاهرة وجه من وجوه السبب الأجنبي الذي ينفي علاقة السبية بين فعل المدعى عليه وبين الضرر الذي لحق بالمدعي، وبشكل عام: تتطلَّب القوة القاهرة وجود علاقة سبيَّة مباشرة بين الحدث المَعْني والفشل في أداء الالتزام التعاقدي (r). وبإنز ال معطيات جائحة كورونا على القوة القاهرة فإنَّ اعتبار الأولى قوة قاهرة يفيد ما هو أبعد من مجرد إرهاق المدين؛ إذ يكون الطرف المتعاقد في وضع يستحيل معه

(1) هذا وتجدر الإشارة إلى أن هذه القو اعد تعتبر غير إلزامية بطبيعتها، وبالتالي فإن للأطراف حرية تنظيم استحالة أو أحداث القوة القاهرة في عقدهم، انظر المرجع السابق ذاته.

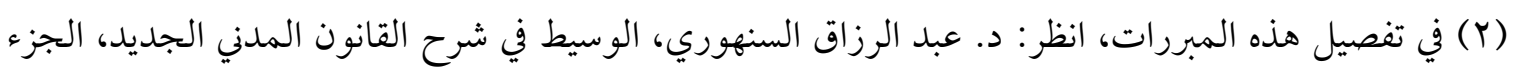

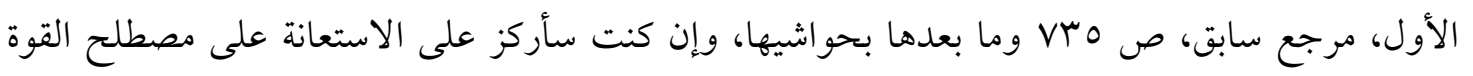

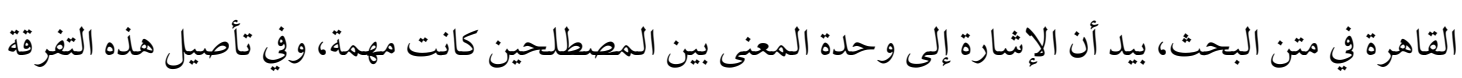

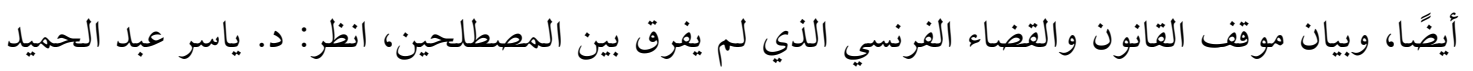

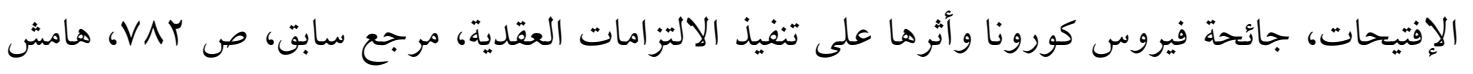

(3) Matteo M Winkler, Practical Remarks on the Assessment of COVID-19 as Force Majeure in International Contracts, Issued by SIDIBlog Official website, Published on 6/5/2020.

See at, http://www.sidiblog.org/2020/05/06/practical-remarks-on-the-assessment-of-covid-19-asforce-majeure-in-international-contracts/, Last visit on 5/7/2020. 
تنفيذ التزامه التعاقدي، جرَّاء تحقق شروط القوة القاهرة، وهو ما يؤدِّي إلى انفساخ

العقد من تلقاء نفسه"(1)؛ فالقوة القاهرة تؤدي إلى استحالة تنفيذ الالتزام، وبالتالي لا

يوجد التزام بالتعويض، ومما يعضِّد التأصيل السابق ما نصَّت عليه المادة (سVY) من

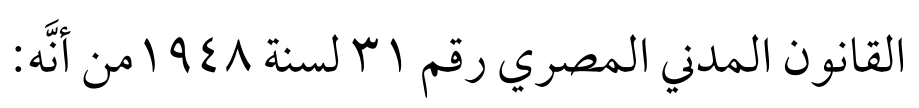

"ينقضي الالتزام إذا أثبت المدين أن الوفاء به أصبح مستحيلًا عليه لسبب أجنبي لا يدّ له فيه"

وعلى إثر الأوصاف السابقة والحجج التي ستقف عندها الدر اسة بالبيان لاحقًا؛ فقد رأى بعض الفقه تكييف جائحة كورونا كقوة قاهرة).

موقف غرفة التجارة الدولية بباريس من القوة القاهرة في سياق جائحة كورونا:

لقد اعتمدت غرفة التجارة الدولية بباريس في شروطها النموذجية لسنة بـ . ب على مصطلح "القوة القاهرة"Clause de Force Majeure، وبحسب الغرفة فالقوة القاهرة تعني: وقوع حدث أو ظرف يمنع أو يُعيق أيَّ طرف من أداء واحد أو أكثر من التزاماته التعاقدية الواردة بالعقد، وذلك إلى الحدّ الذي تأثَّر فيه الطرف (الأطراف) المتعاقدة بالحادث والمتضرر، وعليه إثبات ما يأتي: أ) أنَّ هذا العائق خارج عن سيطرته المعقولة.

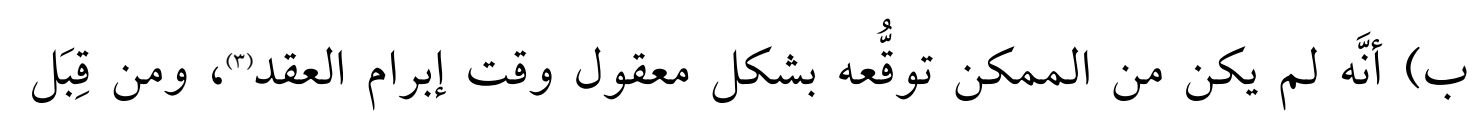

(1) - د. إبراهيم أحاطب، مقالة سابقة الإشارة.

(2) For more details, Claudia Galvis, Jose Moran, et al, Coronavirus Outbreak: Global Guide to Force Majeure and International Commercial Contracts, Issued by global compliance news official website, published on 19/3/2020.

See at, https://globalcompliancenews.com/coronavirus-outbreak-global-guide-to-force-majeure-andinternational-commercial-contracts/, Last visit on 5/7/2020.

(3) Matteo M Winkler, Practical Remarks on the Assessment of COVID-19 as Force Majeure in 
شخص عادي في وقت العقد، وفي الظروف التي تمَّ فيها') (أي إنَّه معيار موضوعي لا شخصي).

ج) أنَّ آثار العائق لم يكن من الممكن للطرف المضرور أن يتجنَّها أو يتجاوزها بشكل معقول

وزيادة في البيان: فقد اعتبرت غرفة التجارة الدولية أنَّ : " الطاعون أو الوباء أو

plague, epidemic, natural disaster or الكوارث الطبيعية أو الأحداث الطبيعية الشديدة extreme natural event وحريٌّ بالذّّكر أنَّ مصطلح القوة القاهرة ذاته قد اعتمدته مبادئ القانون الموحَّد أو المبادئ المتعلقة بعقود التجارة الدولية: (مبادئ معهد روما) مبادئ (\&nidroit في المادة V/ / / بنصِّها على أنَّه: "يُعفى المدين من أثر عدم التنفيذ الذي يثبت أنه يعود لحدث خلارج نطاق توقُّه، والذي من غير المعقول أن يأخذه بعين الاعتبار عند إبرام العقد، أو أن يتوقَّهه أو يتجاوزه

International Contracts, op, cit.,

(1) Ewan McKendrick, Force Majeure and Frustration of Contract, op, cit., Ch. 1.

(2) ICC FORCE MAJEURE CLAUSE (“Clause”), Issued by International Chamber of Commerce, op, cit., p. 1.

(3) Ibid. 2.

$$
\text { ولمن أراد الاستزادة في شرح الشرط، انظر: }
$$

Matteo M Winkler, Practical Remarks on the Assessment of COVID-19 as Force Majeure in International Contracts, op, cit.,

(ع ) "تُعدُّ مبادئ اليونيدروا تقنينًا غير رسمي للقواعد الجوهرية التي تحكم العقود التجارية الدولية، وهى تهدف

إلى تدعيم وتقوية القانون الخاص الدولي، وعلى الرغم من ذلك فبالإمكان تمتع مبادئ اليونيدروا بقيمة قانونية لا تقل عن تلك التي تتمتع بها القواعد القانونية المستمدة من مصادر دولية أخرى "، ولمن أراد الاستزادة، انظر، د. أبو العلا على أبو العلا النمر، دراسة تحليلية لمبادئ معهد روما "اليونيدروا" المتعلقة بعقود التجارة

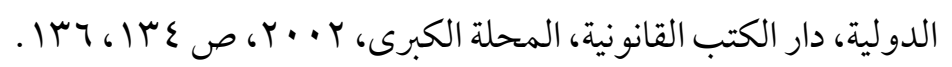




$$
\text { أو يتوقَّع أو يتجاوز آثاره" (1). }
$$

ويُدلِّل الطرح السابق على أنَّهَ ثََّّة فكرة أو مضمون عالمي مألوف يستشعر أهمية

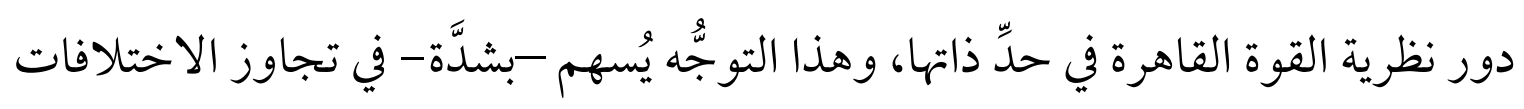
التي قد تبدو جذرية بين النظم القانونية الوطنية، والتي تعيد قانونيَّها تقديم نصوص مبادى التجارة العالمية المشتركة lex mercatoria أو أو كما يُطِلق عليه الفقه الأمريكي بـ "قانون عبر الدول"، أو ما يفضِّل الفقه الأوروبي تسميته بالقانون التجاري المشترك، و التي ساعد على ظهورها استعمال العقود النموذجية من ناحية، وحِرْص المتعاملين على الالتجاء في هذا المجال إلى التحكيم كوسيلة لفضِّ المنازعات التي قد تنشأ بينهم من ناحية أخرى (r)

وإن كان يُلاحظ إجمالًا أنَّ المواقف التي تمَّ تبنِهها على الصعيد الوطني قد تنطوي على اختلافات كبيرة، وفي سبيل التغلّب على هذه المشكلة قد تميل الأطر اف التعاقدية إلى الاتفاق على حلول مستقلَّة، من خلال تضمين بنود عقود القوة القاهرة التي تحتوي

(1) Marcel Fontaine, The evaluation of the Rules on Hardship from the First Study on Hardship Clauses to the Enactment of specific Rules, op, cit., Ch. 1.

$$
\text { ولاطلاع على النص الكامل، انظر: }
$$

Michael Joachim Bonell, An International Restatement of Contract Law: The UNIDROIT Principles of Intonational Commercial Contracts, Third Edition, Transnational Publishers, USA, 2005, p. 473.

ولمزيد من التفاصيل، د. هني عبد اللطيف، حدود الأخذ بفكرة إعادة التفاوض في العقد، رسالة لنيل درجة

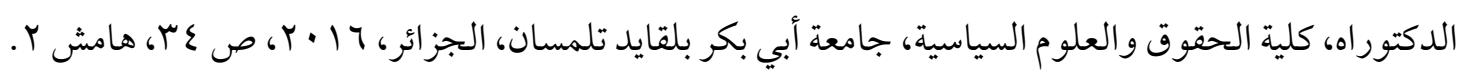

$$
\text { : r) }
$$

Matteo M Winkler, Practical Remarks on the Assessment of COVID-19 as Force Majeure in International Contracts, op, cit.,

(Y) د. هشام صادق، د. عكاشة عبد العال، القانون الدولي الخاص: تنازع القوانين والاختصاص القضائي الدولي،

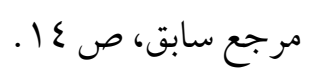


على حلولٍ في عقودهم التي لا تعتمد على خصوصية القوانين الوطنية(1)، وهذا الفهم يقودنا إلى الوقوف بقليل من البيان عند مفهوم العدالة في مجال التجارة الدولية.

\section{مفهوم العدالة في مجال التجارة الدولية:}

لمَّا كان العدل في ذاته ثابتًا لا يتغيَّر، و التعبير عنه يمكن أن يتغيَّر من وقت لآخر ومن مجتمع لآخر(r)، فإنَّ تطبيق مثل هذه "الأفكار على مجتمع التجارة والأعمال العابرة للحدود يقتضي التسليم بأنَّ القانون التجاري الدولي هو تعبير عن العدل الذي صنعه هذا المجتمع، لا العدل المطلق الذي لا يتغير". وعليه: فإنَّ المراد بالعدالة التي يستلهم منها القاضي أو المحكم الحلَّ الواجب لهب لهي الاتباع في حالتنا ليس هو العدل المطلق، وإنما مفهوم العدل كما يعرفه مجتمع التجارة والمال؛ فالقاضي أو المحكم يستلهم العدل المطلق ليخلق حلَّ يواجه به النقص في التشريع أو القانون بصفة عامة، فهو يقوم بما كان يقوم به المشرع فيما لو تبيَّن هذا النقص؛ أي أنَّه يقدّم حلَّا وضعيَّا مستلهمًا من القانون الطبيعي، أي نوعًا من العدل المصنوع، ومن هنا كان حقّ القاضي -بل واجبه- في تغيير الحلول القضائية التي خلقها؛ إذ لم تَعُد ملائمة للتطور الاقتصادي والاجتماعي، فهذه الحلول ليست من العدل المطلقِ، وإنما هي مجرد عدل صنعه القضاء بدلًا من المشرع، ومن ثََّّمَانت الحاجة إلىى تغييرها لمالاءمة تغيُّ الزمان والمكان، ولتيَّقق دائمًا -بقدر الإمكان- مع مطلق

(1) ICC FORCE MAJEURE CLAUSE (“Clause”), Issued by International Chamber of Commerce, op, cit., p. 1.

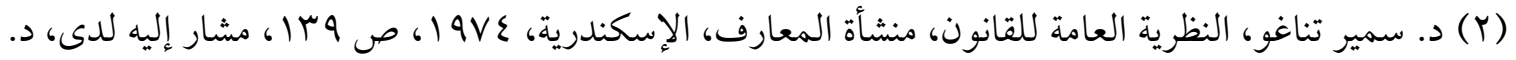
هشام على صادق، القانون الواجب التطبيق على عقود التجارة الدولية، منشأة المعارف، الإسكندرية، 1990 1 


\section{العدل أو العدل في ذاته"(1)}

وبذا يتحلَّد مفهوم العدالة كأحد مكونات القانون التجاري الدولي بوصفه قانونًا

عرفيّا وتلقائَّا في الوقت نفسه؛ فهو "مجموع الأفكار والمفاهيم التي تسود لدى

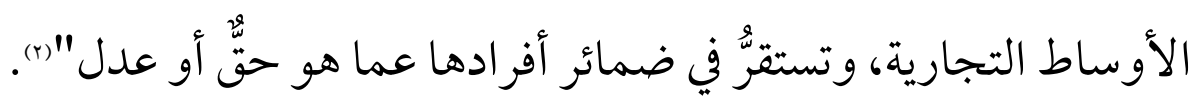

ومكمن الرابط بين القوة القاهرة وقواعد العدالة تمثَّل في ضرب الفقه لبعض الأمثلة

الشهيرة على القواعد التي استلهمها التحكيم باسم العدالة في مجال التحكيم التجاري الدولي؛ كفكرة "التوزيع المتساوي للمخاطر الناتجة عن القوة القاهرة"(r)، رغم أن القوة القاهرة تُعفي المدين أصلًا من التزامه"، ولا يخفى ما في المثال السابق من رسم دقيق للخطوط الفاصلة بين كلٍ من المبادئ العامة وفكرة العدالة أو العدل المصنوع؛ فعلى الرغم من اقتراب فكرة كلٍٍ منهما من الآخر إلَّا أنهما لا يختلطان؛ فالعدالة: هي العدل الذي يضعه قضاء التحكيم في خصوص المنازعات التجارية الدولية استلهامًا من فكرة

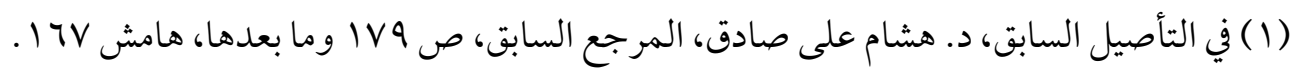

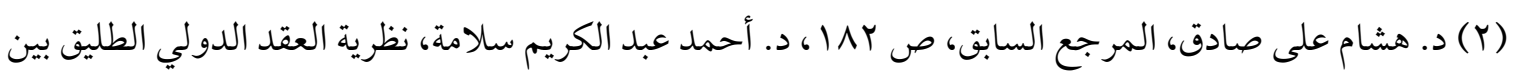
القانون الدولي الخاص وقانون التجارة الدولية، دار النهضة العربية، القاهرة، 919 1، ص الهوب، وحري بالذكر

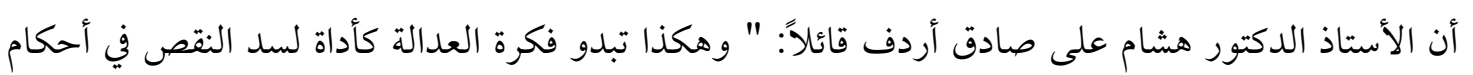
القانون التجاري الدولي دون أن تختلط به. فهذا الأخير يعد نظامًا مستقلاً عن كل القوانين الداخلية من ناحية ومطلق العدالة من ناحية أخرى"، لمزيد من التفاصيل، انظر ذات الموضع السابق لمرجع الأستاذ الدكتور

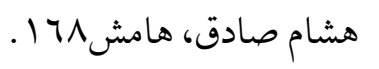

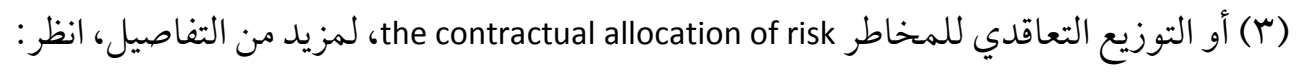
Ewan McKendrick, Force Majeure and Frustration of Contract, op, cit., Ch. 1, Ft. 10, Also, Philipp Reusch , Laura Kleiner Distribution of risk in connection with coronavirus-related trade disruptions, Issued by reuschlaw Legal Consultants German Law firm, March 2020.

See at, https://www.reuschlaw.de/en/news/distribution-of-risk-in-connection-with-coronavirus-relatedtrade-disruptions/ Last visit on 4/7/2020. 
العدل المطلق، أما المبادئ العامة: فهي في حقيقتها تقف في مرحلة وسطى بين العدل

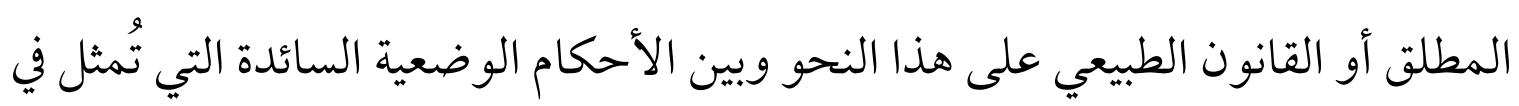
حالتنا الأعراف و العادات التجارية"(1)، ولا يخفى ما في فحوى الطرح السابق من مرتبات مبعثها إنزال مقتضياتها على جائحة كورونا.

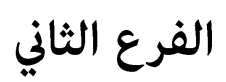

مدى انطباق الشروط التقليدية للقوة القاهرة على جائحة كورونا وآثار انطباقها

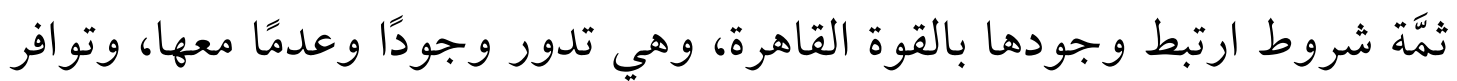
هذه الشروط مدعاة لتوافر مسوغات تطبيق النظرية، ومن ثَمََّّتبيب آثارها القانونية، والعكس صحيح. وعليه: ستقف سطور الدراسة القادمة عند كلا الأمرين على التوالي.

\section{الغصن الأول}

\section{الشروط التقليدية للقوة القاهرة في ضوء جائحة كورونا.}

هناك مناقشات عدَّة تدور في الأروقة الآن بين جماهير الفقه، فحواها مدى إمكانية انطباق الشروط التقليدية للقوة القاهرة على جائحة كورونا؛ كي تتجلَّى من خلاله أبعاد الفكرة محالّ البيان في ذات المقام، وذلك على ما يأتي:

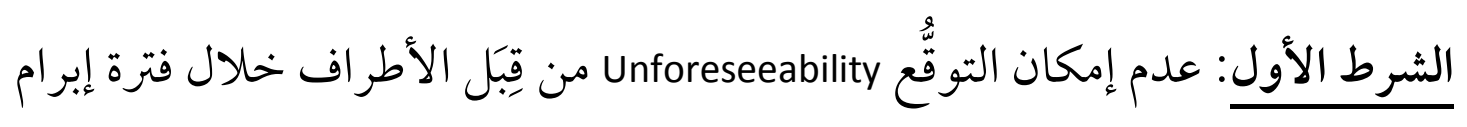
العقد. وهذا الشرط يُراد به أن يكون الحادث ذاته، الذي يتمّ التذرّع بكونه قوة قاهرة غير

$$
\begin{aligned}
& \text { (1) في هذا التأصيل السابق، د. هشام على صادق، المرجع السابق، ص (1 | وما بعدها. } \\
& r \cdot 01
\end{aligned}
$$


ممكن التوقُع؛ فإذا أمكن توقُعه حتى لو استحال دفعه (وهو الشرط الثاني) لم يكن قوة

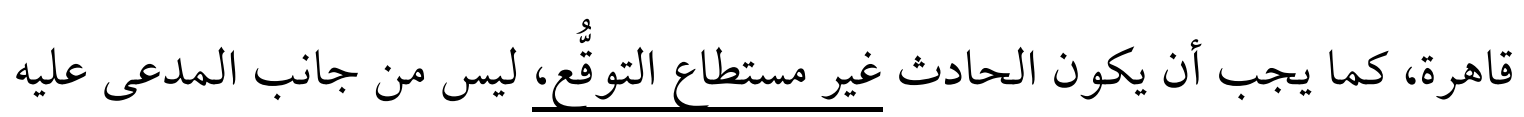

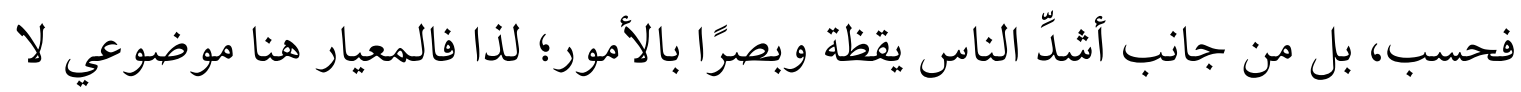

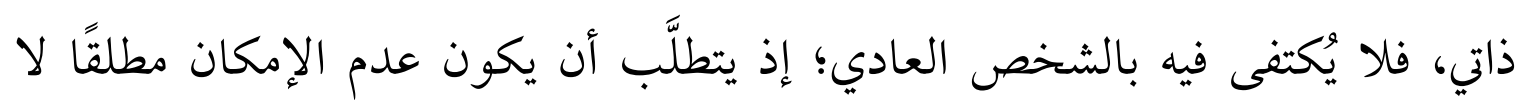
نسبيَّا

وعليه: فالحادث يكون ممكن التوقُع لمجرد أنَّهَ سبقَ وقوعه فيما مضى، فقد يقع

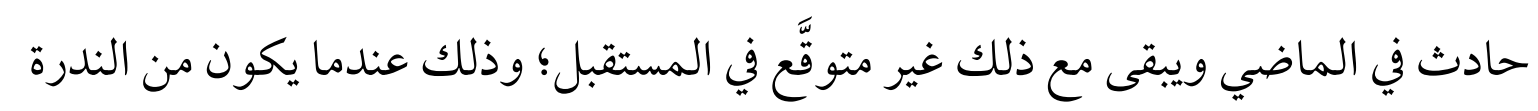

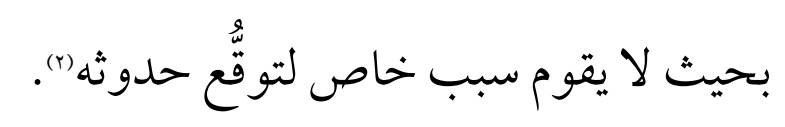

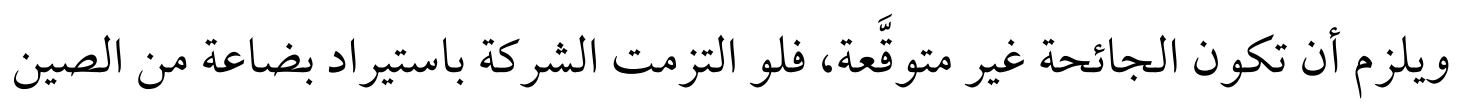

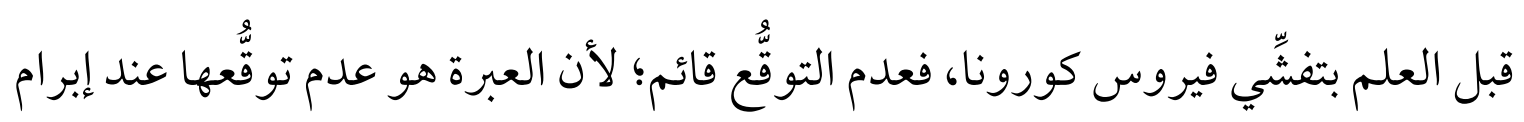

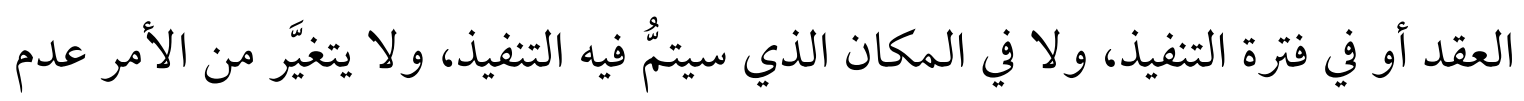
اعتبار الفيروس في أوَّله وباء، فما دام لم يسبب اضطر ابًا في المكان الذي يلزم المدين

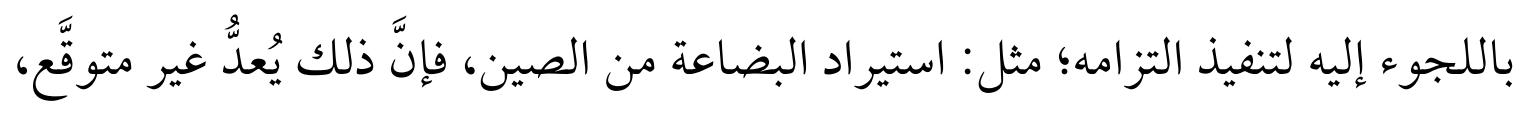

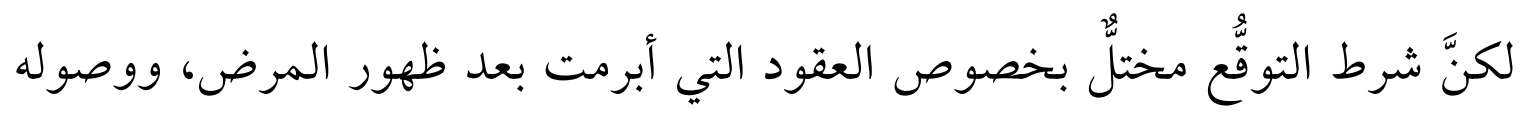

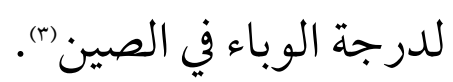

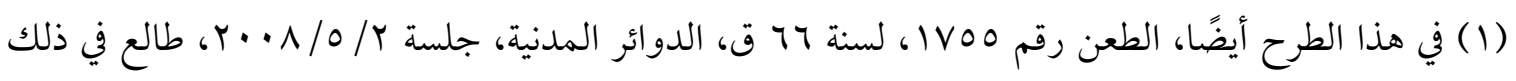

$$
\text { الرابط الالكتروني الرسمي لمحكمة النقض المصرية، }
$$

See at, https://www.cc.gov.eg/judgment single?id=111273720\&ja=72131 , Las visit on 23/6/2020.

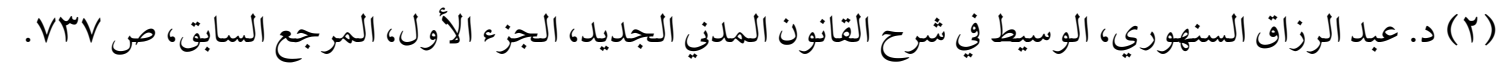

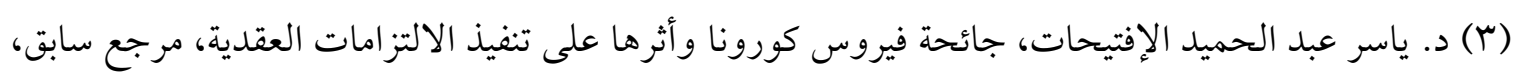
.VAVGVAT ص 
ولقد ذهبت بعض الأنظمة القضائية بالفعل إلى عدم اعتبار بعض الحالات الوبائية من قبيل القوة القاهرة؛ كالسارس الذي قيل بأنَّ كون الفيروس له لقاح يجعل منه حدثًا

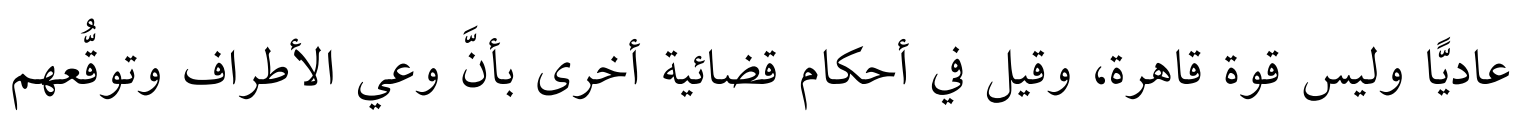
بوجود الحدث ينفي تو افر أحد شروط القوة القاهرة"). وعلى صعيد متَّصل: فالنظر في موقف المشرع الفرنسي من القوة القاهرة -على

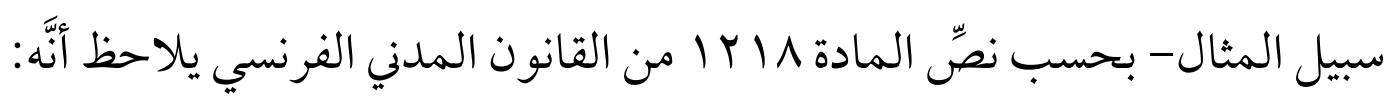
"إذا تعلَّق الأمر بوجود قوة قاهرة في العقود، عندما يكون هناك حدث خارج عن سيطرة المدين، وهو ما لم يكن من الممكن توقُّهُ بشكل معقول عند إبرام العقد، وِلا يمكن تجنبّ آثاره باتخاذ التدابير المناسبة، وعلى نحو يمنع المدين من أداء التزامه؛ وإذا كان العائق أو الحدث مؤقتًا: يتمُّ تعليق تنفيذ الالتزام ما لم يبرر التأخير الناجم عن ذلك إنهاء العقد، وإذا كان العائق نهائيَّا: يتمُّ إنهاء العقد تلقائيّا، ويتمُّ تحرير الأطراف من التزاماتهم

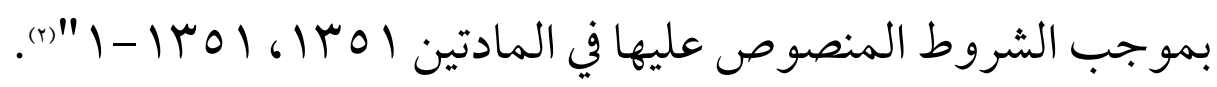

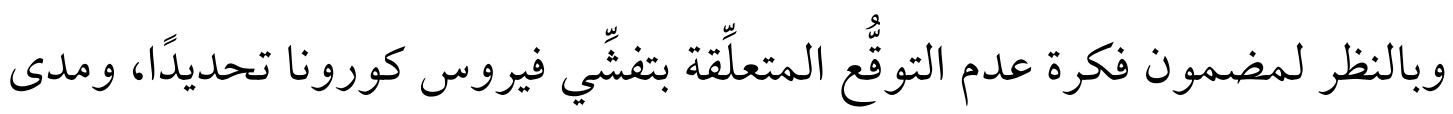
إمكانية تطبيق هذا الشرط عليه، فهناك احتمالية لتذّرع الأطراف المتعاقدة في العقود فيرون

(1) في هذا الطرح، راجع الندوة افتراضية بعنوان الآثار القانونية لفيروس كورونا المستجد على العقود الدولية للأعمال التي نظمتها كلية القانون، جامعة أبو ظبي، سابقة الإشارة، وبالتحديد كلمة الدكتور سمير أوخليفا.

(2) Luc Grynbaum, Force majeure et épidémie de COVID -19: une première décision vient d'être rendue, op, cit.; Also Constance Verroust-Valliot et Serge Pelletier, L'impact du covid-19 sur les contrats de droit privé, Issued by DALLOZ official website, ÉDITION DU 9 JUILLET 2020, Éditions précédentes, published on 09 Juin 2020.

Available online at, https://www.gide.com/fr/actualites/covid-19-lois-de-police-et-ordonnances-2020, Last visit on 9/7/2020. 
التجارية بأحكام القوة القاهرة بغرض تبرير التأخير أو عدم الأداء(1)؛ لذا لا يُعدُّ مبالغةً

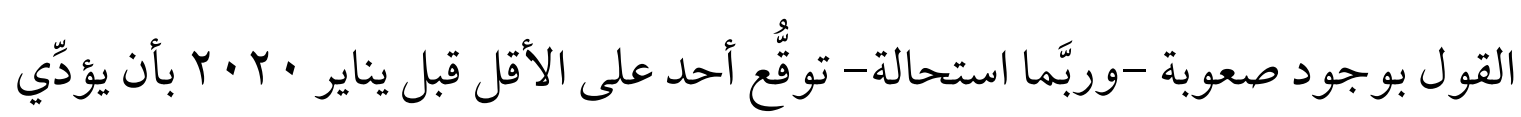

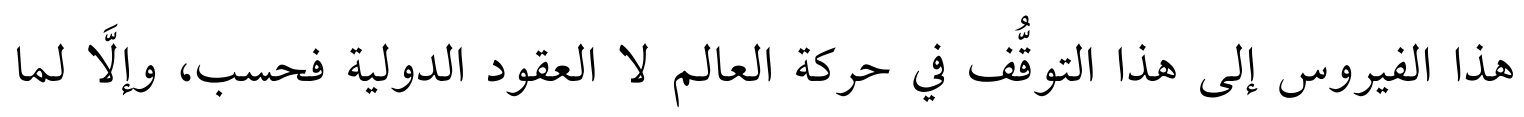
تزامنت بدايات الإجراءات الصحية الاحترازية لكثير من دول العالم مع شهر مارس

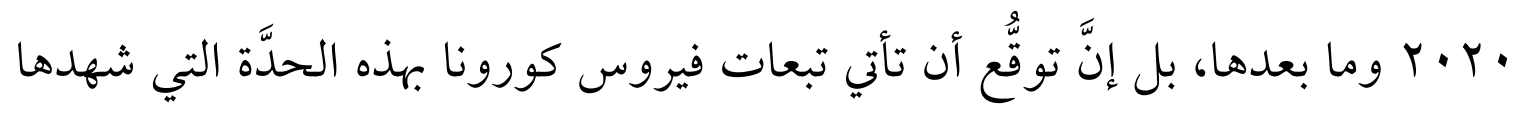

$$
\text { العالم هو درب من دروب الخيال العلمي. }
$$

لذا فلو أتى إبرام العقد بعد حصول جائحة كورونا، وكاب مكان مكان استير اد البضاعة من بلد لم ينتشر فيه الوباء، فإنَّ الشركة لها أن تحتجّ بعدم التوقُّع عندما تقوم السلطات إنهات

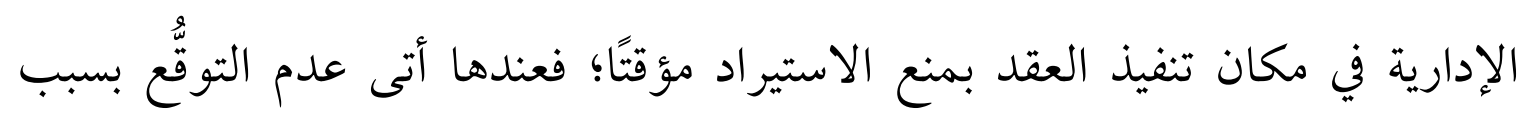

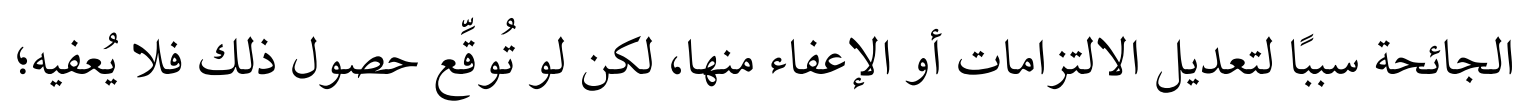
حيث إنَّهَ لا يمكن أن يعدَّ ذلك مثل القوة القاهرة)(1).

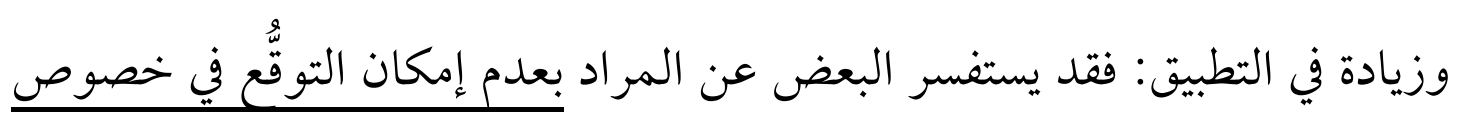

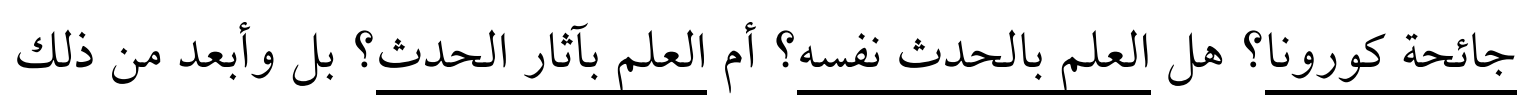

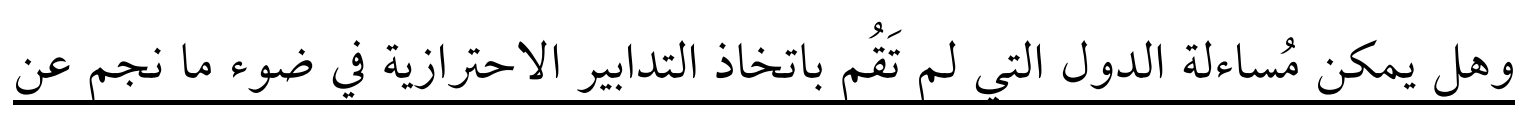
ذلك من أضرار لحقت بالشركات التي حملت جنسيتها؟

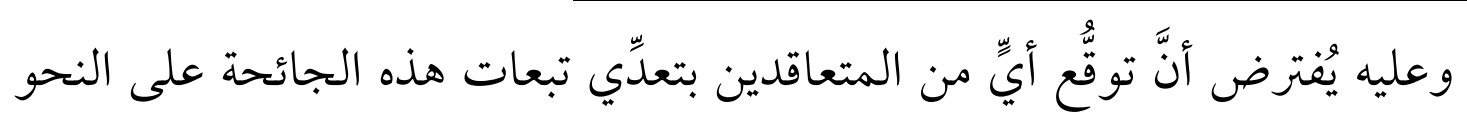

(1) Claudia Galvis, Jose Moran, et al, Coronavirus Outbreak: Global Guide to Force Majeure and International Commercial Contracts, op, cit.,

(Y) د. ياسر عبد الحميد الإفتيحات، جائحة فيروس كورونا وأثرها على تنفيذ الالتزامات العقدية، مرجع سابق،

$$
. \vee \wedge V_{ص}
$$


الذي حدث من شأنه تغيُّ الموقف الذي يتعيَّن اتخاذه تجاههم؛ فمعلوم أنَّ الجائحة لم تتطرَّق أبواب دول العالم بين عشية وضحاها؛ إذ كان هناك فارق زمني بين ظهورها في الصين، ثم انتشارها تباعًا في كافة دول العالم، الواحدة تلو الأخرى، حتى وصل الحال إلى ما نحن عليه الآن، هذا هو العلم بالحدث. وعليه: فيمكن لأيٍّ من الأطراف التعاقدية التذرّع بمعرفته بوجود الوباء، دون آثاره أو الأبعاد التي وصل إليها هذا الوباء في ضوء الإجراءات الصحية الاحترازية التي قامت بها العديد من الدول، و التي قد تختلف في أبعادها من دولة لأخرى - إلَّا أنَّ ما يعنينا هنا هو أنَّ ميعاد بدايتها الذي يختلف -بطبيعة الحال- من دولة لأخرى؛ فهل كان عليهم القيام بإجراءات أخرى لتجاوز هذا الوباء من عدمه؟ وبالنسبة للتساؤل حول مدى إمكانية مُساءلة الدول التي لم تَقِم باتخاذ التدابير الاحترازية بالنظر لما لحق بالشركات التي حملت جنسيتها من أضرار؛ فلعلَّ من الأولى في هذا السياق النظر إلى طبيعة النشاط ذاته محل الحديث للبحث: هل رخصت الدولة في القيام به من عدمه؟ فهناك أنشطة سمحت الدول القيام بممارستها على الرغم مما اتخذته من إجراءات احترازية في هذا الخضم، ثم يعقب ذلك النظر في مدى قيام مسئولية

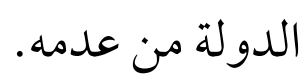
الشرط الثاني: استحالة الدفع استحالة مطلقة؛ بمعنى أنَّه يجب أن يكون الحادثُ ذاته الذي يتمُّ التذرع بكونه قوة قاهرة أو حادث فجائي مستحيلَ الدفع، فإذا أمكن دفع الحادث حتى لو استحال توقُعه (وهو الشرط الأول) لم يكن قوة قاهرة أو حدثًا فجائيًا، وأن تكون الاستحالة مطلقة؛ فلا تكون استحالة بالنسبة إلى المدين وحده، بل استحالة بالنسبة إلى أيّّ شخص يكون في موقف المدين، وهذا هو الذي يميّز بين نظرية القوة 
القاهرة ونظرية الحوادث الطارئة، ففي الأخيرة يصبح تنفيذ الالتزام مرهقًا لا

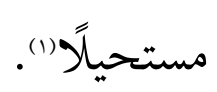

وفي مجمل شرطي استحالة الدفع وعدم إمكان التوقُع: فقد عبَّرت محكمة النقض

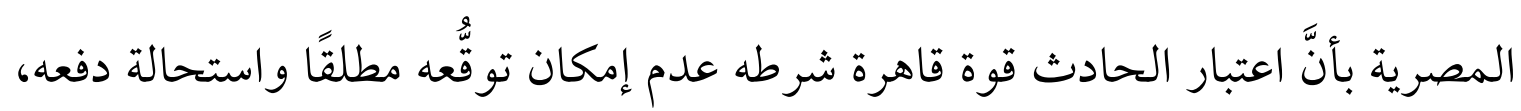

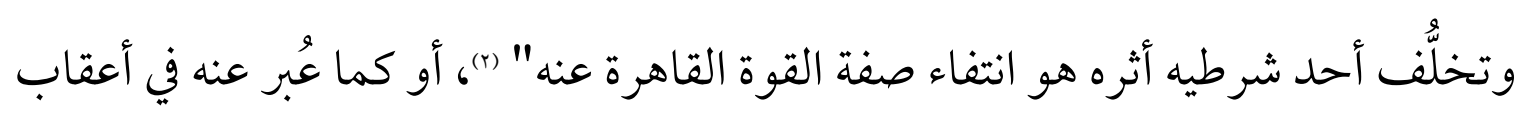
جائحة كورونا عدم إمكان دفعه أو السيطرة عليه؛ وعليه: فإذا فرضت الحكومة مثلًا حظرًا إجباريًّا، أو منعت التجمعات وشدَّدت على التباعد الاجتماعي، فهنا لا يمكن للشركة أن تدَّعي وجود عوائق لا يمكن السيطرة عليها إذا كان العمل عن بُعد ممكنًا، وبالتبعية: هناك إمكانية للوفاء بالالتزامات التعاقدية المنصوص عليها بالعقد وممكن

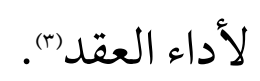

وعليه: يجب أن يكون الحادث من شأنه أن يجعل تنفيذ الالتزام مستحيلًا استحالة

مطلقة، ليست فقط استحالة بالنسبة إلى المدين وحده، بل استحالة بالنسبة لأيِّ شخص في موقف المدين (2) - مون.

(1) في هذا الشرط، انظر، د. عبد الرزاق السنهوري، الوسيط في شرح القانون المدني الجديد، الجزء الأول، المرجع إنقا

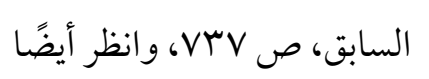

Ewan McKendrick, Force Majeure and Frustration of Contract, op, cit., Ch. 1.

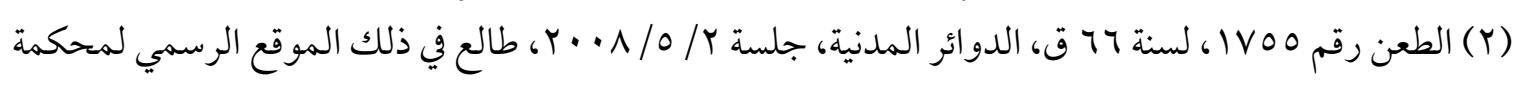

$$
\text { النقض المصرية، }
$$

See at, https://www.cc.gov.eg/judgment single?id=111273720\&ja=72131 , Last visit on 23/6/2020.

(3) Sophia Tang, Coronavirus, force majeure certificate and private international law, op, cit., p. 4.

(ع) انظر، د. عبد الرزاق السنهوري، الوسيط في شرح القانون المدني الجديد، الجزء الأول، المرجع السابق، ص

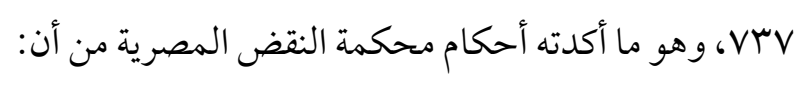


لذا قيل بأنَّ شرط إمكانية التوقُع لا شكَّ في وجوده ولن تتمَّ مناقشته؛ ففيروس كورونا هو فيروس جديد فعلاً، وعليه يبقى السؤال قائمًا عن -الشرط الثاني- عدم استحالة الدفع؛ فهل يمكن للمسافرين أن يأمنو اعلى أنفسهم من عواقب هذا الفيروس، وبخاصة في غياب العلاج الوقائي (اللقاح)، وكذا العلاج ولو في الوقت الحالي؟ وهو ما أجاب عليه البروفيسور والمحامي Luc Grynbaum بأنَّ فيروس كورونا هو حدث لا يُمكني للمسافرين دفعه".

وعليه: فإذا افترضنا وجود مجموعة من الأنشطة قد رخصت الدول في القيام بإجر اءات صحيحة صارمة بصددها، ولكن الحادث هو أنَّ بعض هذه الأنشطة ماز الت متاحة في بعض الدول بشكل يُصعب على المتعاقدين الدفع بشرط استحالة التنفيذ؛ مثل: صعوبة تنقّل العمال لأماكن العمل لتوقُّ المواصلات، وعليه: فالقوة القاهرة يجب أن تتعلق بحادث، ليس فقط مستحيل الدفع بل -أيضًا - غير ممكن التوقُّع (r). وبالنسبة لتقييم مدى استحالة التنفيذ، فلابد أن يُبتبت المتعاقدان استحالة التنفيذ، وكلما كانت هناك إمكانية للتنفيذ تكون القوة القاهرة منعدمة. وإمعانًا في إنزال مضمون شرط استحالة الدفع على جائحة كورونا: فقد فرَّق بعض

"ويجب أن يكون الحادث من شأنه أن يجعل تنفيذ الالتزام مستحيلاً استحالة مطلقة؛ فلا تكون استحالة بالنسبة إلى

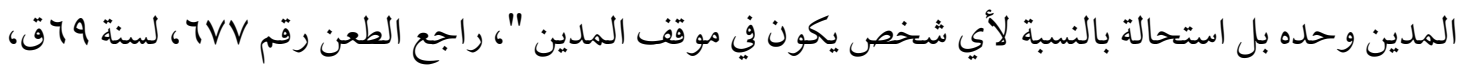

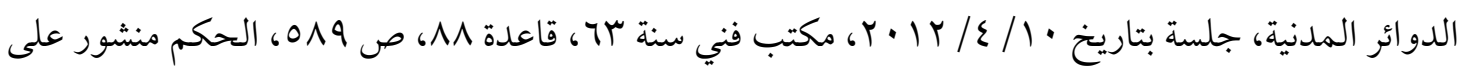

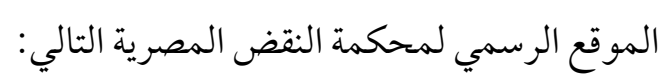

See at, https://www.cc.gov.eg/judgment single?id=111237663\&ja=69812, Last visit on 23/6/2020

(1) Luc Grynbaum, Force majeure et épidémie de COVID -19: une première décision vient d'être rendue, op, cit.,

$$
\text { (Y) د. عبد الرزاق السنهوري، الوسيط في شرح القانون المدني الجديد، المرجع السابق، ص VYO وما بعدها. }
$$


الفقه") بين مدى تأثير الفيروس ومدى استحاله دفعه بين فرضين: العقود التي أبرمت قبل الجائحة، و التي أصبح تنفيذها مستحيلًا بعدما استشرى الوباء، والعقود التي أبرمت بعد انتشار الوباء، والتي لا يمكن القول بأن تنفيذها أصبح مستحيلًا لسبب خارج عنهم، مع أهمية التفرقة بين إبرام العقد وتجديده.

ومما تجدر الإشارة إليه أنَّ شرط استحالة الأداء قد يُفسَّر في بعض الظروف الاستثنائية بتوجُه معين، حتى في حالة عدم وجود نصِّ تعاقدي، وذلك بالنظر للمو اقف التي جعلت التدابير الحكومية من خلالها الأداء مستحيلً، حتى قيل بأنه يمكن القول بأن التدابير الفعلية التي اتخذتها السلطات الوطنية في الصين في أعقاب تفشّي جائحة كورونا يمكن أن تؤدّي إلى عذر ينطبق عليه استحالة الأداء (أو القوة القاهرة) كون هذه التدابير قد جعلت تنفيذ الأداء في الو اقع أمرًا مستحيلًا. وفي المقابل فإذا اعتّبر أنَّ تفشِّي فيروس كورونا أو التدابير الحكومية ذات الصلة تُتِّب استحالة مؤقتة، فلن يُعفى من الأداء إلَّا في الفترة التي ظلَّ فيها الأداء مستحيلًا قانونيًّا أو ماديَّا (r).

الشرط الثالث: هذا الحدث لا يرجع لسبب يعود إلى أيِّ من المتعاقدين أو أحدهما

$$
\begin{aligned}
& \text { (1) راجع، كلمة د. جابر محجوب، أثر جائحة كورونا على تنفيذ العقود، الندوة القانونية الأولى بعنوان "جائحة }
\end{aligned}
$$

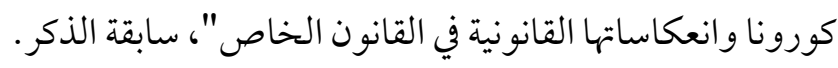

(2) Anton A. Ware, Jeffrey Yang et al, What to Do When You Receive a Coronavirus-Related Force Majeure Notice, , Issued by Arnold \& Porter official website, 4/3/2020.

See at, https://www.arnoldporter.com/en/perspectives/publications/2020/03/what-to-do-when-youreceive-a-coronavirus Last visit on 4/7/2020.

$$
\text { ولمن أراد الاستزادة في موقف محاكم نيويورك من القوة القاهرة، انظر المقالة التالية سابقة الإشارة: }
$$

Claudia Galvis, Jose Moran, et al, Coronavirus Outbreak: Global Guide to Force Majeure and International Commercial Contracts, op, cit., 
Externality (المؤثر الخارجي)

ثمَّة شرط ثالث اشترطته البعض، وبمقتضاه لا يمكن للطرف المدين أن يتهرب من مسئوليته التعاقدية إذا كان الحادث أو الضرر الناتج عن الحدث يعود لأيِّ من الطرفين؛ و إلَّا فلم يتنصل الطرف المتعاقد حينئ من تنفيذ التزامه، وفي هذا الأمر تطبيقات عدَّة، لا يتّسع المقام لذِكرها؛ لعمومها وعدم اتصالها المباشر بالفكرة محالّ البحث (1) . ويكفينا هنا الإشارة إلى أنَّ هذا الشرط في حدّ ذاته قد اختلفت حوله الآراء فقهيَّا وقضائَّا؛ فجائحة كورونا يتو افر فيها هذا الشرط المؤدِي لاستحالة التنفيذ، بشرط أن لا يُثبَت وجود إهمال من الطرف المدعي للضرر؛ فمثلاً: لو طالبت شركة استير اد لبضاعة بتعديل التزاماتها العقدية بسبب الجائحة، فستكون ملزمة بأن تُبتِت عدم وجود إهمال وتأخير بالتنفيذ عن الموعد المحلَّد لهذا التنفيذ من جانبها، وأن تُثبت كذلك بذلها العناية اللازمة في حفظ المواد المستوردة، وأنَّا الجائحة هي التي أخَّرت التنفيذ خوفًا من التلوث، ولنفاذ مثل هذا الشرط يلزم إثبات أنَّ عنصر الخارجية هو سبب التأخير في التنفيذ.

فلا يُعدُّ عنصرًا خارجيَّا -في مثالنا- إذا ثَبْت أنَّ الشركة لم تتَّع التعليمات التي صدرت من الجهات المختصة؛ مثلاً: في منع استيراد البضاعة من الصين بعد الإعلان عن الوباء فيها، على اعتبار أن خطأ الشركة هو السبب في عدم التنفيذ(r).

$$
\text { (1) (1) ولمن أراد الاستز ادة، انظر: }
$$

Ewan McKendrick, Force Majeure and Frustration of Contract, op, cit., Ch. 1.

(Y) د. ياسر عبد الحميد الإفتيحات، جائحة فيروس كورونا وأثرها على تنفيذ الالتزامات العقدية، مرجع سابق،

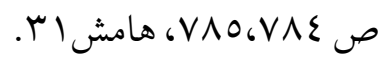


وبناء عليه: فقد يبدو من الأفضل عدم استخدام لفظ الخارجية كونه مثيرًا للاختلاف، على أن تكون العبرة في كون الحدث المعتبر قوة قاهرة غير منسوب للمدين على نحو أو آخر، على اعتبار أنَّ اشتراط الخارجية يضع قيدًا لا مسوٌّغ له، فما دام القاضي

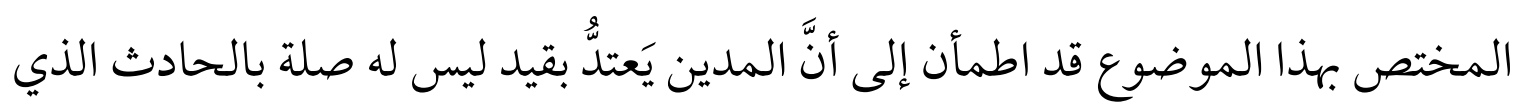

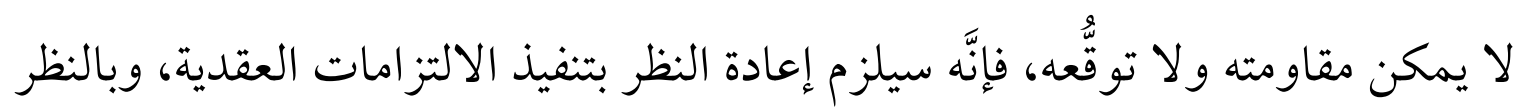
لما في هذا الطرح من صون لمصلحة الأطر اف التعاقدية (1). وبتسليط الضوء على مواقف بعض التشريعات المقارنة من شروط القوة القاهرة؛ كالمشرع القطري على سبيل المثال الذي جعل القوة القاهرة سببًا أجنبيّا يُعفي من

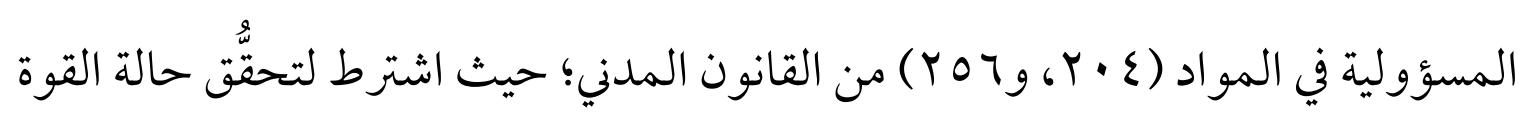
القاهرة استحالة تنفيذ الالتزام، وأن تكون غير متوقَّعة الحصول وقت التعاقد ويستحيل

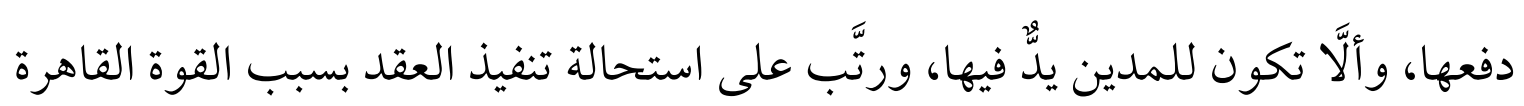
انفساخَ العقد من تلقاء نفسه، وعودة المتعاقدين إلى الحالة التي كانا عليها قبل

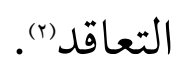

\footnotetext{
(Y) لمزيد من التفاصيل، انظر الحوار الذي أُجري مع بعض المحامون وخبراء القانون، منشور بالموقع الرسمي

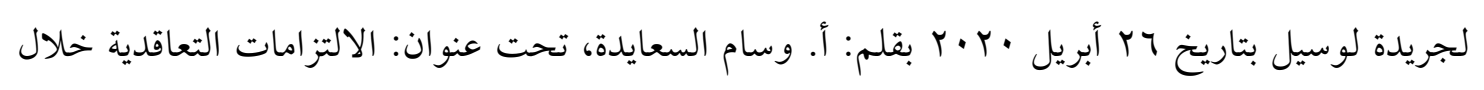

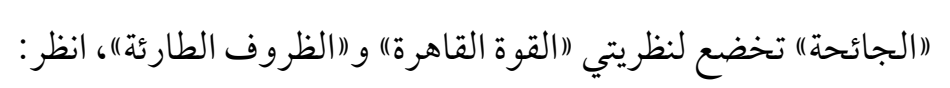

See at, https://lusailnews.net/article/knowledgegate/files/26/04/2020/\%D8\%A7\%D9\%84\%D8\%A7\%D9\%84\% D8\%AA\%D8\%B2\%D8\%A7\%D9\%85\%D8\%A7\%D8\%AA-\%D8\%A7\%D9\%84\%D8\%AA\%D8\%B9\%D8\% A7\%D9\%82\%D8\%AF\%D9\%8A\%D8\%A9-\%D8\%AE\%D9\%84\%D8\%A7\%D9\%84\%D8\%A7\%D9\%84\%D8\% AC\%D8\%A7\%D8\%A6\%D8\%AD\%D8\%A9-\%D8\%AA\%D8\%AE\%D8\%B6\%D8\%B9-\%D9\%84\%D9\%86\% D8\%B8\%D8\%B1\%D9\%8A\%D8\%AA\%D9\%8A-\%D8\%A7\%D9\%84\%D9\%82\%D9\%88\%D8\%A9-\%D8\%A7\% D9\%84\%D9\%82\%D8\%A7\%D9\%87\%D8\%B1\%D8\%A9-\%D9\%88\%D8\%A7\%D9\%84\%D8\%B8\%D8\%B1\% D9\%88\%D9\%81-\%D8\%A7\%D9\%84\%D8\%B7\%D8\%A7\%D8\%B1\%D8\%A6\%D8\%A9 , Last visit on 20/9/2020. 
وتجدر الإشارة في هذا المقام إلى بعض التطبيقات العملية للقوة القاهرة التي أشار إليها العلامة السنهوري، والتي اعتبرت قوة قاهرة نظرًا لاجتماع شرطي استحالة التوقُّع واستحالة الدفع؛ منها: وقوع حرب، أو زلزال، أو حريق أو غرق، أو هبوب عاصفة، أو حدوث مرض طارئ، أو إضراب غير متوقَّع، أو سرقة، أو تلف (1). كما دلّل الفقه كذلك على بعض الأحداث الواقعية ذات الصلة منها اعتبار وباء التيفويد قوة قاهرة؛ كونها منعت الممثّل من استئناف أعماله الفنية، وبحسب ما أشار حكم محكمة الاستئناف الفرنسية(r). ولعلَّ الطرح السابق يؤيّده توجُه العلامة السنهوري من تطبيقات متعددة للقوة القاهرة، وعدَّد من بينها حدوث مرض طاري؛ فعلى الرغم من الاختلاف بين المرض و الوباء إلَّا أنهما يتفقان في الأساس الصحي الطبي، فقد أفاد الفقيه السنهوري أنَّ المرض الطارئ يُعدُّ من قبيل القوة القاهرة التي ترفع المسئولية عن المدين، مادام شرطا استحالة التوقُع واستحالة الدفع قد توافرا، إذن فالبادي أنَّ العبرة بالأثر المترتِّب على الحدث تِّن الذي يُقال باعتباره قوة قاهرة'(r).

( (1) لمزيد من التفاصيل، حول هذه الأمثلة، د. عبد الرزاق السنهوري، الوسيط في شرح القانون المدني الجديد، مرجع

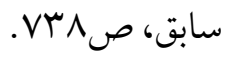

$$
\begin{aligned}
& \text { (Y) لمن أراد الاستز ادة، راجع: }
\end{aligned}
$$

"a typhoid epidemic in a town in which an actor had undertaken to appear was held to constitute force majeure" , Ewan McKendrick, Force Majeure and Frustration of Contract, op, cit., Ch. 1.

$$
\text { وللوقوف على القضية المذكور، انظر المرجع ذاته. }
$$

(r) في تفصيل ذلك، انظر، د. عبد الرزاق السنهوري، الوسيط في شرح القانون المدني الجديد، مرجع سابق، ص

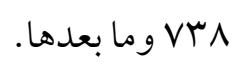


ثمة نقطة أخرى ينبخي الوقوف عندها مادام السياق متصلاً بمدى انطباق الشروط التقليدية للقوة القاهرة على جائحة كورونا وآثار انطباقها؛ ألا وهى التزامات المدين الذي يدفع باعتبار جائحة كورونا قوة قاهرة، وهو ما ستقف عنده السطور القادمة.

\section{التزامات المدين الذي يدفع باعتبار جائحة كورونا قوة قاهرة:}

إنَّ الحديث عن العلاقة بين القوة القاهرة وفيروس كورونا في سياق عقود التجارة الدولية يتطلَّب التأكيد على أنَّ المدين المتعاقد الذي يريد إنهاء عقده أو عدم الوفاء

$$
\text { بالتزاماته العينية، يتعيَّن عليه إثبات (1): }
$$

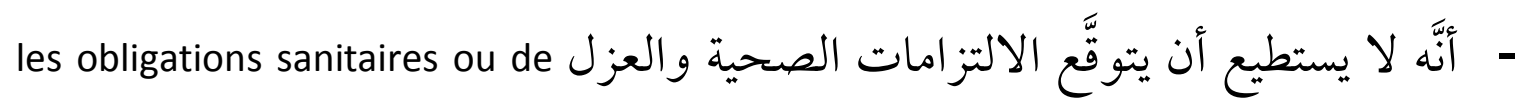

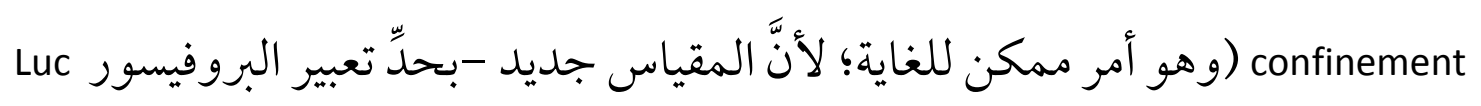

.(Grynbaum

$$
\text { - أنَّه لم يكن من الممكن إيجاد حلول أخرى لتنفيذ التزامه التعاقدي. }
$$

- ـوجود علاقة السبية بين عدم قدرته على الوفاء بالتزامه أو التنفيذ وفيروس كورونا؛ فعلى سبيل المثال عليه أن يُبرهن بالمستندات الداعمة ما واجهه من صعوبات مادية،

$$
\text { تتمثل في عدم توافر السيولة النقدية لديه، والتي نشأت خلال فترة تفشّي المرض. }
$$

وبناءً على ما مضى: فالنظر إلى تأثير جائحة كورونا يفيد أنَّه ينبغي توافر الشروط السابقة على تنفيذ الالتزام التعاقدي كي يمكن الدفع على إثر تو افرهم بالقوة القاهرة، وفي القول تفصيل سيوضحه الغصن القادم.

(1) Luc Grynbaum, Force majeure et épidémie de COVID -19: une première décision vient d'être rendue, issued by le club de jurists official website, published on 25/3/2020.

See at, https://www.leclubdesjuristes.com/blog-du-coronavirus/que-dit-le-droit/force-majeure-etepidemie-de-covid-19-les-premieres-decisions-viennent-detre-rendues/, Last visit on 10/7/2020. 


\section{الغصن الثاني}

\section{أثر انطباق الشروط التقليدية للقوة القاهرة على جائحة كورونا}

إنَّ اجتماع شرطي القوة القاهرة اللذين تمَّت الإشارة إليهما؛ بأن يكون الحدث نفسه

لا يتعلق بالمدين، فهو خارج نطاق سيطرته، ولا يمكن نسبته إليه، ولا يمكن التنبؤ به؛ أي إنَّه لم يكن من الممكن توقُّهُ بشكل معقول عند إبرام العقد، ويُستحال دفعه. وكأنَّ استحالة الدفع هذه قد ولَّدت استحالة التنفيذ، فلا يمكن حتى تجنبّ هذه الآثار بإعمال بعض التدابير المناسبة، فهي استحالة حقيقية تشّكّل عقبة في طريق تنفيذ الالتزامات التعاقدية، ولا يمكن التغلُّب عليها، وليست مجرد صعوبات عادية مرهقة، و إلََّّ فإذا كان بإمكان المدين تنفيذ العقد، فإنَّهَ يكون ملزمًا به، حتى لو كان هذا التنفيذ باهظًا للغاية بالنسبة له(1)، إلى جوار خارجية المؤثِّ. وعليه: فالنتيجة القانونية المباشرة للشروط المذكورة هي إمكانية تحلُّل المتعاقدين من الالتزام، ومن ثَمَّ فسخ العقد من دون تعويض، وهو ما يعني تحقيق ما يصبو إليه المتمسّك بالقوة القاهرة من ناحية الإعفاء من المسئولية وربما إنهاء العقد، حال كون استحالة تنفيذ الالتزام التعاقدي استحالة مطلقة)، وبعبارة أخرى: فإنَّ اجتماع وجود الشروط المذكورة نتيجته القانونية المباشرة هي تحلّل المتعاقد من الالتزام والمسئولية، وقد يترتَّب على ذلك فسخ الالتزام بدون تعويض، وبخاصة إذا قام المتعاقد بما يلزم

(1) Constance Verroust-Valliot et Serge Pelletier, L'impact du covid-19 sur les contrats de droit privé, op, cit., (Y) د. عبد الرزاق السنهوري، الوسيط في شرح القانون المدني الجديد، مرجع سابق، ص بrلا، وفي عموم تبعات توافر شروط القوة القاهرة، انظر:

Ewan McKendrick, Force Majeure and Frustration of Contract, op, cit., Ch. 1. 


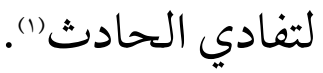

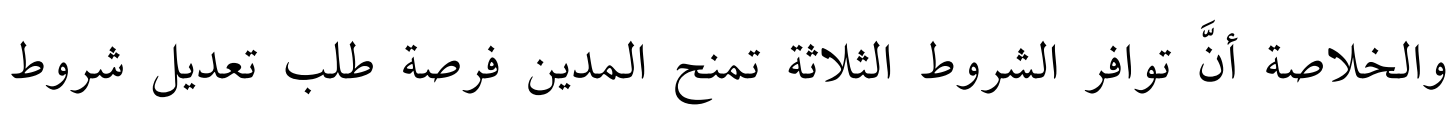

الالتزامات العقدية، أو طلب الإعفاء من المسئولية عند عدم تنفيذ الالتزام، مع التأكيد

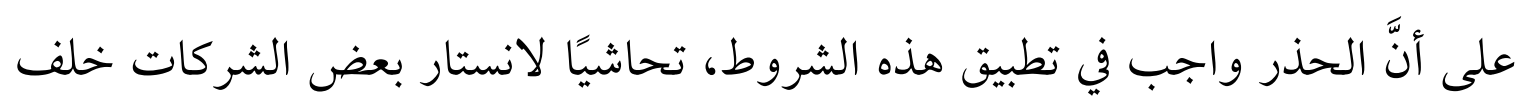

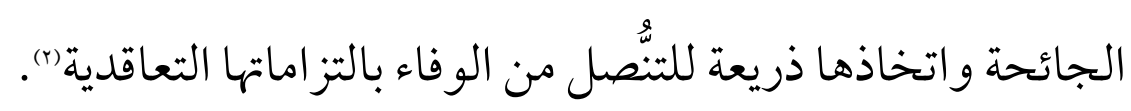
مواقف القضاء والفقه المؤيِّد لاعتبار جائحة كورونا قوة قاهرة:

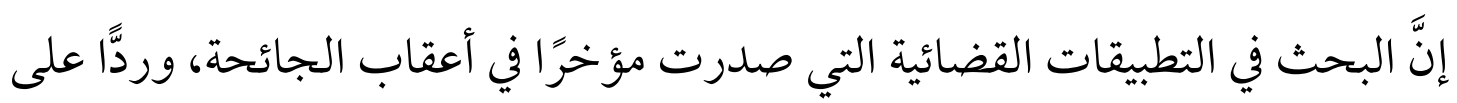

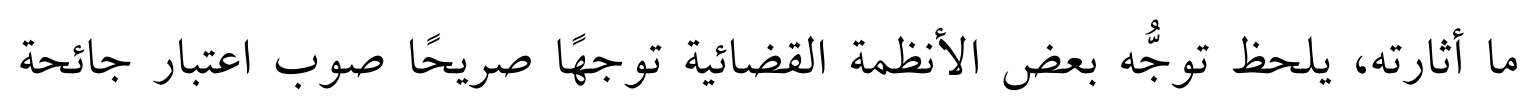

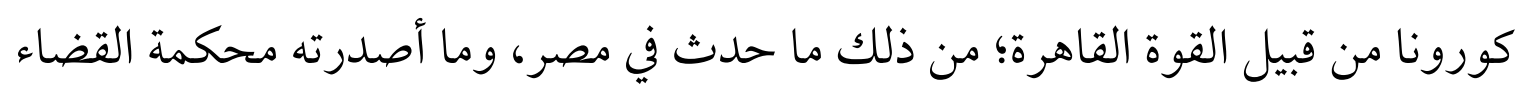
الإداري من الحكم الذي ورد بحيثياته:

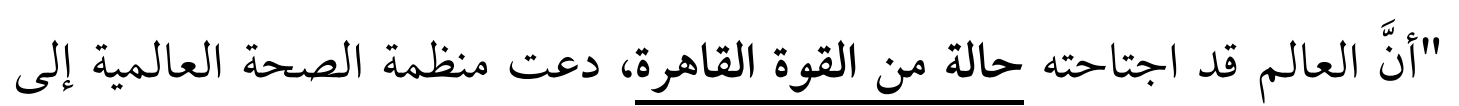
اعتبار فيروس كورونا المستجد جائحة، واتخذت الدولة بعض الإجراءات الاحترازية

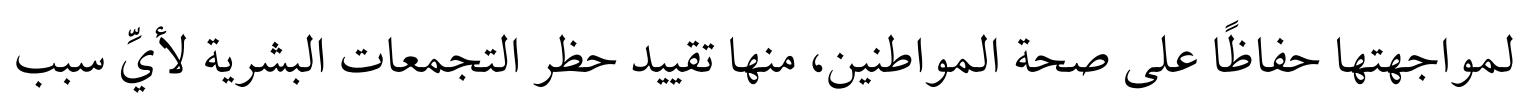
من الأسباب، ومن هذه الأسباب التجمع في جمعية عمومية لإجراء انتخابات النقابة، ولقد جاء هذا الحكم على خلفية قرار النقيب العام لأطباء الأسنان بوقف الانتخابات

$$
\text { (1) و ولمن أراد الاستز ادة في الآثار المترتبة على القوة القاهرة في خصوص العقود الدولية، انظر: }
$$

Victoria Lee, Mark Lehberg, et al, COVID-19 Contract Issues Reach Beyond Force Majeure, Issued by Law 360 official website, published on 13 March 2020.

See at, https://www.law360.com/articles/1251749/covid-19-contract-issues-reach-beyond-forcemajeure, Last visit on 12/8/2020.

(r) لمزيد من التفاصيل، بتصرف، انظر، د. ياسر عبد الحميد الإفتيحات، جائحة فيروس كورونا وأثرها على تنغيذ

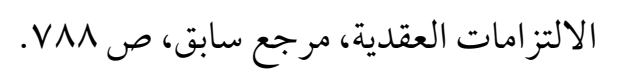


لحين تحسُّن الأوضاع واستقرارها في البلاد وعودة الحياة الطبيعية في مؤسسات

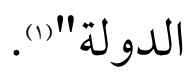

وعن آراء الفقه من المسألة؛ فمنهم من انتهى إلى اعتبار فيروس كورونا من قبيل القوة القاهرة كنتيجة لإنزال مقومات شروط القوة القاهرة على جائحة كورونانان.

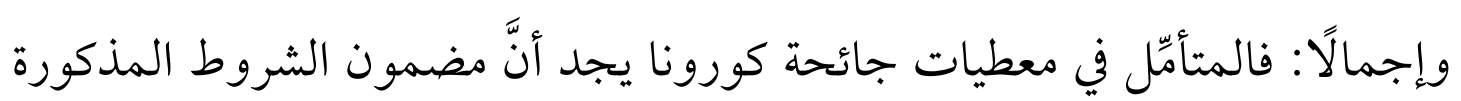

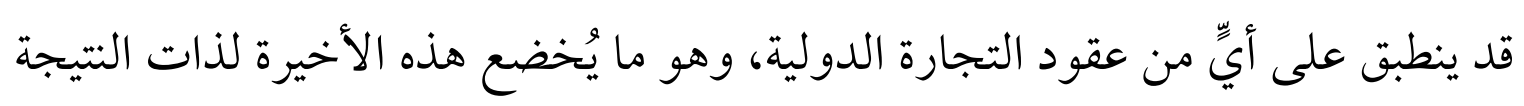
التي مضت الإشارة إليها.

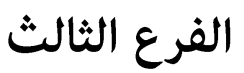 \\ القانون الواجب التطبيق على العقود الدولية

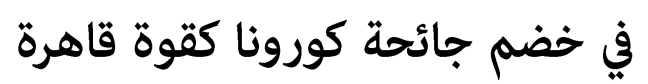

إنَّ القول الفصل باعتبار فيروس كورونا قوة قاهرة من عدورة فأهده في إطار اتفاق تعاقدي

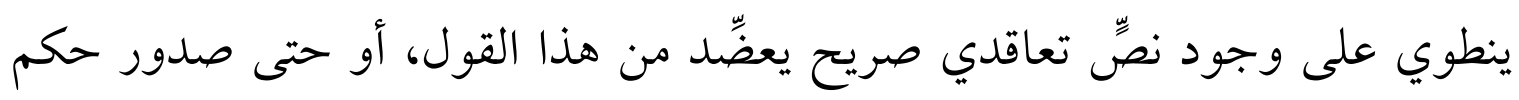

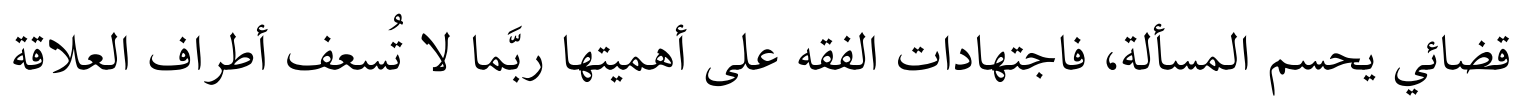

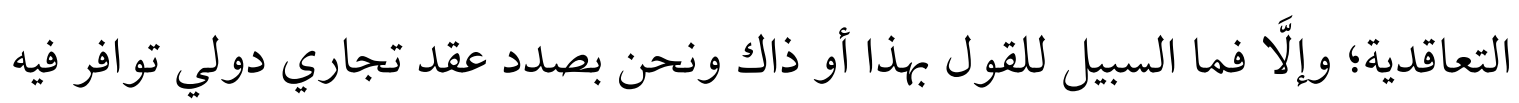
عنصر أجنبي، اعترض المدينَ حادثٌ حالَ بينه وبين الوفاء بالتزامه التعاقدي.

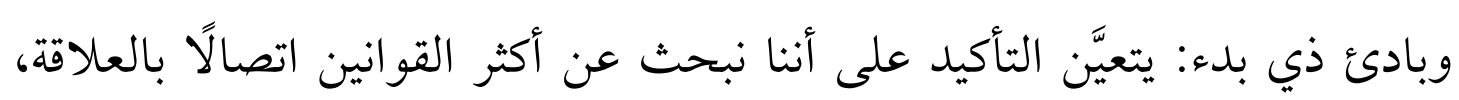
ومتى لم يكن في هذا القانون ما يتعارض مع النظام العام في الدولة فلا يكون هناك ما يبرِّر

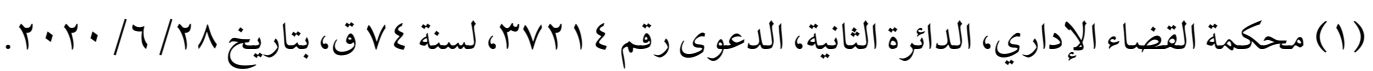
(Y) في هذا الرأي، د. أمينة رضوان، مدى مساهمة فيروس كورونا في إنهاء العلاقة الشغلية، مجلة الباحث

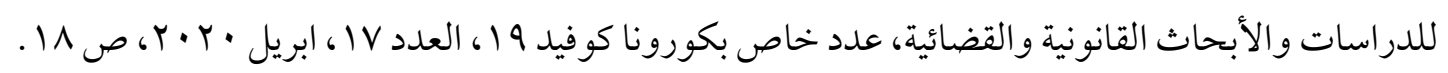


عدم تطبيقه (1).

ويناء عليه: فإنَّ إنزال فحوى معطيات جائحة كورونا على عقود التجارة الدولية من

منظور وجود قوة قاهرة من عدمه يُرتبّب فرضين اثنين، سيكونان محلَّ هذا الفرع في

غصنيْن على التوالي، ومكمن اختلافهما هو ما اتفَّق عليه الأطراف وما نُصَّى عليه

بعقدهم (r)، على أن يُكلَّل الفرضين السابقين وقوفًا عند القانون المحلَّد لمدى اعتبار الحادث قوة قاهرة من عدمه، ونطاق تطبيقه.

\section{الغصن الأول}

\section{وجود نص عقدي يفيد اتفاق الأطر اف على اعتبار الأوبئة}

أححد أسباب القوة القاهرة

لا مراء في أنَّ وجود شرط بالعقد يتَّصل بالقوة القاهرة، ويفيد اعتبار الأوبئة قوة

قاهرة، هو شأن يفرض على الجميع الالتزام بتنفيذ ما اتفق المتعاقدين عليه، وبعبارة

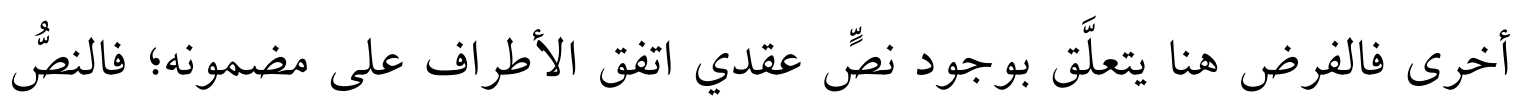
العقدي صريح في الإشارة إلى أنَّ الوباء قوة قاهرة، فهنا لا مجال للشكِّ؛ فالعقد شريعة المتعاقدين، وبطبيعة الحال فاتفاق الأطراف المتعاقدة المذكور يسري على القضاء

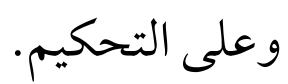
وبناء عليه: فإذا وُجِد بالعقد ما يفيد أنَّ أحداث القوة القاهرة يجب أن "تمنع" من

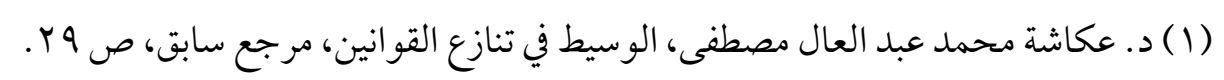

(2) Christian Ule, The Effects of COVID- 19 on International Contracts, Published in Official Legalmondo website, without date.

See at, https://www.legalmondo.com/coronavirus-international-contract-help-desk/?cv=eg , Last visit on $23 / 6 / 2020$. 
تنفيذ الالتزام العقدي؛ فهنا يجب على الطرف المتأثّر أن يُثبت بشكل عام أنَّ أداءه لالتزامه قد أصبح مستحيلًا من الناحيتين القانونية والمادية، وليس فقط أكثر صعوبة

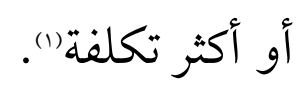

وعلى الجانب الآخر: فإذا كان من حقّّ الأطراف النصٌّ صر احةً على اعتبار الأوبئة قوة قاهرة، فإنَّه يُتصوَّر أن يُستني اعتبار الأوبئة من قبيل القوة القاهرة، وهنا يُتساءل عن

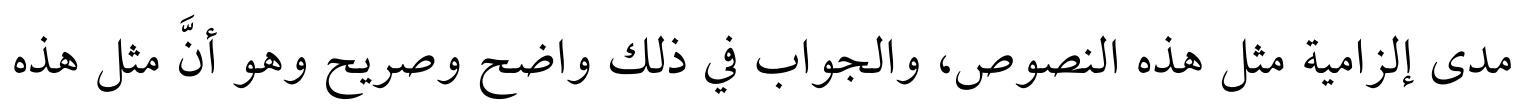
النصوص لها قوة ملزمة شأنها شأن النصوص الأخرى.

وكملاحظة إجمالية في نصوص عقود التجارة الدولية عمومًا، وبالنظر لما خلَّفته جائحة كورونا تحديدًا فإنَّ توافر مثل هذه الشروط للقوة القاهرة العقدية تُمثّل أداة

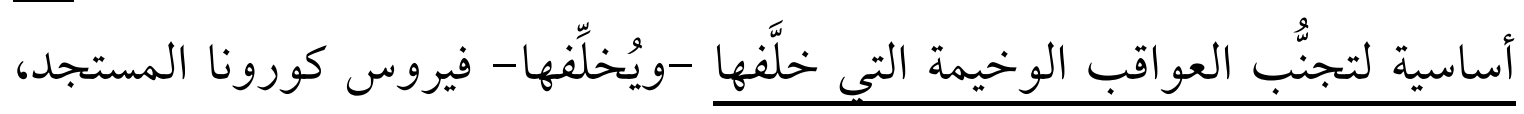
حتى وإن اعترفنا بعدم سلامة هذه الشروط من الناحية اللغوية أو من ناحية اتساقها مع الفرض المطروح في بعض الأحوال، إلَّا أنَّ هذه الشروط ماز الت في المجمل تُمثّل مأوى قويَّا للأطراف التي ما برحت تعاني من مِحَن جرَّاء الوباء، وبخاصة مع تزايد الدعاوى القضائية ذات الصلة بعدم تنفيذ الالتزامات العقدية نتيجة فيروس كورونا، من ذلك قضية Standard Retail Pvt. Ltd vs Gs Global Corp، التي رفعت في الثالث من شهر

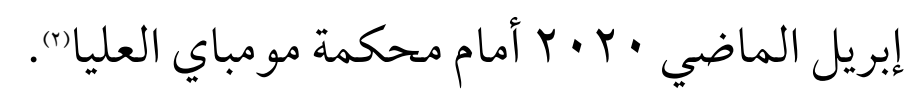

(1) Claudia Galvis, Jose Moran, et al, Coronavirus Outbreak: Global Guide to Force Majeure and International Commercial Contracts, op, cit.,

$$
\text { (Y) لمن أراد الوقوف على حيثيات هذه القضية المعروضة، طالع الرابط الالكتروني الرسمي التالي: }
$$

See at, https://indiankanoon.org/doc/, Last visit on 6/7/2020.

وفي عموم بيان الرأي السابق، بتصرف، انظر : Matteo M Winkler, Practical Remarks on the Assessment of COVID-19 as Force Majeure in International Contracts, op, cit., 
وعليه: فلن تقوم المحكمة من تلقاء نفسها بإعمال نظرية القوة القاهرة دون الوجود الصريح لشروطها التي مضى بيانها، وفي هذا الفرض الذي نحن بصدد الحديث عنه، ووجود شرط القوة القاهرة في حدّ ذاته بين نصوص العقد، بل أكثر من ذلك؛ إذ قد تنطبق

$$
\text { فكرة "الإنهاء" المقيد }
$$

وطالما نصَّ الأطر اف بعقدهم على حكم معين للقوة القاهرة فطبيعيُّ حينئذ التساؤل عن آلية تبليخ الأطراف أنفسهم بالقوة القاهرة.

\section{آلية تبليغ الأطراف بالقوة القاهرة:}

يبدو مهمَّا التأكيد على فحوى آلية تبليغ المتعاقد بالقوة القاهرة، والتأكُّد كذلك من اتِّاع المواعيد والآجال القانونية المنصوص عليها بالعقد، وإلَّا فستكون النتيجة هي سقوط الحقّ في التمشُك بالقوة القاهرة؛ فوسائل تبليخ المتعاقد بخضوع العقد لشروط القوة القاهرة قد تتمٌّ من خلال البريد الإلكتروني أو البريد العادي أو حتى من خلال القضاء، إلى غير ذلك من طرق التبليخ الأخرى التي قد يتفق عليها الأطراف. ويُراعى في التبليغ أهمية الالتزام بالشكليَّات التي قد تَرِد بالعقد؛ كاتفاق الأطراف على اللجوء إلى خبير لتحديد مدى وجود قوة قاهرة من عدمه؛ فطالما وُجِد نصٌّ يفيد ذلك بالعقد فمُتعيَّن الالتزام به والاستعانة بالخبير الذي ربما حُدِّدت صفته بالعقد، ومن

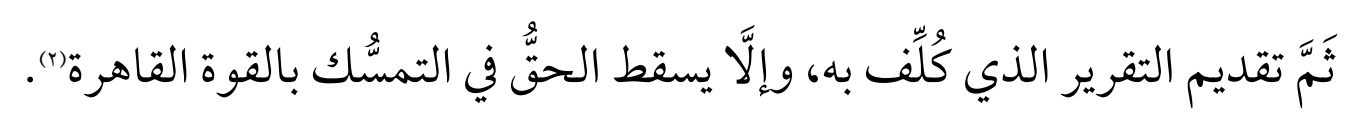

(1) For more details, Sophia Tang, Coronavirus, force majeure certificate and private international law, op, cit., p. 4,5.

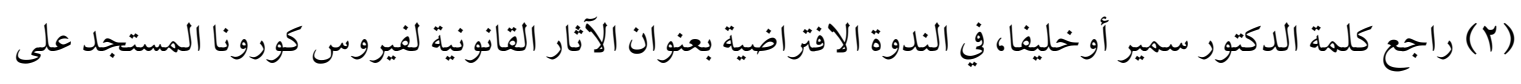
العقود الدولية للأعمال التي نظمتها كلية القانون، جامعة أبو ظبي، سابقة الإشارة. 


\section{الغصن الثاني}

\section{عدم وجود نصِّ عقدي يفيد اتفاق الأطر اف على اعتبار الأوبئة}

أحد أسباب القوة القاهرة

وهذا الفرض هو ما يُثار الجدل بشأنه جرَّاء عدم وجود نصٍِ بالعقد يُشير إلى اعتبار الوباء قوة قاهرة، فهنا ستتوجَه المعايير صوب التساؤل عما يأتي: هل فيروس كورونا قد

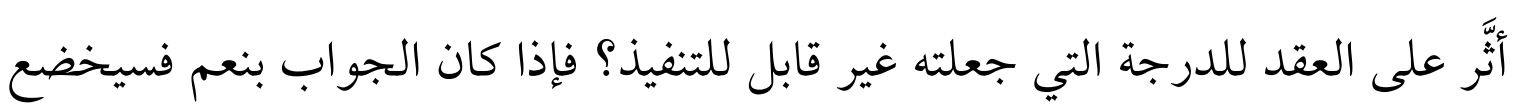
تنفيذ العقد لاحتمالية تكييف الجائحة كقوة قاهرة، وذلك إذا أصبح تنفيذ الالتزام أو الوفاء بالالتزامات التعاقدية أمرًا مستحيلًا وليس مرهقًا فحسب، ونتيجة لذلك فقد يُعفى المدين كليَّة من التزامه؛ فعلى سبيل المثال: يمكن اعتبار فيروس كورونا قوة قاهرة لشركات الطيران ووكلاء السفر؛ حيث وقفت حركة الطيران كليَّة، وحال ذلك دون استيفاء شروط النظرية.

وإجمالًا: فعلى الرغم من احتمالية غياب نصِّ صريح بشأن القوة القاهرة في العقد، إلَّا أنَّ هناك سبلًا أخرى للإعفاء من مسئولية الالتزامات التعاقدية على خلفية تفشِّي وباء كورونا المستجد، من خلال كفالة مستوى أضيق من مستويات الحماية والاعتماد على سبيل المثال- على مبدأ عدم القابلية للتطبيق impracticability المتعارَف عليه من قِبَل القانون الأمريكي؛ فالمبدأ المذكور قد يكفل حلَّ مناسبًا للأطر اف التعاقدية في الحالات التي أصبح من غير المعقول أو غير المنطقي طلب القيام بمثل هذا الالتزام التجاري في ضوء هذه الأحداث(1) .

(1) Victoria Lee, Mark Lehberg, et al, COVID-19 Contract Issues Reach Beyond Force Majeure, op, cit.; Also, Klaus Peter Berger, Daniel Behn, Force Majeure and Hardship in the Age of Corona: A Historical and Comparative Study, op, cit., p. 25-29. 
وعلى أيَّة حال: فإنَّ عدم وجود نصِّ بالعقد يفيد اعتبار الأوبئة قوة قاهرة يتمّ الدفع بها كي لا يتمُّ تنفيذ الالتزام من ذلك -لا يشكّل عقبة في إعمال القوة القاهرة طالما توافرت شروطها، من ذلك عدم قيام الممثّل بتنفيذ التزاماته الفنية في ظلّ انتشار وباء التيفويد؛ حيث شكَّل قوة قاهرة منعته حينئ من التمثيل (1). الحلول المنصفة التي تقدِّمها القوانين ذات الصلة حال عدم وجود نصِّ عقدي يتعلَّق

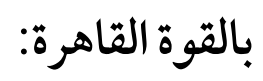

ليس ما سبق بيانه فحسب هي الحلول التي يمكن الأخذ بها في هذا المقام؛ فثمَّة حلول أخرى ذات صلة منصفة يمكن الاعتماد عليها في ظلّ عدم وجود نصِّ بالعقد يُبِيِن. الموقف إزاء اعتبار أحداث معينة كالأوبئة من قبيل القوة القاهرة؛ فقد رجَّح بعض

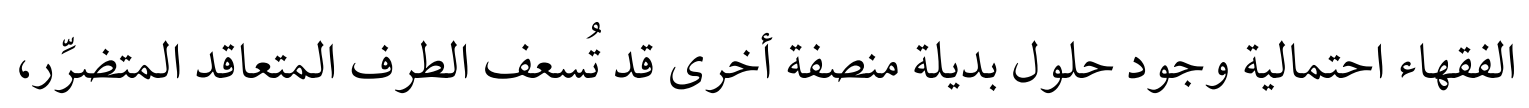
اعتمادًا على القانون الو اجب التطبيق على العقد.

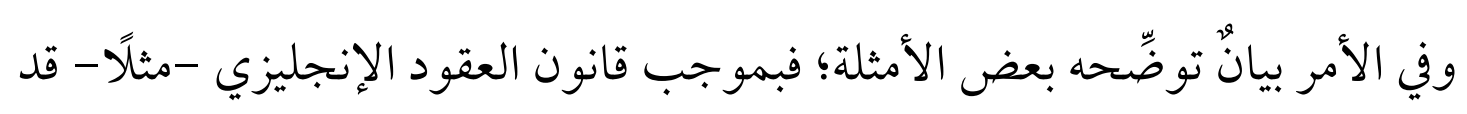
يُطالب الطرف المتضرّر الإعفاء بموجب مبدأ إنهاء العقد frustration الذي يسمح للأطر اف بالتوقُّف عن أداء التزاماتهم التعاقدية إذا أصبح من المستحيل القيام بها؛ نظرًا لقيام ظروف تبتعد عن مسئولية هؤلاء الأطراف، حتى إن اعترفنا أنَّ فكرة إنهاء العقد المشار إليها في حدِّ ذاتها قد يشوبها بعض الصعوبات؛ كمحدوديَّة تطبيقهات.

(1) "a typhoid epidemic in a town in which an actor had undertaken to appear was held to constitute force majeure" "Ewan McKendrick, Force Majeure and Frustration of Contract, op, cit., Ch. 1.

(2) Claudia Galvis, Jose Moran, et al, Coronavirus Outbreak: Global Guide to Force Majeure and International Commercial Contracts, op, cit., 


\section{الغصن الثالث}

\section{القانون المحدَّد لمدى اعتبار الحادث قوة قاهرة من عدمه ونطاق تطبيقه}

يختصُّ قانون القاضي أو القانون المحلي بتحديد أسباب نفي المسئولية في المجمل،

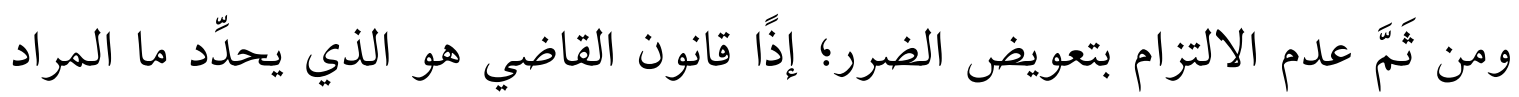

بالسبب الأجنبي؛ كالحادث المفاجئ أو القوة القاهرة، أو خطأ المضرور، وخطأ الغير،

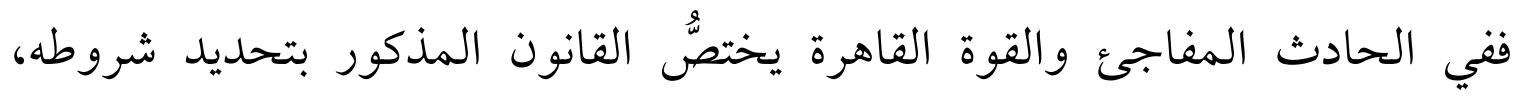

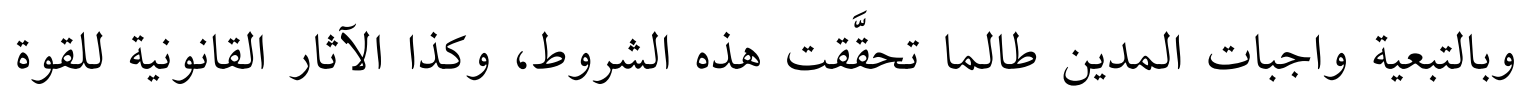
القاهرة في انتفاء المسئولية، وحالات ترتيب المسئولية، ولو كانت ناشئة عن قوة قاهرة

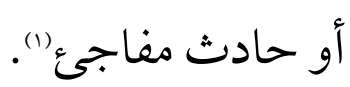

وهنا تتجلَّى الأهمية البالغة للتكييف بشأن تحديد القانون الواجب التطبيق، وبيان ما

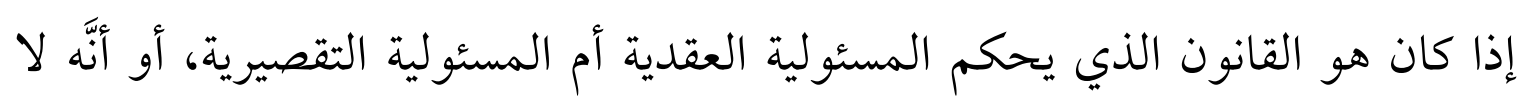
مسئولية مطلقًا (). وبشكل عامِّ: فإِنَّ الاتفاقات التي تشدِّد من المسئولية؛ كتلك التي تُحمّل المسئول

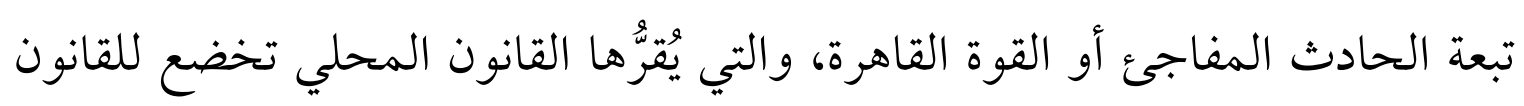
المذكور (r).

وبتسليط الضوء على موقف قانون العقود الصيني على سبيل المثال من المسألة؛

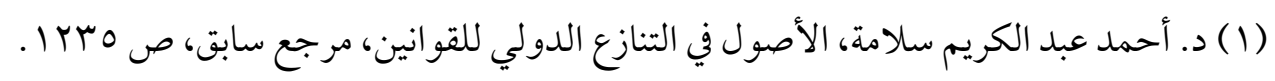

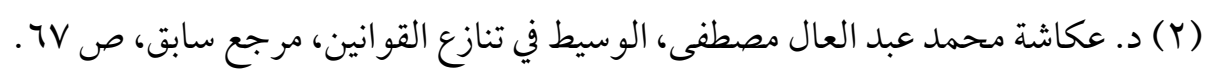

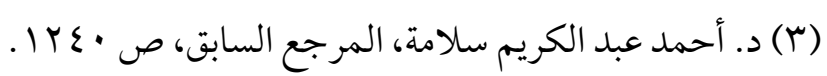


فالوضع في الصين تحديدًا حيال مواقف العقود المتضرّرة من فيروس كورونا، ومدى

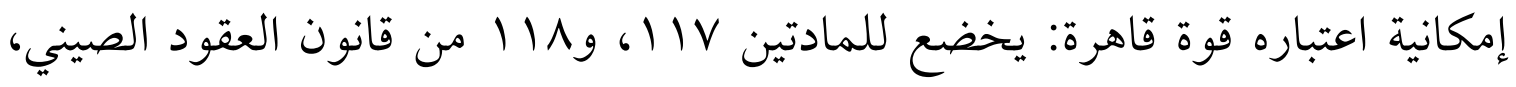
وبموجبهما يُعفى الطرف المتضرِّر مؤقتًا من التزاماته في حالة القوة القاهرة، ويلزمه تقديم إشعار مع الأدلة للطرف الآخر خلال فترة معقولة، كما أوضحت لجنة الشؤون التشريعية التابعة للجنة الدائمة لمجلس النواب الصيني أنَّ الطرف الذي يُمنع من أداء التزاماته التعاقدية، نتيجة للتدابير الحكومية المتخذة لاحتواء تفشّي فيروس كورونا، يجب أن يكون له الحقّ في إجبار القوة القاهرة بموجب قانون جمهورية الصين (1)، ويلاحظ ما في النهج المذكور من اتفاق مع تطبيق قانون بلد القاضي.

\section{المطلب الثاني}

\section{ثهادة القوة القاهرة كقرينة على اعتبار كورونا قوة قـاهرة}

لقد ابتدعت بعض الدول في أعقاب جائحة كورونا حلولًا قانونية قد تبدو مبتكرة -

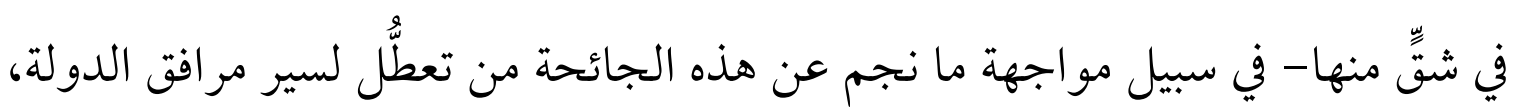
وتأثّر غالبية قطاعاتها، يعنينا منها تأثير ها على عقود التجارة الدولية. وفي مقدمة هذه الحلول المبتكرة ما اصطلح على تسميته بـ "شهادة القوة القاهرة" Force Majeure Certification إصدار هذه الشهادة خلال فترة انتشار فيروس كورونا، من خلال التوجُه إلى بعض الجهات المعنية التي أوكلتها الدولة الاختصاص بهذا المَنح، والتي تختلف بطبيعة

Arnold \& Porter الأمريكي للمحاماة، أحد أكبر مكاتب المحاماة في 
الحال من دولة إلى أخرى، وعلى نحو ما سيُظهر متن الدراسة لاحقًا بالتفصيل. الشاهد أنَّ مثل هذه الحلول التي من أمثلتها شهادات القوة القاهرة بحاجة للتأمّل في مضمونها وآثارها، فإذا كان يتعيَّن على الجهات المتضرِّرة من الجائحة؛ فردية كانت أو شركات، الراغبة في استصدار هذه الشهادة التقدّم بطلب مكتوب لجهة معينة -ولتكن دائرة التجارة والصناعة والخدمات مثلًا - فعلى هذا الطرف أن يُّبت عدم قدرته على الوفاء بما التزم به عقديَّا نتيجة التزامات دولية أو حتى وطنية تجاه شركائهم في العقد؛ سواء أكانوا من القطاع الخاص أم العام، بسبب ظروف غير متوقَّة لا يمكن دفعها كمسوغات لوجود قوة قاهرة؛ فمثل هذه الشواهد ضرورية لضمان استمرارية نشاطات هذه المؤسسات، و كذا للتبت من احترام تنفيذ تعليمات الأمن الصحي فقط دون ترتيب أيَّة التزامات تعاقدية تجاه الالتزامات التعاقدية.

وعلى الرغم من اعتبار إصدار شهادات القوة القاهرة من بعض الدول يُعدُّ بمثابة تسهيلات قانونية تتماشى مع تبعات فيروس كورونا المؤثِّة على العقود الدولية؛ كحال الصين وروسيا وغيرهما من الدول التي ستقف عندها الدراسة، فعلى الجانب الآخر فقد رفضت دول أخرى هذا التوجُه، مُعرضة عن الاعتداد بمثل هذه التوجهات، ومن ثَمَّم رفض اعتبار فيروس كورونا قوة قاهرة، مُكتفية بتخويل ما يُعرف بغرف التجارة و الصناعة إصدار "شو اهد لحالة بحكم القانون état du droit" كحال فرنسا"، خلال فترة

$$
\text { (1) (1) حال صحت الترجمة، لمزيد من الثفاصيل، طالع الموقع الإلكتروني التالي: }
$$
See at, https://www.medef.com/fr/actualites/covid-19-comment-obtenir-des-certificats-etat-du-droit, Last Visit on 15/6/2020. 


$$
\text { انتشار فيروس كورونا"()، وسيقف البحث لاحقًا عند طبيعة هذه الشهادات. }
$$

وعليه: كان الوقوف عند مواقف الدول التي خوَّلت الأطراف الحتَّ في إصدار مثل

هذه الشهادات وغير هذه الدول -أيضًا- أمرًا مهمَّا، وعليه: خُصِّص الطرح الآتي لبيان مواقف دول؛ كالصين وروسيا(() من هذه المسألة تحديدًا فيما يأتي: الغصن الأول : موقف الصين

في محاولة من الحكومة الصينية لحماية شركاتها من تحمُّل المسئولية عن مغبّة

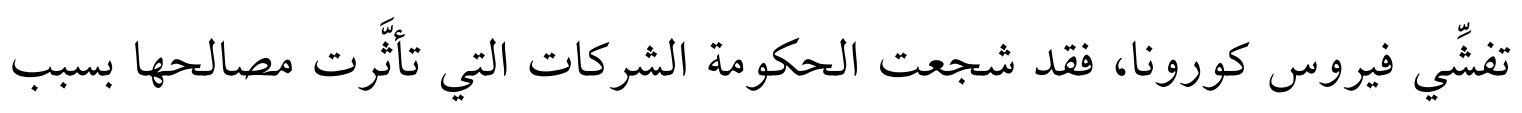
الفيروس على الحقّ في المطالبة بحماية القوة القاهرة(()، وعليه: مكَّنت دولة الصين Force Majeure- الحقَّ في تقديم طلب الحصول على ما يُسمى "شهادات القوة القاهرة China Council for the Promotion من المجلس الصيني لتعزيز التجارة الدولية certificates of International Trade (CCPIT)

وتتمثل أهمية هذه الشهادات في إمكانية استخدامها كدليل في إجراءات المحكمة تجاه الأطراف المتعاقدة، كما يمكن أن تكون الشهادات ذات أهمية للشركات التي لديها مصانع إنتاج في المناطق المتضرّرة في الصين، ولا يمكنها الامتثال لالتزاماتها المتعلقة بالتوريد بسبب اضطرابات الإنتاج المتعلقة بالوباء، وبالتبعية تواجه مطالبات

(1) راجع كلمة د. محمد عبد الهادي المكنوزي، ندوة افتراضية بعنوان الآثار القانونية لفيروس كورونا المستجد

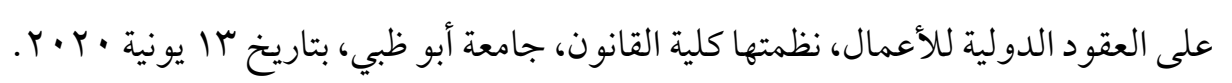

(2) Ralf Michaels, Jakob Olbing, Corona and Private International Law: A Regularly Updated Repository of Writings, Cases and Developments, Issued by Conflict of Laws. Net official website, published on $16 / 5 / 2020$.

Available online at, https://conflictoflaws.net/2020/corona/?print=pdf , Last visit on 2/7/2020.

(3) Anton A. Ware, Jeffrey Yang et al, What to Do When You Receive a Coronavirus-Related Force Majeure Notice, op, cit., 


$$
\text { الضرر من الشركاء المتعاقدين (1) - م }
$$

هذا: وتجدر الإشارة إلى أن المجلس المذكور CCPIT قد أصدر قرابة OYץ,ץ شهادة قوة قاهرة(r)، كما تبلغ القيمة الإجمالية للتعاقدات r^,0 مليار دولار أميركي لإعفاء الشركات الصينية من التزاماتها التعاقدية.

وبالنظر في مضمون هذه الشهادات: فإنَّ الوقائع المسجلَّة في الشهادات تتضمَّن تأكيدًا على تفشّي فيروس كورونا، وطبيعة تأثيره، ومدد القرارات الحكومية وتاريخها بالإغلاق أو بالحجر الصحي، ومدى إلغاء أيِّ وسيلة نقل، وما إلى ذلك من إجراءات، مع التأكيد على أنَّ هذه الشهادة لا تُعدُّ وثيقة قانونية، وليس لها آثار تنفيذية أو قانونية مباشرة؛ فهي فقط بمثابة شهادة على ما حدث بالفعل من تفاصيل واقعية، وليس أدلّ الّ force majeure factual certificate"على ذلك من تسميتها بـ "شهادة واقعية للقوة القاهرة بحسب ما أطلق عليها المجلس الصيني نفسه، صاحب الصفة في إصدارها على موقعه

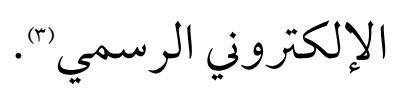

وعليه: فالبحث في القوة الإلزامية لهذه الشهادات يُسفر كيف أنَّها تمثّل دليلً على

(1) Ulrike Glueck, Micheal Munzinger, et al, Does the Coronavirus outbreak constitute Force Majeure, Published by CMS Law Firm, UK, 03/02/2020.

See at, https://cms.law/en/chn/publication/does-the-coronavirus-outbreak-constitute-force-majeure , Last visit on 30/6/2020.

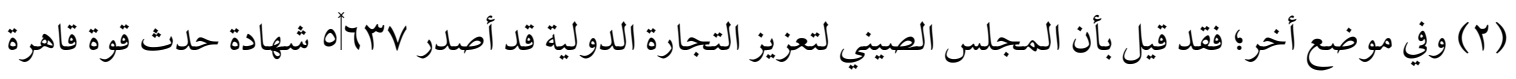

في مختلف فروعها، تم منحها للشركات المتضررة من تفشي فيروس كورونا، وبحسب تقرير صادر عن تشاينا

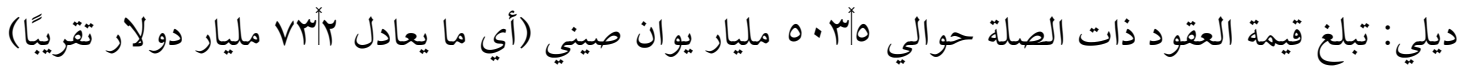

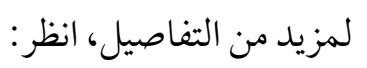

Anton A. Ware, Jeffrey Yang et al, What to Do When You Receive a Coronavirus-Related Force Majeure Notice, op, cit.,

(3) See at, http://en.ccpit.org/info/info 40288117668b3d9b017019772b5706b0.html , Last Visit on $7 / 3 / 2020$. 
وجود أحداث تمثّل قوة قاهرة، وتؤثّ بالتبعية على قدرة الشركة على تنفيذ العقد

وبعبارة أخرى: فإنَّ الشهادة المذكورة هي مجرد إثبات للظروف الموضوعية

و الو اقعية، تمنح للشركات الصينية غير القادرة على تنفيذ العقود بسبب تأثير وباء كورونا عليها، وهذه الشهادة بإمكانها أن تثبت حقائق موضوعية كما قيل؛ كتأخر استئناف العمل، ومراقبة حركة المرور، والإرسال المحدود للعاملين، وبناءً على هذه الشهادة يمكن للمؤسسة أن تطلب تأخير الأداء أو إنهاء العقد.

والقول الفصل في مدى الإعفاء الكلي أو حتى الجزئي من تنفيذ الالتزام يعتمد على

ظروف كلّ حالة على حده، وعليه: ينبخي على الأطر اف التعاقدية أن تأخذ في اعتبارها القانون الو اجب التطبيق، وجميع الظروف ذات الصلة لإثبات علاقة السبية بين "وباء الكورونا وتدابير الوقاية منه ومكافحته"، و "عدم القدرة على تنفيذ الالتزام التعاقدي" (r)"، مع الاعتراف بأنَّه من المرجَّح أن يكون إثبات علاقة السبية هو التحدِّي الأكثر شيوعًا الذي يواجهه المدعون مهَّن يرفعون دعاوى قضائية ضدَّ المورِّدين الرئيسيِّن والموزِّعين وتجار التجزئة ("). كما أنّ من الفقه من آثر التمييز بين مواقف الأنشطة التجارية -في خصوص عقود

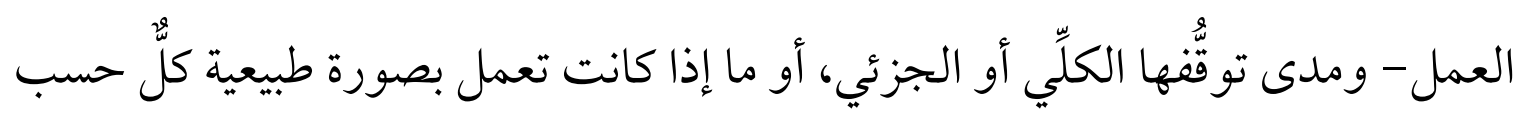

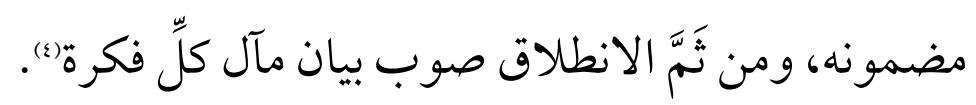

(1) Sophia Tang, Coronavirus, force majeure certificate and private international law, op. cit., p. 1.

(2) Ibid. 1,2.

(3) Kashish Jaitley, Niharika Kuchhal et al, The COVID pandemic: Time to 'ramp-up' India's conflict of law rules in matters of tort?, op, cit.,

(عزيد من التفاصيل، انظر، د. أنس فيصل التورة، تأثيرات فيروس كورونا على عقد العمل بين الظروف

$$
\text { الطارئة والقوة القاهرة، مرجع سابق، ص V.r و وما بعدها. }
$$


مدى إمكانية الاعتداد بشهادات القوة القاهرة أمام المحاكم الصينية وخارجها: إنَّ النظر لمضمون المسألة من الناحية النظرية يعني أنَّه يجب أن تطبّق المحاكم الصينية النهج ذاته بالمعطيات التي مضى بيانها، والذي تتبعه كحال غيرها من المحاكم المختصة عند إعمال القانون الواجب التطبيق، ومن ثَمَّم معاملة شهادات القوة القاهرة الصادرة عن CCPIT المجلس الصيني لتعزيز التجارة الدولية كدليل واقعي لما حدث"(.). بيد أنَّ إبداء موقف المحاكم الصينية من المسألة يُير التساؤل عن وضع شهادات القوة القاهرة الصادرة عن المجلس الصيني لتعزيز التجارة أمام غيرها من محاكم الدول الأخرى؟ ولعل هذا التساؤل قد فرض نفسه في ظلّ ما خلَّفه تفشّي فيروس كورونا من تأثيرات شملت كافة أرجاء المعمورة، وعليه يُتساءل: هل من الممكن الاعتر اف بشهادة القوة القاهرة الصادرة عن المجلس الصيني لتعزيز التجارة الدولية CCPIT خارج الصين؟ ويُجاب بحسب المجلس الصيني لتعزيز التجارة الدولية، فإنَّ شهادات القوة القاهرة معترفت بها من قِبَل الحكومات وووكالات الجمارك و الاتحادات التجارية والمؤسسات في أكثر من · · ب دولة ومنطقة حول العالم، وعلى الرغم من القول السابق؛ فقد عقَّب البعض أنَّ شهادة القوة القاهرة قد لا تكون ذات فائدة واضحة أو تلقائية خارج الصين (r). وبشكل عامً: فقد تُفِّل المحاكم الصينية تطبيق قانونها الوطني إذا كانت اتفاقية الأمم المتحدة للبيع الدولي للبضائع -التي سيتم الوقوف عندها لاحقًا- لا تنطبق شروطها، ولم يختر الطرفان قانون دولة أخرى، بغية إعطاء قيمة أكبر لشهادة القوة

(1) Sophia Tang, Coronavirus, force majeure certificate and private international law, op, cit., p. 4,5.

في هذا التأصيل، ولمزيد من التفاصيل، انظر، Anton A. Ware, Jeffrey Yang et al, What to Do When You Receive a Coronavirus-Related Force Majeure Notice, op, cit., 
القاهرة الصادرة عن المجلس الصيني لتعزيز التجارة الدولية CCPIT مقارنة بمحاكم الدول الأخرى، وبأن يكون أكثر تساهلًا في تطبيق معايير القوة القاهرة لدعم مطالب

$$
\text { الشركات الصينية فيما يتعلق بانتشار فيروس كورونا") }
$$

\section{الغصن الثاني: موقف روسيا}

اتفق موقف دولة روسيا مع إجمال موقف دولة الصين؛ إذ خوَّلت الدولة الروسية

للأطر اف التعاقدية الحقَّ في استصدار "شهادات قوة قاهرة" من غرفة التجارة و الصناعة الروسية CCl(r)، مع وجوب الإشارة إلى أنَّ ممارسة الحقّّ في استصدار شهادات قوة قاهرة

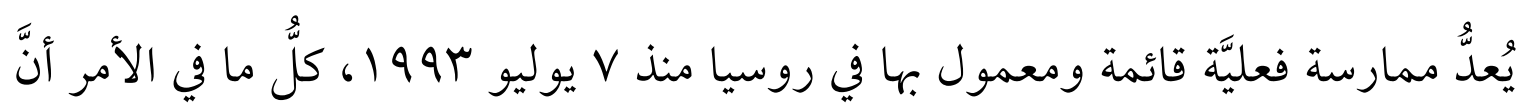
الطلب عليها قد ازداد مؤخرًا على خلفية تفشِّي فيروس كورونا وما خحلَّفه من تبعات على تنفيذ الالتزامات الواردة بعقود التجارة الدولية. وعليه: يحقٌّ للشركات الروسية الوطنية والأجنبية كذلك -على حدٍّ سواء- التقدّم لغرفة التجارة والصناعة الروسية بطلب استصدار شهادات القوة القاهرة، وبحسب القانون الروسي يمكن أن تُشكّل "شهادة القوة القاهرة" جزءًا من الأدلة في النزاعات المستقبلية المحتملة؛ إذ يتمُّ تحديد تأثيرها على نتائج النزاع في نهاية المطاف بواسطة المحاكم أو هيئات التحكيم (الروسية أو الأجنبية)(r).

(1) Sophia Tang, Coronavirus, force majeure certificate and private international law, op, cit., p. 5.

$$
\text { (Y) لمزيد من التفاصيل، يمكن مطالعة الموقع الرسمي للغرفة على شبكة الإنترنت }
$$

See at, https://tpprf.ru/en/ , Last visit on 4/7/2020.

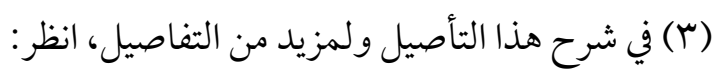

Ekaterina Pannerbakker, Force majeure certificates' issued by the Russian Chamber of Commerce and Industry, Issued by Conflict of Laws.Net official website, published on 17/4/2020.

Available online at, https://conflictoflaws.net/2020/force-majeure-certificates-by-the-russianchamber-of-commerce-and-industry/, Last visit on 4/7/2020. 
وربَّ متسائل: ما القيمة العملية التي يمكن لشهادة قوة قاهرة أن تؤدِّيها في نزاع

$$
\text { تعاقدي يتعلَّق بتبعات الوباء؟ مُّك }
$$

إنَّ الأساس القانوني لاختصاص غرفة التجارة والصناعة الروسية CCI لإصدار

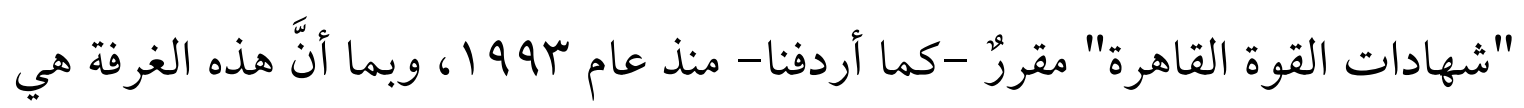
جهة غير حكومية أُشئت لتعزيز الأعمال التجارية والتجارة الدولية، إلى جانب اختصاصاتها الأخرى، فهي بمثابة "خبير مستقل " يقدّم خدمات معلومات في الأمور المتعلقة بالتجارة الدولية، وإحدى هذه الخدمات هي إصدار "شهادات قوة قاهرة"، إذ يتمٌّ تحديد قواعد إصدار الشهادات من قبل مجلس إدارة الغرفة؛ فلدى الأخيرة قسم قانوني عُهِد إليه لتقييم طلبات إصدار شهادات قوة قاهرة، ومن ثََّّ إبلاغ ما إذا كان يجب إصدار الشهادة من عدمه اعتمادًا على ما يُقََّّم من مستندات من قِبَل الطرف المتعاقد الذي يتذرَّع بالقوة القاهرة كي يُثبت بها الطرف المتعاقد طلبه'.(. كما تجدر الإشارة إلى أنَّ قائمة المستندات المطلوبة لاستصدار هذه الشهادة تتضمَّن نسخة من العقد، "الذي يحتوي على بند بشأن القوة القاهرة"، وبطبيعة الحال فهذا الشرط ليس من قبيل الصدفة؛ فالأمر بالطبع غير إلزامي للحكم القانوني المتعلق بالقوة القاهرة؛ إذ تنصُّ المادة (1 ع / م) من القانون المدني الروسي على جواز الإعفاء

(1) ولمعرفة لو ائح إجر اءات غرفة التجارة والصناعة الروسية حسب تعديلها في 10 • r، والمحددة لظروف القوة

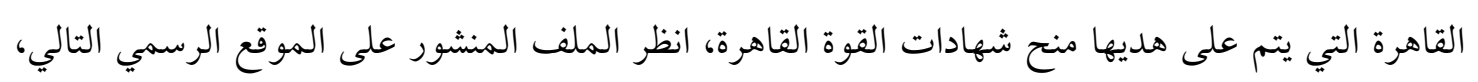

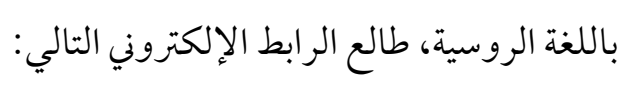

See at,

https://uslugi.tpprf.ru/\%D0\%9F\%D0\%BE\%D0\%BB\%D0\%BE\%D0\%B6\%D0\%B5\%D0\%BD\%D0\%B8\%D0\%B5 \%20\%D0\%BE\%20\%D0\%A4\%D0\%9C 2015.pdf , Last visit on 4/7/2020. 
من المسئولية عن عدم تنفيذ الالتزام التعاقدي، إذا أثبت الطرف أنَّ عدم الأداء كان بسبب القوة القاهرة، كما يجوز للطرفين تقديم خلاف ذلك بتضمين بند حول الظروف الطارئة أو الإنهاء أو القوة القاهرة أو ظروف مماثلة في العقد. والشاهد أنَّ غرفة التجارة والصناعة الروسية لا تنحرف عن الامتثال للنهج الذي الذي سلكته دولة الصين، وهو ما مفاده تبنِي بعض الحلول التي تهدف من ورائها أن تَعبرٌ هي وشعوبها بسلام من هذه المرحلة الدقيقة، وبيان أوضاع الشركات التي أبرمت عقودًا دولية من هذه المسألة، والحرص غاية الحرص على ألَّا يرافق استصدار مثل هذه

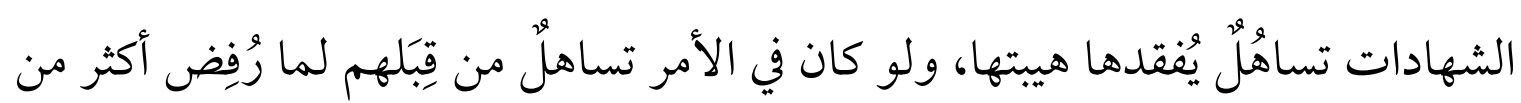
ه \% من الطلبات المقدَّمة إلى الغرفة والتي تطلب إصدار "شهادات القوة القاهرة" (1)، فبحسب ما أعلن رئيس الغرفة في السادس من شهر إبريل · r · ف فشهادات القوة القاهرة التي صدرت في مناطق روسية متعددة هي إلى الآن عشرات الشهادات فحسب(r).

(1) ولاطلاع على توثيق ذلك باللغة الروسية، طالع الموقع الإلكتروني التالي: See at, https://tass.ru/ekonomika/8172063, Last visit on 4/7/2020.

وفي مجمل شرح هذا التأصيل ولمزيد من التفاصيل، انظر : Ekaterina Pannerbakker, Force majeure certificates' issued by the Russian Chamber of Commerce and Industry, op, cit.,

( ( ) لمزيد من التفاصيل، انظر تقرير رئيس غرفة التجارة والصناعة الروسية المنشور على الموقع الرسمي لوكالة

See at, https://tass.ru/ekonomika/8172063, Last visit on 4/7/2020.

أنباء Tass الرئية من التفاصية:

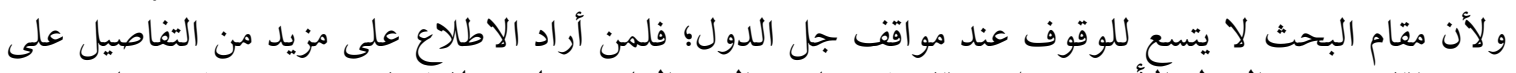

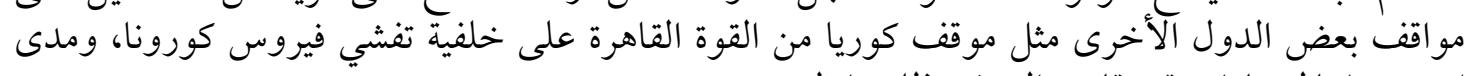

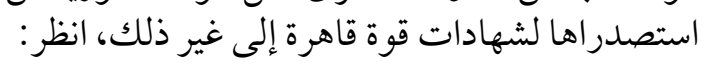

Bae, Kim \& Lee LLC , COVID-19 and Force Majeure in Sales Transactions: South Korea, Issued by lexology official website.

See at,

https://www.lexology.com/library/detail.aspx?g=d07462e8-7b46-4b20-9b59-9855e3bdaeb5 , Last Visit on $4 / 7 / 2020$. 
وقبل مغادرة هذا المقام و التعقيب عليه فالإشارة واجبة إلى أنَّ الجهة المختصة التي يتقدَّم إليها الطرف المتعاقد طالبًا استصدار شهادة القوة القاهرة تختلف من دولة لأخرى

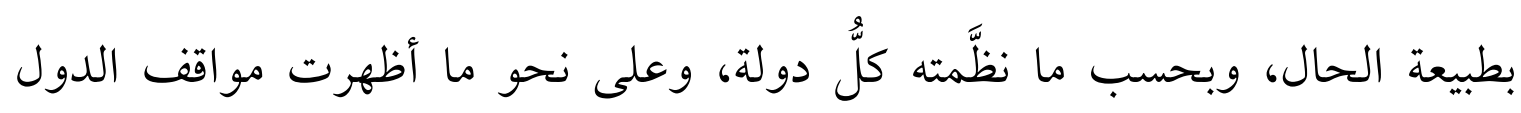
السابقة؛ كاختصاص غرفة التجارة والصناعة في أوكرانيا بإصدار هذه الشهادات(1)، وهكذا وعلى نحو ما بيَّنت الدراسة بالنسبة لكلّ دولة على حدة فيما سبق. تعقيب:

قد يبدو من غير المتصوَّر تخويل السلطات التنفيذية الحقَّ في إصدار وثائق تتعلَّق بالقوة القاهرة، أو حتى تخويل الحقِّ ذاته للجهات المهنية؛ كالمؤسسات مثلاً، وآية ذلك أنَّ الأمر هنا متروك للسلطة التشريعية بالنسبة للتشريعات الوطنية، ويبقى حينئذ

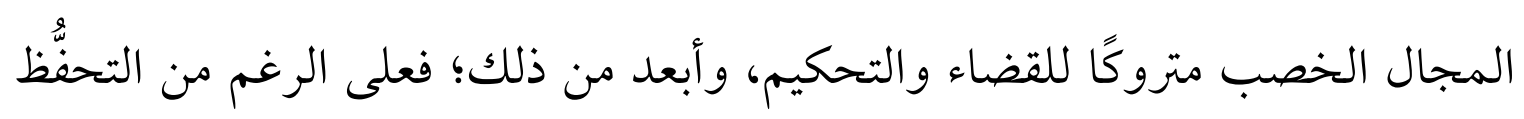
على القول جزافًا باعتبار فيروس كورونا من قبيل القوة القاهرة من دون المرور الدقيق بمرحلة التأكُّد من تو افر شروطها من عدمه، وفي ضوء ملابسات كلٍّ عقد على حده (r). إلَّا أنَّه يلزم التأكيد على أنَّ اعتبار فيروس كورونا قوة قاهرة من عدمه أمر رهين بوجود تشريع يصرّح بذلك من عدمه، فهي مهمة المشرع يشاطره في ذلك القضاء و التحكيم ليقرِّرا مدى تو افر شروط أيِّ منهما على العقد، ومن ثَمَّم ترتيب الآثار.

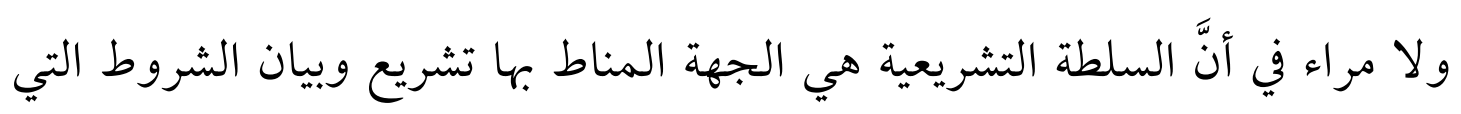

$$
\text { (1) للاطلاع على شروط استصدار الشهادة المذكورة في أوكرانيا، طالع الموقع الإلكتروني التالي: }
$$

See at, https://ucci.org.ua/en/services/zasvidchennia-fors-mazhornikh-obstavin , Last visit on $15 / 6 / 2020$.

(2) Constance Verroust-Valliot et Serge Pelletier, L'impact du covid-19 sur les contrats de droit privé, op, cit., 
يُسار على هداها بما تصدره من تشريعات، يُحلَّد من خلالها ما إذا كان الحادث يشكّل

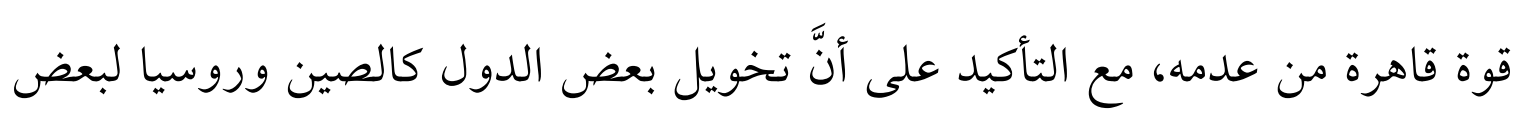

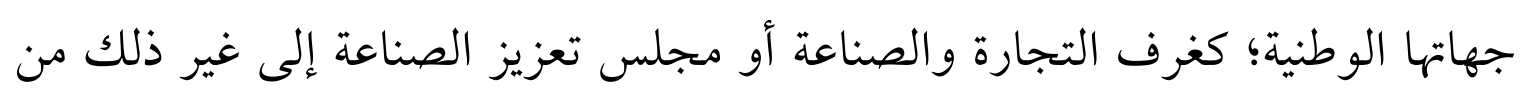

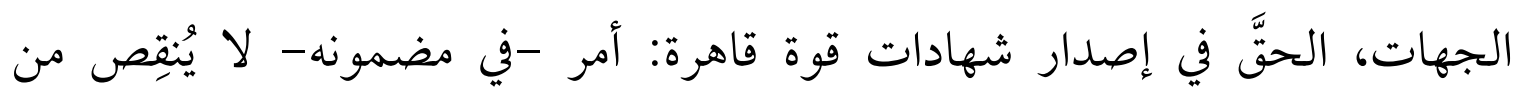

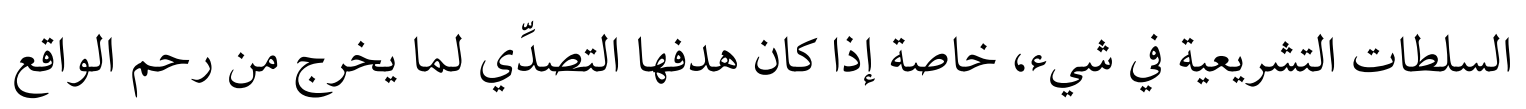

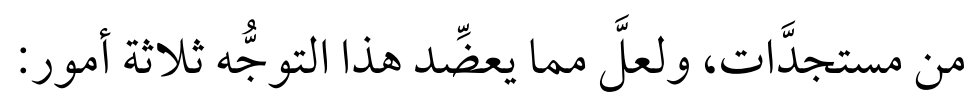

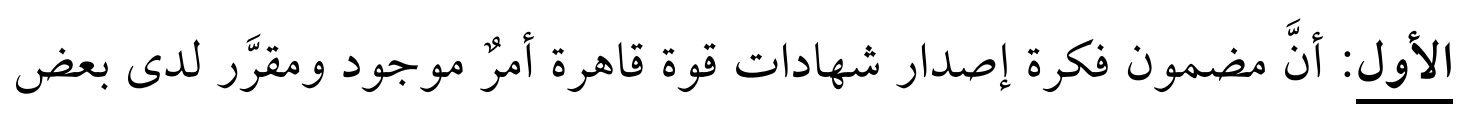

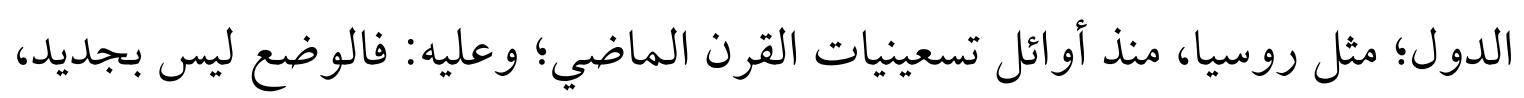

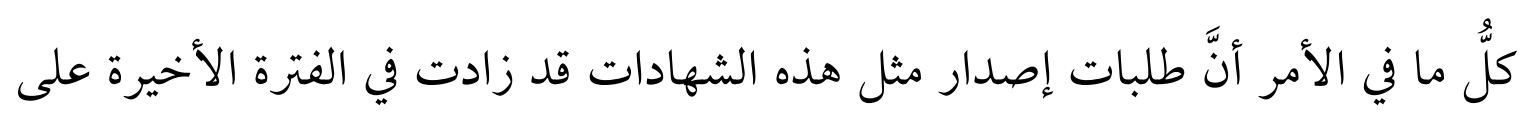
خلفية تفِّيّ فيروس كورونا المستجد.

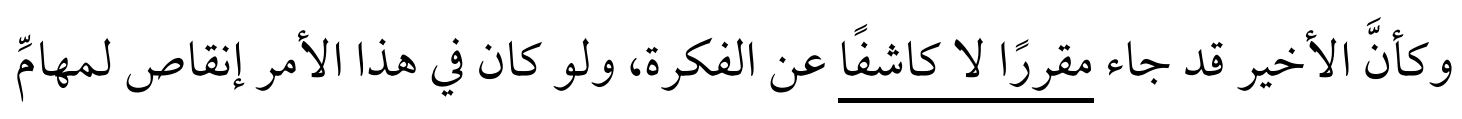

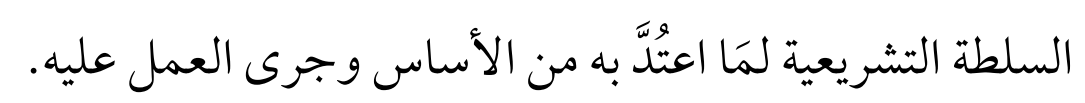

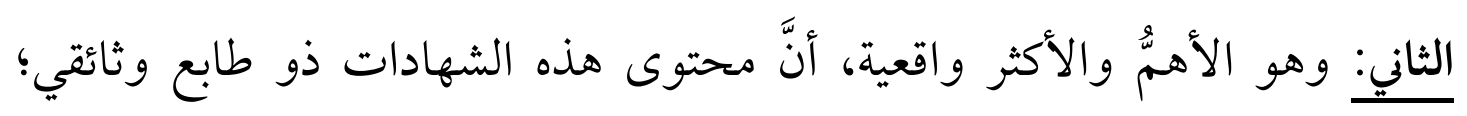
فشهادات القوة القاهرة -التي تُصدرها الدول على خلفية تفشّي جائحة كورونا تحديدًا-

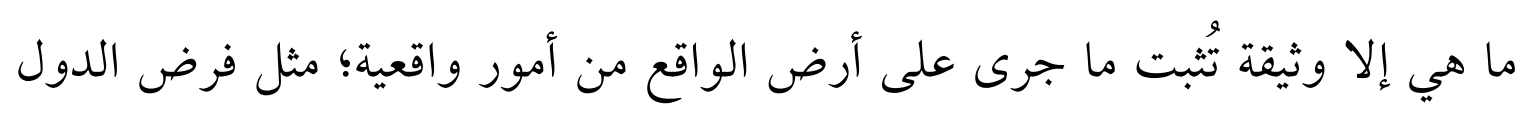

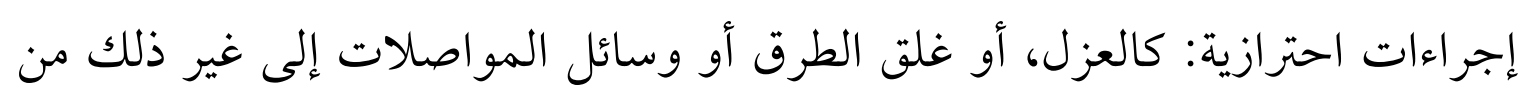
التدابير الحكومية التي من شأنها أن تَحُولَ دون تنفيذ الالتزام التعاقدي.

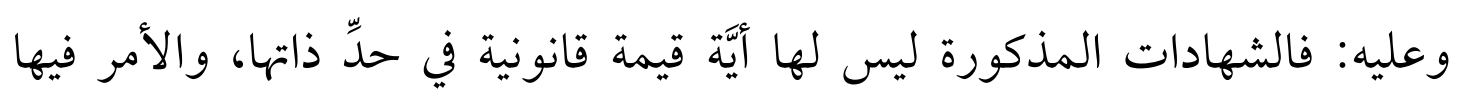

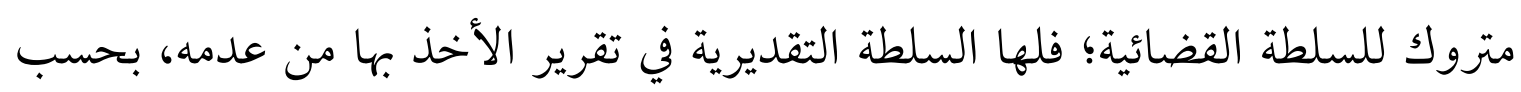
وقائع كلّ حالة وظروفها على حدة، وعليه: يقتصر دور شهادة القوة القاهرة الصادرة 
على تقديم دليل على وقوع حدث معين، وهو على ذلك بمثابة عنصر واحد فقط من عناصر تحليل فكرة القوة القاهرة'(1).

إذ إنَّ الشهادات الصادرة من المجلس المذكور -من اسمها- تشهد فقط على وقوع

الحدث، الذي قد يكون مؤهلا كحدث قوة قاهرة وقد لا يكون كذلك، ويبقى متصوَّرًا احتمالية الامتناع عن التصديق عليه كحدث قوة قاهرة؛ لأنَّ التصديق عليه قد يضفي قدرًا من المصداقية عند إرفاق مستندات القوة القاهرة إلى الأطراف الأخرى(().

ولعل مما يُبرهن على صواب التوجُه السابق ما لاحظه اللورد موستيل في قضية

من من أنَّه على الرغم من أنَّ شهادة

القوة القاهرة التي تصدر عن المجلس الصيني لتعزيز التجارة الدولية قد تكون "مفيدة" كدليل على "وجود القوة القاهرة"، بيد أنَّها ستكون "عديمة الفائدة _pointless " متى ما طُلب من المجلس المذكور CCPIT تحليل علاقة السببية في قضية أو مسألة بعينها، ناهيك عن أنَّ هذا السؤال "يجب أن يُنظر مرة أخرى في مرحلة التقاضي أو التحكيم" (s)، وهذا هو مكمن الارتباط الذي يؤكِّ أنَّ الجهةً الغير تشريعية المناط بها إصدار شهادة القوة القاهرة دوزرها محصورّ في هذا الخصوص.

الثالث: الواقع يثبت أنَّنسبة إصدار مثل هذه الشهادات نسبة قليلة مقارَنةً بما يُرفضض؛

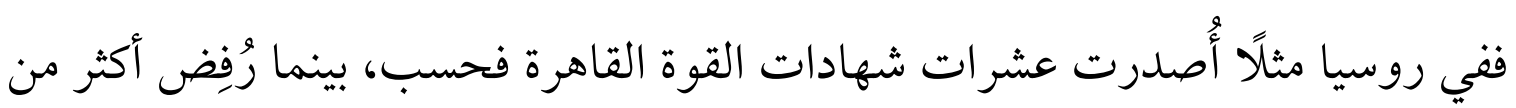

(1) Anton A. Ware, Jeffrey Yang et al, What to Do When You Receive a Coronavirus-Related Force Majeure Notice, op, cit.,

(2) Claudia Galvis, Jose Moran, et al, Coronavirus Outbreak: Global Guide to Force Majeure and International Commercial Contracts, op, cit.,

(3) Hoechong Products Co. Ltd v. Cargill Hong Kong Ltd, (Privy Council (Hong Kong) [1995] 1 W.L.R. 404).

(4) "would have to be looked at all over again at the stage of litigation or arbitration", Anton A. Ware, Jeffrey Yang et al, What to Do When You Receive a Coronavirus-Related Force Majeure Notice, op, cit., 
9 ٪ من الطلبات المقدَّمة لاستصدار شهادات قوة قاهرة -بحسب ما أعلن رئيس غرفة التجارة والصناعة الروسية- وبخاصة في ظلّ اللوائح والاشتراطات التي تفرضها الدولة لتقييم مدى تو افر شروط إصدار مثل هذه الشهادة"(1). وخلاصة القول: إنَّ في تبنِي بعض الدول لفكرة إمكانية إصدار شهادات قوة قاهرة

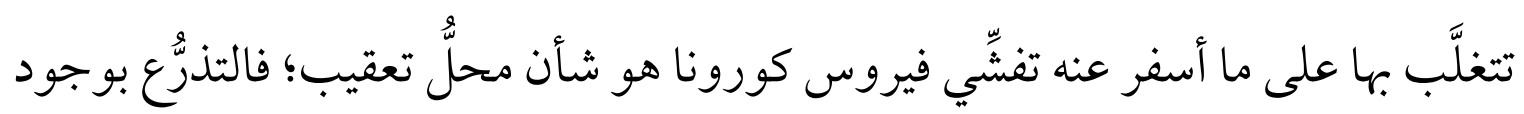
قوة قاهرة تحولُ دون تنفيذ الالتزام التعاقدي هو شأن يخضع في المقام الأول لاعتبارات قانونية واتفاقية؛ فالأولوية تمنح لما اتَّتق عليه الأطر اف، هذا من ناحية.

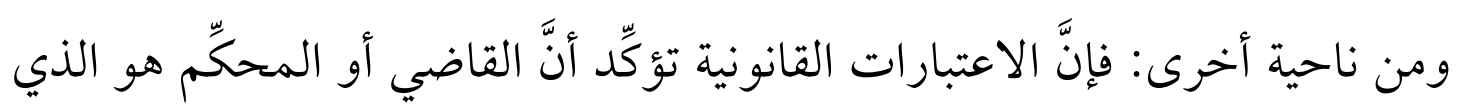
يحقّ له تقدير تحققّ مثل هذه القوة القاهرة من عدمه، بينما الجهات التجارية الصناعية كتلك المخولة إصدار شهادات القوة القاهرة في الصين وروسيا وغيرهم - لا تُعدُّ جهات قضائية، ناهيك عن أنَّه لا يمكنها أن تحلَّ محلَّ إرادة الأطر اف المتعاقدة في الالتزامات

$$
\text { الدولية و لا حتى الوطنية) }
$$

وإجمالًا : يمكن اعتبار كورونا فيروس من قبيل القوة القاهرة حال توافر أيِّ من

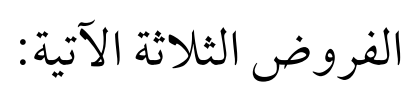

- و وجود نصِّ عقدي صريح يُفيد اعتبار الجوائح أو الأوبئة من قبيل القوة القاهرة.

(1) لمزيد من التفاصيل، انظر تقرير رئيس غرفة التجارة والصناعة الروسية المنشور على الموقع الرسمي لوكالة

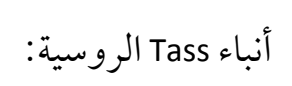

See at, https://tass.ru/ekonomika/8172063, Last visit on 4/7/2020.

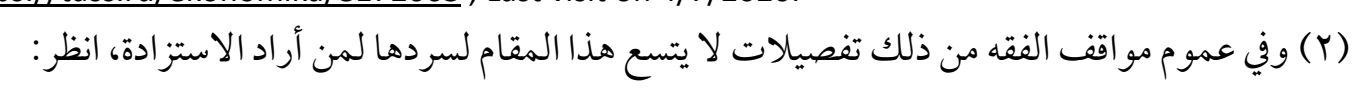

Ewan McKendrick, Force Majeure and Frustration of Contract, op, cit., Ch. 1.

ولمن أراد الوقوف على موقف القانون الإنجليزي من القوة القاهرة المثير للجدل، انظر، ذات الموضع السابق. 
- انطباق الشروط القانونية للقوة القاهرة مجتمعة على الحدث الذي يَُّّعى كونه قوة قاهرة.

- - إصدار شهادة قوة قاهرة بحسب ما مضت الإشارة إليه، وبالتالي اعتداد المحاكم المقدَّم إليها بها، التي قد تكون محكمة الدولة التي أصدرتها في كثير من الأحوال.

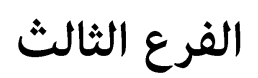

\section{الخطوات التي يجب اتخاذها عند استلام إشعار بالقوة القاهرة}

إنَّ التساؤل عن الخطوات التي تُتبّع عند استلام أيِّ من طرفي العلاقة التعاقدية إشعارًا بالقوة القاهرة، مبعثه إعلان المدين رغبته في أنَّه غير قادر على الوفاء بالتزاماته العقدية على إثر تفشّي فيروس كورونا، وهذا التساؤل ذو أبعاد منطقية وواقعية، وإجمالًا يُجاب بأنَّه يتعيَّن على الطرف الأول المتلقي للإشعار بالقوة القاهرة ما يأتي: ( التحقُّ مما إذا كان بالعقد شرط للقوة القاهرة من عدمه. (Y) تحديد القانون الو اجب التطبيق على العقد.

(ץ) مراجعة اللغة الدقيقة وتحليلها أو حتى صياغة شروط القوة القاهرة لمعرفة ما إذا كان الحدث المطالَب به مؤهلاً بالفعل كحدث قوة قاهرة على النحو المحلَّد

$$
\text { بموجب العقد. }
$$

(ع) تقيم ما إذا كانت هناك علاقة سبية بين حدث القوة القاهرة المدَّعى بها وعدم تنفيذ

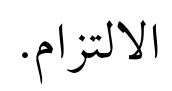

(0) في حالة عدم وجود شرط للقوة القاهرة في العقد، يُنظر فيما إذا كان يمكن أن يُعفى من تنفيذ الالتزام بموجب إنهاء العقد وفقًا للقانون الإنجليزي، أو غيره. الإصرار على أنَّ الطرف المطالِب بالقوة القاهرة يقدِّم ما يأتي: 


$$
\text { (أ) القر ائن على الظروف التي يُزعم أنها تمنع تنفيذ الالتزام. }
$$

(ب) تحديثات منتظمة تتعلق بجهوده لاستئناف تنفيذ أدائه؛ أو التخفيف من تأثير عدم

(V) النظر في التفاوض على تعديل مكتوب للعقد للوصول إلى حلٍ تجاري معقول") وتجدر الإشارة في هذا المقام إلى النصائح التي وجَّهرا مجموعة من الخبراء القانونيين(") للطرف الذي يتلقى إشعارًا بالقوة القاهرة مضمونها ما يأتي:

- أهمية أن يضع في اعتباره أنَّ تلقيه إشعارًا بالقوة القاهرة قد يشير إلى بداية نزاع، قد إلد يحتاج في النهاية إلى حلٍٍ من خلال التحكيم أو التقاضي.

- من المهمّ اتخاذ جميع الاحتياطات المعتادة في حالة النزاع؛ بما في ذلك مثلاً: الحفاظ على جميع المستندات ذات الصلة.

الحرص على عدم الإدلاء بييانات أو وعود دون قصد قد تشكّل أساسًا للطرف الآخر أن يدَّعي أنَّك وافقت على التنازل أو التخلي عن الحقوق التعاقدية. - إذا تناقش الطرفان شفهيًّ حول قرار أو أمر تجاري فيما بينهما، فينبغي التأكُّد من

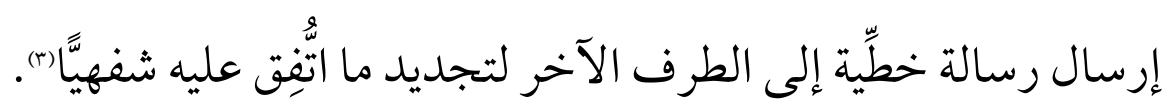

(1) في بيان هذه الخطو ات، انظر:

Anton A. Ware, Jeffrey Yang et al, What to Do When You Receive a Coronavirus-Related Force Majeure Notice, op, cit.,

(Y) ويحسب مؤلفي المقالة فهؤلاء من العاملين بمكتب Arnold \& Porter الأمريكي للمحاماة، أحد أكبر مكاتب المحاماة في العالم هم Jeffrey Yang Yingxi Fu-Tomlinson Timothy C. SmythAnton A. Ware ، ولمزيد من التفاصيل، انظر المرجع السابق.

(3) $\underline{\text { Ibid }}$ 


\section{شهادة القوة القاهرة في ميزان القانون الواجب التطبيق:}

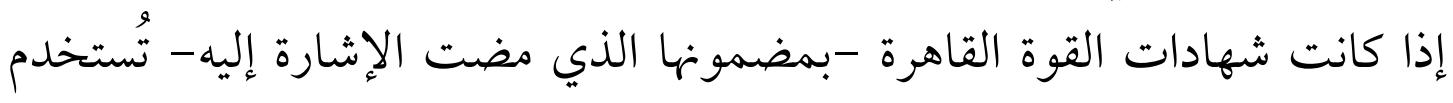

بصفة أساسية كمسوِّ كي تُبت للمتعاقد الآخر وجود بعض الصعوبات الواقعية التي تعوق تنفيذ التزامه، ومن ثََّمَ فمُبتغى الشهادة هو السعي للوصول إلى تفاهم لتسوية

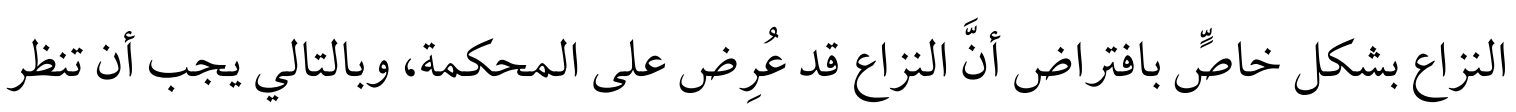
المحكمة حينئذ فيما إذا كان تفشّي الوباء والتدابير التي اتخذتها في عمومها ذات الصلة بالوباء ذاته يشكّلان أحداثًا قاهرة وفقًا لقانونها الو اجب التطبيق أم لا، مستعينة في تقدير ذلك بطبيعة الحال بمضمون شهادة القوة القاهرة كدليل على الوقائع. والفيصل هنا يكمن في عدم وجود سياسة دولية موحَّدة للقوة القاهرة يمكن أن تستظلَّ الدول تحت لوائها، بل إنَّ الواقع يؤكّد تبنِّي الدول لمذاهب مختلفة في شأن المخاطر التعاقدية في ظلّ حدوث تغيُّ غير متوقَّع للظروف، وفي ضوء الملابسات المطروحة كان المهُمّ البحث عن مدى وجود دور قائم ربما تؤدِّيه اتفاقية دولية لتتصدَّر المشهد حينئذِ، ومن ثََّّ التساؤل عن وضع اتفاقية الأمم المتحدة بشأن البيع الدولي للبضائع CISG ")، مع العلم بأنَّ الاتفاقية المذكورة لم تكن ذات أهمية كبيرة في قانون العقود الدولية منذ زمن طويل، ولكنَّها أصبحت الآن خاضعة للعديد من المناقشات من قِبَل جملة من الفقهاء(r)، وهو ما أفردت له الصفحات القادمة.

(1) Sophia Tang, Coronavirus, force majeure certificate and private international law, op, cit., p. 2,3.

$$
\text { (r) ولمن أرادة الاستز ادة فبالإمكان مطالعة البنك المعلوماتي الإلكتروني التالي: }
$$

Ralf Michaels, Jakob Olbing, Corona and Private International Law: A Regularly Updated Repository of Writings, Cases and Developments, op, cit., 


\section{الغصن الرابِع \\ مدى إمكانية الربط بين القوة القاهرة واتفاقية الأمم المتحدة بشأن عقود البيع الدولي للبضائع}

على الرغم من الأهمية النسبية لاتفاقية الأمم المتحدة بشأن عقود البيع الدولي للبضائع CISG في قانون العقود الدولية، بيد أنَّ هذا لم يَحُل دون خضوعها في الوقت الحالي للعديد من المناقشات ذات الصلة، مؤدَّاها عرض تحليلات مفصَّلة للإعفاءات من المسئولية ومسائل الظروف الطارئة بموجب الاتفاقية المذكورة'). إنَّ الدول الموقِّعة على هذه الاتفاقية، والتي من بينها مصر (() ينطبق عليها نصٌّ الفقرة الأولى من المادة V9 من الاتفاقية المذكورة، والتي تنصُّ على أنَّه:

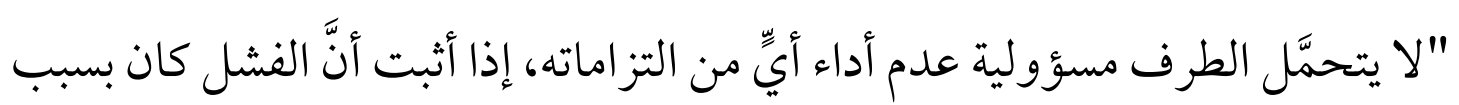
عائق خارج عن إرادته، وأنَّه لا يمكن أن يكون من المعقول أن يتخذ العائق بعين الاعتبار في وقت إبرام العقد أو تجنبّها أو التغلُّب عليها أو على نتائجها" (r).

(1) Ibid.

(Y) لمعرفة كل الدول الموقعة على الاتفاقية، وعددها قرابة ع^ دولة في الوقت الذي تخط فيه هذه السطور See at, https://iicl.law.pace.edu/cisg/page/cisg-list-contracting-states, Last visit on 23/6/2020.

وانظر أيضًا

Chia-Jui Cheng, Basic Documents on International Trade Law, Fourth Revised Edition, Wolters Kluwer, USA, 2012, Part 2, Ch. I, No. 4.

$$
\text { (r) للوقوف على النص الكامل للاتفاقية المذكورة، طالع الموقع الرسمي التالي: }
$$

See at, https://www.uncitral.org/pdf/english/texts/sales/cisg/V1056997-CISG-e-book.pdf Last visit on 23/6/2020.

See also, Matteo M Winkler, Practical Remarks on the Assessment of COVID-19 as Force Majeure in International Contracts, op, cit., 
وبشكل عامً: تُجيز الاتفاقية -إذا تبيَّن أنَّ البضائع المسلَّمة معيبة- للمشتري أن

يُقاضي البائع على هذا الأساس، طالما أخطر الأول بذلك في الوقت المناسب"(1).

وحريٌّ بالذّّكر أنَّهَ يُاحظ اختلاف موقف اتفاقية الأمم المتحدة بشأن عقود البيع

الدولي للبضائع عISG عمَّا ورد بالمبادئ المتعلقة بعقود التجارة الدولية (مبادئ اليونيدروا) في خصوص القوة القاهرة؛ إذ تحتوي الأخيرة على أحكام منفصلة بشأن القوة القاهرة(1)، وقد سبق التعرّّض لموقف المبادئ المذكورة في موضع سابق. ولمَّا كانت الصين أحد الدول الأعضاء في اتفاقية الأمم المتحدة بشأن البيع الدولي للبضائع، فالوضع ينطبق عليها وعلى أيَّة دولة عضو بالتبعية، بيد أنَّ حُسنَ عرض المسألة ذات الصلة يقتضي تقسيمها إلى فرضين: الفرض الأول: الطرف المتعاقد عضو في اتفاقية الأمم المتحدة بشأن البيع الدولي للبضائع: تنطبق الاتفاقية إذا كان محلٌّ عمل الطرف في دولة متعاقدة أخرى، أو إذا اختار الأطراف تطبيق نصوص هذه الاتفاقية تحديدًا واتفقوا هم على ذلك، وبالنظر لنصِّ المادة Vq من الاتفاقية البيع، التي مضى بيانها؛ فهي تُعفي الطرف المتعاقد من دفع التعويضات إذا كان السبب وراء عدم تنفيذ الالتزام التعاقدي خارج عن سيطرته، أو أنَّه

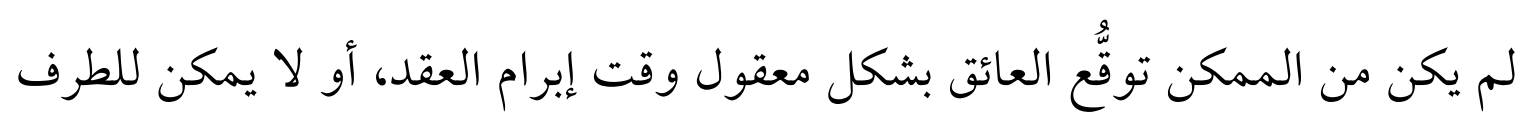
المتعاقد أن يتجنَّب أو يتغلَّب بشكل معقول على هذا العائق أو عواقبه؛ على اعتبار أنَّه

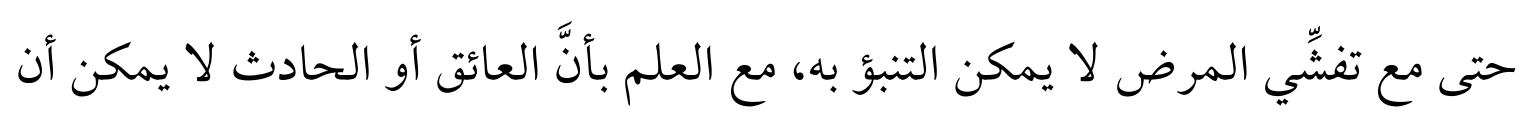

(1) Sonja Adrienne Kruisinga, (Non-) conformity in the 1980 UN Convention on Contracts for the International Sale of Goods: Aa Uniform Concept, Intersentia, USA, 2014, p. 150.

(2) Ibid 154. 


\section{يكون كذلك إلَّا إذا جعل الأداء مستحيلًا.}

وبناء عليه: إذا كان تفشّي الوباء يجعل الإنتاج أكثر صعوبة أو كلفة ومشقَّة فلا يُعدُّ

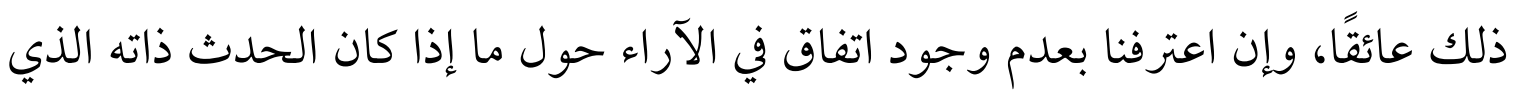

يجعل الأداء مرهقًا للغاية يمكن اعتباره -أيضًا- عائقًا في اتفاقية البيع، بالإضافة إلى بـانى

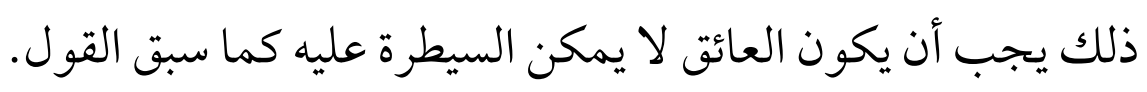

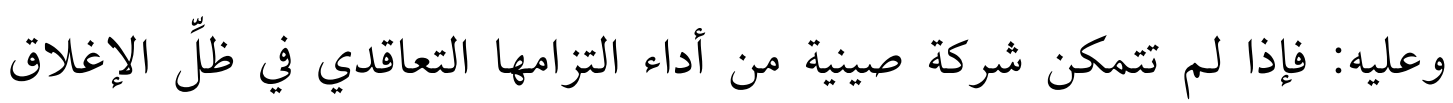

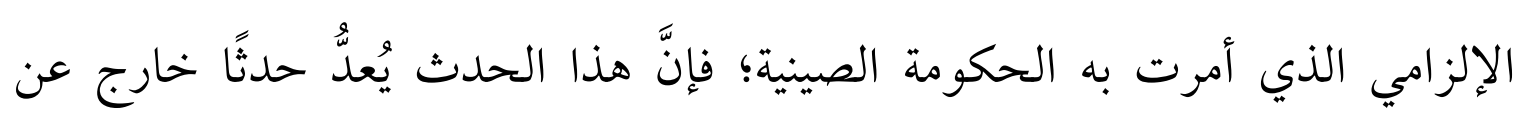

السيطرة").

الفرض الثاني: الطرف المتعاقد ليس عضوًا في اتفاقية الأمم المتحدة بشأن البيع

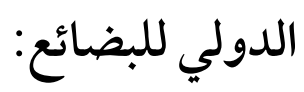

وفي هذا الفرض يُثار التساؤل حول ما إذا كان انتشار فيروس كورونا من شأنه أن

يعفي المصدِّرين الصينيين من التزاماتهم التعاقدية؟ والجواب هنا يعتمد على القانون الوطني الذي يحكم العقود، وعمومًا فمعظم الشركاء التجاريين الرئيسيين للصين هم دول أعضاء في اتفاقية البيع، باستثناء بعض الدول؛ مثل: الهند، وجنوب إفريقيا، نيجيريا و المملكة المتحدة. وعليه فسيكون الرجوع هنا للقانون الوطني المطبق على العقد وبحسب كل عقد.

(1) في هذا التأصيل، ولمزيد من التفاصيل، انظر، Sophia Tang, Coronavirus, force majeure certificate and private international law, op, cit., p. 2,3. 


\section{المطلب الثالث \\ موقف القضاء والقوانين المقارنة

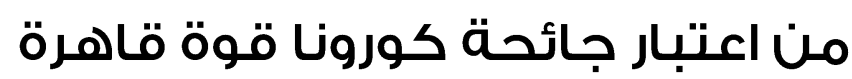

تمهيدٌ وتقسيمٌٌ:

من المعلوم أنَّ الحديث حول مدى اعتبار فيروس كورونا قوة قاهرة من عدمه هو

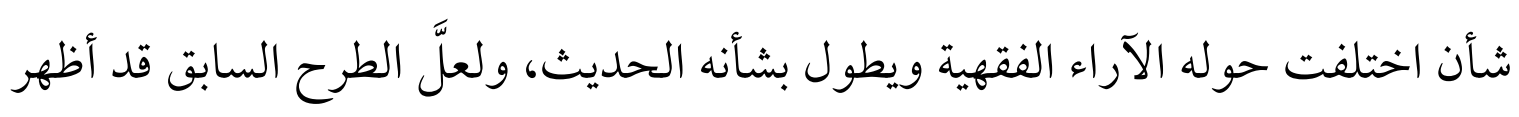
بعضًا من أبعاد هذا القول.

وعليه: خصَّصت الدراسة شطرًا منها للوقوف عند بعض هذه الآراء من منظور

القضاء و القوانين المقارنة حسب ما اقتضته حاجة الدراسة، وهو ما يحمل في مضمونه بحسب الأصل - بيانَ التوجُهات المعمول بها في هذا الخصوص، وعليه: كان مهمًّا البحث عمَّا إذا كانت التوجُهات قد توحَّدت صوب اعتبار فيروس كورونا قوة قاهرة من عدمه؟ وهذا هو ما سيكون محلَّل لهذا المطلب. ولقد قُسِم المطلب إلى فرعين؛ تناول أوَّلهما موقف القضاء المقارن من اعتبار جائحة كورونا قوة قاهرة، وبالتحديد القضاء الفرنسي والأمريكي والمصري على نحو يُثري المناقشة في ضوء ما بينهما من اختلافات، أعقبه فرع ثانٍ؛ وضَّح موقف القانون المقارن من المسألة ذاتها، مقتطفًا موقف المشرعين الإنجليزي والصيني؛ كبُعِد آخر للطرح من منظور مختلف.

الفرع الأول

موقف القضاء المقارن من اعتبار جائحة كورونا قوة قاهرة تمهيدٌ وتقسيمٌٌ: موقف يسلِّط مضمون هذا الفرع الضوء على مواقف القضاء من اعتبار جائحة كورونا قوة 
قاهرة من وجهة نظر قضاء علَّة دول مختلفة، نستهلُّها بييان موقف القضاء الفرنسي ثم المصري، ونختتمها بموقف القضاء الأمريكي في ثلاثة غصون متتالية. الغصن الأول

\section{موقف القضاء الفرنسي}

تمتلُّ جذور القوة القاهرة في أعماق التاريخ الفرنسي، بما لها من تاريخ طويل لا تتَّسع صفحات الدراسة للوقوف عنده، ويكفينا في هذا المقام الإشارة لما قيل في حقِّها من أنَّ مفهوم القوة القاهرة في صياغتها الحديثة -كشرط تعاقدي- مستمدّ من واضعي القانون المدني الفرنسي (كود نابليون أو القانون المدني (Code Napoléon or Code Civil) لعام ع •1 أم، الذي نصَّ على القوة القاهرة كعذر لتنفيذ الالتزام التعاقدي"(1). ولعلَّ من الأنسب في هذا السياق أن يُوضع معيارٌ زمنيُّ، يُجرى من خلاله بيان مو اقف القضاء الفرنسي من مدى اعتبار الأوبئة قوة قاهرة من عدمه؛ لتصل أبعاد الفكرة

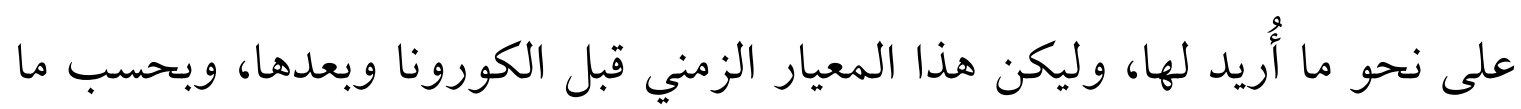

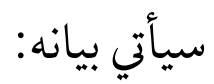

\section{(1) موقف القضاء الفرنسي من اعتبار الأوبئة قوة قاهرة "قبل " جائحة كورونا}

إنَّ توجُه القضاء الفرنسي صوب اعتبار الأوبئة قوة قاهرة من عدمه قبل زمن

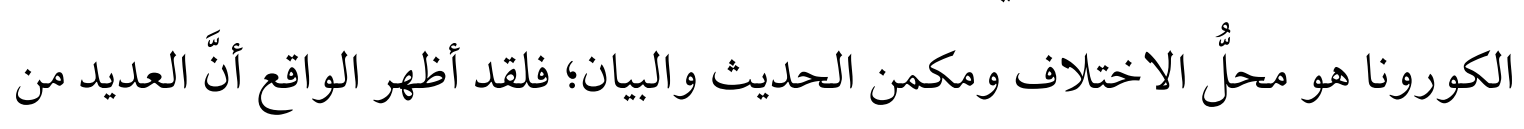
المسافرين قد عرضوا مرارًا دعواهم أمام القضاء الفرنسي، والدفع بالقوة القاهرة على

(1) For more details, Klaus Peter Berger, Daniel Behn, Force Majeure and Hardship in the Age of Corona: A Historical and Comparative Study, op, cit., p. 16, ft. 80, referred to, James Gordley, Impossibility and Changed and Unforeseen Circumstances, The American Journal of Comparative Law, Volume 52, Issue 3, Summer 2004, 01 July 2004, p. 513-518,. 
إثر تفشّي وباء في مناطق بعينها كانوا يخطّطون الذهاب إليها لتبرير إلغاء حجزهم، وطلب استرداد المبالغ المدفوعة، لكنَّ المحاكم الفرنسية رفضت صراحة اعتبار حمى الضنك Dengue ووباء الطاعون بمثابة قوة قاهرة.

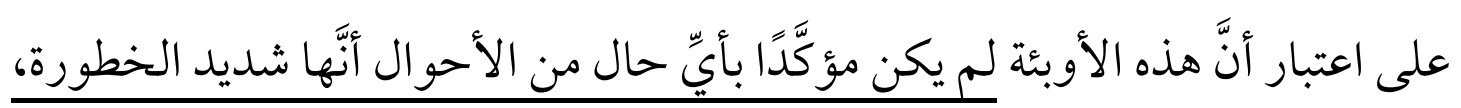
ولم تُعَ تعليمات لشركات الطير ان أو وكالات السفر لتجنبّ السفر إلى مناطق بعينها، بالإضافة إلى إمكانية ضمان الحماية من خطر العدوى عن طريق العلاج بالمضادات الحيوية الوقائية، ناهيك عن أنَّ السلطات العامة للدول أو منظمة الصحة العالمية لم

تعلن عن وجود هذا الوباء، فهو في رأيها حينئذ ليس له صفة القوة القاهرة"). وإجمالًا : فقد كان من المستقرِّ عليه في القضاء الفرنسي اعتبار أنَّ الأوبئة مثل سارس وغيره في حدّ ذاتها لا تُشكّل قوة قاهرة، بالنظر لعدم فتكها الكامل، ناهيك عن وجود لقاح لمثل هذه الأوبئة، ولا أدلَّ على ذلك من توجُه محكمة النقض الفرنسية بالنظر لمفهوم القوة القاهرة في قرارها الصادر في 17 سبتمبر ع ا • ب من أنَّه:

"لا يمكن إعفاء المدين من التزامه التعاقدي ... عن طريق الاحتجاج بوجود قوة قاهرة"

ومما يُلاحظ على موقف القضاء الفرنسي السابق مخالفته للوضع في الصين؛ إذ

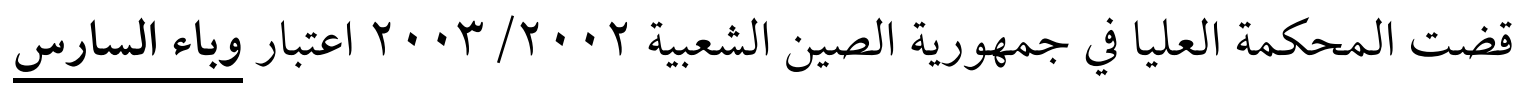

(1) For more details, Luc Grynbaum, Force majeure et épidémie de COVID -19: une première décision vient d'être rendue, op, cit.,

(2) Com. 16 sept. 2014, $n^{\circ}$ 13-20.306, Xavier Delpech, La caution et la force majeure, Issued by DALLOZ official website, published on 2/10/2014.

See at, https://www.dalloz-actualite.fr/flash/caution-et-force-majeure\#results box , Last visit on 10/7/2020. 


\section{"قوة قاهرة"، معوّّلة في ذلك على التعريف القانوني لمصطلح "القوة القاهرة" بحسب}

ما ورد بالقانون المدني الصيني"، ولنا وقفة لاحقة مع موقف دولة الصين.

وعليه: فإنَّ تنبُّع عموم السوابق القضائية في فرنسا الخاصة ذات الصلة بالأوبئة يعني

أنَّ مجرَّد وجودها في فرنسا لا يكفي لتشكيل حالة من الظروف القاهرة، على أساس أنَّ

الوباء بهذا المعنى لا يتمتَّع عمومًا بخصيصتي عدم القدرة على التبؤ، وبخاصة استحالة

الدفع ()؛ ولقد اعتّر وباء انفلونزا الخنازير H1 N1 هو الآخر الذي تذرَّعت به إحدى

الشركات أمام المحاكم الفرنسية كي تُنهي عقدها مع الشركة المصنِّة، ليس سبِّا للقوة

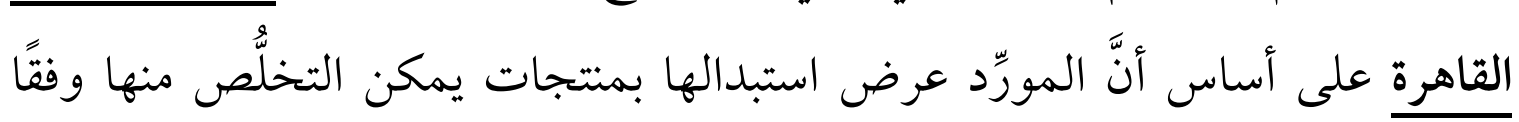
للمعايير الصحية الجديدة المعتمدة نتيجة للوباء (إمكانية الدفع) الذي أُعلن عنه أيضًا

$$
\text { وخُطِّط له على نطاق واسع (إمكانية التنبؤ) (م). }
$$

ورغم التوجُه القضائي الفرنسي السابق الرافض لاعتبار جائحة كورونا قوة قاهرة،

والذي ظهرت بعض أبعاده مما سبق، وسيظهر بعضها الآخر لاحقًا، إلَّا أنَّ حكمًا حديثًا

قضت به محكمة استئناف كولمار في مارس الماضي وفي أعقاب تفشّي فيروس كورونا غيَّر من مجرى الأحداث، ومما استقِقِّر عليه.

(Y) موقف القضاء الفرنسي من اعتبار الأوبئة قوة قاهرة "بعد" جائحة كورونا:

(1) The coronavirus and its consequences :Legal impact on supply and production relationships, published by the official website of deloitte, op, cit., See also, Ulrike Glueck, Micheal Munzinger, et al, Does the Coronavirus outbreak constitute Force Majeure, op, cit.,

(2) "L'étude de la jurisprudence historique spécifique aux épidémies démontre que leur seule existence ne suffit pas à constituer un cas de force majeure, au motif que l'épidémie en cause ne présente généralement pas les caractères ", Constance Verroust-Valliot et Serge Pelletier, L'impact du covid-19 sur les contrats de droit privé, op, cit.,

(3) Besançon, 2e ch. comm., 8 janv. 2014, $n^{\circ}$ 12/02291, Luc Grynbaum, Force majeure et épidémie de COVID -19: une première décision vient d'être rendue, op, cit.,

Also, Constance Verroust-Valliot et Serge Pelletier, L'impact du covid-19 sur les contrats de droit privé, op, cit., ft. 15. 
(حكم محكمة كولمار الفرنسية في خصوص حيثيات اعتبار فيروس كورونا قوة

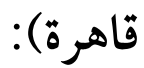

أصدرت محكمة استئناف كولمار الفرنسية مؤخرًا -وبالتحديد في با مارس

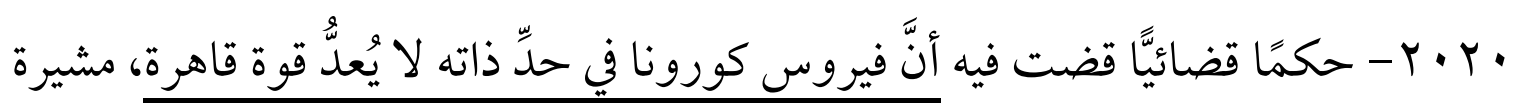
إلى أنَّ عدم وجود لقاح، بالإضافة إلى خطر العدوى، وكونه فيروسًا مميتًا، هو الذي شكَّل قوة قاهرة")، بالإضافة إلى أنَّ إعلان السلطات العامة للدول ومنظمة الصحة العالمية عن وجود هذا الوباء يُدخله في نطاق احتمالية التمتُع بالقوة القاهرة.

وقد جاء هذا الحكم في أعقاب عدم قدرة المستأنف -وهو أجنبي خاضع للاعتقال الإداري في فرنسا- من حضور جلسة الاستئناف بسبب الاشتباه في إصابته بفيروس كورونا، وهو ما علَّقت عليه المحكمة بأنَّ الظروف التي منعت المستأنف من الحضور هي "ظروف استثنائية" (d' exceptionnelles)؛ فمثل هذه الظروف خارجة عن إرادته، وليس لديه القدرة على التنبؤ بها أو دفعها، ناهيك عن أنَّ خطر العدوى من المستأنف (()، وعدم وجود الآلات التي تُمكِن من عقد الجلسة عن طريق النقل الأثيري "الفيديو

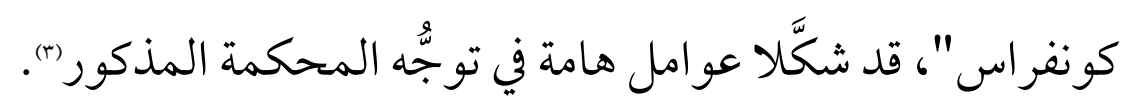

(1) "Il s'agit d'un virus létal, il n'existe ni vaccin ni médicament et la prise en charge consiste à traiter les symptôme", See, Covid-19 et Force majeure: la Cour d'appel de Colmar est la première à se prononcer, Issued by Actance Avocats official website, published on 8/4/2020.

See at, https://www.actanceavocats.com/actualites/actualite-jurisprudentielle-/covid-19-et-forcemajeure-:-la-cour-dappel-de-colmar-est-la-premiere-a-se-prononcer-227 , Last visit on 10/7/2020

(Y) لمزيد من التفاصيل راجع، كلمة د. الهيثم سليم، أثر جائحة كورونا على المسئولية المدنية، الندوة القانونية

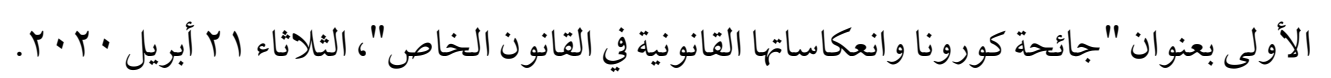

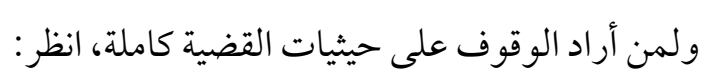

Covid-19 et Force majeure: la Cour d'appel de Colmar est la première à se prononcer, Issued by Actance Avocats official website, published on 8/4/2020. 
ويشاطر ما سبق ملاحظة أنَّ توجُه الحكومة الفرنسية نفسه قد اختلف عما سارت

عليه المحاكم الفرنسية من قبل؛ فها هو وزير الاقتصاد الفرنسي أيضًا برونو لومير Bruno Le Maire "حالة قوة قاهرة" للشر كاتِ"، وأنَّ العقوبات على التسليم المتأخر لن تطبَّق في عقود

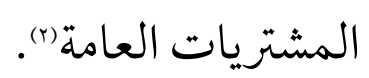

\section{التعقيب على حكم محكمة كومار الفرنسية:}

وتعليقًا على هذا الحكم الفريد لمحكمة الاستئناف الفرنسية الذي غيَّ تهرت به ما

تواترت عليه أحكام القضاء الفرنسي من قبل؛ فإنه يلاحظ أنَّ حكم محكمة كولمار قد خرجت عن المبدأ المستقرِ عليه، معتبرةً الحدث قوة قاهرة بالنظر لعدم وجود لقاح، وبالتالي عدم إمكانية الوقاية منه، وإلَّا فإنَّ وجود لقاح لفيروس كورونا مدعاة لخروجنا من هذا السياق كليَّة، وكأنَّ تقييم الحدث مسألة واقع تختصُّ بها محاكم الموضوع.

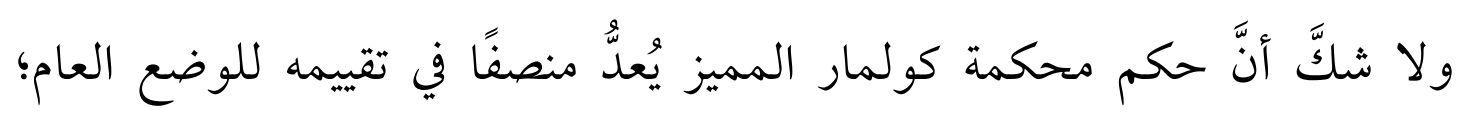
لمواكبته لما حدث بعدما تحوَّل العالم إلى غرف مغلقة أو سجن كبير، وكأنَّ ما مَّ به

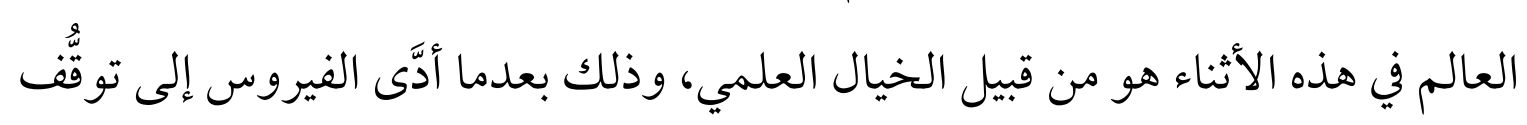
حركة الإنسان بل العالم، أو على أقل تقدير عما اعتدنا عليه، وما ترَّتب عليه من استحالة

See at, https://www.actanceavocats.com/actualites/actualite-jurisprudentielle-/covid-19-et-forcemajeure-:-la-cour-dappel-de-colmar-est-la-premiere-a-se-prononcer-227, Last visit on 10/7/2020.

(1) Ibid.

(2) Klaus Peter Berger, Daniel Behn, Force Majeure and Hardship in the Age of Corona: A Historical and Comparative Study, op, cit., p. 2.

$$
\text { وللاطلاع على النص الكامل لهذا الإعلان، انظر الر ابط الإلكتروني الرسمي التالي: }
$$

Visit, https://www.vie-publique.fr/discours/273763-bruno-le-maire-28022020-coronavirus , Last visit on $12 / 7 / 2020$. 
تنفيذه لالتزاماته بشكل مجمل، التي من بينها التزاماته التعاقدية"(1).

$$
\text { الغصن الثاني }
$$

\section{موقف القضاء المصري}

في حكمٍ لقي صدى" فقهيّا واسعًا بالنظر لصدوره في مرحلة دقيقة من عمر البشرية، صدر حكم مجلس الدولة المصري قاضيّا -وبالتحديد في الثامن والعشرين من شهر يونيو - يقضي صراحةً أنَّ: فيروس كورونا المستجد 19 COVID- يُعدٌّ جائحة، ويشكّل حالة قوة قاهرة بعدما اجتاح العالم، وأثَّر كقوة قاهرة على ممارسة الحياة الديمقراطية السليمة، وهو ما دعت على إثره منظمة الصحة العالمية إلى الإعلان أنَّه يُعدُّ جائحة، وبعدما ظلَّ الفقه -ومازال- يخوض غمار البحث عن تكييف قانوني مالائم منذ شهور لهذه الجائحة، وازاه خروج هذا الحكم إلى النور (r).

وبحسب ما جاء بالحكم المذكور فإنَّ الحياة الإنسانية هي أغلي ما يمكن للحكومات والدول والمجتمعات والمؤسسات المحافظظة عليها، فحفظ النفس يُعدُّ أولى مقاصد الشريعة الإسلامية وسابقًا على حفظ الدين، وبغير حياة الإنسان لا تقوم الدنيا، ومن أحيا نفسًا فكأنما أحيا الناس جميعًا، وفي إطار مسئوليات الدولة بالحفاظ على صحة المواطن وحياته: فقد قامت الدولة -أيضًا- بكافة الإجراءات التي سايرت

(1) في هذا الطرح، راجع الندوة افتراضية بعنوان الآثار القانونية لفيروس كورونا المستجد على العقود الدولية للأعمال التي نظمتها كلية القانون، جامعة أبو ظبي، سابقة الإشارة، وبالتحديد كلمتي د. سمير أوخليفا، د.

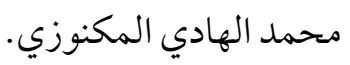

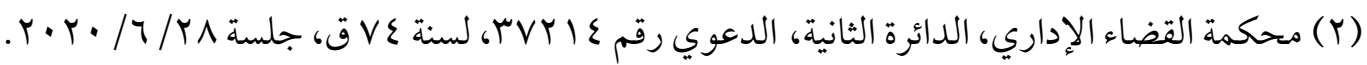


توصيات منظمة الصحة العالمية، وكذلك المؤسسات الصحية الوطنية، وصدر استنادًا لها قرار رئيس مجلس الوزراء رقم Y •T لسنة ·r ·r المشار إليه، وما تلاه من قرارات، بما يفيد حظر التجمعات البشرية لأيّ سبب من الأسباب؛ ومن هذه الأسباب التجمٌّع في جمعية عمومية لإجراء انتخابات النقابة المدعى عليها، ولئن كانت الحياة الديمقر اطية

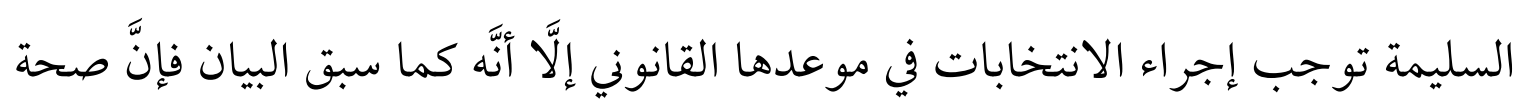
المواطن وحياته لايُعادلها مقصد آخر.

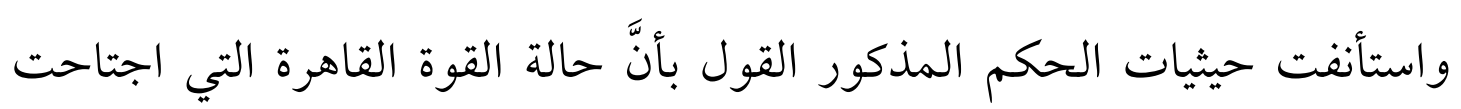

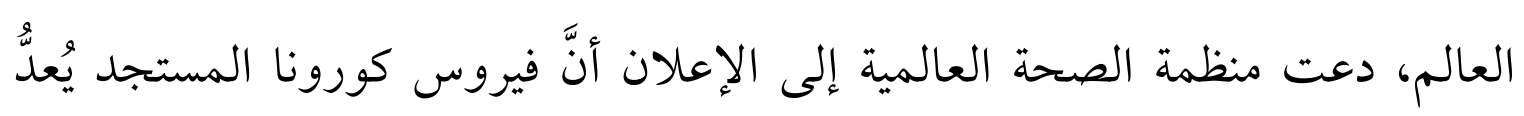
جائحة، وفي سبيلها اتخذت الدولة بعض الإجراءات الاحترازية لمواجهة تلك الجائحة حفاظًا على صحة المواطنين؛ حيث صدر قرار رئيس مجلس الوزراء رقم 7 •7 لسنة

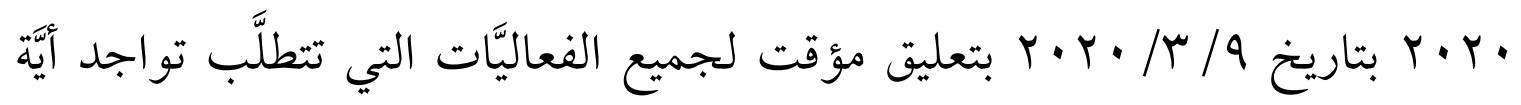

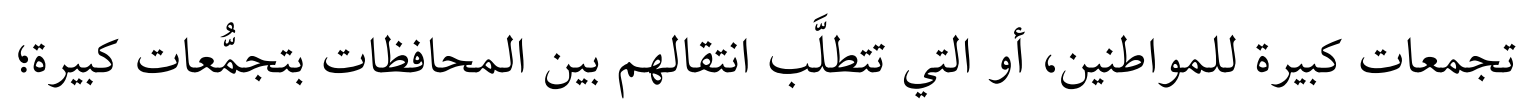

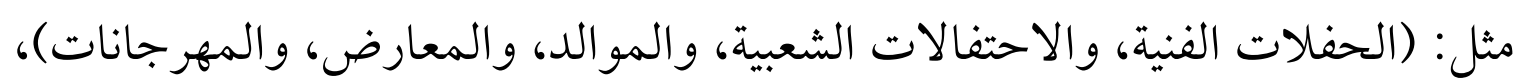

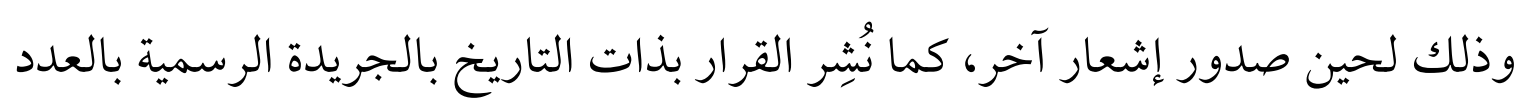
•ا (مكرر).

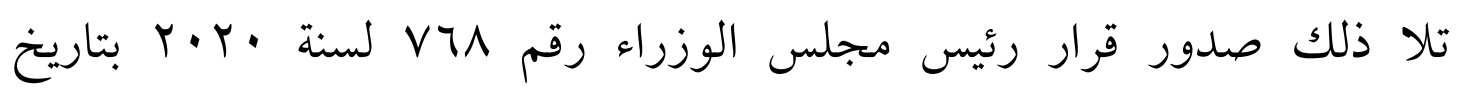

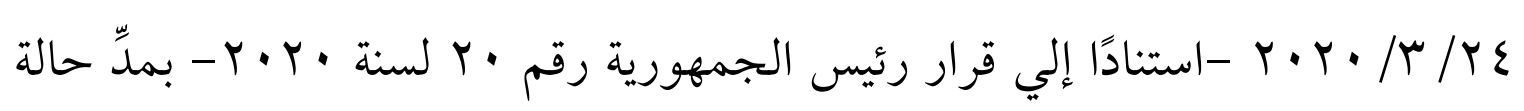
الطوارئ المعلنة بالقرار رقم 000 لسنة 19 • ب في جميع أنحاء البلاد لمدة ثلاثة أشهر،

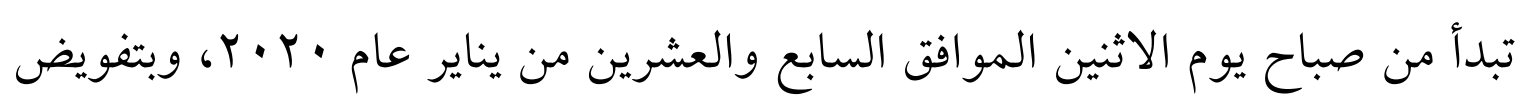
رئيس مجلس الوزراء في اختصاصات رئيس الجمهورية المنصوص عليها في القانون 
رقم با7 17 لسنة 1901 بشأن حالة الطوارئ وحظر الانتقال على المواطنين بكافة أنحاء الجمهورية في المواعيد المحلَّدة بالقرار درءًا لأيَّة تداعيات محتمَلة لفيروس كورونا، وعلى النحو الوارد بالقرار، وتوالت قرارات رئيس مجلس الوزراء بتنظيم الانتقال والعمل ببعض مرافق الدولة والمدارس، في إطار خطة الدولة الشاملة للحفاظ على صحة المو اطنين وحياتهم من أيِّ مخاطر محتملة لفيروس كورونا.

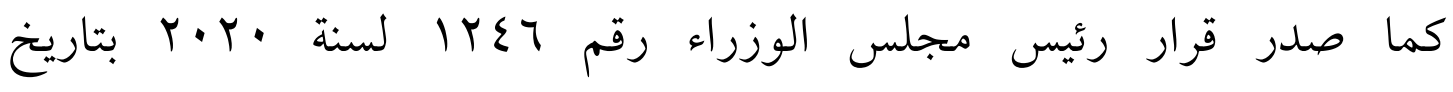

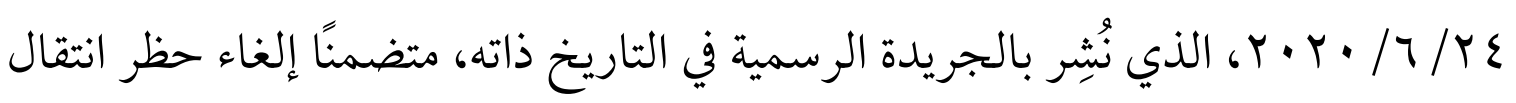
المواطنين وتحرُّكهم بكافة أنحاء الجمهورية على الطرق جميعها، وتضمَّنت المادة

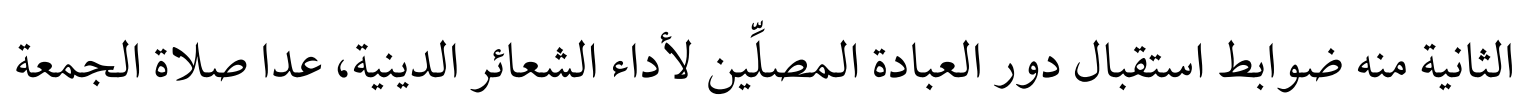
بالنسبة للمسلمين والصلوات الرئيسية الجماعية التي تحدِّدها السلطات الدينية بالنسبة

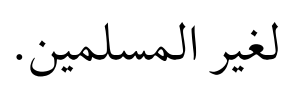
وبحسب المادة الثالثة حُدِّدت ضو ابط استقبال الجمهور بالمقاهي والمطاعم، وما يماثلها من: المحالّّ، والمنشآت، ومحالّّ الحلويات، ووحدات الطعام المتنقلّة، وغيرها من الضوابط المتعلِّة باستقبال الجمهور بالمحالّ التجارية والحِرفية، وبيع السلع وتقديم الخدمات، والمراكز التجارية، وكذلك الأندية الرياضية والشعبية، ومراكز الشباب، وصالات الألعاب و النوادي الرياضية، ودور الثقافة والسينما و المسارح، وذلك في حدود الضو ابط التي تضمَّنت ألَّا تزيد نسبة الإشغال عن ه ٪٪ من الطاقة الاستيعابية. وفي المادة الثامنة تضمَّن القرار استمرار غلق جميع الحدائق والمنتزهات والشواطئ العامة، وجاءت المادة التاسعة باستمرار تعليق جميع الفاعاليَّات التي تتطلَّب تتو اجد أيَّة تجمعات كبيرة للمواطنين؛ مثل: (الحفلات الفنية، والاحتفالات الشعبية، والموالد، 
والمعارض، والمهرجانات، والأفراح)، الأمر الذي يفيد أنَّ قرار رئيس مجلس الوزراء الأخير لم يتضمَّن إلغاء للقرار السابق، وإنما يهدف إلى تنظيم سير بعض المرافق الاقتصادية في ظلّ الجائحة العالمية، التي مازالت آثارها الخطيرة مستمرة، مع الالتزام بعدم السماح بأيَّة تجمُّعات للأفراد يترتَب عليها خطر داهم على الصحة العامة للمو اطنين (1)

إذًا موقف القضاء المصري -ممثلًا في مجلس الدولة- كان صريحًا في اعتبار جائحة كورونا قوة قاهرة، وعلى إثر هذه الصر احة لم نكن بحاجة إلى تتبّع المواقف السابقة.

\section{الغصن الثالث}

\section{موقف القضاء الأمريكي: نيويورك نموذجًا}

إنَّ المحاكم في نيويورك تعمل القوة القاهرة صراحةً وفقًا لمدى توافر شروطها من

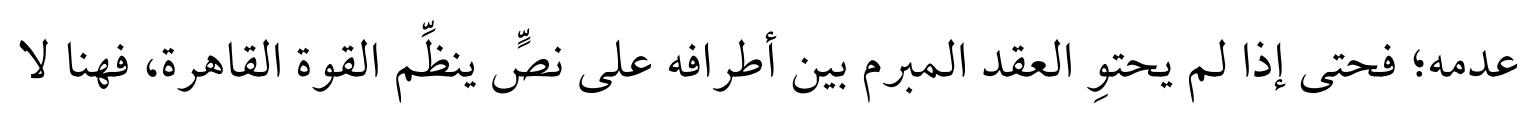
يوجد مدعاة من حيث الأصل للدفع بالقوة القاهرة، وعليه: فالمحاكم -لديها- على استعداد -في الظروف الاستثنئية- أن تُعفي من عدم أداء الالتزامات على أساس استحالة القيام بالأداء في حدِّ ذاته، ولو لم يوجد نصّّ عقدي للقوة القاهرة.(1). بيد أنَّ القول السابق يحدُّه ما رآه الفقه من أنَّ شروط القوة القاهرة تُفسَّر في ولاية نيويورك -تحديدًا - تفسيرًا ضيقًا؛ حيث تعفي فيه من عدم تنفيذ الالتزام التعاقدي فقط عندما يكون الحدث بسبب ظروف خارجة عن سيطرة الأطراف وغير متوقَّع، وتنقسم

(1) في هذه التفاصيل راجع: الحكم الصادر من محكمة القضاء الإداري، سابق الإشارة.

(2) Anton A. Ware, Jeffrey Yang et al, What to Do When You Receive a Coronavirus-Related Force Majeure Notice, op, cit., 
محاكم نيويورك نفسها حول ما إذا كان الحدث المعنيُّ يجب أن يكون غير متوقَّع أيضًا، في حالة عدم وجود شرط عقدي بنصِّ القوة القاهرة بطبيعة الحال (1).

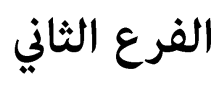

موقف القانون المقارن من اعتبار جائحة كورونا قوة قاهرة

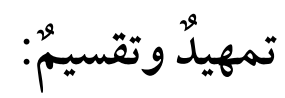

إذا كان تناول موقف القضاء المقارَن من اعتبار جائحة كورونا قوة قاهرة قد سلَّط الضوء على مو اقف القضاء في كلٍ من: فرنسا ومصر والو لايات المتحدة الأمريكية، فإنَّ بيان موقف القانون المقارن من المسألة ذاتها سيكون بالنسبة لموقف نظامين قانونيْن مختلفين إثراءً للدر اسة؛ ألا وهما: موقف قانون العقود الإنجليزي، ثم نظيره الصيني في غصنيْن متتالينْن.

\section{الغصن الأول}

\section{موقف قانون العقود الإنجليزي}

يُّير التساؤل عن موقف قانون العقود الإنجليزي من اعتبار جائحة كورونا قوة قاهرة من عدمه البحثَ الأوَّلي في مدى إمكانية إنهاء العقد بسبب القوة القاهرة بموجب

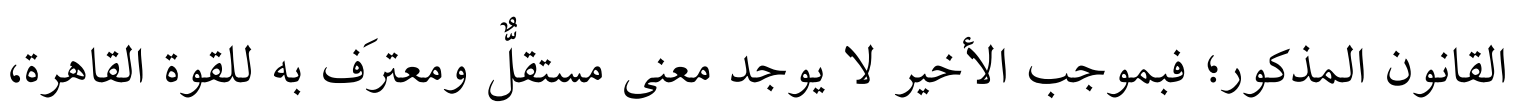
وبالتبعية لم يُتضمَّن في قانون العقود الإنجليزي، ومع ذلك يمكن التذرّّع بالقوة القاهرة إذا كان هناك نصٌّ صريح يتعلَّق بالقوة القاهرة أُدرِج بالعقد، وبالنسبة للظروف التِّي

(1) Ibid.

ولمن أر اد الاستزادة في موقف محاكم نيويورك من القوة القاهرة، انظر المقالة التالية سابقة الإشارة: Claudia Galvis, Jose Moran, et al, Coronavirus Outbreak: Global Guide to Force Majeure and International Commercial Contracts, op, cit., 
يمكن للطرف المتعاقد أن يعتمد عليها كقوة قاهرة، ومدى تأثيرها فيكون بالرجوع إلى النصِّ الصريح ذاته، الو ارِد بالعقد، الذي يُفيد بالقوة القاهرة.

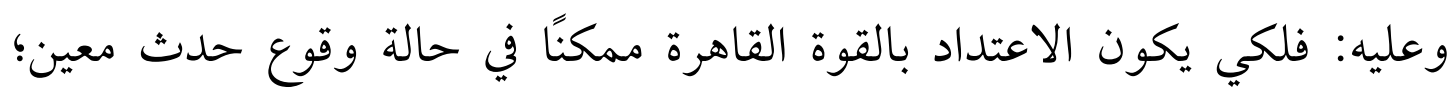

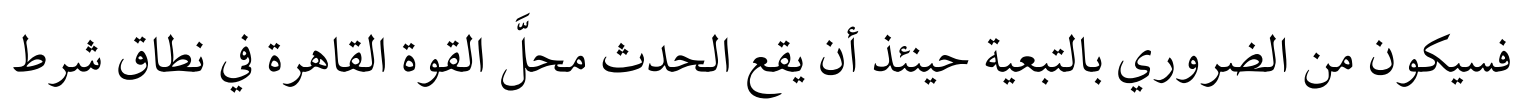

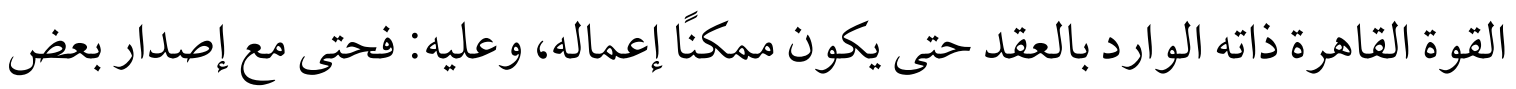

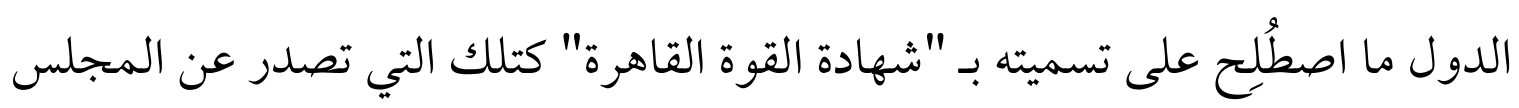
الصيني لتعزيز التجارة الدولية -على نحو ما بين البحث - فهذه الشهادة قد تكون دليلًا

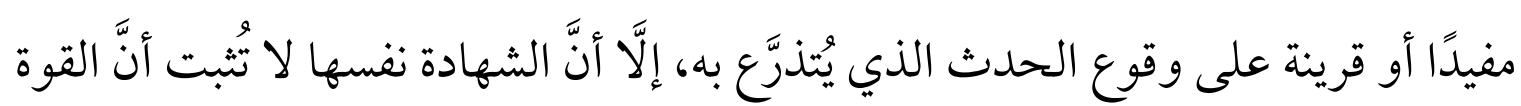
القاهرة ممكنة بموجب قانون العقود الإنجليزي، وعليه: فسيظلٌ الطرف الصيني المتعاقد بحاجة إلى إثبات أنَّ ظروفه المدعى بها تقع ضمن نطاق حكم القوة القاهرة التي نُصَّ عليها في عقدهم، وأنَّ عدم قدرته على تنفيذ العقد كانت في الو اقع ناتجة عن إنى لهن الحدث المدعى بكونه قوة قاهرة"(1).

ويوازي ما سبق التأكيد على أنَّه بموجب القانون الإنجليزي فإنَّ الصياغة المحددة

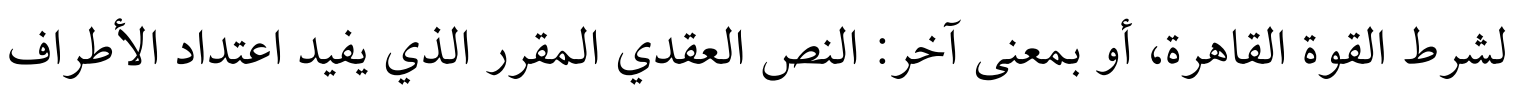

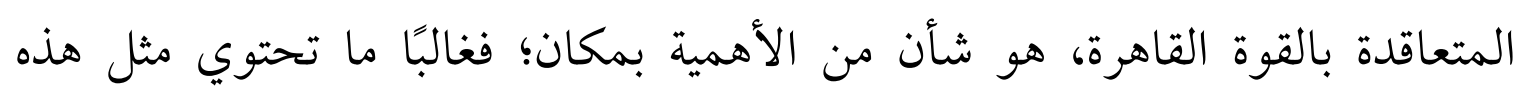

: (1) Anton A. Ware, Jeffrey Yang et al, What to Do When You Receive a Coronavirus-Related Force Majeure Notice, op, cit.,

ولمن أراد الاستزادة في موقف المحاكم الإنجليزية من القوة القاهرة، وغيرها من محاكم الدول الأخرى؛ مثل هونج كونج وسنغافورة والتي سارت على ذات الدرب، انظر المقالة التالية، سابقة الإشارة:

Claudia Galvis, Jose Moran, et al, Coronavirus Outbreak: Global Guide to Force Majeure and International Commercial Contracts, op, cit., 
النصوص على قائمة بالأحداث التي تُعدّ مؤهلة للقول باعتبارها قوة قاهرة، ويلزم هنا التأكيد على أنَّ مثل هذه القوائم قد تكون حصرية أو غير حصرية، على ما يأتي: (1) القوائم غير الحصرية: وهي تسمح بإمكانية إدراج أحداث أخرى قد تكون غير مدرجة، طالما وُصِفت بأنَّها قوة قاهرة اعتمادًا على طبيعة الأحداث المدرجة ذاتها وصياغة النصِّ العقدي، ويجوز للمحاكم الإنجليزية أن ترى أنَّ الأحداث غير المدرجة تقع فقط ضمن النطاق العقدي المقرَّر للقوة القاهرة إذا كانت من ذات فئة

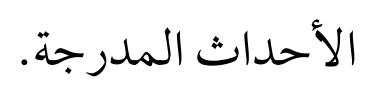

(Y) القوائم الحصرية: إذا كانت القائمة حصرية فيجب أن يتناسب الحدث -المؤهَّل لاعتباره قوة قاهرة- مع نطاق أيِّ واحدة من العناصر المُدرَجة بالقائمة العقدية والمحددة للقوة القاهرة، وعليه: فمثلًا يبدو أن تفشّي وباء كورونا في الصين يقع بشكل مباشر ضمن نطاق مصطلح "وباء"، ولكنه لا يتناسب بالضرورة مع نطاق مصطلح "مجاعة أو طاعون" (1).

مع العلم بأنَّ استيفاء أيِّ حالة ممَّا وردت بالقوائم السابقة يُكمله ضرورة استيفاء الشروط الإضافية الصريحة الأخرى؛ كاشتراط أن يكون الحدث خارجًا عن السيطرة المعقولة للطرف المدعي، ولم يكن من الممكن بشكل معقول أن يتجنَّه الطرف المدعي (r)

(1) وتجدر الإشارة إلى أنَّ مثل هذا النظام المعتمد على القوائم الحصرية وغير الحصرية تتبنَّى فكرته ولاية

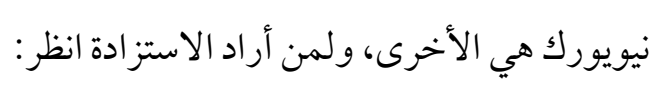

Anton A. Ware, Jeffrey Yang et al, What to Do When You Receive a Coronavirus-Related Force Majeure Notice, op, cit.,

(2) Ibid. 


\section{الغصن الثاني}

\section{موقف قانون العقود الصيني}

ينطوي موقف قانون العقود الصيني على الاعتداد بمبدأ "تغيُّ الظروف أو الوضع"

change of circumstances or situation توفُّر شروط القوة القاهرة، وهو مبدأ يبدو في مضمونه اتفاقٌ مع فحوى نظرية تغيُّ الأحكام أو النصوص بتغيُّ الظروف، التي مضت الإشارة إليها في مستهلّ البحث،

$$
\text { ويعمل مبدأ "تغيُّ الظروف أو الوضع " المذكور عندما: }
$$

(1) يحدث تغيير مادي جوهري غير متوقَّع (لا يمكن التنبؤ به) في الالتزامات الأساسية التي اتَّتق عليها الأطراف عند إبرام العقد، ومكمن تميّز جائحة فيروس كورونا المستجد تكمن في اشتمالها على خصائص وبائية مميزة تجعلها فريدة بين جميع

$$
\text { الأوبئة المعروفة، وبالتالي لا يمكن التنبؤ به". }
$$

فعلى الرغم مما شهده العالم في سنوات العقدين الماضيين من أمراض ذات صلة؛

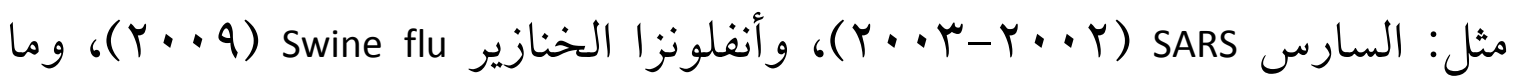

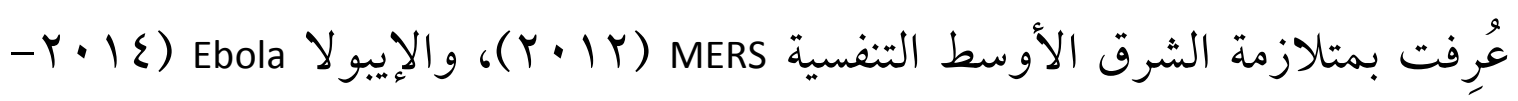

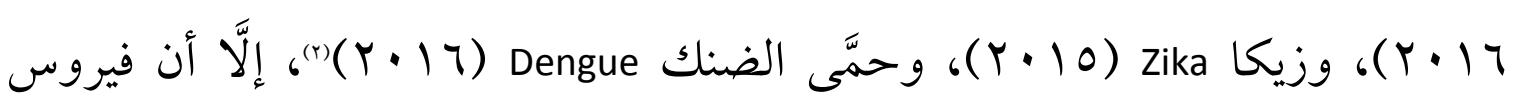
كورونا المستجد قد ظلَّ يحمل خصائص وبائية تميّزه عما سبقه من فيروسات، بل ربما

(1) Matteo M Winkler, Practical Remarks on the Assessment of COVID-19 as Force Majeure in International Contracts, op, cit.,

(2) Victoria Lee, Mark Lehberg, et al, COVID-19 Contract Issues Reach Beyond Force Majeure, Issued by Law 360 (A LexisNexis) Company, Published on 13/3/2020.

See at, https://www.law360.com/articles/1251749/covid-19-contract-issues-reach-beyond-forcemajeure, Last visit on 6/7/2020. 


\section{ميَّزته عما هو آت أيضًا!}

فلا يخفى أنَّ فيروس كورونا هو فيروس استثنائي -بكلّ المقاييس - وغير مألوف،

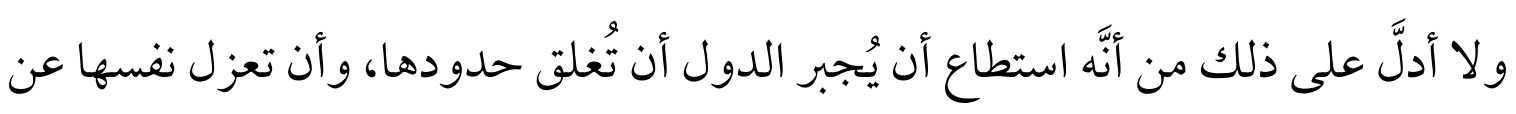
باقي دول العالم في سبيل تفادي تفاقمه، وليس الدول فحسب بل والأسر، بالإضافة إلى فرض حجر صحي على من كان أهلًا لذلك، ولا يخفي ما خلَّفه فيروس كورونا من تداعيات جمَّة على عقود الأفراد والشركات على حدٍ سو اء، وهو ما أثار ويُثير منازعات متعدِّدة، تتصل بتنفيذ الالتزامات الدولية محالّ الدراسة سواء أكانت مدنية أم تجارية أم

\section{(Y) يحدث تغيير خارج نطاق المخاطر التجارية المعتادة.}

(r) يكون من شأن هذا التغيير جعل استمرار تنفيذ العقد بشروطه الأصلية غير عادل

بصورة كبيرة للطرف المتضرر (1).

وإجمال النظر في القانون الوطني الصيني يؤَِّّ إعمال كلٍ من القوة القاهرة و الظروف الطارئة؛ وعليه: فالطرف الذي لم يوفِ بالتزاماته التعاقدية كليَّا أو حتى بشكل جزئيّ لا يُمكنه أن يُعى منها إلَّا إذا كان من غير الممكن التبؤ بالحدث، وفي الوقت ذاته لا يمكن السيطرة عليه، ويستحيل بالتبعية أداء التزامه التعاقدي، بحسب المادة VV من قانون العقود الصيني لسنة 1999 . the كما يمكن للطرف المتعاقد كذلك أن يطلب بتبديل العقد (تغيير نصوصه) alternation of contract

(1) For more details, Claudia Galvis, Jose Moran, et al, Coronavirus Outbreak: Global Guide to Force Majeure and International Commercial Contracts, op, cit., 
متوقَّةة، حتى جعلت الوفاء بالالتزام التعاقدي غير منصف بشكل واضح (المادة جr من

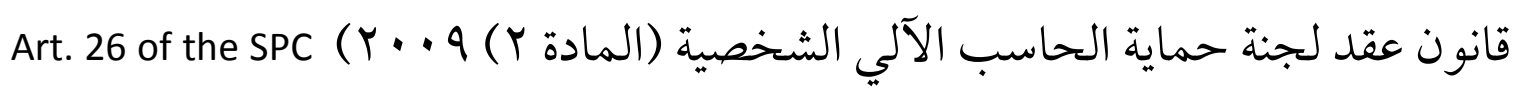
2009 (II) Contract Law Interpretation (وذا التوجُه عضَّددته التطبيقات القضائية المؤيدة؛ Jiangsu Flying Dragon Food Machinery v. Ukraine CF Mercury من ذلك ما حدث في قضية . (1), Ltd ولمَّا كانت نظرية القوة القاهرة ليست النظرية الوحيدة التي قيل باتفاق شروطها مع معطيات جائحة كورونا؛ فقد رأى اتجاه فقهي آخر اتفاق معطيات هذه الجائحة مع نظرية الظروف الطارئة؛ وعليه: أفرد محلًّ لها بهذه الدراسة، وآثرت في هذا المحلّ الجمع بين الظروف الطارئة وشرط إعادة التفاوض نظرًا لبعض الاعتبارات التي ستظهر في سياق الدراسة؛ في مقدمتها سعي كليهما لرفع الحيف التعاقدي واختلال التوازن العقدي الذي نجم عن الجائحة.

(1) Sophia Tang, Coronavirus, force majeure certificate and private international law, op, cit., p. 4.

ولمن أراد الاستزادة في خصوص نص المادة المذكورة انظر: Victoria Lee, Mark Lehberg, et al, COVID-19 Contract Issues Reach Beyond Force Majeure, op, cit., 


\section{المبحث الثناني \\ جائحة كورونا بين الظروف الطارئة وإعادة التقاوض تمهيدٌ وتقسيهم:}

لََّّا كان اختراق جائحة كورونا قد أسفر عنه هرولة الفقه إلى البحث عن سبل قانونية

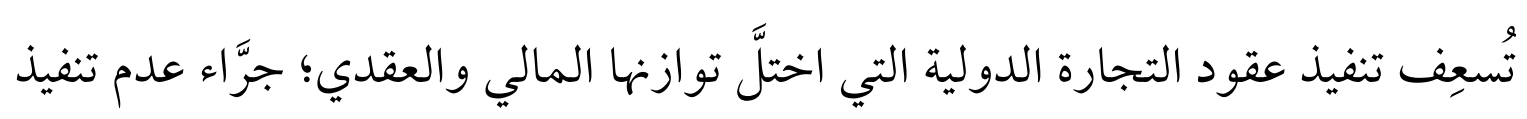
الأطراف لالتزاماتهم التعاقدية أو على الأقل التخفيف منها، في ضوء ما أسفرت عنه الجائحة من تغييرات جوهرية في سير عقود التجارة الدولية. وما بين مؤيّد لنظرية القوة القاهرة ومؤيّد لنظرية الظروف الطارئة انقسم جزءٌ من الآراء الفقهية حول تحديد أيّ النظريات هي الأولى بالانطباق على معطيات جائحة كورونا، ولمَّا كان المقام السابق قد أُفرِد لوضع الجائحة في ميزان القوة القاهرة من لهن منظور فقهيِّ عمليِّ تشريعيِّ قضائيِّ مقارن؛ فقد بقي مهمَّا بيان ثمرات وضع الجائحة ذاتها في ميزان نظرية الظروف الطارئة بمزيد من التأصيل والبيان، وهو ما أُفرِد له المطلب

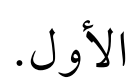

ولما كانت الحلول التي طرحها الفقه لأطراف عقود التجارة الدولية مهَّن تأثَّر تنفيذ عقودهم بجائحة كورونا لم تقتصر على محاولة إسقاط فحوى النظريتين المذكورتين على معطيات الجائحة فحسب، بل أُضيف عليهما البحث عن حلول داخلية تنبع فكرتها من العقد ذاته؛ كإعادة التفاوض، فقد كان مهمَّا إفراد شطر من الدراسة لهذه المسألة في المطلب الثاني، ولقد آثرتُ الجمع بين فكرتي نظرية الظروف الطارئة وإعادة التفاوض في موضع واحد بهذه الدراسة، بالنظر لما يجمع بين مضمونهما من منظور أنَّهما يسعيان لإيجاد حلول لاختلال التوازن العقدي. 
وبختام هذه الموضوعات الثلاثة يُفترَض أنَّ أعمدة الحلول القانونية المطروحة

لأطر اف العقود الدولية تكون قد اكتملت.

\section{المطلب الأول \\ آثار تكييف جائحة كورونا كظرف طارئ}

تمهيدٌ وتقسيمٌْ:

إنَّ وضع المعطيات التي خلَّفتها جائحة كورونا على عقود التجارة الدولية في ميزان نظرية الظروف الطارئة ذات الصبغة التشريعية لدى كثير من الدول يُظهِرِ أهمية تناول بعض المسائل التي يتعيَّن أن تُطرَح في موضوعِ هذا سياقه.

وعليه قُسِّم هذا المطلب إلى أربعة فروع يجمعها الهدف ذاته؛ ألَا وهو محاولة

الوصول بعقود التجارة الدولية التي تأثرت بجائحة كورونا إلى أنسب الحلول القانونية التي تعيد التوازن للعقد؛ لذا استُهَّ المطلب بفرعٍ أوَّل تناول ماهية نظرية الظروف الطارئة في ضوء جائحة كورونا، تلاه فرع ثانٍ تناول بُعًَا عمليَّا للمسألة من خلال بيان مضمون إنزال شروط نظرية الظروف الطارئة على عقود التجارة الدولية التي تأثرت بجائحة كورونا، أعقبهما فرع ثالث خُصِّص لشرح أبعاد دور قانون العقد في نظرية الظروف الطارئة، وكُلّل الطرح بفرع رابع يشرح حجج الرأي المقترح في اعتبار فيروس فورس

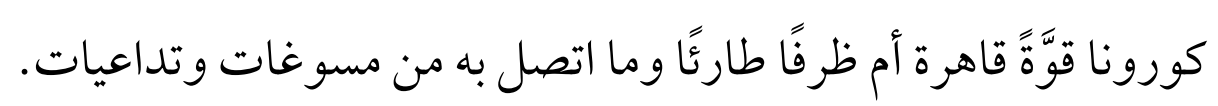
الفرع الأول

إطلالة على ماهية نظرية الظروف الطارئة في سياق جائحة كورونا

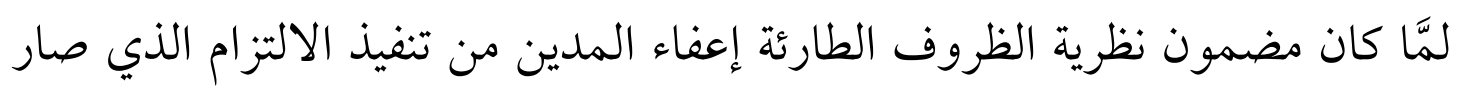


تنفيذه مرهقًا له(1)؛ فقد أسَّس أنصار الرأي المؤيد لدخول معطيات جائحة كورونا في سياق نظرية الظروف الطارئة hardship قرارهم على الفقرة الثانية من نص المادة ( القانون المدني التي نصَّت على أنه:

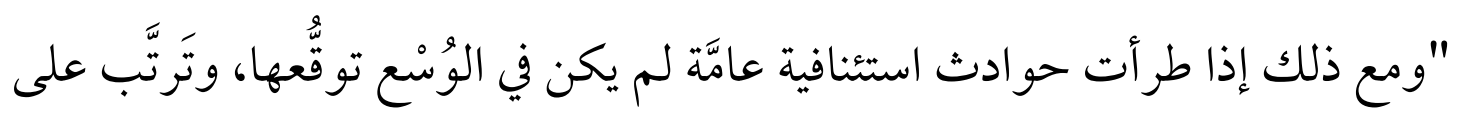
حدوثها: أنَّ تنفيذ الالتزام التعاقديَّ -وإن لم يُصبح مستحيلًا - صار مرهقًا للمدين بحيث يُهذدّده بخسارة فادحة؛ جاز للقاضي تبعًا للظروف وبعد الموازنة بين مصلحة الطرفين أن يَردَّ الالتزام المرهق إلى الحد المعقول، ويقع باطلًا كل اتفاق على خلاف ذلك".

وبناءً عليه فقد أُخِذ من فحوى نظرية الظروف الطارئة مدعاة لتطبيقها على الجائحة؛ كون تنفيذ الالتزام التعاقدي قد أصبح مرهقًا ويؤدي إلى اختلال التوازن، و لا يبتعد ذلك عن مقتضى ما ورد بنص المادة (T/ / ) من مبادئ اليونيدروا ذاتها؛ حيث قيل بأنه: "لا يجوز التذرع بالظروف الطارئة إلَّا إذا وُجِد تغييرٌ في التوازن العقدي" ل(r).

وعليه فإنَّ قوام نظرية الظروف الطارئة يكمن في السعي لردّ ما لَحِقَ بتنفيذ الالتزام

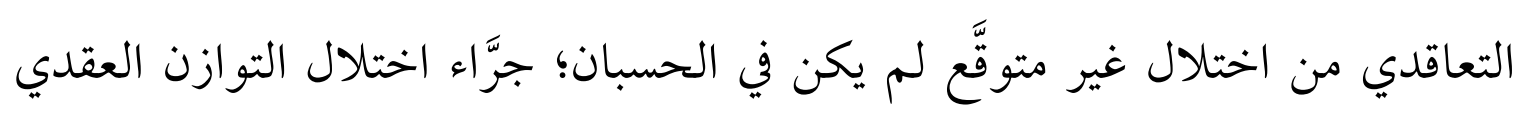

(1) راجع: كلمة د. جابر محجوب، أثر جائحة كورونا على تنفيذ العقود، الندوة القانونية الأولى بعنوان "جائحة

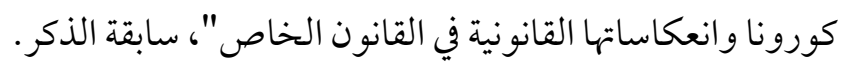

(2) "hardship may not be invoked unless the alteration of the equilibrium of the contract is fundamental"

وللاطلاع على النص الرسمي الكامل لليونيدروا باللغة الإنجليزية، يمكن زيارة الر ابط الإلكتروني الرسمي التالي: See at, https://www.unidroit.org/instruments/commercial-contracts/unidroit-principles-2016 , Last visit on 30/6/2020.

See also, Sonja Adrienne Kruisinga, (Non-) conformity in the 1980 UN Convention on Contracts for the International Sale of Goods: A Uniform Concept, Intersentia, USA, 2014, p. 150; Matteo M Winkler, Practical Remarks on the Assessment of COVID-19 as Force Majeure in International Contracts, op, cit., 
اختلالاً ظاهرًا، بما يعني وجوب تحميل المدين الخسارة المألوفة التي يمكن توقُّها عند التعاقد، وتقسيم ما يزيد على ذلك من خسارة غير مألوفة بالتساوي بين المتعاقدين، ولا عبرة في ذلك بالظروف الذاتية للمدين، وبحسب ما تواترت عليه أحكام محكمة النقض منذ عقود مضت (1)، ناهيك عمَّا لنظرية الظروف الطارئة من باع طويل؛ كونها

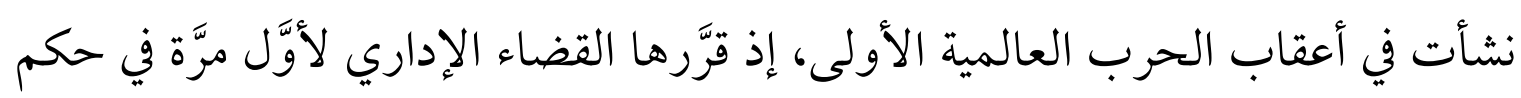

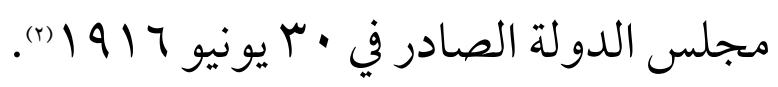
وعليه فإذا كانت نظرية الظروف الطارئة في المبادئ العامة تُخِّل القاضي سلطة فئس

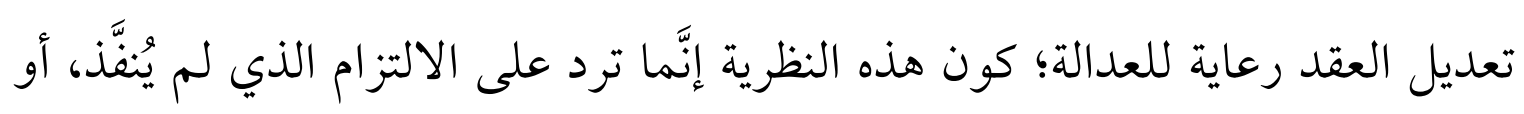

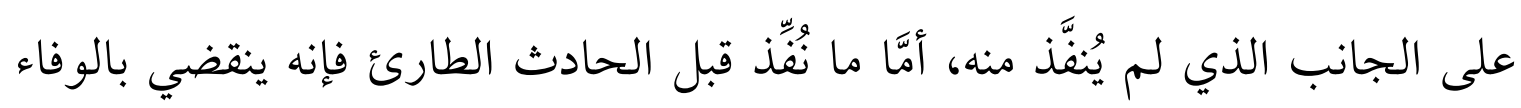

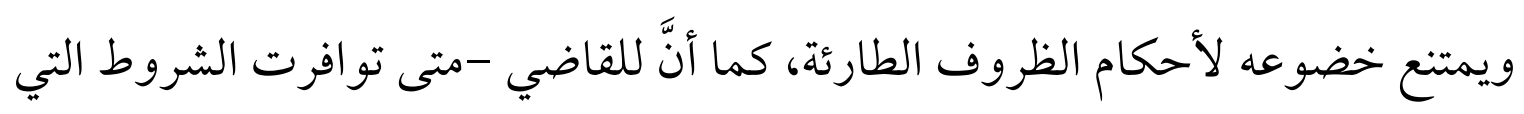
يتطلَّها القانون في الحادث الطارئ وعلى ما جرى به قضاء محكمة النقض - تعديل

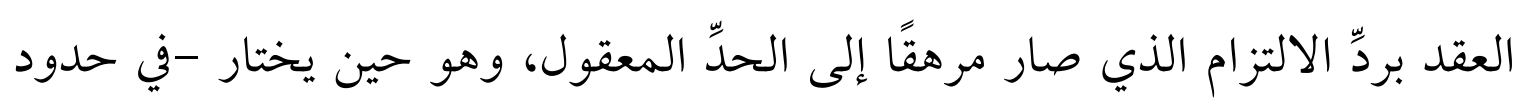

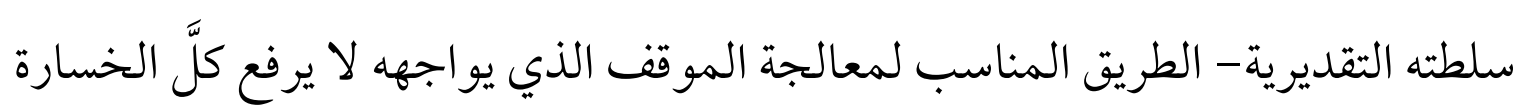

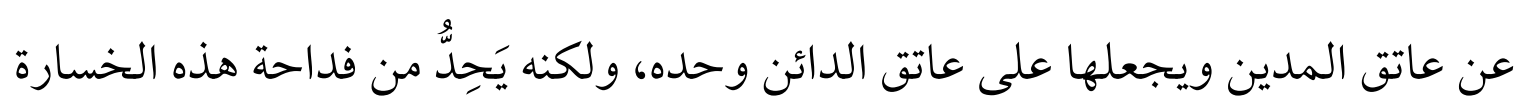
التي ستصيب المدين ويصل بها إلى الحد المعقول؛ وذلك بتحميل المدين الخسارة

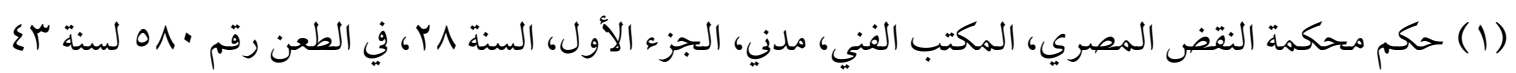

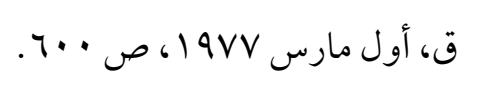

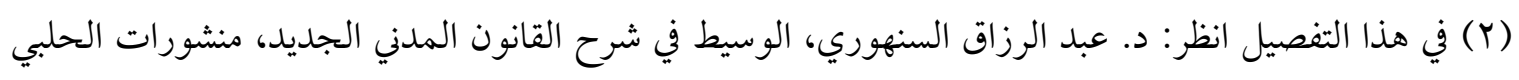

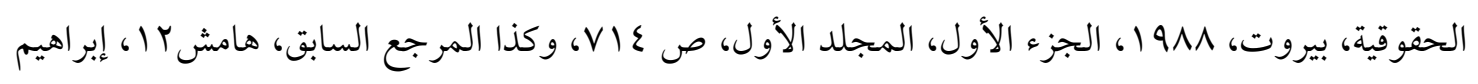
أحاطب، فيروس كورونا "كوفيد 1 1" بين القوة القاهرة ونظرية الظروف الطارئة، مقالة سابقة الإشارة. 
المألوفة التي كان يمكن توقُعها عادة وقت التعاقد، ويقسم ما يزيد على ذلك من خسارة

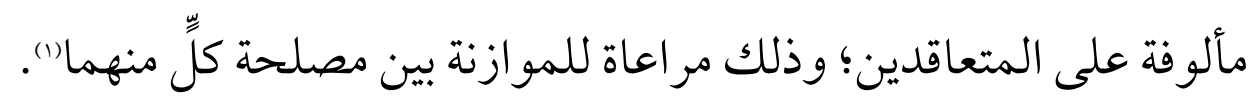
وعليه قيل بأن مضمون نظرية الحوادث الطارئة يفيد كونها ثغرةً ينفذ منها القاضي إلى العقد فينال من قوته الملزمة؛ إذ هو يعدل العقد بطلب من أحد المتعاقدين دون رضاء الآخر (()، وهو ما كان محلَّ للتعقيب على اعتبار أن الإقرار بمبدأ القوة الملزمة للعقد بصفة مطلقة يتناف في كثير من الحالات مع اعتبارات العدالة، مع الاعتر اف بأنَّه لا لهات شيء يمنع إعمال نظرية الظروف الطارئة في تطبيقاتها الكلية إذا تو افرت شروطها. وإذا كان قد نُودي في أعقاب جائحة كورونا بـ "نسبية مبدأ القوة الملزمة للعقد" كي لا يُطبَّق على كافة العقود(r)، على اعتبار أنَّ العقود فورية التنفيذ هي المعنَّةّ به أساسًا؛ لكون عنصر الزمن لا يؤدي دورًا فيها، بينما العقود الزمنية والمستمرة أو الفورية أو المؤجلة التنفيذ فإنها تتأثَّر بتغير الظروف لوجود فاصل زمني بين انعقاد العقد وتنفيذه؛ فهي وإن أُبرمت في ظروف عادية إلَّا أن تراخي تنفيذها إلى ما بعد انتشار فيروس كورونا يترتَّب عليه زيادة في أعباء المدين وإرهاقه حدَّ إلحاق الخسارة الفادحة به إذا ما نفَّذ

(1) حكم محكمة النقض المصري، المكتب الفني، مدني، الجزء الأول، السنة ج؟، في الطعن رقم • مه لسنة بع

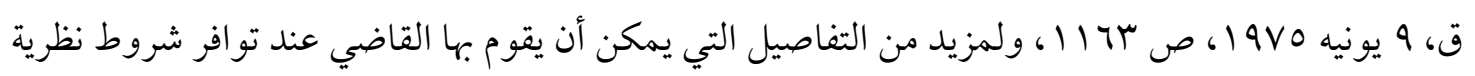

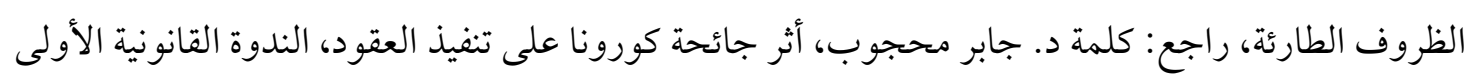

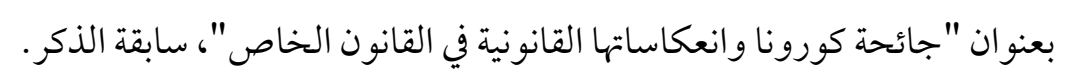

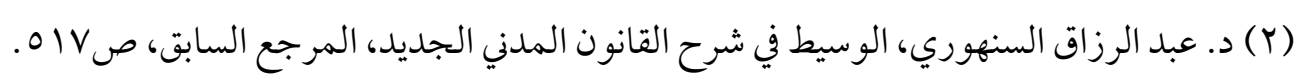

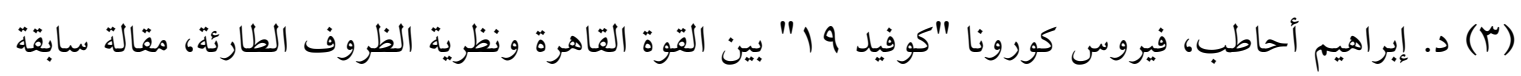


التزاماته على النحو المتفق عليه في العقد، الشيء الذي تفرض معه مبادئ العدالة تعديل العقد وإعادة النظر فيه حفاظًا على التوازن العقدي".

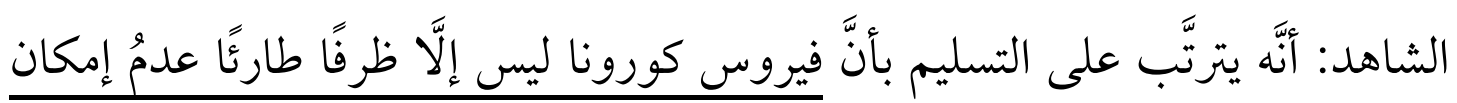

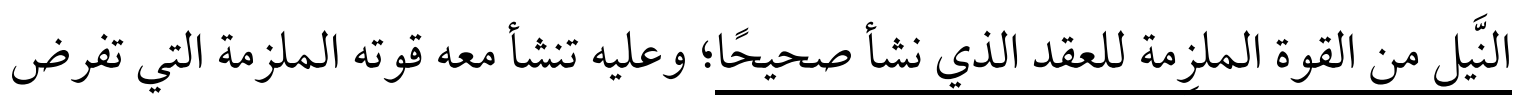

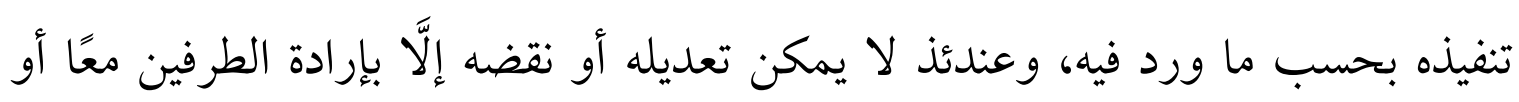

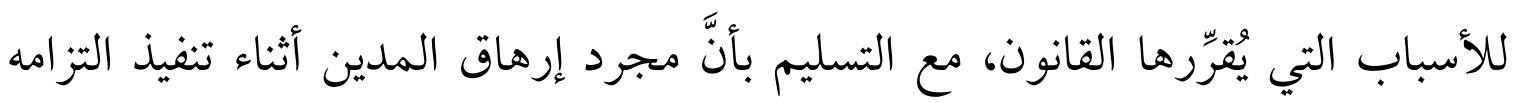

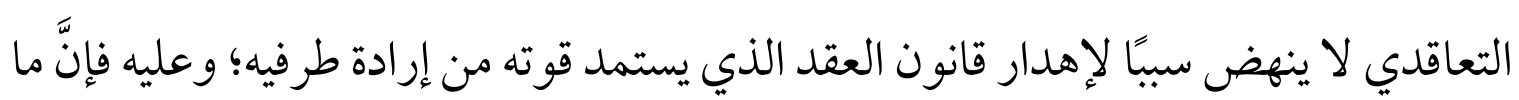
قد يُستجد من الحوادث الاستثنائية -يندرج تحتها الأوبئة مثلاً- والتي يصبح معها تنفيذ

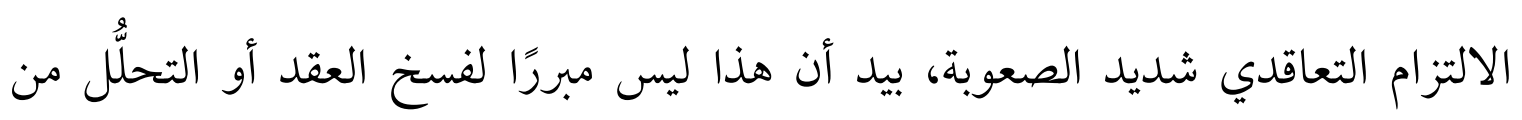

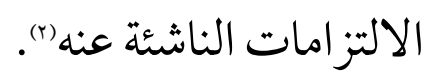

وكأنَّ فيروس كورونا قد أثََّّ على الالتزامات التعاقدية وأدَّى إلى استحالةٍ نسبية

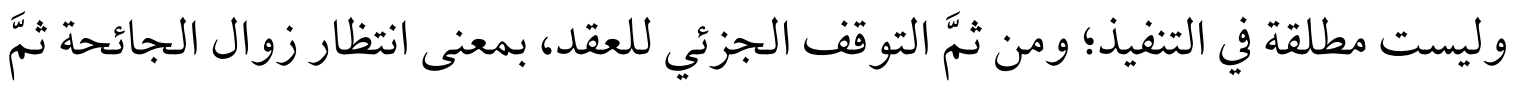
يعود بعدها الوضع طبيعيًا، ويُستمَر في تنفيذ العقد متى ما كان ذلك ممكنًا. وإذا كانت نظرية الظروف الطارئة في المبادئ العامة تخول القاضي سلطة تعديل العقد رعاية للعدالة؛ فإن إعمال قضاء التحكيم لنظرية الظروف الطارئة في المجال

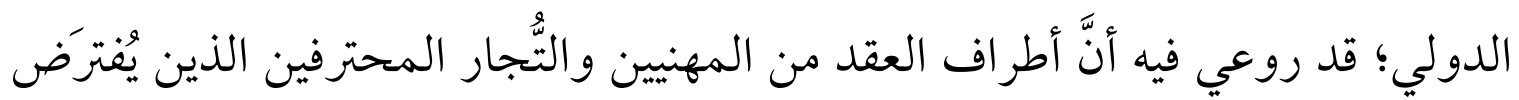

(1) انظر: د. نبيل إسماعيل عمر، سلطة القاضي التقديرية في المواد المدنية والتجارية، دار الجامعة الجديدة،

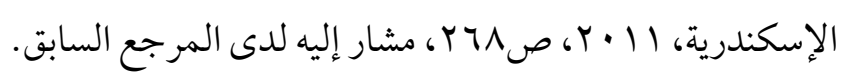

(Y) د. إبراهيم أحاطب، فيروس كورونا "كوفيد 9 (" بين القوة القاهرة ونظرية الظروف الطارئة، مرجع سابق. 
توقُعْمم لمخاطر الأسو اق ممَّا استوجب تقييد سلطان المحكِّم في تعديل العقد في إطار عقود الإنتاج التي يتطلب تنفيذها أمدًا طويلًا؛ مثل: عقود المفتاح في اليد أو تسليم المفتاح، دون غيرها من عقود التجارة الجارية').

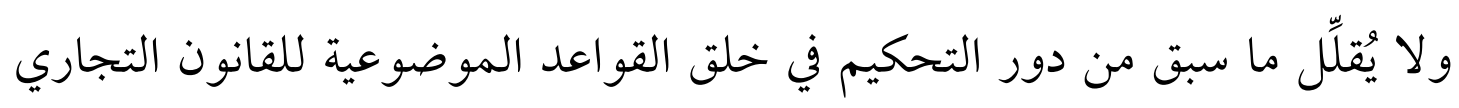

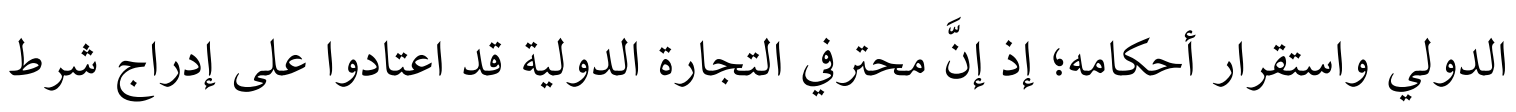
التحكيم في عقودهم لأسباب متعددة؛ من بينها: رغبتهم في تدويل هذه العقود وتحريرها

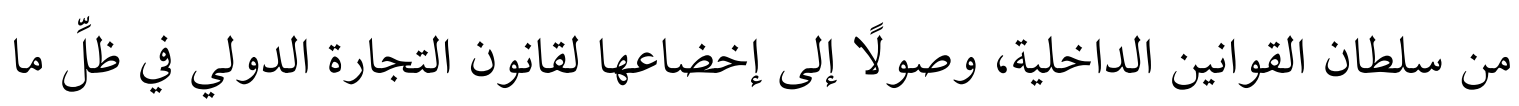

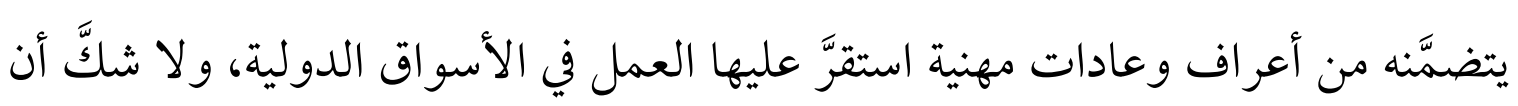
إخضاع عقود التجارة الدولية لمثل هذه الأحكام الموضوعية التي درج التجار ورجال الأعمال على اتباعها يُشعرهم بالأمان القانوني ويصون توقعاتهم المشروعة هُه.

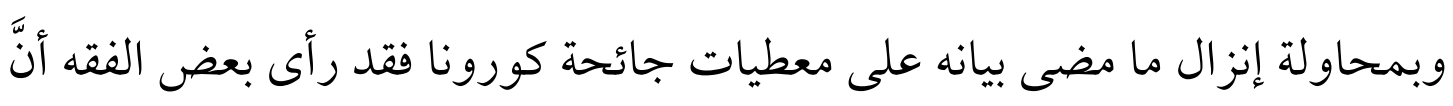

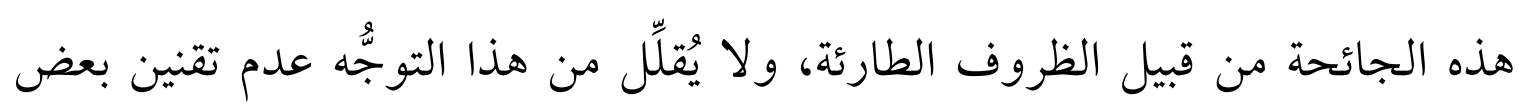

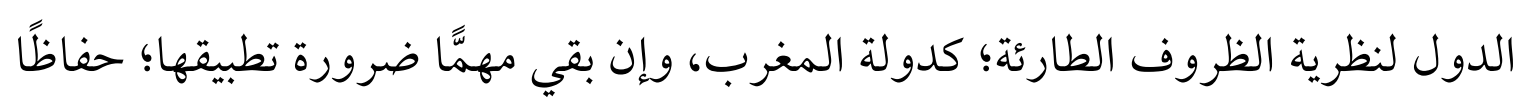
على التوازن والاستقرار العقديين، شريطة انطباق شروط هذه النظرية مجتمعة -على

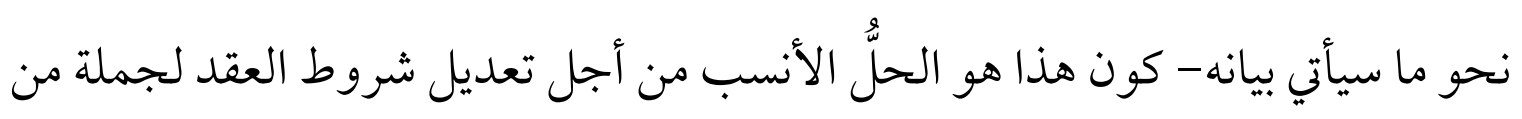

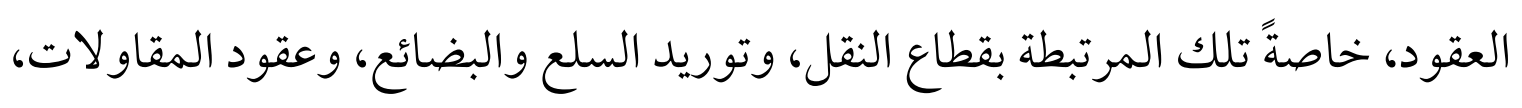

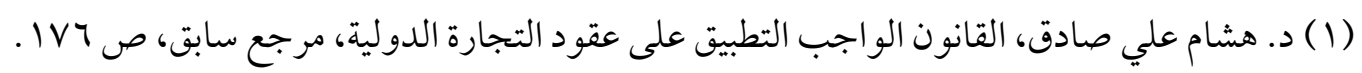

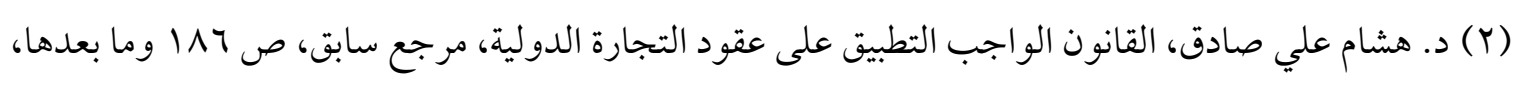

$$
\text { هامش } 111 .
$$




$$
\text { وعقود بيع الخدمات الفندقية، والتنشيط السياحي". }
$$

ويقترب من موقف المملكة المغربية موقف فرنسا التي رفضت رفضًا تامَّا الأخذ بنظرية الظروف الطارئة حتى عام 1 ا • Y؛ إذ بدأت تُطبِّها حينئذ ولكن تطبيقًا ضيقًا (r).

وفي ختام هذا الطرح يُشار إلى أنه -وحتى في ظل غياب وجود نص عقدي يُبِين موقف الأطراف من الحادث الذي اعترض طريق تنفيذ التزاماتهم التعاقدية- إذا اتفق الطرفان على تأجيل تنفيذ العقد حتى نهاية الحادث الذي اعترض طريقَ تنفيذ التز امهم، مما جعل تنفيذ الطرفين للعقد مرهقًا لهم ولكنه ليس مستحيلًا؛ فهنا يمكن للقاضي أن يُعمِل الفقرة الثانية من المادة ( IV ) من القانون المدني المصري، ويجوز له حينئذ بناءً على طلب المدين - ردٌّ العقد إلى الحدّ المعقول؛ كأن يتمَّ تأجيل العقد أو تمديد مدته في سبيل التغلب على هذه الظروف الطارئة. وبالنظر لما قد يقع من لبس بين القوة القاهرة والظروف الطارئة فقد آثرتُ الوقوف

(1) د. إبراهيم أحاطب، فيروس كورونا "كوفيد 9 ا" بين القوة القاهرة ونظرية الظروف الطارئة، مقالة سابقة

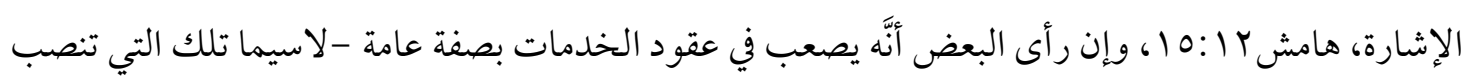

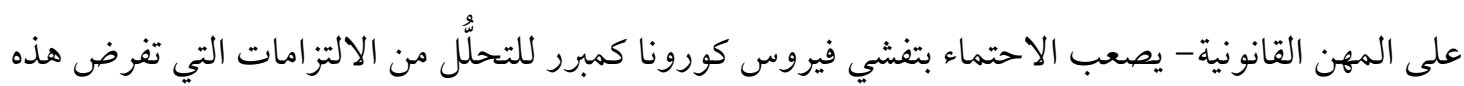

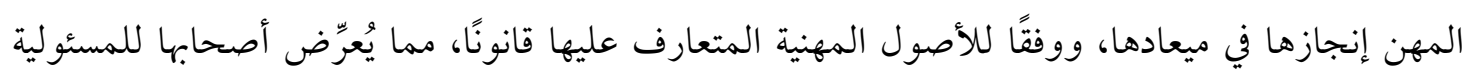

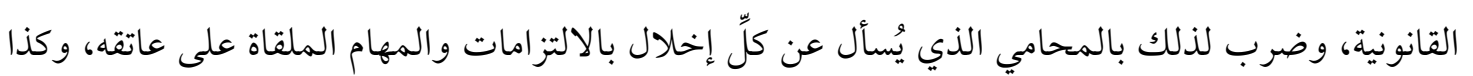

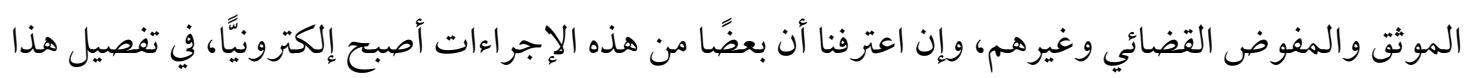

$$
\text { الرأي انظر : المرجع السابق ذاته. }
$$

(Y) ولمن أراد الاستز ادة في موقف فرنسا من تطبيقها لنظرية الظروف الطارئة، وغيرها من الدول كألمانيا، انظر : A

Klaus Peter Berger and Daniel Behn, Force Majeure and Hardship in the Age of Corona: A Historical and Comparative Study, Revue de règlement des différends de McGill, Volume 6, Number 4, (20192020), pp. 117-125. 
على مكمن الفوارق بينهما في موضع مستقل، بحسب ما يأتي: مكمن الفارق بين القوة القاهرة والظروف الطارئة في سياق جائحة كورونا:

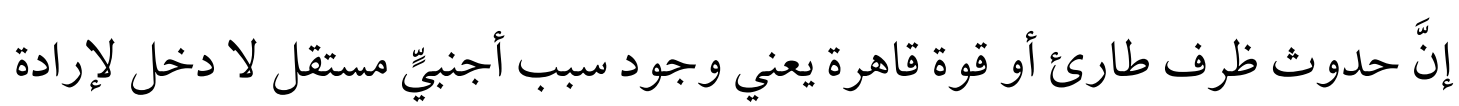

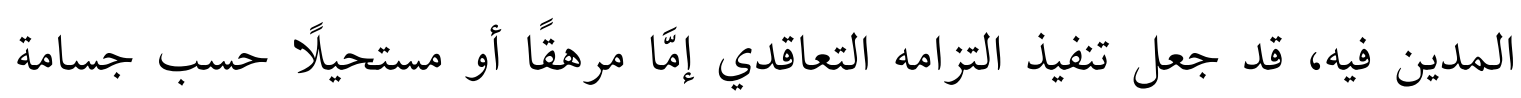

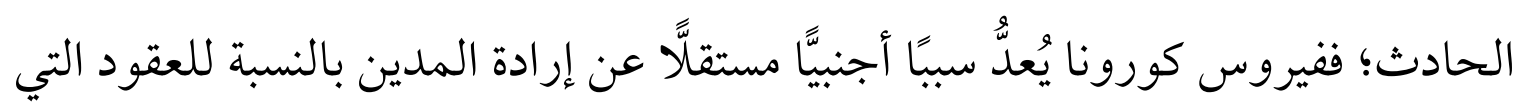

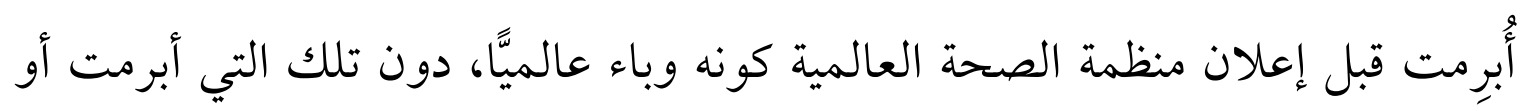
جددت بعد هذا الإعلان").

الشاهد: أنَّ التزام المدين لم يبق على حالأله بل بل بات مرهقًا حال استيفاء الحادث

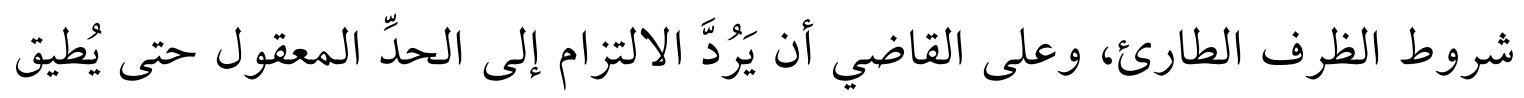

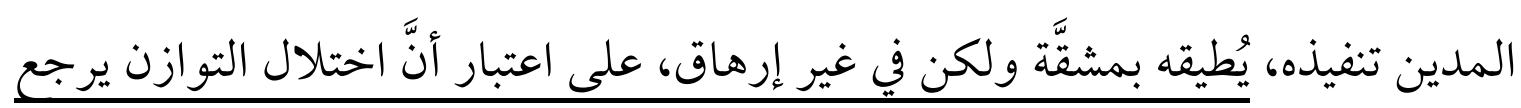

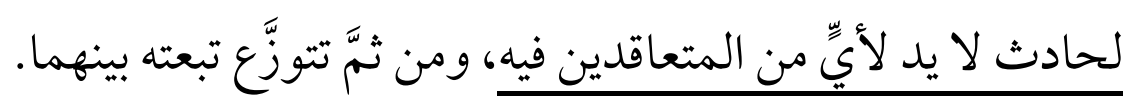

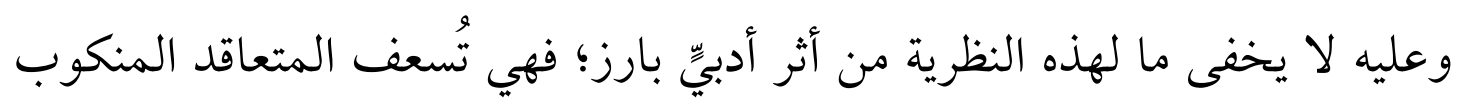

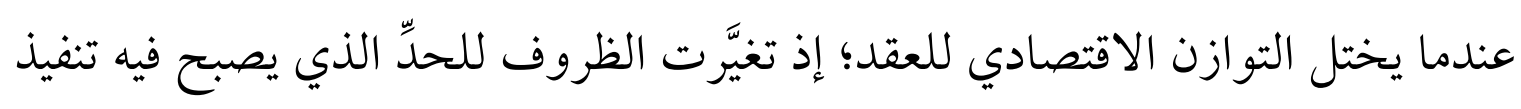
العقد جائرًا بالنسبة لأحد المتعاقدين، حتى وجب تعديل العقد ليزول الحيف الناشئ عن هذا التغيير المفاجئ في الظروف الاقتصادية"). وعليه: فإنَّ أهم أوجه الاختلاف بين كلٍّ من القوة القاهرة أو الظروف الطارئة الطئة

(1) راجع: كلمة د. جابر محجوب، أثر جائحة كورونا على تنفيذ العقود، الندوة القانونية الأولى بعنوان "جائحة

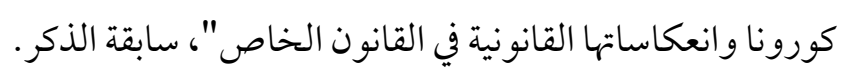

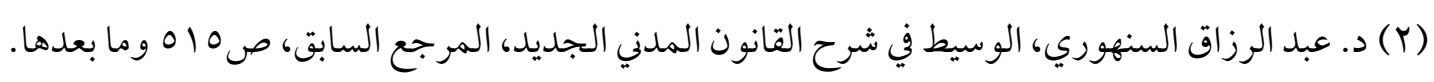
r 110 
عمومًا، وفي ضوء تأثير جائحة كورونا تحديدًا على الالتزامات التعاقدية، يكمن في مدى الإمكانية المرافقة لتنفيذ الالتزام التعاقدي؛ هل استحالة التنفيذ مطلقة أم هناك

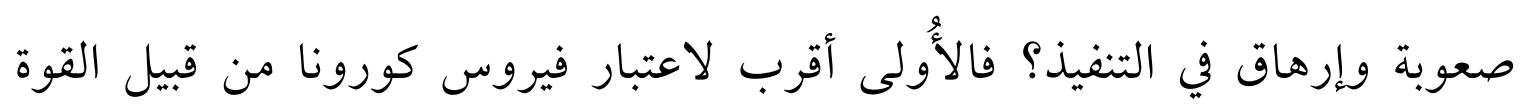
القاهرة، بينما الثانية أقرب لاعتباره من قبيل الظروف الطارئة.

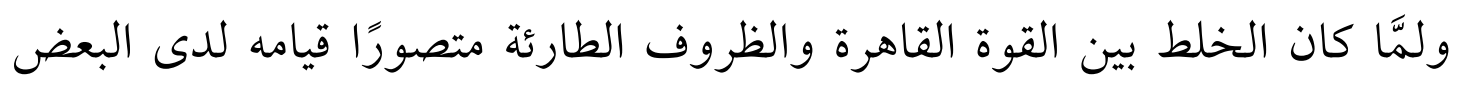
نظريَّا وعمليَّا؛ فقد لا يتمُّ في بعض الأحيان التمييز بين القوة القاهرة والظروف الطارئة

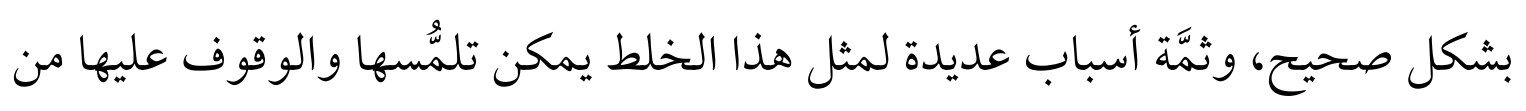

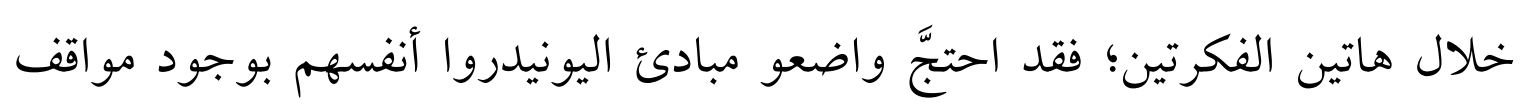

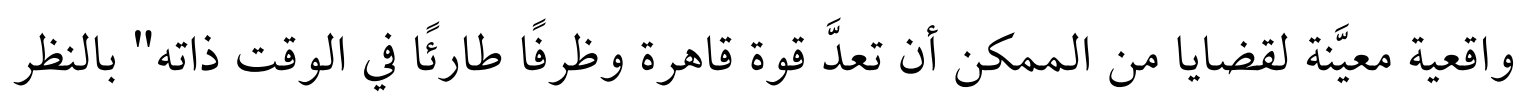

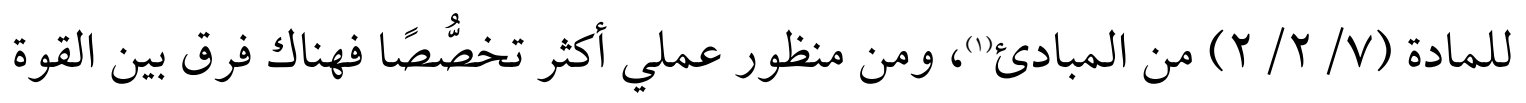

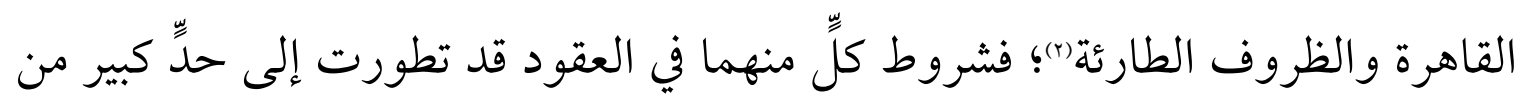

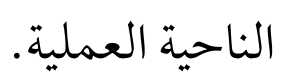
إنَّ التفرقة بين فكرتي القوة القاهرة والظروف الطارئة أمرٌ مهمٌّم عمومًا، وبالنظر لتبعات فيروس كورونا على العقود الدولية خصوصًا، في ضوء ما تذرَّعت به الأطراف

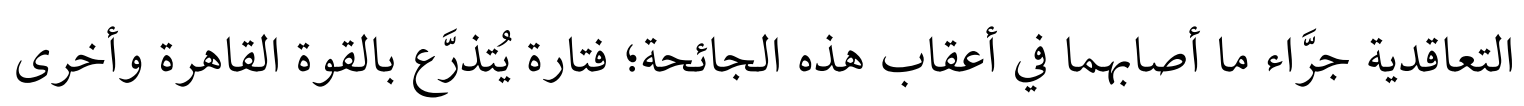

(1) (1) في التأصيل السابق، ولمزيد من التفاصيل، انظر: "there may be factual situations which can at the same time be considered as cases of hardship and of force majeure", Klaus Peter Berger, Daniel Behn, Force Majeure and Hardship in the Age of Corona: A Historical and Comparative Study, op, cit., p. 10, 11, ft. 60.

$$
\text { وللوقوف على النص الكامل لمبادئ اليونيدروا (7 ( ب )، انظر الرابط الإلكتروني الرسمي التالي: }
$$

See at, https://www.unidroit.org/instruments/commercial-contracts/unidroit-principles-2016 , Last visit on 12/7/2020.

(2) Klaus Peter Berger, Daniel Behn, Force Majeure and Hardship in the Age of Corona: A Historical and Comparative Study, op, cit., p. 10, 30. 
بالظروف الطارئة، ولأنَّ الفارق بينهما جِدُّ مهم كان لزامًا هذه الوقفة.

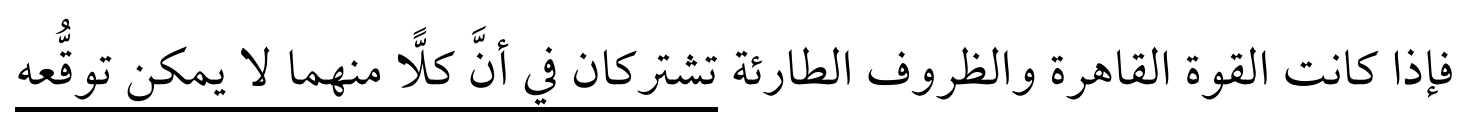

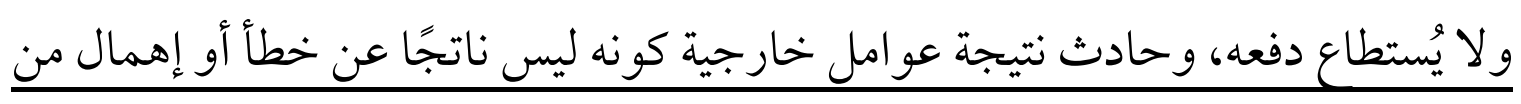

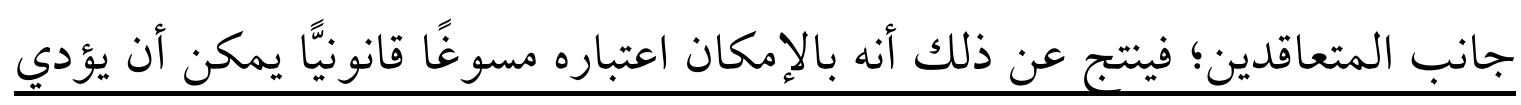
إلى المساس بالقوة الملزمة للعقد.

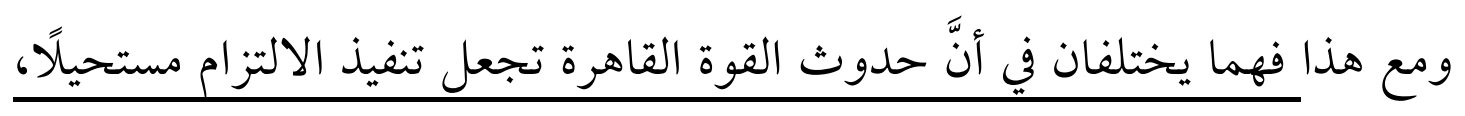
بينما الظروف الطارئة لا يكون تنفيذ الالتزام فيها مستحيلًا و إنما يكون مرهقًا فحسب؛

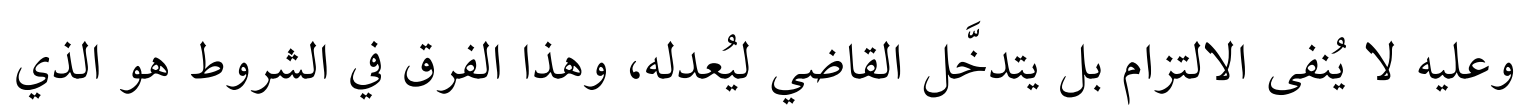

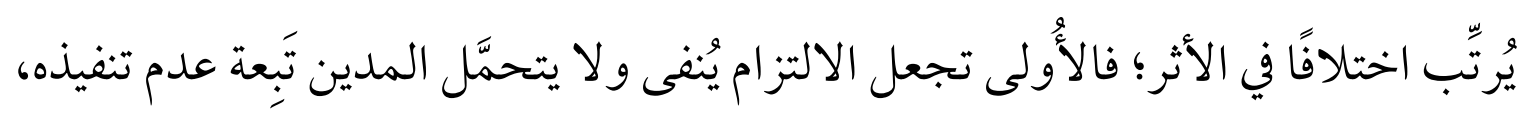

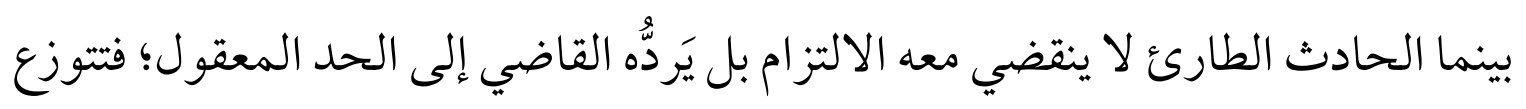

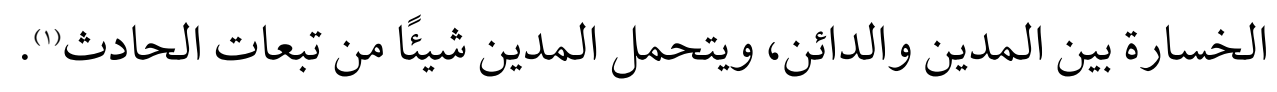

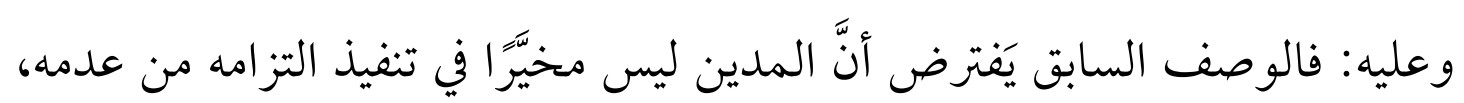

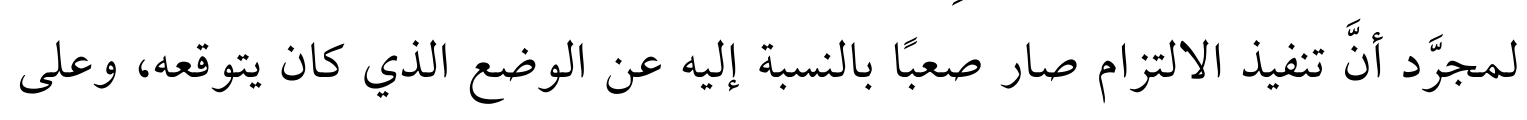

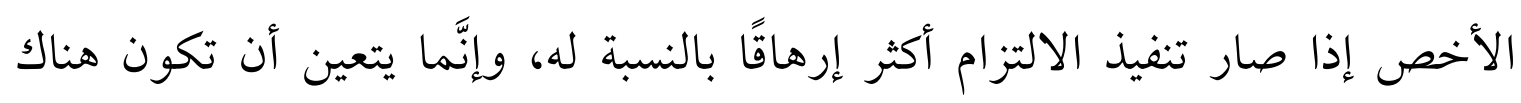

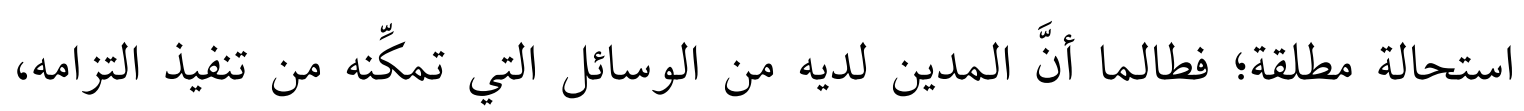
وبصرف النظر عن التضحيات التي سيتحملها المدين في سبيل ذلك؛ فإنه يظلّ ملتزمًا

(1) د. عبد الرزاق السنهوري، الوسيط في شرح القانون المدني الجديد، الجزء الأول، المرجع السابق، ص4rvort 
بالتنفيذل) ولعلَّ جائحة كورونا فرضت على الواقع التعاقدي فروضًا عديدة قد ينطبق على بعضها معطيات الظروف الطارئة وعلى بعضها الآخر معطيات القوة القاهرة، وفي

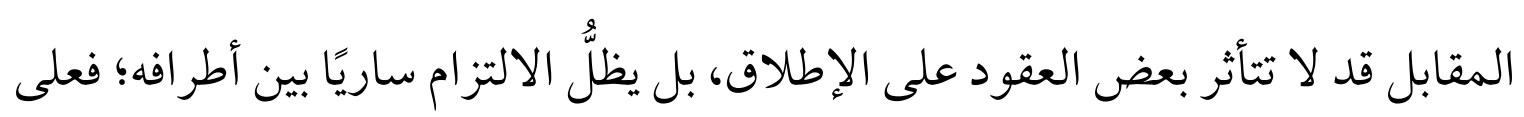

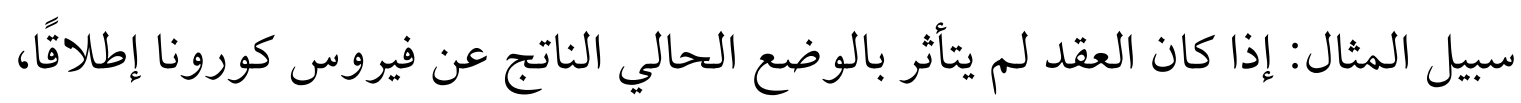

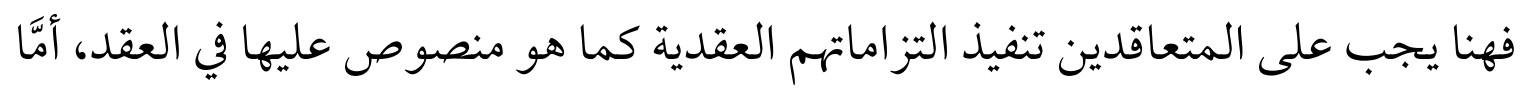

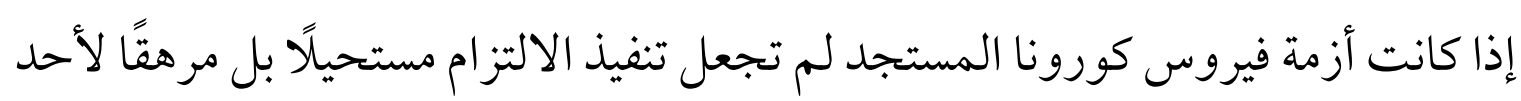
الأطراف أو لكليهما فهنا من الأولى تطبيق نظرية الظروف الطارئة، ويقوم القاضي بردّّ الالتزام إلى الحدّ المعقول، ومن ثمَّ توزيع الخسارة على الطرفين، وفي الأمر أبعاد كثيرة سيتضح بعضها في هذا المقام والبعض الآخر في مقام الحديث عن الظروف الطارئة. وثمَّة فارق آخر بين كلٍّ من القوة القاهرة والظروف الطارئة في مدى إمكانية اتفاق الأطراف على استبعاد تطبيقها؛ إذ لا يجوز الاتفاق مقدمًا على استبعاد حكم نظرية الظروف الطارئة، بينما بالنسبة للقوة القاهرة يجوز الاتفاق على أن يتحمل المدين تبعة

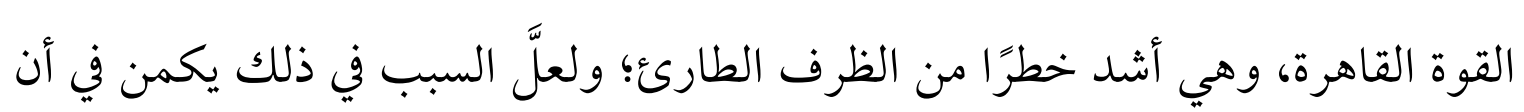
الأخيرة أكثر وقوعًا في الحياة العملية، وهو ما يحمل المتعاقد القوي أن يحتاط لنفسه

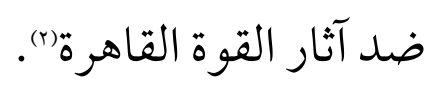

(1) (1) د. إبراهيم أحاطب، مقالة سابقة الإشارة.

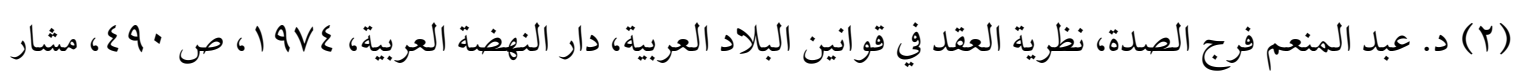

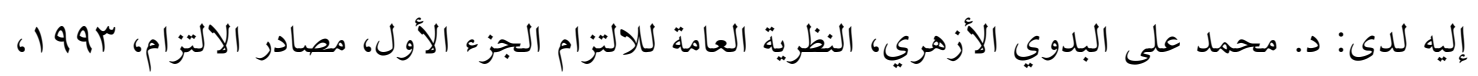

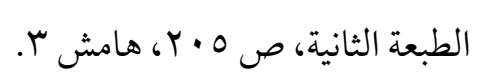




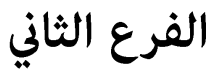 \\ مضمون إنزال شروط نظرية الظروف الطارئة على عقود التجارة الدولية \\ المتأثرة بجائحة كورونا}

ثمَّة شروط يُفترَض تو افرها كي تُطَّقَ نظرية الظروف الطارئة؛ وحتى بالنسبة للدول

التي لم تنصَّ تشريعاتها على نصوص صريحة تفيد إعمال نظرية الظروف الطارئة -

كالقانون المغربي الذي مضت الإشارة إلي - وعليه فطالما توافرت الشروط المذكورة مجتمعة فهذا مدعاة لتطبيت أثرها؛ وتتمثل هذه الشروط فيما يأتي":

الشرط الأول: أن يكون عنصر الزمن جوهريَّا في العقد (عقدًا متراخيًا في تنفيذه)(()؛

وعليه يكون العقد متراخيًا في تنفيذه، وشرط التراخي شرط غالب لا شرط ضروري(م)، فهو وضع غالب في بعض العقود؛ مثل: عقود المقاولات، والخدمات الفندقية، وعقود النقل، وتوريد السلع و البضائع وغيرها.

وعليه فالعقود الزمنية أو "عقود المدة" أو العقود ذات التنفيذ المستمر أو ذات

التنفيذ الدوري أو ذات التنفيذ المؤجل (): هي المجال الطبيعي لنظرية العقود الطارئة؛ إذ

(1) في هذه الشروط، انظر، د. عبد الرزاق السنهوري، الوسيط في شرح القانون المدني الجديد، المرجع السابق،

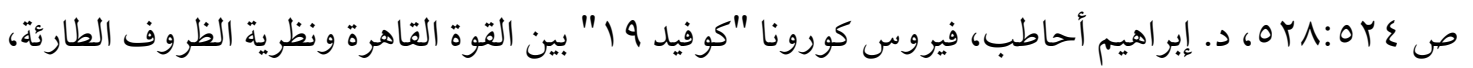
مقالة سابقة الإشارة.

(Y) بحدِّ تعبير د. جابر محجوب، أثر جائحة كورونا على تنفيذ العقود، الندوة القانونية الأولى بعنوان "جائحة

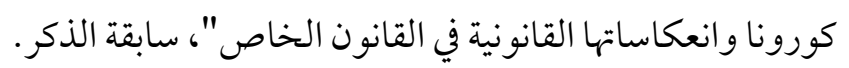

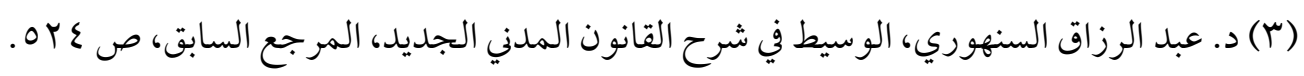

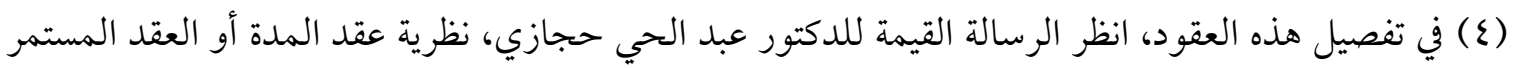

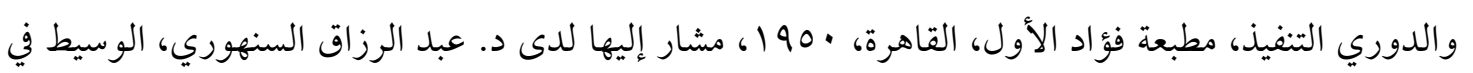

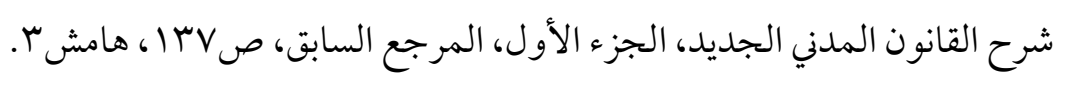


يَجمع بين هذه العقود أنَّ هناك فاصلًَ زمنيَّا بين صدور العقد وتنفيذه؛ فهي عقود متراخية، بينما العقود الفورية لا يمكن أن تنطبق عليها هذه النظرية إلَّا إذا كان تنفيذها

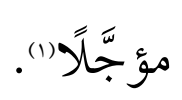

وبناء عليه: فالملاحظ بالنسبة لنطاق العقود التي يمكن أن تعمل في سياقها نظرية

الظروف الطارئة، أنَّ مقتضيات الأخيرة تتفق مع العقود طويلة الأجل أو المستمرة(()؛ ومن ذلك:

- عقود السِّلع (بما في ذلك خام الحديد و الفحم و النحاس). - عقود الغاز الطبيعي المُسال.

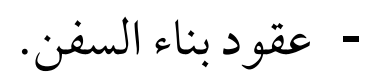

- عقود توريد المنسوجات و المواد الغذائية والمعدات الميكانيكي. - عقود المعدات الكهربائية و المكونات الإلكترونية. - عقود تصنيع المعدات الطبيَّة).(r).

الشرط الثاني: ألَّاّ يكون العقد احتماليّّا؛ فالعقد الاحتماليٌّ بطبيعته يقتضي أن يكون

مقدار الكسب و الخسارة نفسه جسيمًا؛ وعليه يكون الإرهاق في التنفيذ من خصو صيات هذه العقود، بينما عدم التوقُع هو جوهر نظرية الظروف الطارئة. وعليه فلو جعل الحادثُ الطارئ تنفيذَ الالتزام مستحيلًا فإنَّه يكون قوةً قاهرة ينقضي

(1) د. عبد الرزاق السنهوري، الوسيط في شرح القانون المدني الجديد، الجزء الأول، نظرية الالتزام بوجه عام،

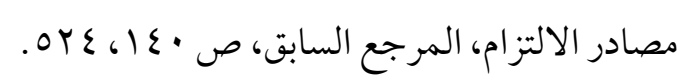

(2) Klaus Peter Berger, Daniel Behn, Force Majeure and Hardship in the Age of Corona: A Historical and Comparative Study, op, cit., p. 2

(3) Claudia Galvis, Jose Moran, et al, Coronavirus Outbreak: Global Guide to Force Majeure and International Commercial Contracts, op, cit., 
بها الالتزام، أو أنه لم يكن من شأنه إلَّا أن يجعل تنفيذ الالتزام يعود بخسارةٍ على التاجر

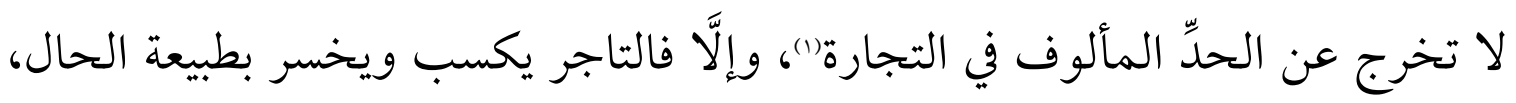
فكلاهما أمر متوقَُّ وعليه فإنَّنا وإن لم نفترض أن تنفيذ الالتزام قد صار مستحيلًا بيد أنَّه

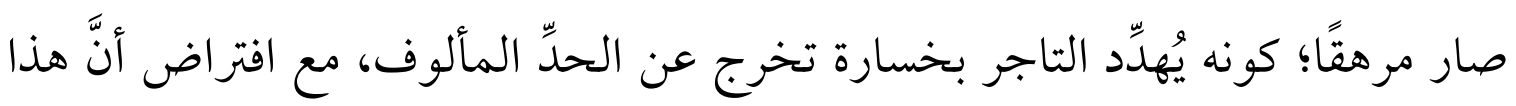
كله لم يكن قائمًا وقت نشوء العقد بل جدَّ عند تنفيذه (r). الشرط الثالث: أن يَجَِّّ بعد إبرام العقد حو ادث استثنائية نادرة الوقوع وغير مألوفة، وفي هذا الوصف تطابق مع فيروس كورونا المستجد، باعتباره يستجيب لهذه الخصائص. وعلى الرغم من أنَّ المشرع المصري في نصه بالفقرة الثانية من المادة ( ( ) ) من

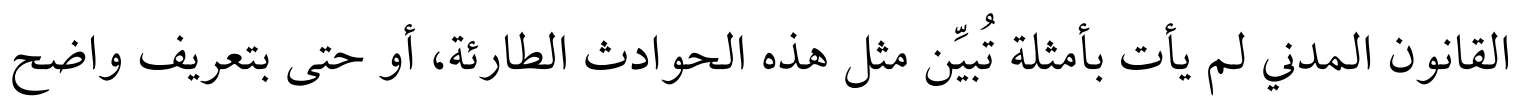

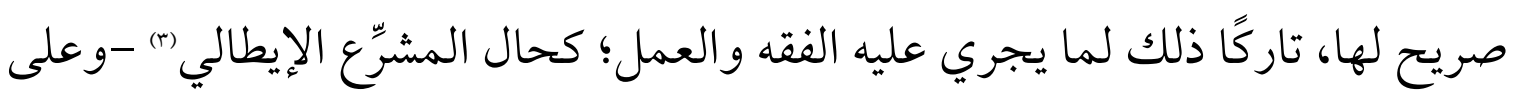
خلاف موقف المشرع البولوني الذي كان حريصًا على ذكر بعض الأمثلة لهذه الظروف

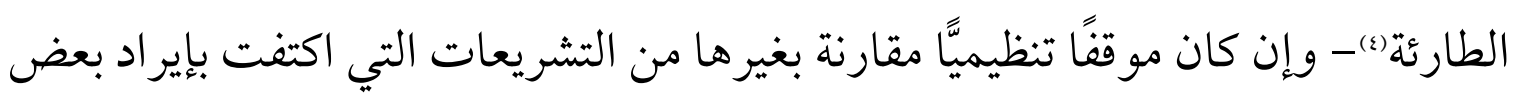

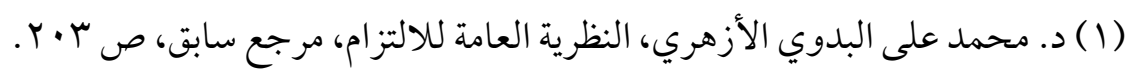

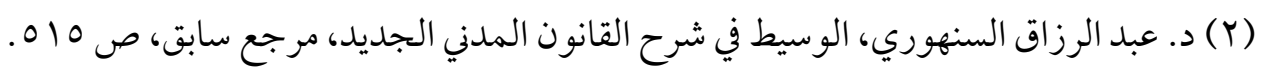

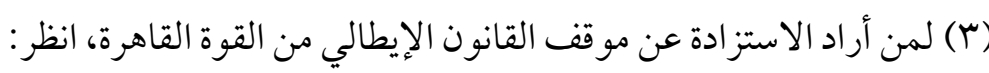

Matteo M Winkler, Practical Remarks on the Assessment of COVID-19 as Force Majeure in International Contracts, op, cit., Also, Matthis Weller Ennio Piovesani, Italian Self-Proclaimed Overriding Mandatory Provisions to Fight Coronavirus, op, cit.,

و انظر في ذلك أيضًا الطرح الوارد بالمقالات المنشورة بجريدة الجازيت الإيطالية على الرابط الإلكتروني الرسمي التالي:

See at, https://www.gazzettaufficiale.it/eli/id/2020/03/02/20G00026/sg ,

Also, https://www.gazzettaufficiale.it/eli/id/1947/12/27/04700001/sg , Last visit on 6/7/2020.

(ع) لمزيد من التفاصيل انظر : د. عبد الرزاق السنهوري، الوسيط في شرح القانون المدني الجديد، الجزء الأول،

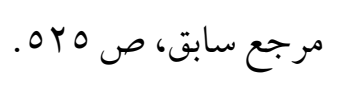




$$
\text { الأمثلة التي تؤدِّي الغرض (1). }
$$

الشرط الرابع: أن يكون الحادث الاستثنائيّ عامَّا وليس في الوسع تصوره؛ وكونه

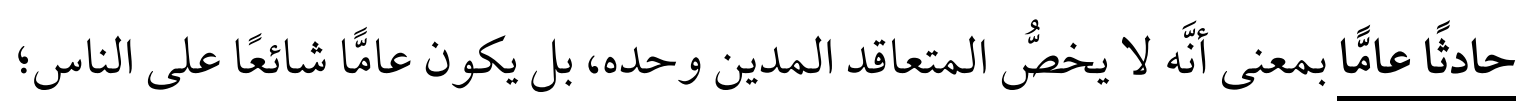
كغارة غير منتظرَة لجراد أو انتشار وباء، وإلا فالحوادث الطارئة التي تعترض شخص المدين -كإفلاسه أو حريق محصوله مثلًا - لا تكفي لتطبيق نظرية الحوادث الطارئة(()، وأما كونه غير متوقع فيعني حدوثه في ظروف لا يتوقعها الرجل العادي الذي يوجد في

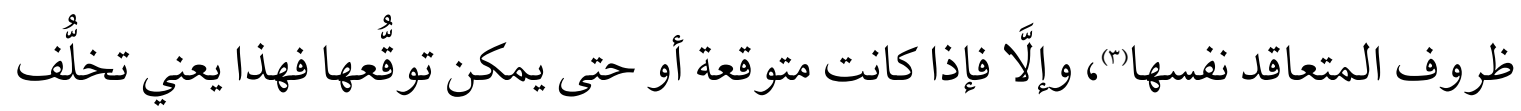
الشرط محلَّ الحديث، وجَليّّ أنَّ الأوبئة عامةً وفيروس كورونا خاصةً يستجيب لهذا الشرط، من حيث إنها تستطيع أن تفرض حَجْرًا صحيَّا على الجميع على نحو يتعذَّر معه مزاولة الأنشطة المهنية و الإنتاجية.

وبإنزال فحوى الشرط السابق على جائحة كورونا: فهي بلا شكَّ حادث استثنائي؛ إذ لم يكن للبشرية عهد بمثل هذه الجائحة، رغم تعاملها مع أوبئة أخرى، فقد كان ظرفًا استثنائَّا غير متكرر، وعامّ كذلك؛ لأنه أصاب العالم بأسره، وبالنسبة لمدى إمكانية توقعه؛ فقد رأى بعض الفقهاء أهمية التمييز بين عقود أبرمت قبل أن يُعلَن عن بدء ظهور هذه الجائحة وبين عقود أبرمت بعد ذلك الإعلان الأول الذي صدر عن منظمة الصحة

(1) The coronavirus and its consequences :Legal impact on supply and production relationships, published by the official website of deloitte, See at, https://www2.deloitte.com/gr/en/pages/about-deloitte/articles/legal-consequences-coronavirusdeloitte-germany.html\#, Last visit on 30/6/2020.

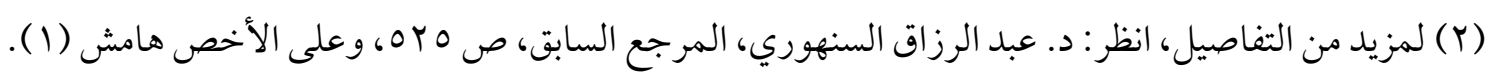

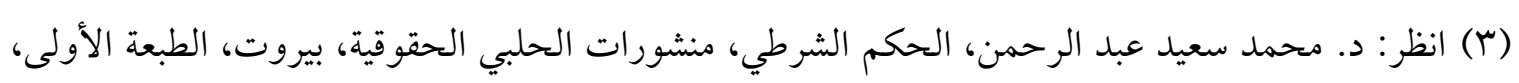

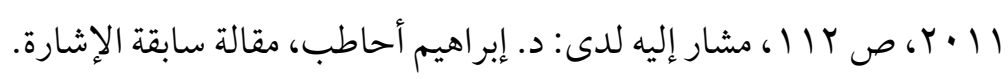




\section{العالمية التي أعلنت فيه عن هذا الوباء".

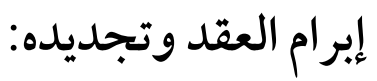

وهنا تتعين التفرقة بين فرضين: العقود التي أبرمت قبل انتشار فيروس كورونا وبين تلك التي أُبِرمت بعد انتشاره الفعلي؛ ففي الحالة الأول دون الثانية يمكن اعتبار الجائحة حادثًا استثنائَّا غير متوقع، وثمة فارق في هذا المقام تجدر الإشارة إليه بين إبرام العقد وتجديده؛ فقد يُبرَم العقد قبل الجائحة وهو ينطبق عليه وصف الشرط من ناحية كونه ظرفًا استثائيَّا للمدين لا يمكن توقُّه أو دفعه، دون تجديد العقد الذي تمَّ بعد ظهور

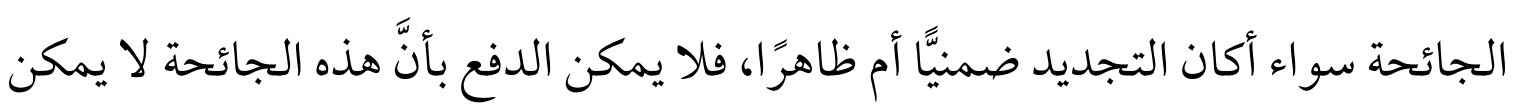

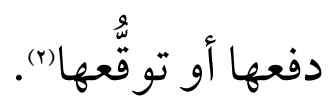

الثرط الخامس: أن يصبح تنفيذ العقد بوقوع هذا الحادث مرهقًا للمتعاقد المدين لا مستحيلًا، بحيث يُهِدّد بخسارة فادحة ولا يجعل تنفيذ الالتزام العقدي مستحيلًا، كما هو الحال بالنسبة للقوة القاهرة التي ينقضي الالتزام بتحقُّها، وعلى إثر هذا الإرهاق الذي سبَّته جائحة كورونا للمدين؛ فإنه يجوز له أن يلجأ للقضاء كي يقوم بتفادي هذه الخسارة الفادحة وأن يردَّ الاختلال التعاقدي الذي وقع جراء الحادث. أثر توافر شروط نظرية الظروف الطارئة:

ثمَّة آثار تترتّبَ على توافر الشروط المتعلِّة بالقوة القاهرة على العقود الدولية في

(1) في مضمون الر اي السابق، راجع كلمة د. جابر محجوب، أثر جائحة كورونا على تنفيذ العقود، الندوة القانونية

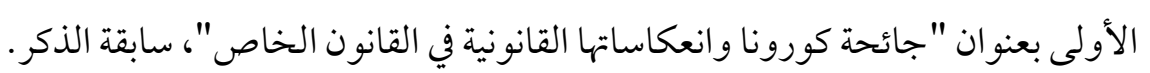

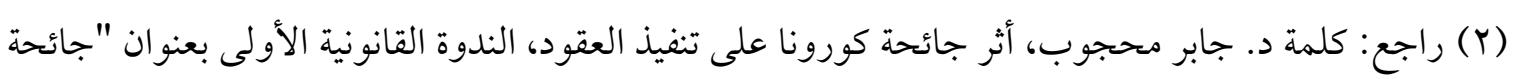

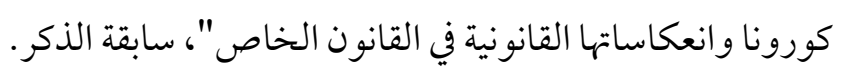


مجمل القول(1)؛ فإذا تو افرت الشروط السابقة جاز للقاضي تبعًا للظروف وبعد الموازنة بين مصلحة الطرفين أن يردَّ الالتزام المرهق إلى الحدّ المعقول، وكما مضى البيان فإنَّ أثر تو افر شروط نظرية الظروف الطارئة هو تخويل القاضي السلطة التقديرية لردّا الالتزام إلى الحد المعقول أو أن يمنح المدين أجلاً للتنفيذ، وقد يرى القاضي مثلًا (r): - أن يوقف تنفيذ العقد حتى يزول الحادث الطارئ، حال كان الحادث وقتيَّا يُقََّّر له الزوال في وقت قصير؛ كأن يتعهَّد مقاول بإقامة مبنى وترتفع أسعار بعض مواد البناء لحادث طارئ ارتفاعًا فاحشًا، بيد أنه ارتفاع على وشك الزوال لقرب فتح باب الاستيراد مثلًا؛ فيوقف القاضي التزام المقاول بتسليم المبنى في الموعد المتفق عليه حتى يتمكن المقاول من القيام بالتزامه دون إرهاق، إذا لم يكن في مثل هذا الموقف إلحاق ضرر جسيم بصاحب البناء(r).

- أو أن يرى زيادة الالتزام المقابل للالتزام المرهق؛ كرفع سعر معين ورد بالعقد لسلعة معينة مثلاً.

(1) Marcel Fontaine, The evaluation of the Rules on Hardship from the First Study on Hardship Clauses to the Enactment of specific Rules, op, cit.,

$$
\text { وللاطلاع على النص الكامل، انظر: }
$$

Michael Joachim Bonell, An International Restatement of Contract Law: The UNIDROIT Principles of Intonational Commercial Contracts, Third Edition, Transnational Publishers, USA, 2005. p. 473.

ولمزيد من التفاصيل، د. هني عبد اللطيف، حدود الأخذ بفكرة إعادة التفاوض في العقد، مرجع سابق، ص ع؟،

$$
\text { هامش r. }
$$

$$
\begin{aligned}
& \text { (r) د. عبد الرزاق السنهوري، الوسيط في شرح القانون المدني الجديد، المرجع السابق، ص ^ ^ه وما بعدها. } \\
& \text { (r) لمن أر اد الاستزادة عن تأثير القوة القاهرة على عقود البناء، وعقود الفيديك في ظل جائحة كورونا انظر: }
\end{aligned}
$$

William J. Shaughnessy, William E. Underwood, et al COVID-19's Impact on Construction: Is There a Remedy? -Time Extension, Force Majeure, or More? Issued by The National Law Review, July 6, 2020 Vol. X, No. 188, published on 3/04/2020.

Available online at, https://www.natlawreview.com/article/covid-19-s-impact-construction-thereremedy-time-extension-force-majeure-or-more, Last visit on 6/7/2020. 
- أو يرى إنقاص الالتزام المرهق؛ كتقليل الكمية التي يلتزم المدين بتوريدها للدائن مثلًا.

وممَّا سبق يتجلَّى: كيف أنَّ الوضع يختلَّفَ بحسب ظروف كل حالة على حدة، إلَّاّ أنه ورُغم المرونة الظاهرة على القرار الذي ينتهي إليه القاضي إلَّا أنَّ هناك أمرًا مهمَّا

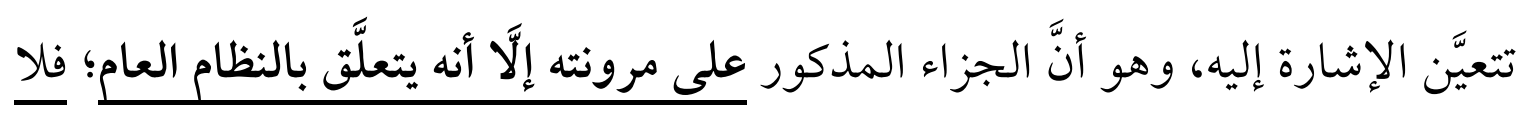

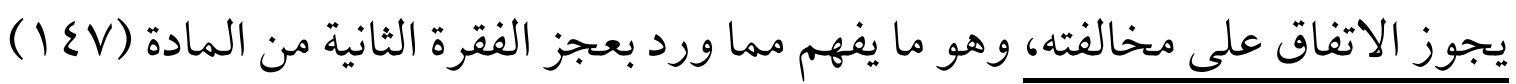

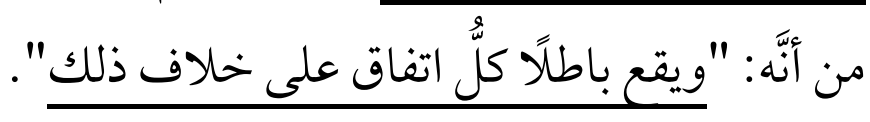

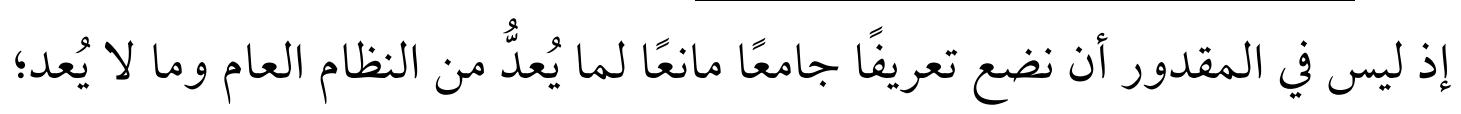

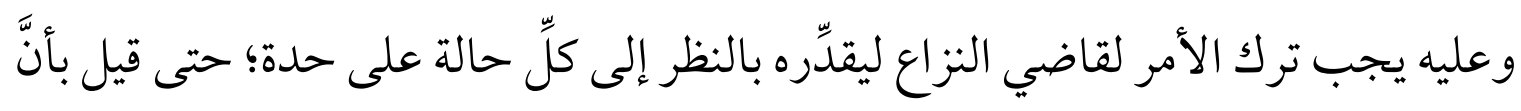

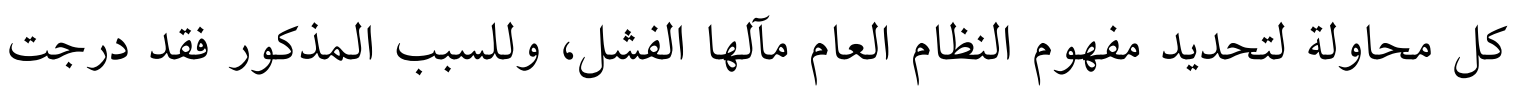

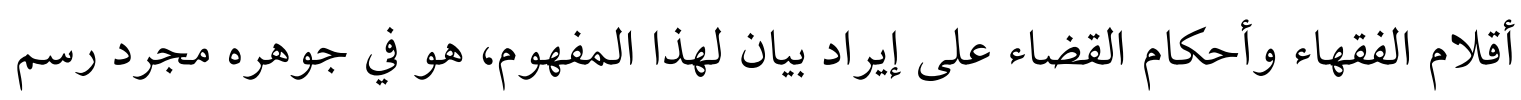

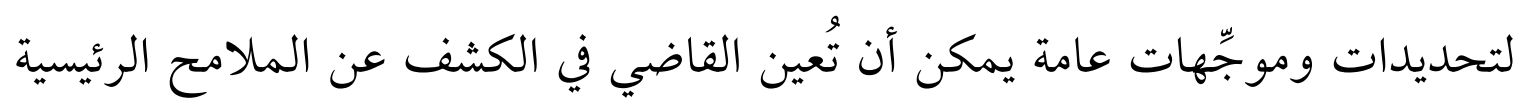

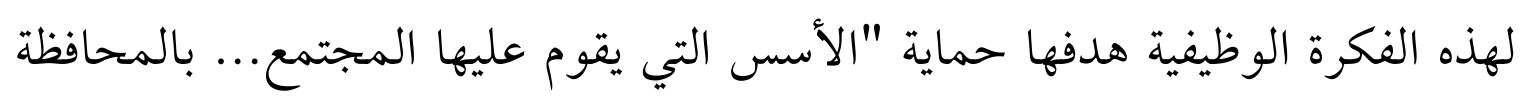
على القواعد الجوهرية التي تحكمه" (1).

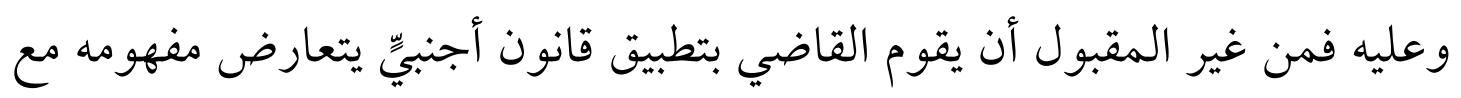

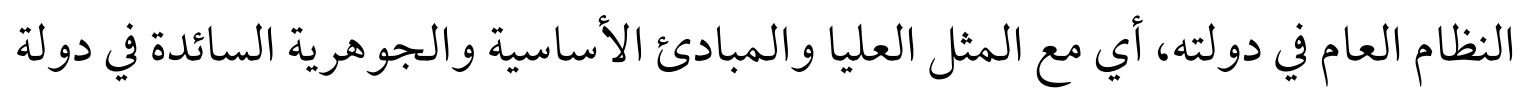

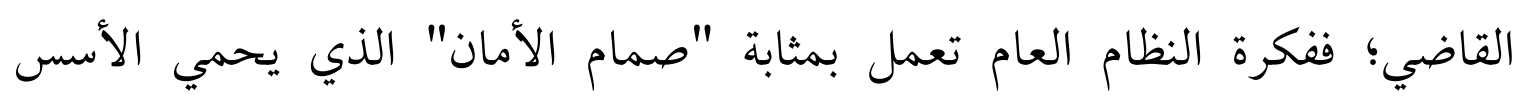

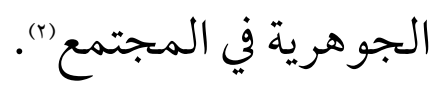

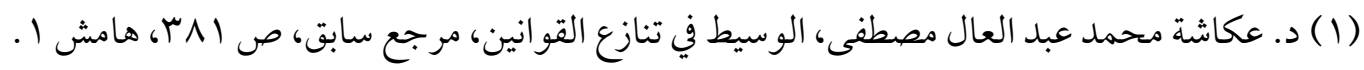

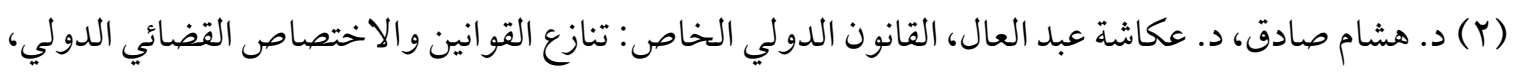

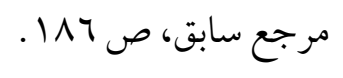


ويكون الحالّ الو اجب الاتباع حينئذ: استبعاد القانون الأجنبيّ الواجب التطبيق أصلً

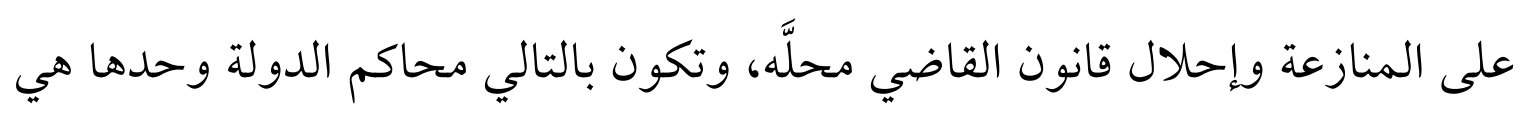
المختصَّة بتطبيق قانونها؛ إذ تكون هي الأقدر على كفالة احترام نظامها العام، وامن والاختصاص التشريعي حينذذ يجلب الاختصاص القضائي".

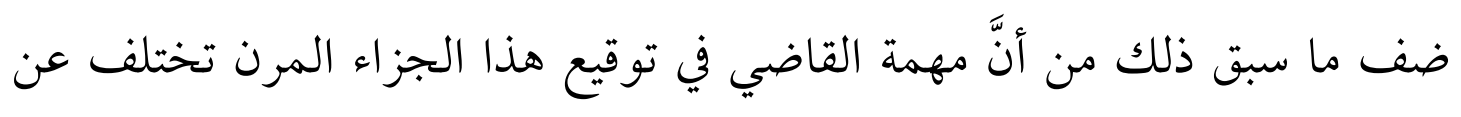
مهمته المألوفة؛ فهو لا يقتصر على تفسير العقد بل يجاوز ذلك إلى تعديله (()؛ إذ إن نظرية الظروف الطارئة هي من النظام العام الحمائي (r).

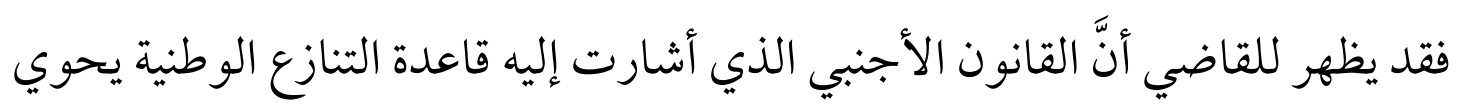

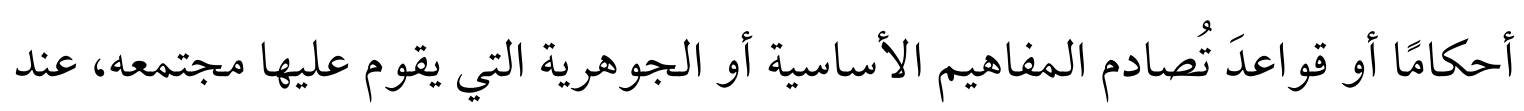
ذاك يرفض تطبيق هذا القانون الأجنبي حفاظًا على نظامه الوطني وحمايةً له من الأحكام التي تتعارض تعارضًا صارخًا مع مفاهيمه؛ فهنا يُقال: إنَّ القانون الأجنبيَّي

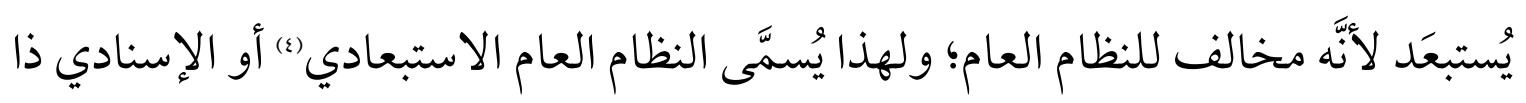

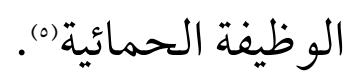

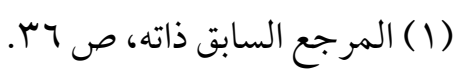

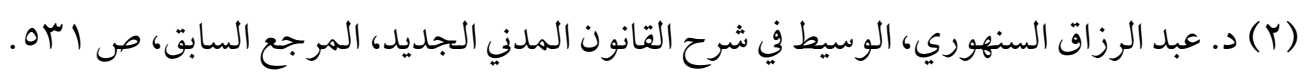

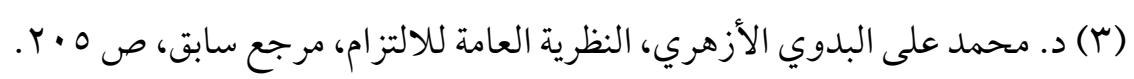

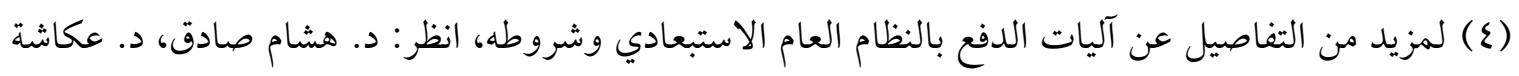

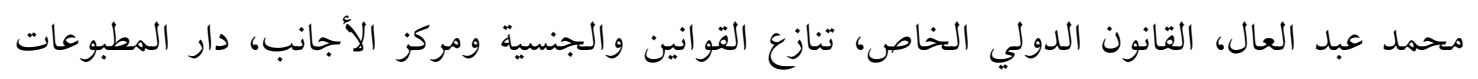

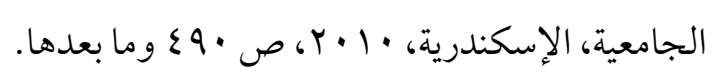

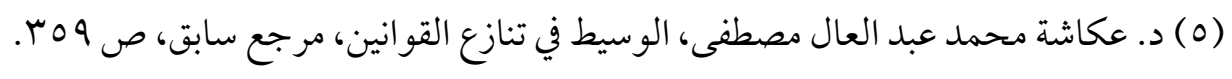


فالدور الاستبعادي الذي يقوم به النظام العام في هذا الشأن أمر ضروري تفرضه طبيعة الأشياء؛ إذ إنَّ المشرع الوطني لا يمكنه أن يعرف مقدمًا مضمون القوانين الأجنبية التي تشير إليها قواعد التنازع في قانونه، فهو لا يستطيع أن يقرأ الغيب ولا يمكنه أن يتباً مسبقًا بمضمون هذه القوانين ومحتو اها؛ ولهذا يَصْدق القول بأن القاضي يقوم بعملية قفز في الظلام(1). والإشارة واجبة إلى أنَّ تأكيد الفقه على أنَّ العبرة في تَعلُّق الأمر بالنظام العام من عدمه هو بوقت نظر الدعوى، وليس بالوقت الذي نشأ فيه المركز القانوني محلَّ النزاع (r). وبتطبيق مقتضيات النظام العام المذكورة على جائحة كورونا يتجلَّى بالنظر إلى ما ورد بالباب الثاني من الدستور المصري الذي يُحدِّد المقومات الأساسية للمجتمع ومميزًا بين المقومات الاجتماعية والاقتصادية والثقافية(r): أنَّ من بين المقومات الاجتماعية الحقَّ في الصحة كمقوم أساسي اجتماعي، ومن هذا المنطلق يمكن اعتبار الحفاظ على الصحة العامة سندًا في عقد جلسات بدون حضور الجمهور (2).

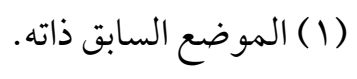

(Y) د. هشام صادق، د. عكاشة عبد العال، القانون الدولي الخاص: تنازع القوانين والاختصاص القضائي الدولي،

$$
\text { مرجع سابق، ص } 190 \text { (r) ولاطلاع على النص الكامل للدستور المصري يمكن تتبع الرابط الإلكتروني التالي: }
$$

See at, https://www.constituteproject.org/constitution/Egypt 2014.pdf?lang=ar , Last visit on 3/8/2020. (ع) في هذا التأصيل، انظر : كلمة د. أحمد عبد الظاهر، بعنوان علانية جلسات المحاكم في زمن الكورونا، سابقة 


\section{الفرع الثالث \\ آثار دور القوانين واجبة التطبيق في ظلّّ تكييف \\ جائحة كورونا كظرف طارئ}

يُعدُّ قانون العقد هو العمود الفقري للتعاملات بين المورِّدين والمشترين؛ فهو الذي طورئ يُحدِّد المعايير التي يسير على نهجها الأطراف، وكذا المتطلبات والآليات البديلة لتسوية المنازعات، وإن اعترفنا بأنَّ مثل هذه العلاقة بين القانون ككلٍ وسلاسل التوريد ذاتها تُخفي وراءها ارتباطًا بقو انين عدَّة؛ مثل: قانون الملكية، وقانون العمل، وقانون التجارة، وقانون الاستثمار، وقانون الملكية الفكرية، وقانون الصحة والسلامة، وقانون الضرر (1). وبشكل عام يخضع لقانون العقد عديد من الأمور يعنينا منها هنا: تطبيقه على فكرة الظروف الطارئة، وشروط تطبيقه، والجزاء المترتب على تحققه، وسلطة القاضي في هذا الخصوص، ومدى تعلق تلك السلطة بالنظام العام. كما يمتدُّ نطاق تطبيق قانون العقد لتحديد المراد بالخطأ العقدي، وكذا تأثير بعض الأسباب على توفره، وكيفية تحديده بالنظر لطبيعة الالتزام، وبيان نظام علاقة السببية بين الخطأ والضرر، وهل يُفترَض وجود السبية أم يُلزم الدائن بإثباتها؟ وحكم السبب الأجنبي الذي يقطع علاقة السبية (r). وبتطبيق فحوى القول السابق على خلفية تبعات جائحة كورونا على العالم، وعلى

(1) Tomaso Ferando,, Law and Global Value Chains at the Time of Covid-19: A Systemic Approach Beyond Contracts and Tort, Published in The European Association of Private International Law (EAPIL), On 20/3/2020.

See at, https://eapil.org/2020/03/20/law-and-global-value-chains-at-the-time-of-covid-19-a-systemicapproach-beyond-contracts-and-tort/, Last visit on 8/7/2020.

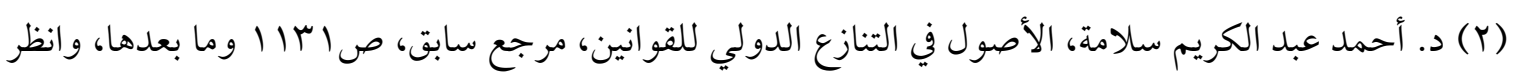

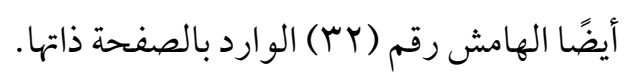


الأخص حكم السبب الأجنبي الذي يقطع علاقة السبية؛ فقد رأى البعض أنه من

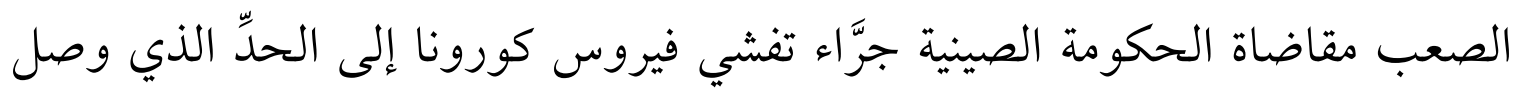
إليه، ومن ثمَّ مطالبتها بالتعويض عن ذلك؛ إذ سيكون من غير اليسير إثبات وجود علاقة سببية بين الأضرار التي نجمت عن فيروس كورونا والإجراءات المتخذَة من قِبل الحكومة الصينية على خلفية هذا الوباء").

فها هي الولايات المتحدة الأمريكية تُحمّل غريمتها الصين مسئولية تفشّي كورونا

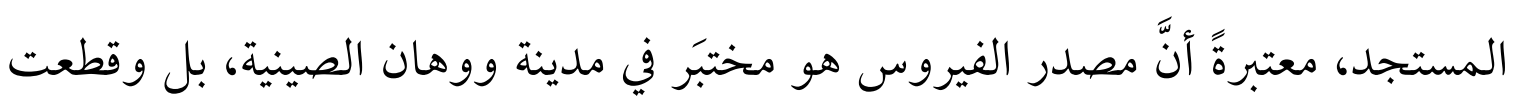
الو لايات المتحدة الأمريكية التمويل المالي عن منظمة الصحة العالمية("). وعلى الرغم من قيام مو اطنين أمريكيين ومعهم شركة برفع دعوى قضائية ضدَّ جملةٍ من المدَّعى عليهم؛ من بينهم: جمهورية الصين الشعبية، ولجنة الصحة الوطنية لجمهورية الصين الشعبية، ووزارة إدارة الطوارئ لجمهورية الصين الشعبية، ووزارة الشؤون المدنية لجمهورية الصين الشعبية، وحكومة مقاطعة هوبي، وحكومة مدينة ووهان؛ إذ استندت الدعوى القضائية على الأضرار التي لحقت بهما جرَّاء وياء كورونا،

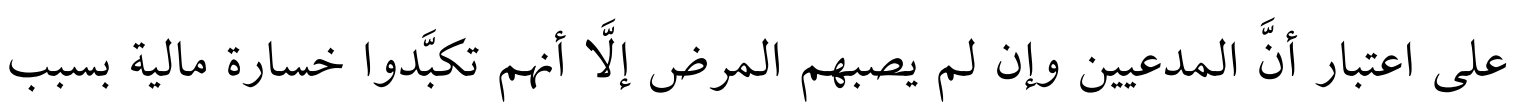
تفشي المرض، كما استند المدعي على علم الحكومة الصينية بحجم خطورة الفيروس وقدرته على التسبب في جائحة ما، بيد أنها مع ذلك قامت بالتعتيم رغم علمها المذكور

(1) Zheng Sophia Tang, Zhengxin Huo, State immunity in global COVID-19 pandemic: Alters, et. al. v People's Republic of China, et. al., op, cit.,

(r) د. يوسف البحيري، تدابير حالة الطوارئ لمكافحة جائحة فيروس كورونا والحريات العامة، مجلة كلية

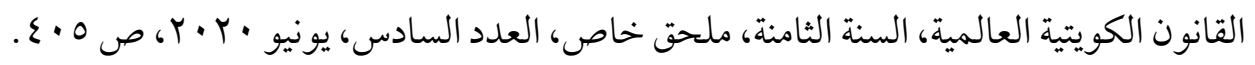


حمايةً لمصالحها الاقتصادية، متسبةً على إثر ذلك في إصابات وأضرار لعدد لا يُحصى

$$
\text { من المدعيين، وإن لم يكونو اهم أنفسهم من بينهم" (1). }
$$

وبنظرة أخرى ولكن لنطاق تطبيق قانون بلد محل الإبرام lex Contractus؛ فهزئ

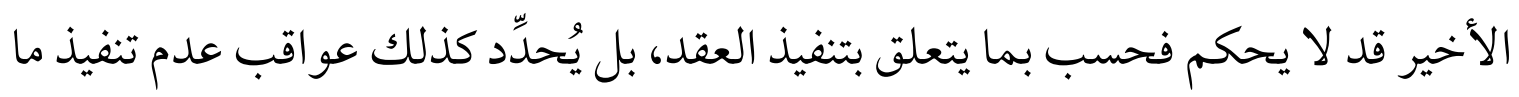

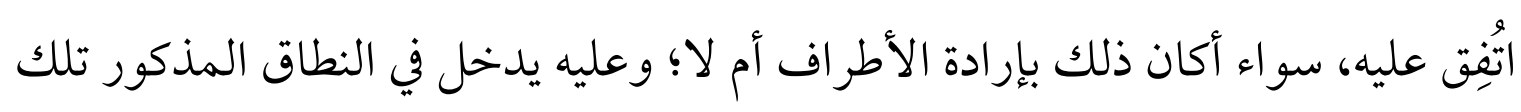

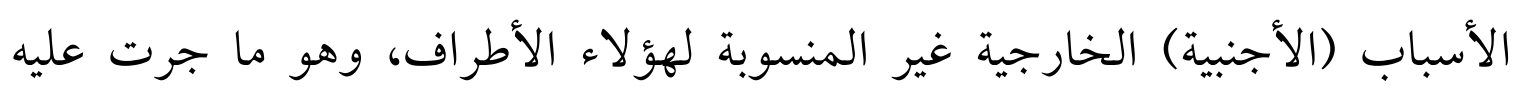
بالفعل بعض المحاكم؛ كما هو الحال في فنزويلا على سبيل المثال (ه).

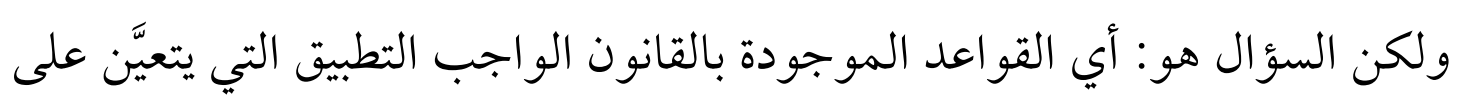

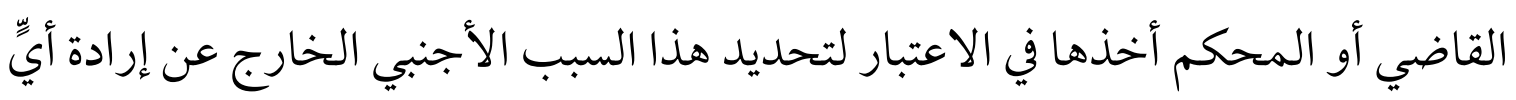

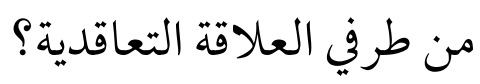

إن جواب التساؤل السابق يعتمد على مضمون الطريقة التي تنظر بها كل دولة إلى

القانون الأجنبي، وبحسب المادة الثانية من القانون الدولي الخاص الفنزويلي DIPR

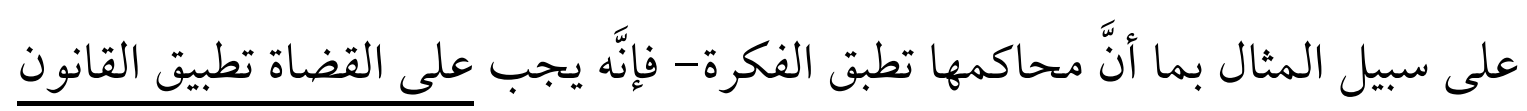
الأجنبي بطريقة تطبيقه ذاتها في بلده الأصلي، بمعني أنه يجب على القاضي الفنزويلي

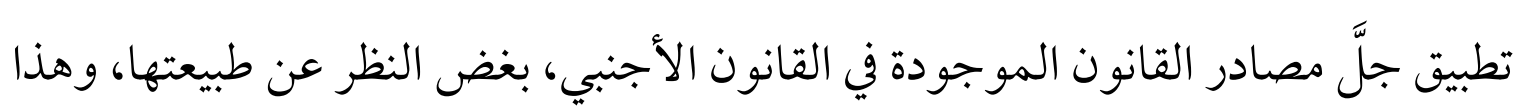

$$
\text { (1) (1) للاطلاع على حيثيات القضية المشار إليها، انظر: }
$$
https://dockets.justia.com/docket/florida/flsdce/1:2020cv21108/568281, Last visit on 2/7/2020.

(Y) لمن أراد الاستز ادة يمكنه الاطلاع على هذه المقالة باللغة الإسبانية، José Antonio Briceño Laborí, El Derecho Internacional Privado ante el COVID-19, issued by "Derecho \& Sociedad" es una Asociación, published on March 2020.

See at, http://www.derysoc.com/especial-nro-3/el-derecho-internacional-privado-ante-el-covid-19/, Last visit on 11/7/2020. 
يحمل في مضمونه دلالة أنه على القاضي الفنزويلي ألَّا ينظر فقط في قواعد القانون الخاص، ولكن أيضًا في قواعد القانون العام، بل وحتى في القواعد ذات التطبيق

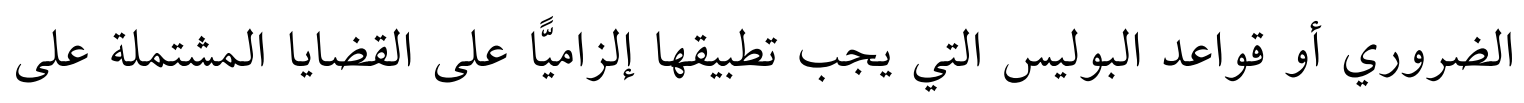
عنصر أجنبي. وبالعودة إلى تساؤلنا السابق عن أيّ القواعد الموجودة بالقانون الواجب التطبيق

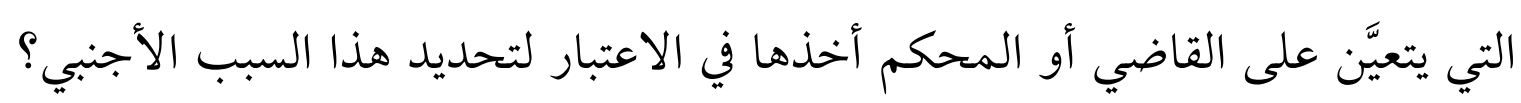

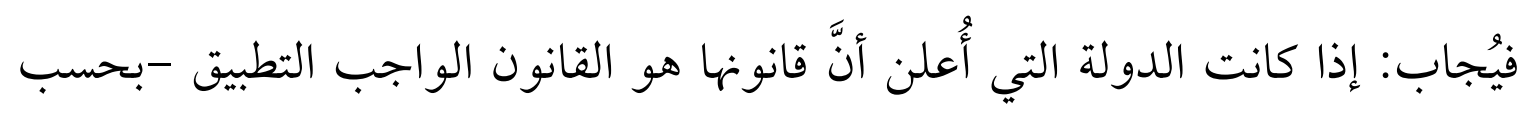
قواعد تنازع القوانين في فنزويلا- قد أصدرت قاعدةً ذات تطبيق ضروري أو قاعدة بوليس على أعقاب جائحة كورونا، وكانت هذه الأخيرة قد جعلت تنفيذ الالتزام

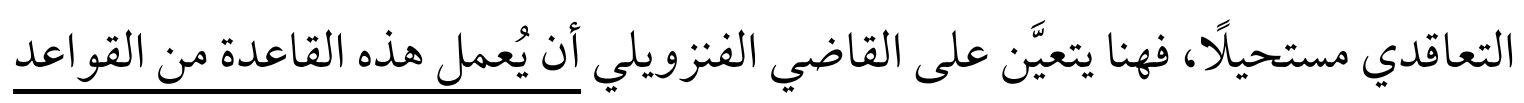

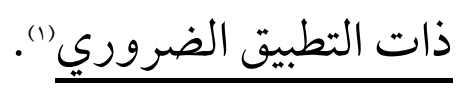
وإجمالًا يلاحظ ما في التوجه السابق من إنصاف على نحو يجعل من الممكن أن يتمَّم وعلى الرغم من أنَّ الطرح السابق قد كشف عن جزء كبير من المسألة إلَّا أنَّهَ أبقى

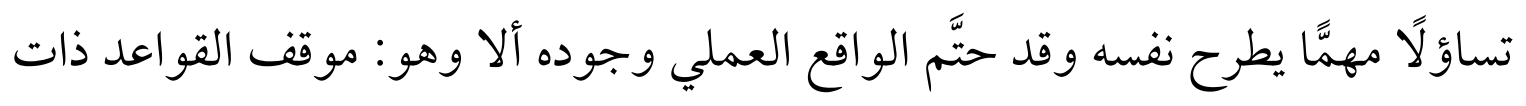
التطبيق الضروري الصادرة في دولة ثالثة مرتبطة بالعقد ولكنها على غير قانون بلد محل إبرام العقد أو القانون الذي اتفق الأطراف على تطبيقه على موضوع العقد، وليكن مثلًا

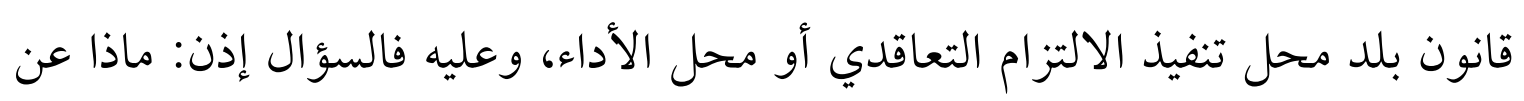

(1) Ibid. 
موقف القواعد ذات التطبيق الضروري الصادرة في هذه الأخيرة من التطبيق؟ ولكي يكون الجواب على السؤال ذا بعد عمليِّ يُيسّر إيصال مضمونه؛ فسيكون الجواب عن التساؤل السابق من خلال طرح مثال عملي يسبقه التعريف الموجز بماهية القوانين ذات التطبيق الضروري أو المباشر؛ فهي مجموعة من القواعد الموضوعية التي

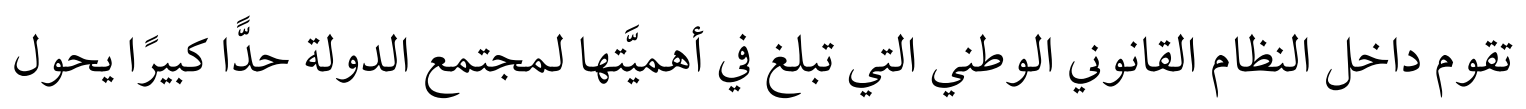

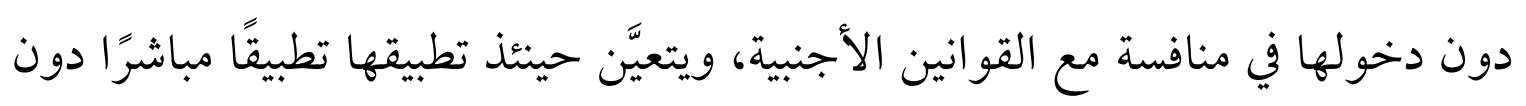

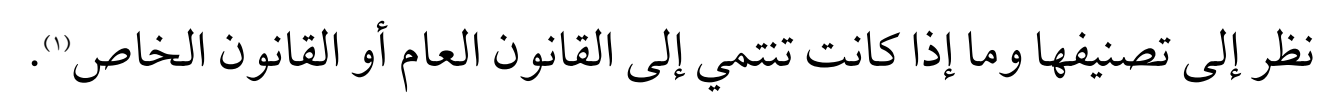

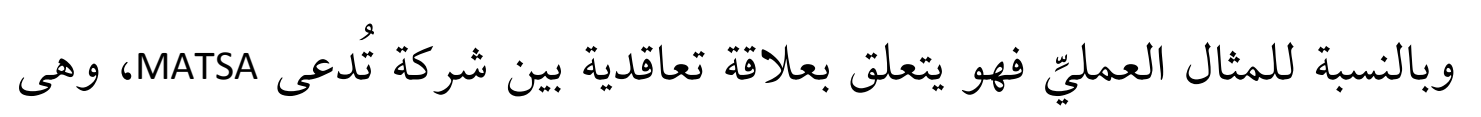

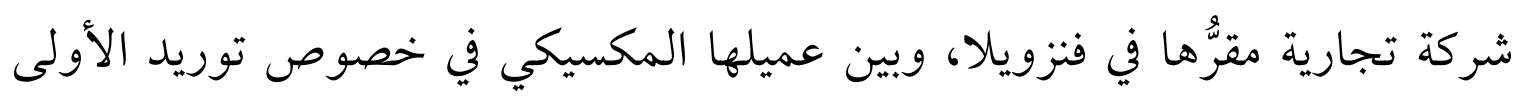
للثاني منتجات إيطالية، والعلاقة بينهما خاضعة للقو انين المكسيكية، لكن النزاع مطروح أمام المحاكم الفنزويلية المختصة للبتّ في الدعوى؛ ففي هذه الحالة ما موقف المحاكم الفنزويلية من القواعد ذات التطبيق الضروري التي أصدرتها الحكومة الإيطالية التي قد يؤدي إعمالها إلى عدم تنفيذ ما ورد بالعقد؟

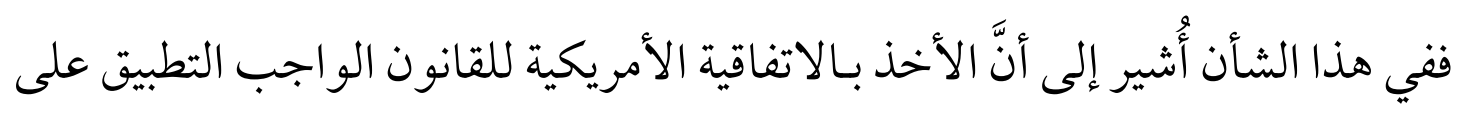

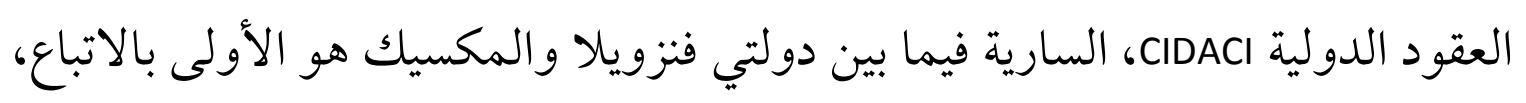
وبحسب ما ورد في مادتها الحادية عشر فإنَّه: "سيكون من اختصاص قانون بلد القاضي- إذا رأى ذلك مناسبًا- تطبيق القواعد ذات التطبيق الضروري الصادرة عن قوانين دول أخرى ما دامت مرتبطة بالعقد ارتباطًا

(1) د. عكاشة محمد عبد العال مصطفى، الوسيط في تنازع القوانين، مرجع سابق، ص ع عب. 


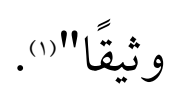

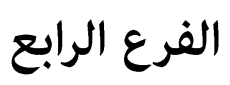

الرأي المقترح في اعتبار جائحة كورونا قوةً قاهرةً أم ظرقًا طاريًا الفَا

إن إمعان النظر في الطبيعة القانونية لفيروس كورونا -وبعد الخوض فيمار فئها قيل في هذا الصدد من اجتهادات مضى الوقوف عندها وما رافقه من عرض للثوابت ذات الصلةيُظهِرِ أنَّا العبرة بالأثر الذي أحدثثه جائحة كورونا لنُحدِّد ما إذا كان قوة قاهرة أو ظرفًا طارئًا، بل والأبعد هو الإقرار باحتمالية ألَّال يعتبر تأثير جائحة كورونا لا هذا ولا ذاك حال عدم انطباق موجبات أيِّ مما تقتضيه النظريتان على الحادث محلَّ البحث؛ وكنتيجة لانعدام هذا الأثر يكون تنفيذ الالتزام التعاقدي على حاله هو الحل الأولى تنفيذه.

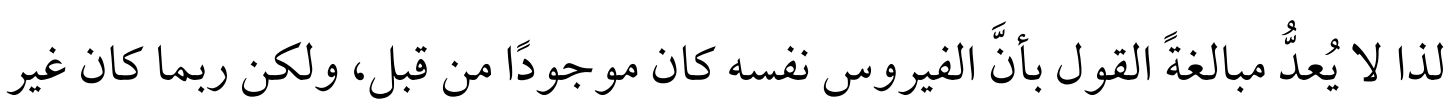
ظاهر، أو لم يُخلِّف ما نجم عنه من تبعات باتت لا تخفى على القاصي والداني. إذن نعود لنؤكد مجددًا أن العبرة بالآثار المترتب على العقد الدولي جراء الجائحة، وهو ما يثبت أنَّ القول باعتبار فيروس كورونا حادثة قوة قاهرة أو ظرفًا طارئًا هو أمر مرجعه النظر في ملابسات كلّ عقد على حدة، والآثار الناجمة عنه، ومن ثمَّ التأكد من تو افر شروط أيِّ منهما من عدمه، فالأمر يتطلَّب كثيرًا من المرونة بالقدر الذي لا يسعف فيه القول بوجود معيار جامع. و الشاهد: أنَّ تبعات فيروس كورونا نفسه في بدايتها ليست هي نفسها تبعاته الآن، ولا يُنكر ذلك أحدُّ؛ فهذا الفيروس قد يكون في فترة زمنية أقرب لاعتباره قوة قاهرة، وفي فترة

(1) José Antonio Briceño Laborí, El Derecho Internacional Privado ante el COVID-19, op, cit.,

$$
\text { وللاطلاع على النص الكامل للاتفاقية يمكن مراجعة الر ابط الإلكتروني الرسمي التالي: }
$$

See at, https://www.oas.org/juridico/spanish/tratados/b-56.html , last visit on 11/7/2020. 
زمنية أخرى ظرفًا طارئًا، وقد لا يكون شيئًا من ذلك؛ لذا فعندما نتحدث عن كورونا فإنَّنا لا نعني الفيروس في حدّ ذاته بل الآثار الناجمة عنه وما خحلَّفه من آثار. وعليه لا يمكن البتة الجزم بأن فيروس كورونا يُعلُّ قوة قاهرة أو ظرفًا طارئًا؛ فالأولى لى هو النظر في طبيعة نصوص كلّ عقد على حدة؛ وما خلَّفه من آثار و اقعية على طرفي العقد الدولي، وعلى نحو ماعبر الفقه في خصوص إعمال نظرية الظروف الطارئة على جائحة كورونا؛ إذ لا تنطبق هذه النظرية مع معظم القضايا، حيث يظل تنفيذ العقد ممكنًا وإن كان بشكل معدَّل، شريطة أن يُكيَّف العقد مع هذه الظروف محلَّ التغيير.

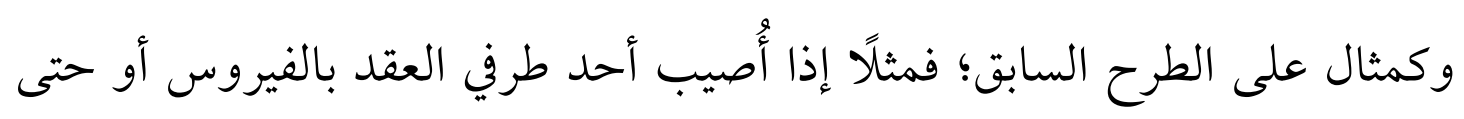
تُوفِّ، وكانت هذه الإصابة أو الوفاة سببًا في عدم وفائه بالتزامه التعاقدي؛ ففي هذه الحالة يمكن القول بأنَّهذا الشخص هو الذي لديه عذر قهريٌّ معين، ولا يخفى ما في الوقائع المذكورة من اختلاف عن القوة القاهرة، التي هي حالة عامة. وبطبيعة الحال سيكون من حقّّ الطرف المتعاقد الذي يدَّعي أن وقائع بعينها هي التي التي

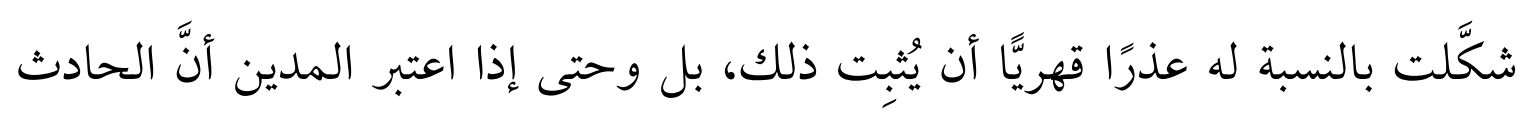

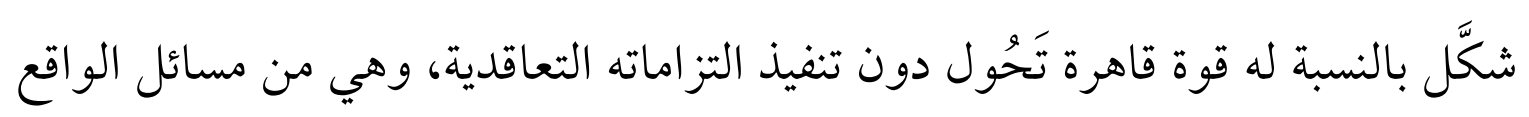

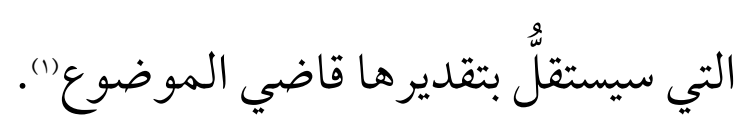
مع الاعتراف بأنَّ فيروس كورونا يُعدُّ واقعة مادية؛ فلا يحتاج المدين المتمسك بها إلى إثبات وقوعها، أو إثبات تاريخ تفشي الوباء أمام محاكم الموضوع؛ إذ من المفروض أن تكون الأخيرة على علم تامِّ بحقيقة قيامها، فهي من حيث العلم بها تنزل

$$
\text { (1) (1) د. نبيل إسماعيل عمر، المرجع السابق، ص VIV. }
$$


منزلةً النصِّ القانوني الذي لا يُعذر القاضي بجهله، على الرغم من أنَّ الأمر لا يتعلق

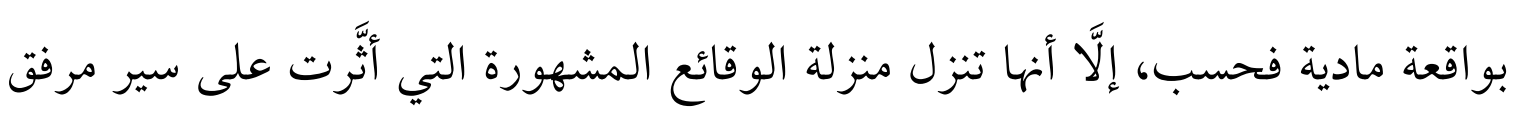
القضاء ذاته؛ فكانت السبب في تعليق انعقاد جلساته، وتغيير نظام العمل داخل الجلسات ذاتها، ناهيك عن تعليق انعقاد الجلسات منعًا للمخالطة وتحقيقًا للتباعد الاجتماعي كإجراءات احترازية هُدِف منها إلى الحيلولة دون تفشي هذا الفيروس بين الجهات القضاة والموظفين وجمهور المتقاضين وغيرهم. مع العلم بأنه إذا أعقب إبرامَ العقد في ظروف انتشار الوباء قرارٌ من السلطات يفيد

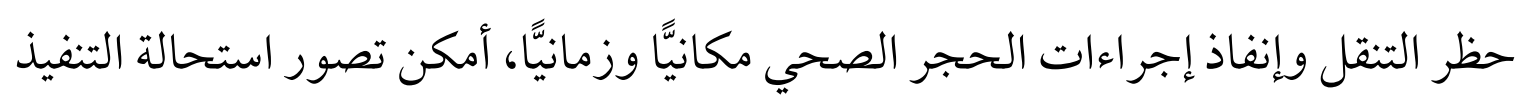

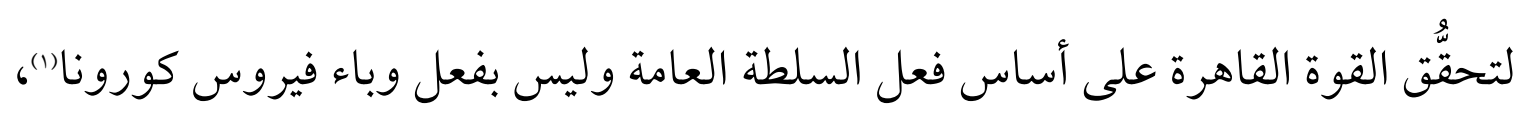

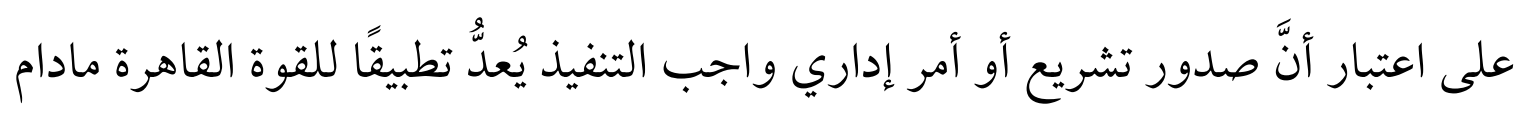
شرطا استحالة الدفع واستحالة التوقع قد توفَّرالمان.

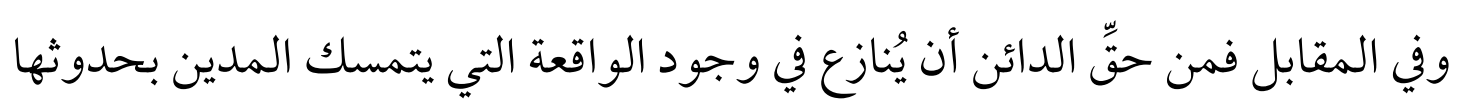

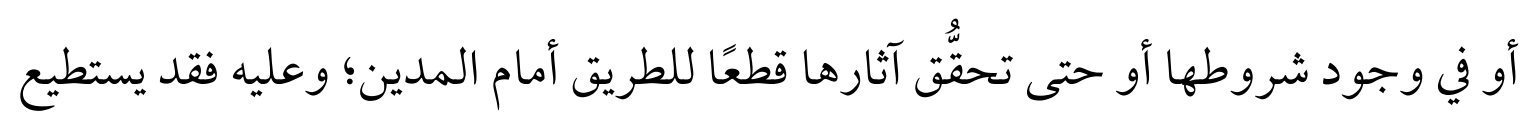
الدائن أن يثبت أن فيروس كورونا لا يسعف مدينه من التحلل من التزاماته التعاقدية التي أبرمها مع المدين إلَّا بشكل جزئي، أو حتى أن الحادث الذي الذي آَّعى المدين أنه قوة قاهرة

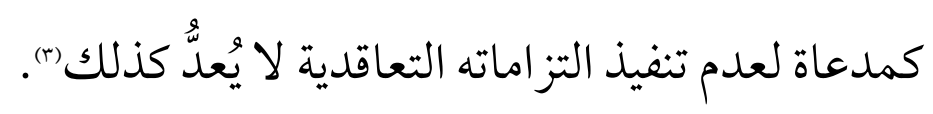

(1) د. إبراهيم أحاطب، مقالة سابقة الإشارة.

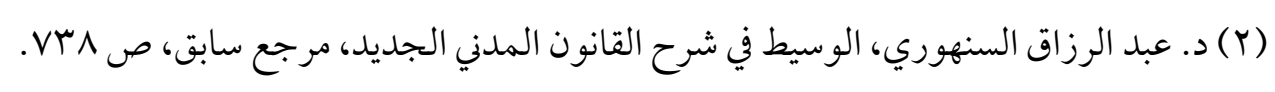
(r) د. إبراهيم أحاطب، مقالة سابقة الإشارة. 
وعليه فالطرف الذي يدَّعي وجود قوة قاهرة هو الذي عليه إثبات عدم التوقع وعدم

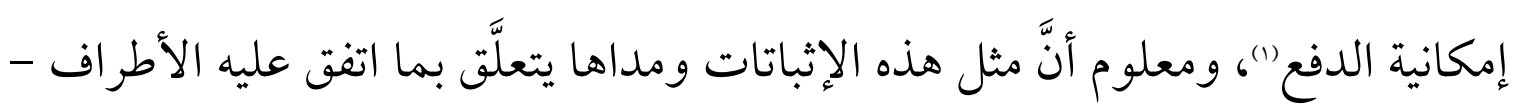

أيضًا- إذ قد يَنصٌ الأطراف بعقدهم على إثبات أيِّ من الشرطين المذكورين فحسب،

تعويلًا عما ورد بمضمون العقد، وعمومًا يقع عبء الإثبات على عاتق المتخلِّف عن إلى السداد؛ أي المدعي الذي يدفع بوجود حادث أثََّّ على قدرته على أدائه لالتزاماته

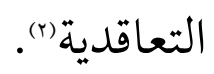

وبحسب القاعدة العامة في توزيع عبء الإثبات أنَّهّ يقع على عاتق المدعي، دون أن

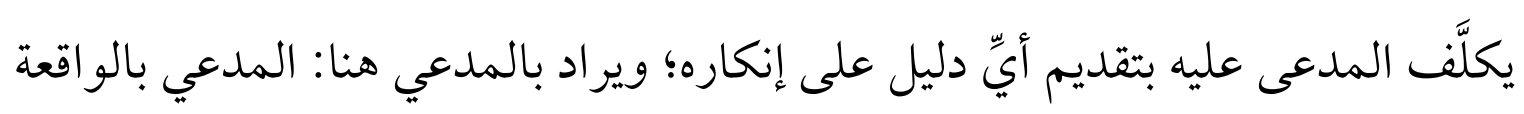
محلَّ الإثبات، وليس المدعي في الدعوى، ويُعدّ الشخص مدعيًا بو اقعة في الإثبات إذا كان ادعاؤه مخالفًا للوضع الثابت أصلًا أو عرفًا أو ظاهرًا (r)، وفي أعقاب جائحة كورونا فإنه يقع عبء الإثبات في القانون الدولي دائمًا على عاتق الطرف الذي يريد إثبات الحقائق.

و أبعد من ذلك ففي الوقت الذي اتخذتْ فيه كثير من دول العالم إجراءات احترازية

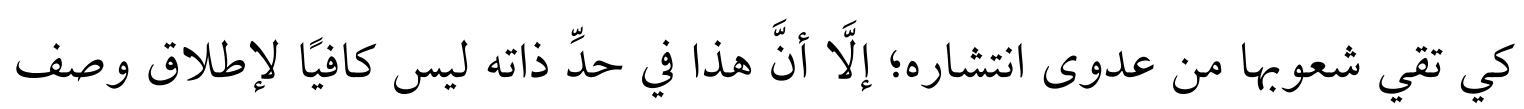
القوة القاهرة أو الظرف الطارى عليه؛ ليس فقط لأنَّ بعض الدول قد اعتمدت

(1) UPDATE: Force Majeure Under the Coronavirus (COVID-19) Pandemic, March 16, 2020, Published by Paul, Weiss, Rifkind, Wharton \& Garrison; Client Memorandum, p. 2, ft. 16.

See at, https://www.paulweiss.com/media/3979438/16mar20-update-force-majeure.pdf , Last visit on 19/6/2020.

(2) Ewan McKendrick, Force Majeure and Frustration of Contract, op, cit., Ch. 1.

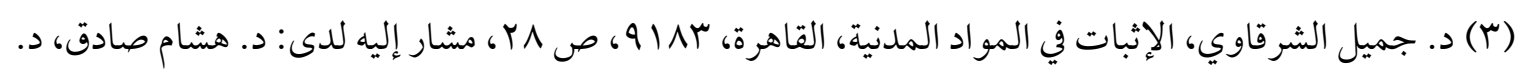

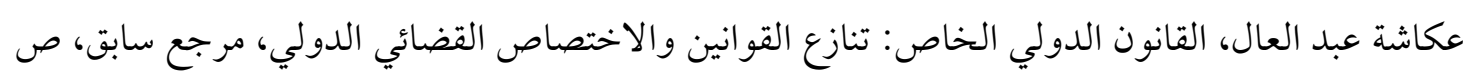

. 19 
استراتيجية "المناعة المجتمعية" أو مناعة القطيع كما يسميها البعض (1)، ولم تتخذ أيَّة إجراءات في هذا الصدد؛ كدولة السويد، وسواء اتفقنا أم اختلفنا مع منهج هذه الدول ومدى ما أثارته الإستراتيجية التي اتبعتها السويد من جدل، وما رآه البعض من ثمارٍ لها لا مجال للخوض فيها هنا(()؛ فإن مما يعضِّد التوجُه السابق، الذي يفيد أهمية النظر في مدى التأثير الحاصل لكلّ عقد على حدة؛ إذ مَثلت جائحة كورونا بالنسبة للبعض المنحة لا المحنة؛ كشركات التسويق الإلكتروني والتوصيل وغيرها؛ فهل يُعقل لمثل هذه التعاقدات التي راجت تجارتها جَّرَاء فيروس كورونا أن يُتذرَّع بعدم تنفيذ التزام تعاقدي بدعوى وجود قوة قاهرة أو ظرف طاري؟ وفي خضم معطيات جائحة كورونا يبقى الملاذ ضرورة أن يُنظر وفقًا لظروف كل عقد على حدة، ولا يقاس على غيره مهما كانت الظروف ضمن ضو ابط موضوعية (م). ووضعًا للر أي السابق في قالبه الصحيح؛ فهذا الأخير لا ينفي بالكلية اعتبار جائحة كورونا قوة قاهرة أو ظرفًا طارئًا، لكنه فقط يولي الاهتمام بالأثر الناجم عن الجائحة وما

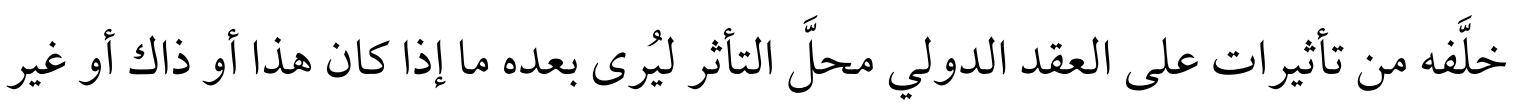
ذلك حسب كلّ حالة.

(1) على حد تعبير د. يوسف عبيدات، كون هذا المصطلح أفضل من مصطلح "مناعة القطيع" لأن مدلو لها يذهب

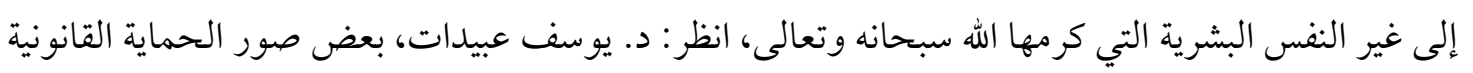

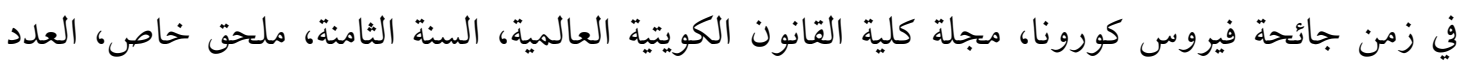

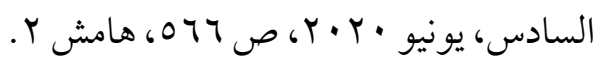

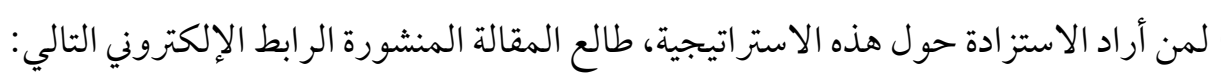

See at, https://www.thenational.ae/world/europe/coronavirus-sweden-s-controversial-herdimmunity-strategy-seems-to-be-paying-off-1.1022466, Last visit on 17/6/2020.

(r) د. ياسر عبد الحميد الإفتيحات، جائحة فيروس كورونا وأثرها على تنفيذ الالنزامات العقدية، مرجع سابق، 
وختام القول: أنَّ الوضع الذي مضى بيانه يتضح منه أنَّ جائحة كورونا لا تستقل

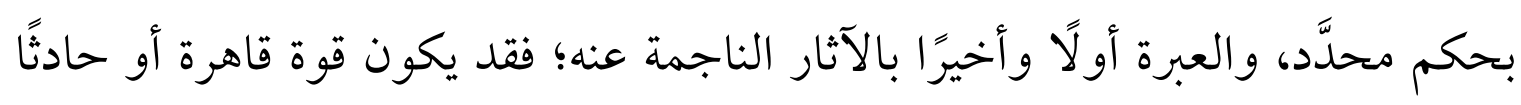
فجائًّا حال انطباق شروطه مجتمعة لصيرورة تنفيذ الالتزام مستحيلًا، أو ظرفًا طارئًا

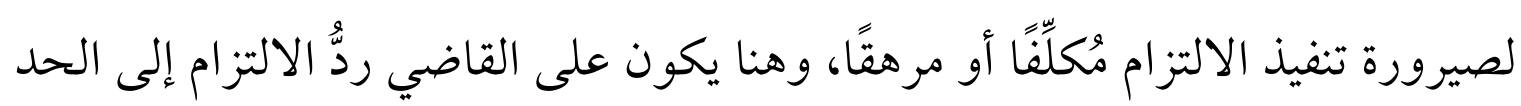

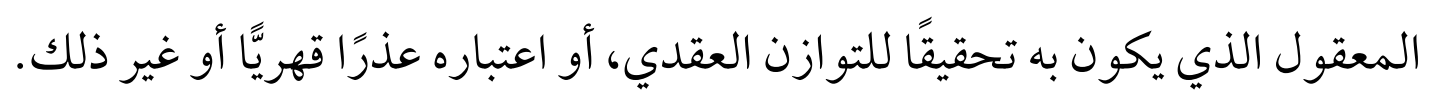

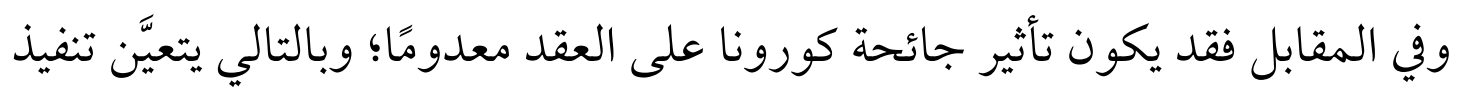

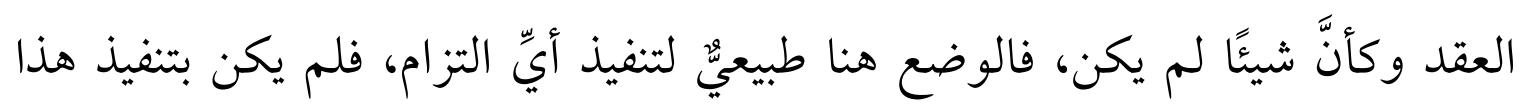

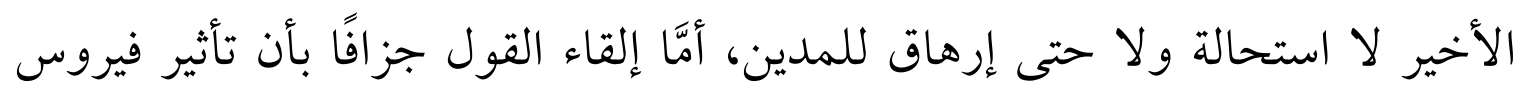

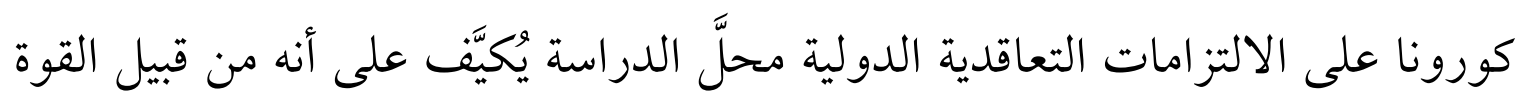

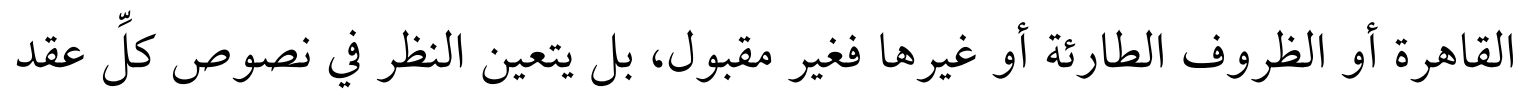
على حدة وما أحاط بتنفيذه من أمور.

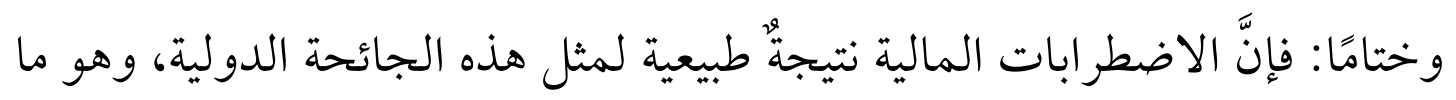

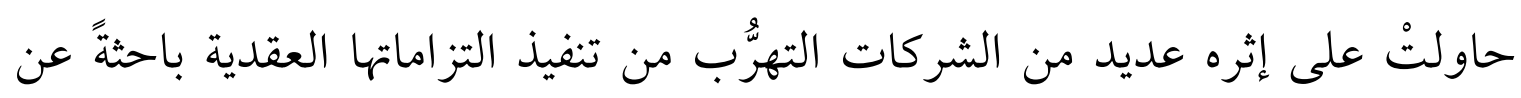

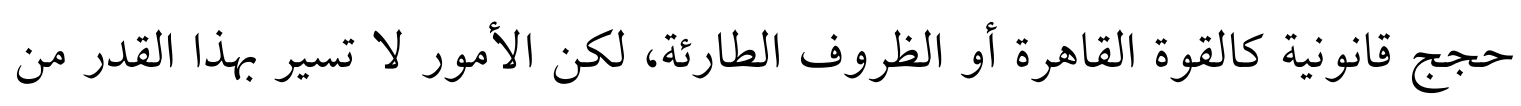

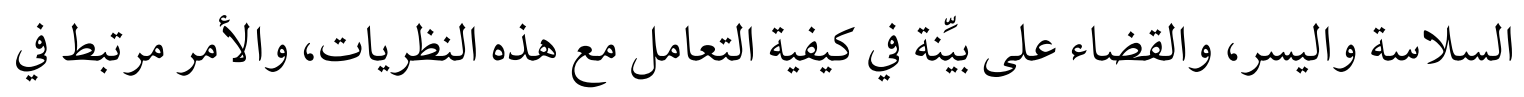

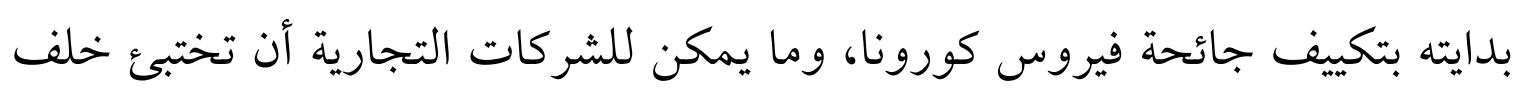

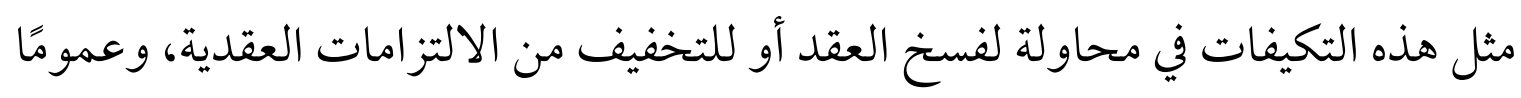

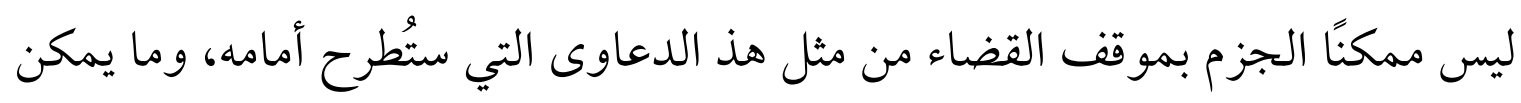

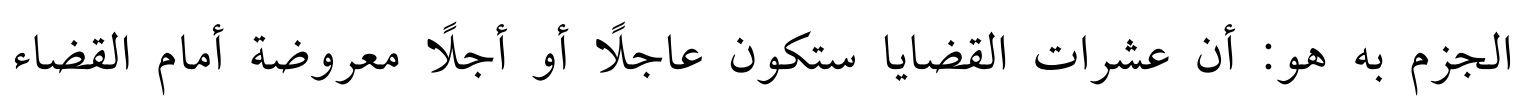

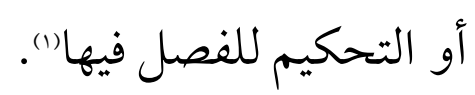

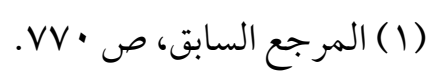




\section{المطلب الثاني \\ شرط إعادة التفاوض في سياق جائحة كورونا}

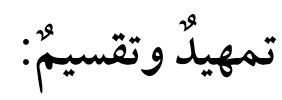

إنَّ الحديث عن شرط إعادة التفاوض يحوي في داخله عديدًا من المسائل، ولقد

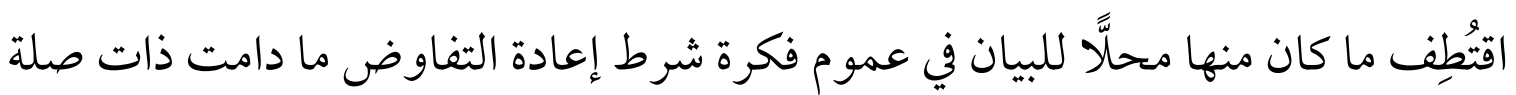
بجائحة كورونا وتصبُّ في صميم الفكرة محلَّ البحث.

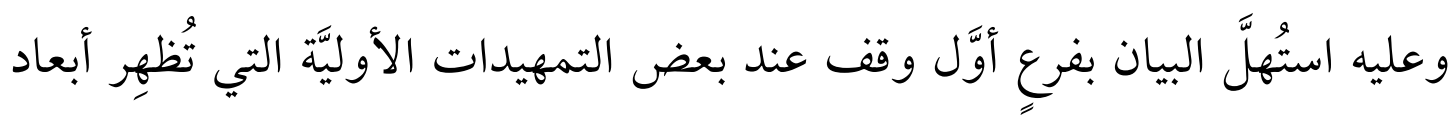
العلاقة بين فيروس كورونا وشرط إعادة التفاوض، بما في ذلك: تعريفها، وآليات

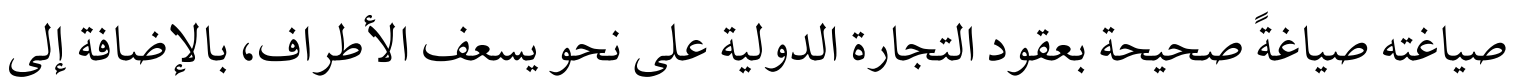

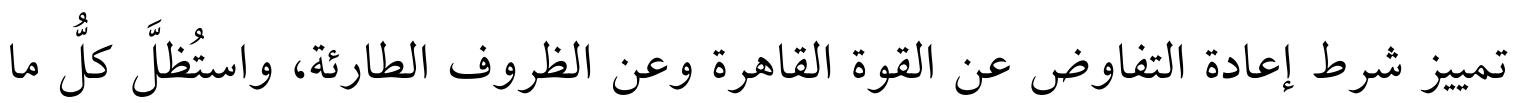
سبق بالجائحة محلَّ البيان.

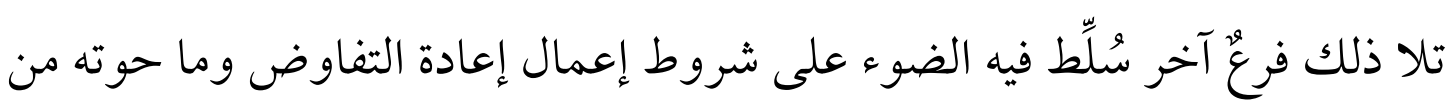

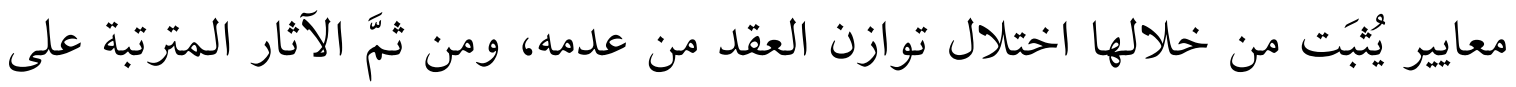
ذلك، إسقاطًا في هذا وذاك على الجائحة الكورونيَّة، ثمَّ فرع ثالث شَرَحَ بعض الوسائل الأخرى لحلّل منازعات عقود التجارة الدولية المتأثرة بجائحة كورونا.

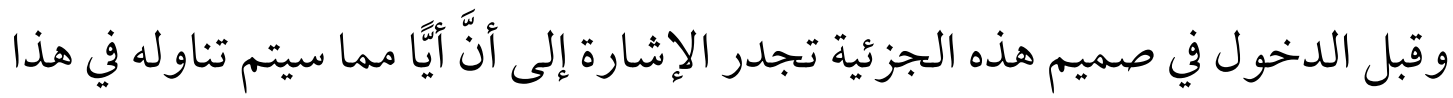
المطلب يمكن إسقاط فحواه على ما خلَّفته جائحة كورونا، حتى ولو بدا من العنس العموم بمكان؛ ولذا فمن المهم التأكيد على أهمية أن يبقى راسخًا في الذهن أن المعطيات المطروحة هنا مرماها الأساسي تقديم حلول لعقود التجارة الدولية المتأثرة بجائحة 


\section{الفرع الأول \\ تمهيدات أوليّة في العلاقة بين جائحة كورونا وشرط إعادة التفاوض الأ

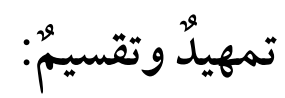

إنَّ استهلال الحديث عن شرط إعادة التفاوض في سياق عقود التجارة الدولية يقتضي بيان بعض الأمور الأوليَّة ذات الصلة التي تُسهِمَ في توضيح الفكرة المرادة، وفي لِّرِ مقدمتها التعريف بشرط إعادة التفاوض في عقود التجارة الدولية في ظلّ جائحة كورونا في غصنٍ أوَّل، ثم يُنطلَق منه إلى تمييز إعادة التفاوض عن القوة القاهرة والظروف الطارئة.

\section{الغصن الأول}

\section{التعريف بشرط إعادة التفاوض في عقود التجارة الدولية}

\section{على خلفيَّة جائحة كورونا}

إنَّ العقود الدولية -وبخاصة الحديثة- هي المجال الخصب لإعادة التفاوض؛ فثمَّة معطيات واقعية بَّرّت استحداث فكرة إعادة التفاوض؛ كطبيعة العقد الدولي ذاته بالنظر إلى طول مدة تنفيذه(1)؛ فاللجوء لإعادة التفاوض أمر طبيعي بالنظر إلى العقد على أنَّه تَآَّي إرادتين، إيجاب يعقبه قبول بعد محادثات وقتية سريعة، في الوقت الذي تنطوي فيه عقود هذه الصفقات على جوانب كبيرة من المخاطرة، ويترتب عليها انتقال سلع وخدمات عبر الحدود تقدر بمليارات الدولارات، وهو ما يوجب إفساح الوقت والمجال أمام الأطراف المتعاملة للدخول في لقاءات ومناقشات مكثَّة حول: الثمن

(1) لمزيد من التفاصيل، د. هني عبد اللطيف، حدود الأخذ بفكرة إعادة التفاوض في العقد، المرجع السابق، ص

$$
\text { الوما بعدها. }
$$


أو الأسعار، ومو اعيد التوريد وكيفية التنفيذ، ووقته ومكانه، وضماناته، وجزاء الإخلال بالالتزامات التي ستنشأ عن ذلك، فضلًا عن مناقشة الأعمال التحضيرية؛ مثل: الفحوص الفنية، ودراسات الجدوى الاقتصادية، وإعداد خطط المشروع، وتوفير وسائل تمويله و التأمين على عناصره"). ولعلَّ كثيرًا مما سبق بيانه من دواعٍ لإعادة التفاوض قد تعرَّضت لها بالفعل عقود التجارة الدولية على إثر تفشي وباء كورونا، وبطبيعة الحال يختلف مدى هذا التأثير بحسب ظروف كلّ عقد وظروف أطر افه؛ لذا فالو اقع الذي تحياه عقود التجارة الدولية ذاتها هو الذي أدَّى إلى وجود مفاهيم جديدة فرضتها ظروف التجارة الدوليـة وملابساتها، حتى جعلت من الواضح عدم ملائمة القواعد القانونية الموجودة في التشريعات الوطنية؛ إذ إنَّ الحلول التي تضمنتها الأخيرة تتصدى بالدرجة الأولى للمشكلات الناجمة عن العلاقات الداخلية تحديدًا، وبالتالي تكون نظرتها إلى العلاقات الدولية وما يصاحبها من مشكلات ناجمة عن تغير الظروف على سبيل الاستثناء.

فمثلًا: نظرية القوة القاهرة لا تستوعب في أغلب الأحيـان الحالات ذات الطـابع الاقتصادي والتكنولوجي في العقود الدولية، بينما تعجز نظرية الظروف الطارئة عن معالجة ما ينجم عن تغير ظروف العقود الدولية بما تخوِّله من سلطة للقاضي في تعـيل العقد؛ في حين أن العقود الدولية تتضمن -مثلًا- شرطًا باللجوء إلى التحكيم لفضِّ أي

(1) د. أحمد عبد الكريم سلامة، قانون العقد الدولي: مفاوضات العقود الدولية - القانون وجب التطبيق وأزمته،

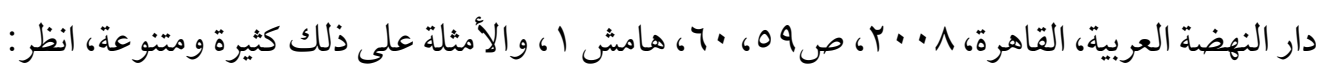
Constance Verroust-Valliot et Serge Pelletier, L'impact du covid-19 sur les contrats de droit privé, op, cit., 
نزاع قد يثور بمناسبة تنفيذ العقد.

لذا أوجد واقع عقود التجارة الدولية حلولًا قد اعترف من خلالهـا للأطر اف بحريَّة واسعة في تنظيم عقودهم بمقتضى نوعين من الشروط، الأول: يُسمَّى شروط التعديل التلقائي للعقد (1)، والثاني: يسمَّى شروط مر اجعة بنود العقد، وتهدف الأخيرة إلى مراجعة بنود العقد عن طريق إعادة التفاوض بين الأطراف، وأهم هذه الشروط وأكثرها رواجًا في واقع العقود الدولية شرط إعادة التفاوض.

وهو شرط اتفاقيّيُّيُرجه الأطراف في العقد، يتفقون فيه على إعادة التفاوض فيما بينهم، ويؤدي إعماله إلى وقف تنفيـذ العقـد وإعادة التفاوض بين الأطر اف بهدف تعديل بعض بنوده جرَّاء وقوع أحداث معينة يحددها الأطراف من شأنها الإخلال بتوازن العقد، وإصابة أحد المتعاقدين بضرر جسيم، وبما يتماشى مع الوضع الجديـد النـاجم

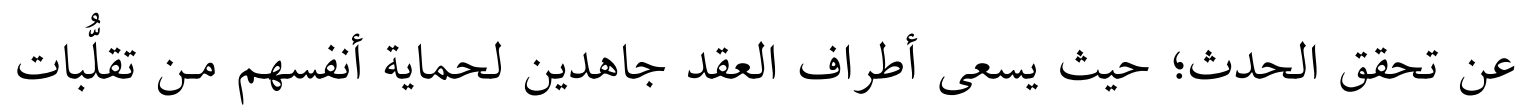
الظروف المحيطة بتنفيذ عقودهم، أيًّا ما كانت طبيعتها(). وعليه فبمقتضاه يُبِيّن الأطراف مفهومهم للشرط والأحداث التي يواجهها، اقتصاديةً كانت أو سياسية أو مالية، وأثرها على العقد، والحلول التي سوف يُلجَأ إليها

(1) "وتهدف هذه الشروط إلى تعديل بنود العقد تلقائيًا، دون حاجة إلى تدخل الأطراف أثناء إجراء التعديل، ومن

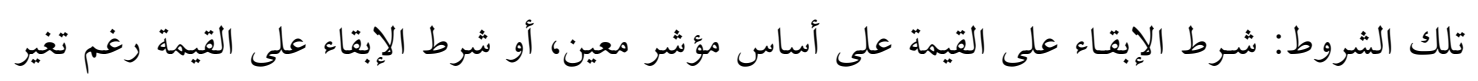

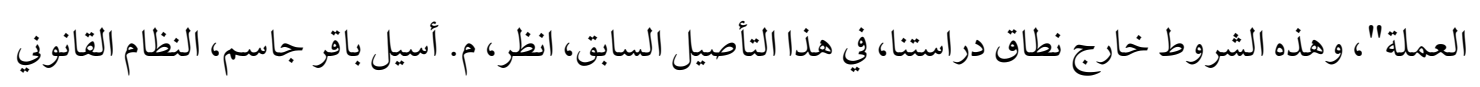
لشرط إعادة التفاوض، دراسة في عقود التجارة الدولية، مجلة المحقق الحلي للعلوم القانونية والسياسية،

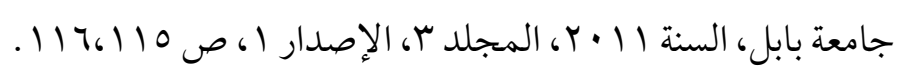

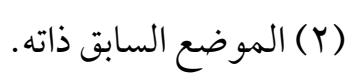


من قبل الأطراف في حالة وقوع تلك الأحداث؛ فالمهم هو أن تكون تلك الأحداث خارجة عن إرادة الأطراف، غير متوقعة الحصول من قبلهم وقت التعاقد، وغير ممكنة

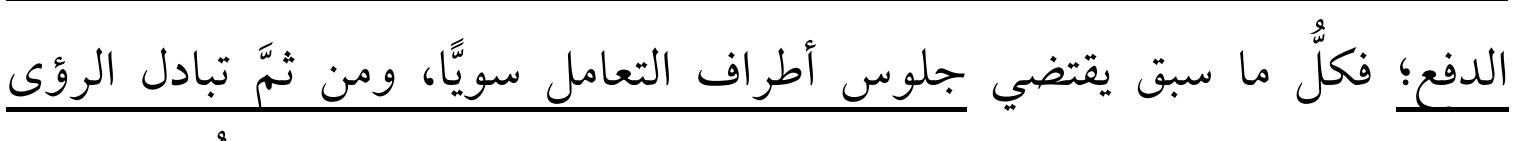

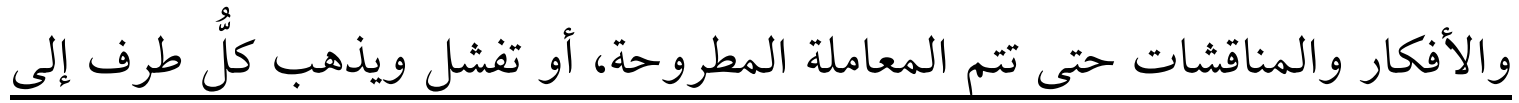
حال سبيله' (1)

وفي ضوء الأهمية الموكولة لشرط إعادة التفاوض بالنظر لمضمونه: فلقد حرصت بعض التشريعات على النصِّ صراحة على الأخذ به؛ فبموجب قانون العقود الفرنسي -

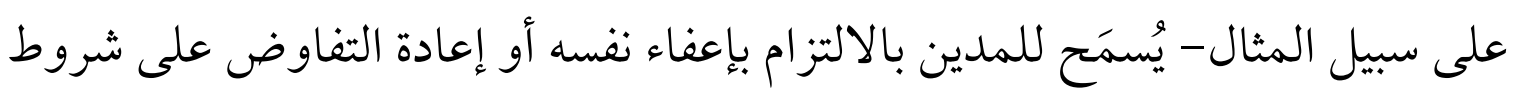

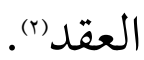

كما أن غرفة التجارة الدولية بباريس قد أعلَّت شرطًا نموذجيًّا بشأن مواجهة الأحداث غير المتوقعة، وجاء فيه: "في حالة وقوع أحداث غير متوقعة من الأطراف من شأنها أن تُغيِّر بشكل أساسيٍّ توازنَ العقد الحالي وتؤدي إلى وقوع أعباء غير عادلة لأحد الأطراف أثناء تنفيذ

(1) في العرض السابق، ولمزيد من التفاصيل، انظر: المرجع السابق، ص 110 وما بعدها، ولمزيد من التفاصيل

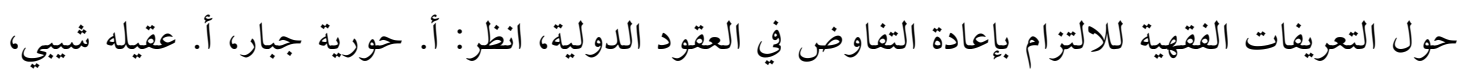

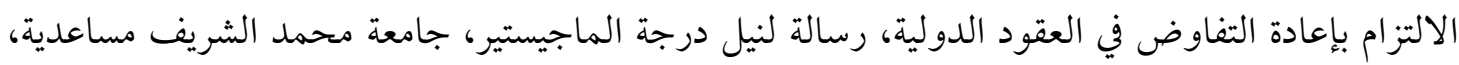

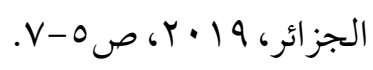

(2) Constance Verroust-Valliot et Serge Pelletier, L'impact du covid-19 sur les contrats de droit privé, op, cit.,

$$
\text { للاطلاع على النص الكامل للمادة المذكورة، يمكن زيارة الر ابط الإلكتروني الرسمي التالي: }
$$

See at, https://www.legifrance.gouv.fr/affichTexte.do?cidTexte=JORFTEXT000041876355\&categorieLien=id , Last visit on $9 / 7 / 2020$. 


$$
\text { التزاماته، فيجـب أن يُتَّجه لتعـديل بنـود العقد"'(1). }
$$

وحرصت المبادئ المتعلقة بعقود التجارة الدولية أو مبادئ Unidroit عام ع99 199 كذلك على إير اد ما يخصها؛ فقد جاء بالفقرة الثالثة من المادة (7 / Y) أنه: "في حالة قيام ظروف طارئة hardship يكون للطرف المتضرّر طلب إعادة التفاوض، ويجب أن يُقدِّم الطلب دون تأخير و أن يكون مسبَّبًا". وحريُّ بالذكر الإشارة إلى ما للتحكيم من دور في تطبيق شرط إعادة التفاوض؛ إذ إنَّ "مبدأ سلطان المحكم في مراجعة العقد لتغيُّ الظروف هو مبدأ مستمَدِّهُ من المبادئ القانونية المشتركة؛ على أن تطبيق هذا المبدأ قد اقتصر على عقود الإنتاج طويلة المدة دون عقود المبادلة التجارية العادية رعايةً لظروف ومتطلبات المجتمع الدولي للمال

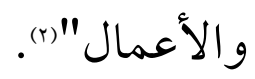

ولمَّا كان شرط إعادة التفاوض هدفه ردٌّا العقد إلى توازنه الذي اختل على إثر حدث معين؛ ففعالية مثل هذا الشرط في عقود التجارة الدولية تحكمها بعض الاعتبارات التي يتعيَّن الوقوف عندها فيما يأتي:

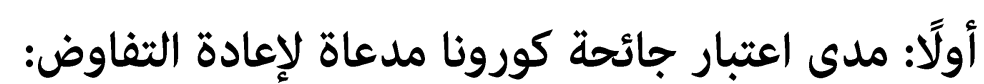

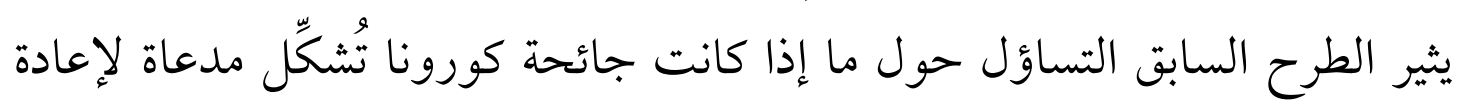
التفاوض من عدمه، على اعتبار أنَّها تنطوي على "تغيير غير متوقَّع في الظروف"، على النحو الذي سمح من الأساس بإعادة التفاوض على العقد؟

(1) في تفصيل ذلك، انظر م. أسيل باقر جاسم، النظام القانوني لشرط إعادة التفاوض، مرجع سابق، ص ه I ا وما بعدها. (Y) د. هشام على صادق، القانون الواجب التطبيق على عقود التجارة الدولية، مرجع سابق، ص Y^I . 
إنَّ الجواب على السؤال السابق -وبمنتهى البساطة والمنطقية الممزوجة بالعدالة-

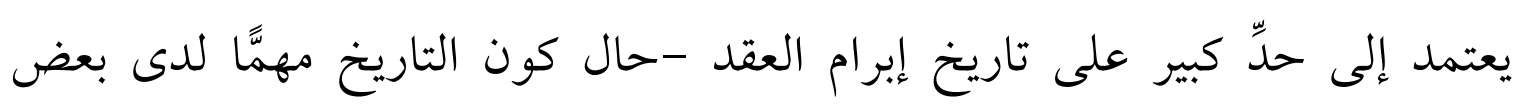
التشريعات؛ كالتشريع الفرنسي مثلاً - وظروف أدائه أثناء ممارسته، وتبقى مراجعة مثل هذه الظروف غير المتوقعة خيارًا مهكنًا في ظلّّ وباء كورونا؛ وعليه فإنَّ تقييم كلّ حالة

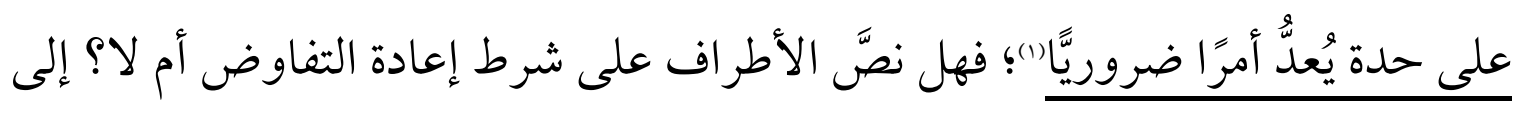
غير ذلك من التساؤلات التي مضى بيانها فيما مضى، والتي تحكم الردَّ على السؤال الأساسي الذي طر حته هذه الفقرة. الشاهد: أنَّا اعتبار جائحة كورونا قوة قاهرة أو ظرفًا طارئًا أو حتى مدعاة لإعادة

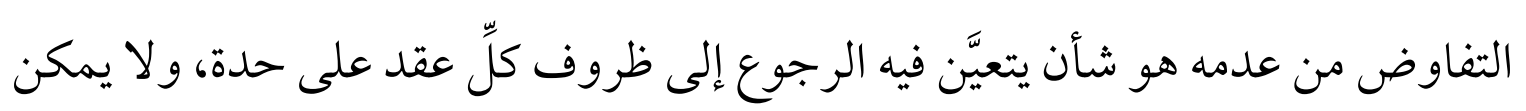
القول جزافًا بأفضلية هذا أو ذاك.

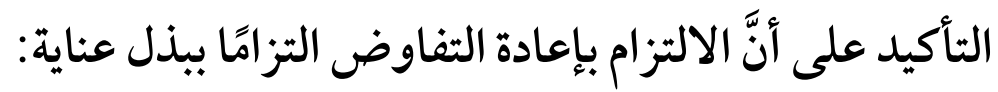

انطلاقًا من الفرضين السابقين (اتفاق الأطراف أو غيابه)، وإذا كان كلاهما يؤدي إلى لى بلى إعادة التفاوض تارةً بنصِّ الأطراف وتارةً أخرى إعمالًا لمبدأ حسن النية في العقود

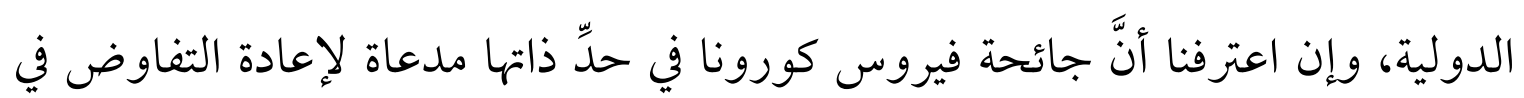

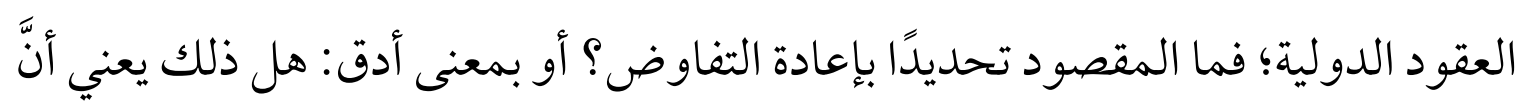
على كلّ من التزم بشرط إعادة التفاوض أن يتفاوض من أجل تحقيق نتيجة أم هو فقط التزام ببذل عناية(r)؛ وبصيغة أخرى: هل لا بد أن يَتُج عن هذا التفاوض نتيجة بعينها، ألا وهي إعادة العقد إلى توازنه، أم هو فقط التزام بالقيام بالمفاوضات ومباشرة إمكانية تعديل العقد في ضوء تبعات فيروس كورونا فحسب؟

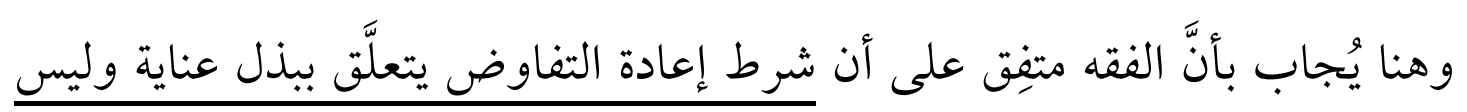

(1) Olivier Kuhn, Hassan Ben Hamadi, Covid-19 and contract Renegotiation: Q\&A, op, cit.,

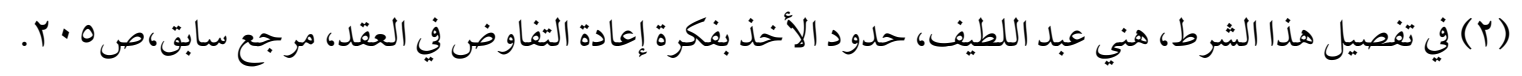


التزامًا بتحقيق نتيجة، فشرط إعادة التفاوض في جوهره التزام ببذل عناية؛ أي: إنه الالتزام

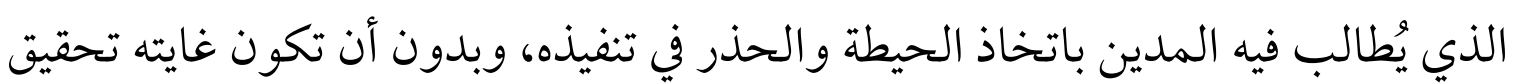

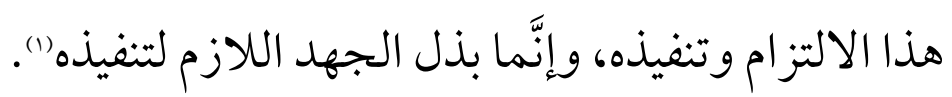

ولكن على الجانب الآخر سيكون متصورًا أن يوجد متعاقِد سيء النية يقبل بهذا

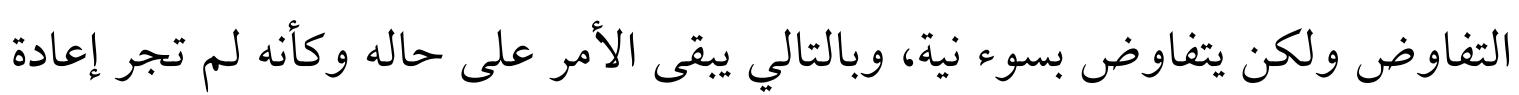

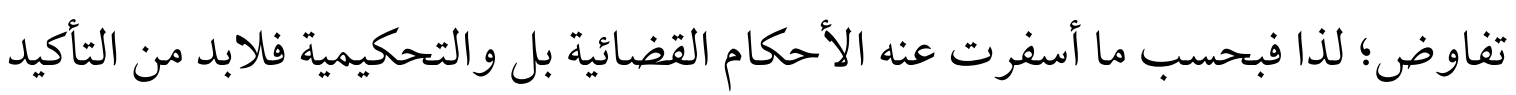

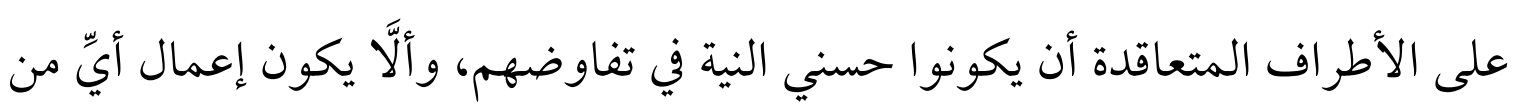

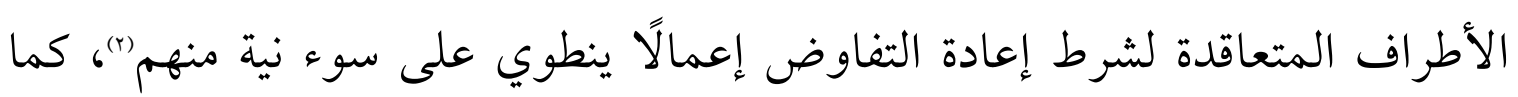
مضى البيان عند غش الطرف المتعاقد وخداعه.

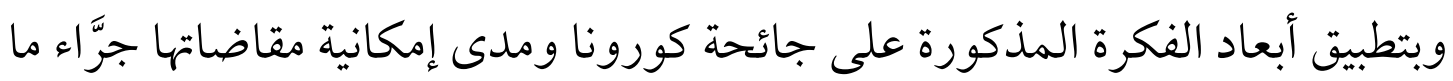

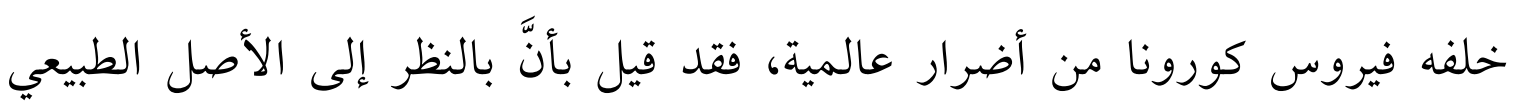

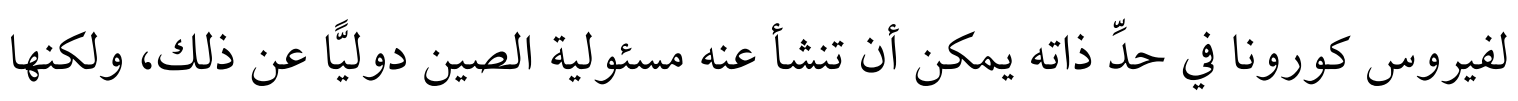

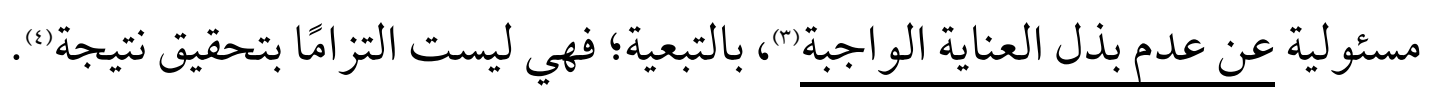

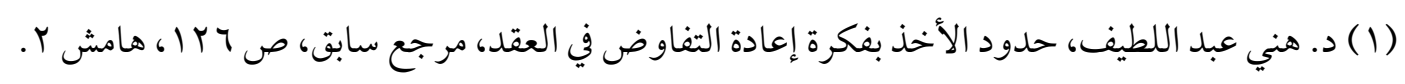

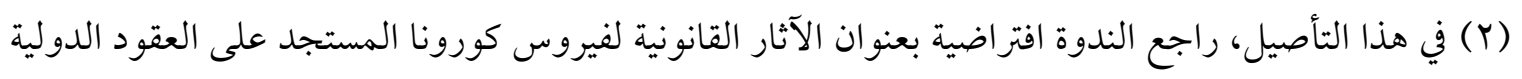

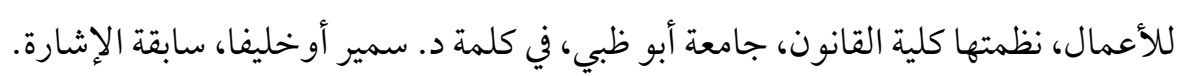

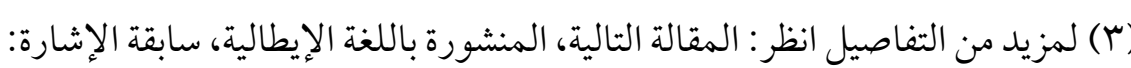

FABRIZIO MARRELLA, LA CINA DEVE RISARCIRE I DANNI TRANSNAZIONALI DA COVID-19? ORIZZONTI AD ORIENTE, Issued by SIDIBLOG official website, published on 16/5/2020.

See at, http://www.sidiblog.org/2020/05/17/la-cina-deve-risarcire-i-danni-transnazionali-da-covid-19orizzonti-ad-oriente/, Last visit on 3/7/2020.

(4) For more details, Antonio Coco and Talita de Souza Dias, Part I: Due Diligence and COVID-19: States' Duties to Prevent and Halt the Coronavirus Outbreak, Blog of the European Journal of International Law (ejil talk), March 24, 2020.

See at, https://www.ejiltalk.org/part-i-due-diligence-and-covid-19-states-duties-to-prevent-and-haltthe-coronavirus-outbreak/, Last visit on 24/7/2020. 
ثانيًا: آليات إدراج شرط إعادة التفاوض كأحد عوامل نجاحه في عقود التجارة

الدولية: - nan

إنَّ شرط إعادة التفاوض على أهميته ومزاياه ومرونته التي بدت من الطرح السابق، إلّاّ أنَّ الإشارة واجبة إلى أنَّ مجرد إشارة الأطراف في العقد إلى مصطلح "إعادة التفاوض" فحسب لا تُعدُّ في حدِّ ذاتها كافية لتطبيق الشرط؛ لأنَّ إدراج المصطلح المذكور وحده في بنود العقد قد ينصرف إلى أكثر من معنى.

ثمَّة نقطة أخرى هي أنه عند وجود نقص أو غموض أو تعارض يعتري تنظيم الأطر اف لشرط إعـادة التفاوض، لا يكون بمقدور القاضي أو المحكَّم التصدي لتحديد مضمون الشرط من تلقاء نفسه، كمـا قد يواجه القاضي أو المحكم صعوبة كبيرة في تفسير النوايا الداخلية للأطر اف وما يقصدون إليه(1)، وهو شأن طبيعي؛ لذا كانت الإشارة واجبة إلى آلية الإدراج الصحيح لهذا الشرط. وممَّا يعضِّد الطرح السابق أنَّ المفاوضات ليست سوى تبادل للتنازلات بين طرفيها، لأنَّ مقتضى ذلك أنَّ هناك نتيجة ينبغي الوصول إليها بأيِّ ثمن، وهو أمر ربما يُصيب المتعاملين في مجال التجارة الدولية بضرر بالغ، بالنظر لقيام التجارة الدولية على

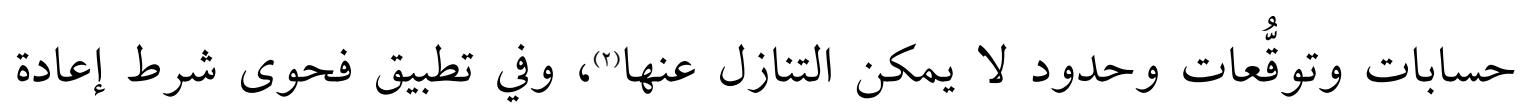
التفاوض تطبيقًا صحيحًا -حال تو افر صياغته القويمة- إنصافٌ لأطر اف عقود التجارة

(1) في العرض السابق، ولمزيد من التفاصيل، انظر م. أسيل باقر جاسم، النظام القانوني لشرط إعادة التفاوض،

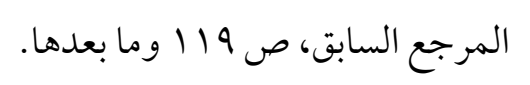

(Y) د. أحمد عبد الكريم سلامة، قانون العقد الدولي: مفاوضات العقود الدولية - القانون واجب التطبيق وأزمته،

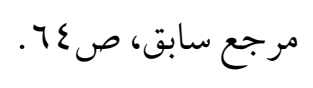


الدولية الذين تأثرت عقودهم عظيم تأثر جرَّاء الجائحة.

وفي هذا المقام تجدر الإشارة إلى أهمية إسداء النصح للأطراف المتعاقدة لأهمية

تحديد الأحداث التي يو اجهها شرط إعادة التفاوض على نحو دقيق قدر الإمكان، وإن لم يكونوا من المتخصصين في ميدان الصياغة القانونية الدقيقة من خلال الاستعانة بذوي الاختصاص في هذا الشأن؛ إذ يؤدي ذلك إلى تلافي كثير من الإشكاليات والصعوبات التي يثيرها تحديد ما إذا كان الحدث المتحقق مشمولًا بنطاق شرط إعادة التفاوض أم أنه يخرج عن نطاق الشرط المذكور.

لذا تتعين الإشارة إلى الدور المهم الذي يقوم به الممارسون القانونيِّن في صياغتهم

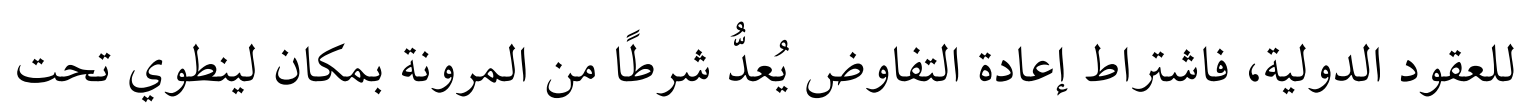
ظلاله أيٌّ عارض كان، طالما كان من شأنه التأثير على التوازن العقدي، ومن ثمَّ اختلال توازنه، ودون الحاجة للدخول في سجالات الفقه حول مدى اعتبار جائحة كورونا قوةً قاهرة أو ظرفًا طارئًا، طالما انضبطت صياغته من الأساس. وبشكل عام يُاحظ أنَّ التعبير عن اختلال التوازن عند صياغة شرط إعادة التفاوض قد يتخذ إحدى صيغتين (1):

1- الصيغة العامة: وفيه يُقِّر الأطراف اختلال التوازن باستخدام مصطلحات عامة بعض الشيء في دلالتها، ويُعبِّون من خلالها عن الأثر الذي ينتج من تغير الظروف أثناء تنفيذ العقد، وقد يستعمل الأطر اف تطبيقًا لذلك عبارة (انقلاب توازن العقد)، أو عبارة

(1) د. جميل الشرقاوي، صعوبات تنفيذ العقود الدولية، بحث مقدم إلى مؤتمر الأنظمة التعاقدية للقانون المدني

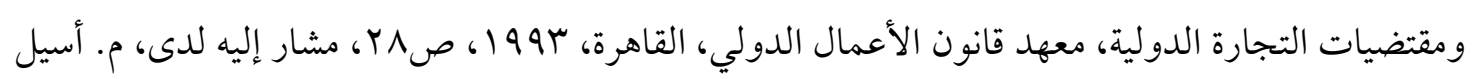

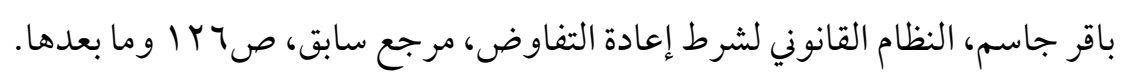


(الاختلال في اقتصاد العقد)، أو عبارة (اضطراب يغيِّ بشكل كبير التوازن الأساسي للأداءات).

وتعدُّ الصياغة عامةً كذلك إذا استعان الأطراف بمصطلحات تعبِّ عن مقدار الضرر

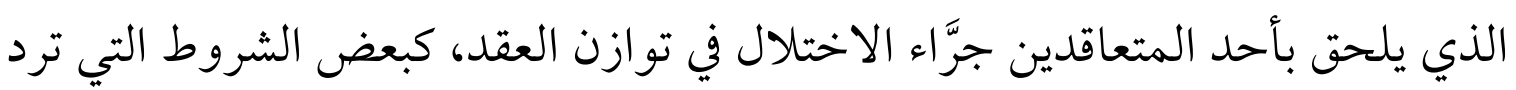

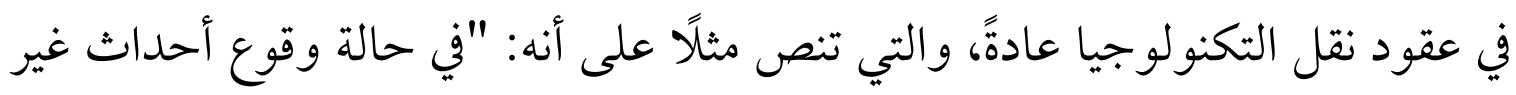
متوقعة يكون من آثارها قلب الأساس الاقتصادي للعقد مسببًا ضررًا فادحًا لأحد

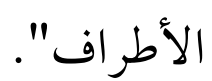

ب ب- الصيغة الخاصة: وفيها يحدد الأطراف أيّا من مسائل العقد الجوهرية هي التي

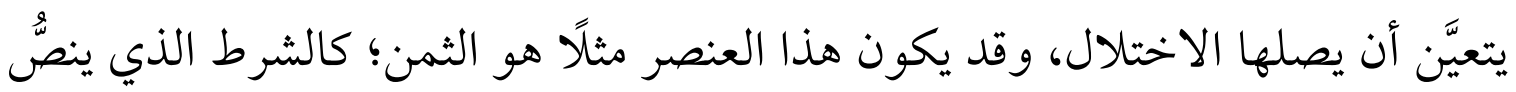
على أنه:

"إذا وقعت أحداث من شأنها ارتفاع تكلفة الحصول على النقد أو الائتمان أو

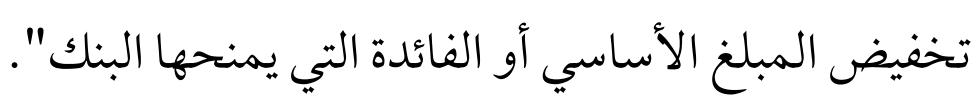
أو الشرط الذي ينصُّ على أنه:

"... إذا أدَّى التغيير إلى تحقيق عائد غير كافٍ لتغطية تكلفة الصفقة...".

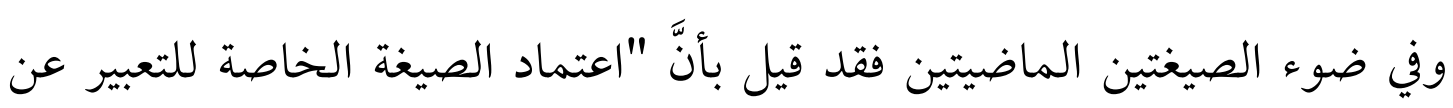

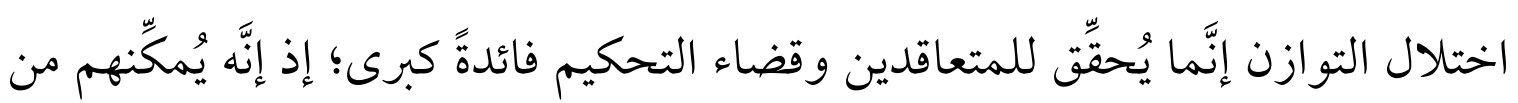
تفادي الصعوبات المتعددة التي قد تنشأ من استعمال مصطلحات عامة قد يشوبهاء

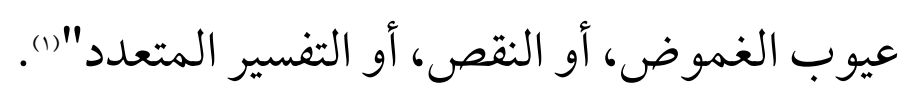
وفي الختام تجدر الإشارة إلى أنَّ الفقهاء قد أسهبو الفي في سرد النصائح لأطراف العقود

(1) في هذا الرأي انظر : المرجع السابق ذاته. 
الدولية التي تأثرت مصالحهم على خلفية جائحة كورونا كمشترٍ أو مورِّد، ولأنَّ بالأمر تفصيل لا تتسع صفحات البحث للوقوف عنده، ناهيك عن خروجه عن صميم فكرة البحث، وحرصًا على دعم الأركان العملية التطبيقية للدراسة وأخذًا بيد أطرافه صوب بيان سبل تلمُّس طرق التصدي لما أثارته الجائحة؛ كان مهمًّا تخصيص هذه الفقرة لتسليط الضوء على هذه الفكرة، ويُكتفى بما تمَّ الوقوف عنده"(1). ولأنَّ آلية الإدراج الصحيح لشرط إعادة التفاوض في عقود التجارة الدولية تُرتِب أهمية تسليط الضوء على ضوابط الكفاية الذاتية للعقد الدولي في اختزال؛ وذلك على

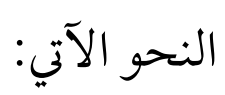

وثمَّة تساؤل مطروح بعد العرض السابق فحواه: التساؤل عن مآل العقد الدولي في الفترة التي يتمٌّ خلالها إعادة التفاوض، وهو ما ستقف عند سطور البحث القادمة. مصير العقد الدولي أثناء فترة إعادة التفاوض: من المهم لفت الانتباه إلى لزوم اتفاق الأطراف على وقف تنفيذ العقد عند إعمال شرط إعادة التفـاوض على نحوِ يتناول بدقة أبعاد هذا الوقف من ناحية مدته، والتزامات

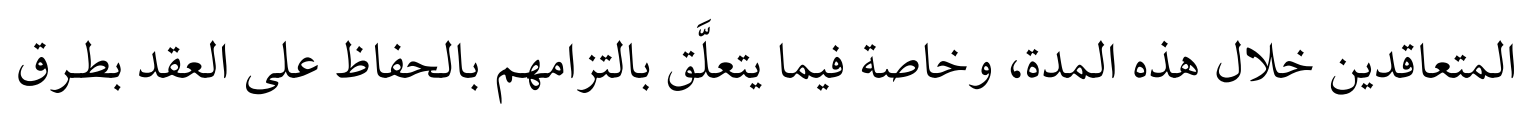
معينة، والتزامهم بالسعي لاستئناف سريان العقد (r). ويُر اد بوقف تنفيذ العقد: توقف الطرفين عن تنفيذ التزاماتهما العقدية المتبادلة لحين

(1) For more details, Claudia Galvis, Jose Moran, et al, Coronavirus Outbreak: Global Guide to Force Majeure and International Commercial Contracts, op, cit., Also, Victoria Lee, Mark Lehberg, et al, COVID-19 Contract Issues Reach Beyond Force Majeure, op, cit., (Y) وفي الأمر تفصيل لا يتسع المقام للوقوف عنده، ولمن أراد الاستزادة، م. أسيل باقر جاسم، النظام القانوني

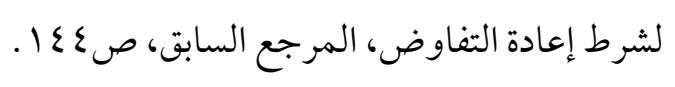


إعادة التفاوض في العقد والتوصُّل إلى اتفاق جديد لتنظيم تلك الالتزامات".. ويلاحظ أنه ما دامت هناك إمكانية لاستمرار تنفيذ العقد؛ فلا مانع من الاستمرار والمتابعة في تنفيذ عقدهم بالوضع الذي تمَّ الاتفاق عليه من قبل الأطراف، تمهيدًا لانتظار النتيجة التي سينتهي إليها شرط إعادة التفاوض.

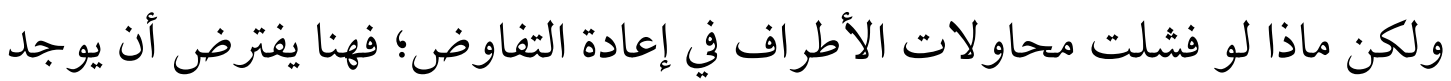

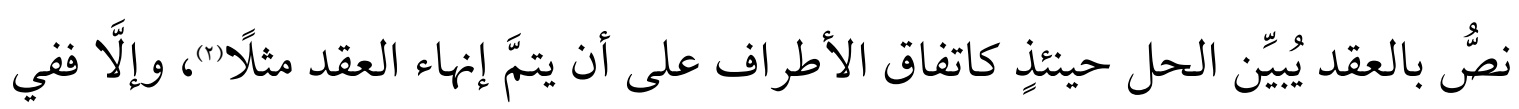
حال عدم وجود نص بالعقد يبين ذلك (وهو الأغلب)؛ فالمفترض حينئذ أن تكون السلطة تقديرية للقاضي في هذا الخصوص. الغصن الثاني

\section{تمييز إعادة التفاوض عن القوة القاهرة والظروف الطارئة}

يلحق بيان أبعاد ماهية شرط إعادة التفاوض تخصيص شطر آخر للوقوف عند

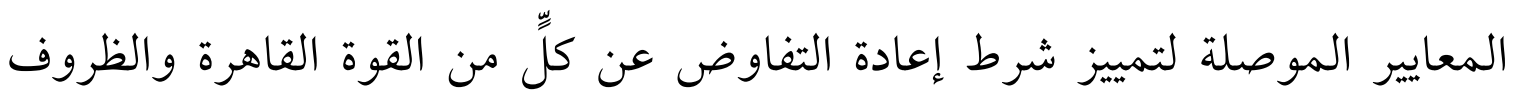

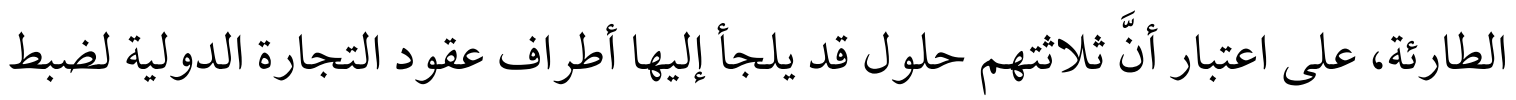

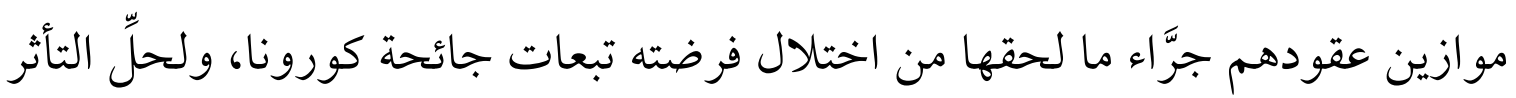

(1) د. محمد نصر الدين منصور، نحو نظام قانوني لوقف عقود العاملين، دار النهضة العربية، القاهرة، 919 19،

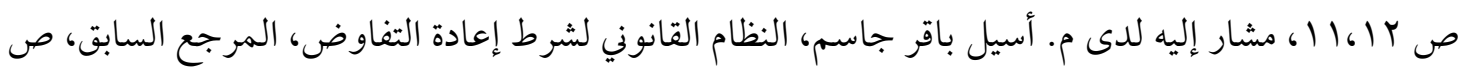

(Y) فها هي غرفة التجارة الدولية تعلن مؤخرًا أنه يجوز أن يتفق طرفا العقد صر احة على أنه يجوز أن يتَّم إنهاء العقد

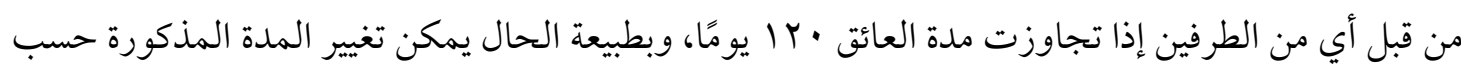

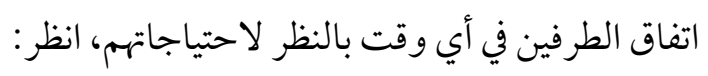
ICC FORCE MAJEURE CLAUSE (“Clause”), Issued by International Chamber of Commerce, op, cit., p. 3. 
الذي حلَّ بعقو دهم خُصِّص هذا المقام، على ما سيأتي بيانه".

\section{أولًا: إعادة الثفاوض والقوة القاهرة:}

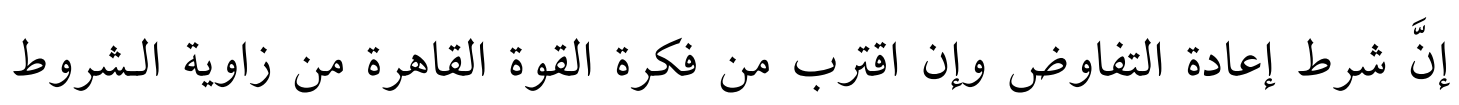

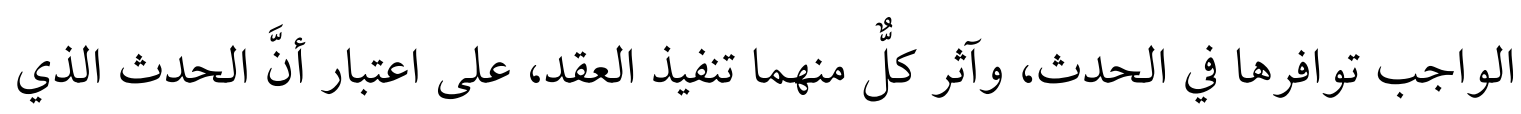

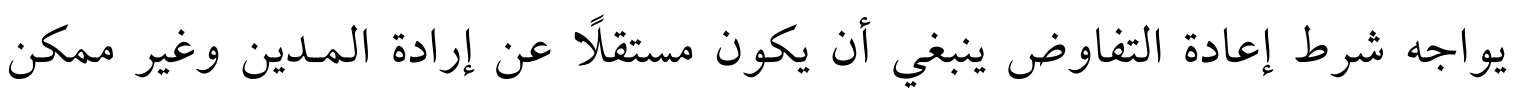

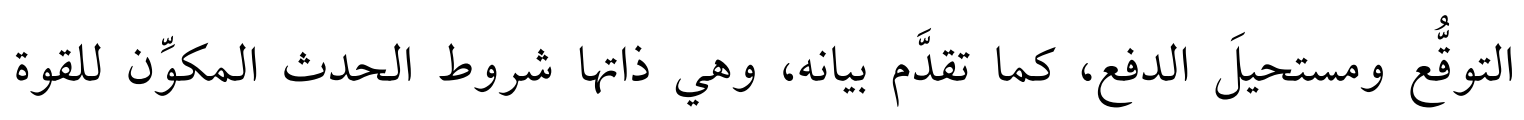

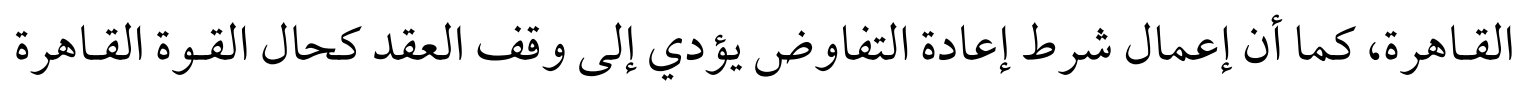

إذا كانت مؤقتَّة.

وإجمالًا: يتم إعمال نظرية القوة القاهرة في مجال العقود الدولية وفق مفهومها

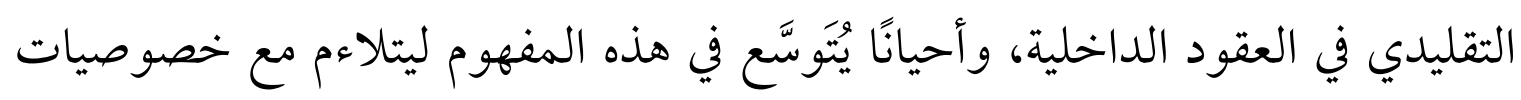

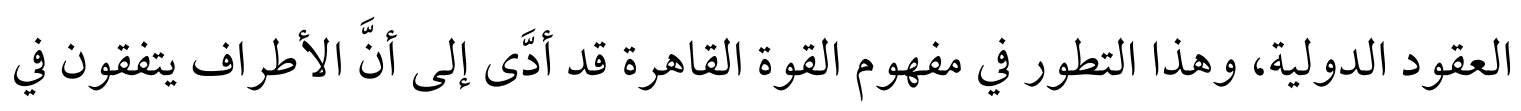
الغالب عند تحقق شروط القوة القاهرة على إعادة التفاوض حول العقد بهدف تعديله،

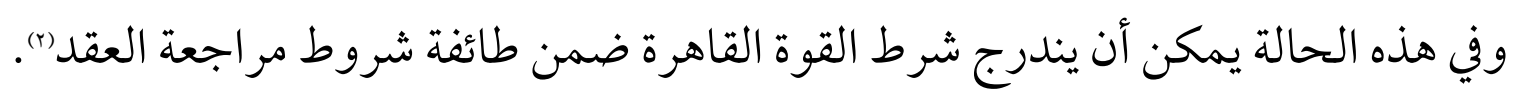

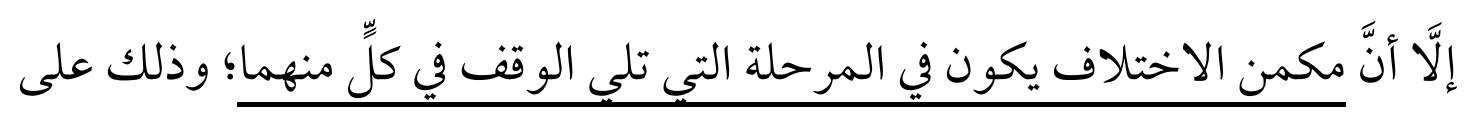
ما يأتي:

- بالنسبة لإعمال شرط إعادة التفاوض: يَعقبُ الوقف أن يُعاد التفاوض في العقد بهدف تعديله.

(1) على أن يخصص بالدراسة شطرًا آخر لباقي هذه الحلول غير الثلاثة المذكورين في موضع لاحق.

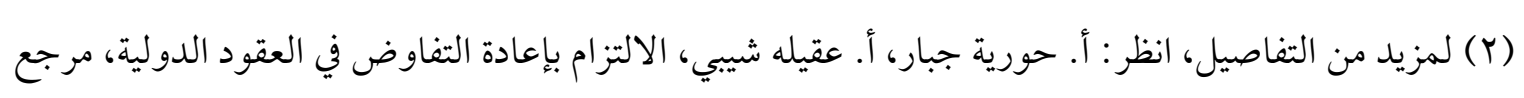

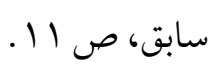


- بالنسبة لإعمال القوة القاهرة: يَعقبُ الوقف تنفيذ العقد ببنوده وشروطه نفسها. كما يمكن التمييز بين شرط إعادة التفاوض والقوة القاهرة من بعض الزوايا؛ كالأساس القانوني لكلٍ منهما، ودرجة التأثير على تنفيذ العقد، وكذا التمييز بينهما من

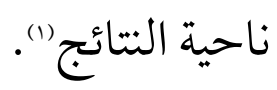

وما دمنا في هذا السياق فتجدر الإشارة إلى موقف مبادئ اليونيدروا من العلاقة بين شرط إعادة التفاوض والقوة القاهرة؛ إذ سمحت المادة (T/ / / / للطرف المتضرر جرَّاء القوة القاهرة أن يطلب إعادة التفاوض، مع العلم أنَّهذه المبادئ أفادت بأنَّ طلب إعادة التفاوض في حدِّ ذاته لا يُخِّول الطرف المحروم وقف الأداء، وفي حال عدم التوصل إلى اتفاق في غضون فترة زمنية معقولة يجوز لأيٍّ من الطرفين اللجوء إلى المحكمة، وإذا وجدت المحكمة صعوبة فيجوز لها -إذا كان ذلك معقولًا ما يأتي:

$$
\begin{aligned}
& \text { (أ) إنهاء العقد في تاريخ معيَّن ويشروط يتم تحديدها، أو .. } \\
& \text { (ب) تكييف العقد بهدف استعادة توازنه(r). }
\end{aligned}
$$

وبناءً عليه يتجلَّى ممَّا مضى أنَّ القوة القاهرة هي الحدث الذي يؤدِّي إلى استحالة تنفيذ الالتزام مؤقتًا أو أبديَّا، جزئيّا أو كليّّا؛ بينما الحدث الذي يعطينا إعادة التفاوض لا لا يؤدي بالضرورة إلى استحالة في تنفيذ الالتزام التعاقدي، بل يؤدي إلى اختلال التوازن العقدي أو إلى صيرورة تنفيذ العقد مرهقًا أو أكثر تكلفة؛ أي إنَّ شرط إعادة التفاوض إِ

(1) (1) ( الموضع السابق ذاته.

(2) For more details, Sonja Adrienne Kruisinga, (Non-) conformity in the 1980 UN Convention on Contracts for the International Sale of Goods: op, cit., p. 150.

وللاطلاع على النص الرسمي الكامل لليونيدروا باللغة الإنجليزية، يمكن زيارة الرابط الإلكتروني الرسمي التالي: See at, https://www.unidroit.org/instruments/commercial-contracts/unidroit-principles-2016 , Last visit on 30/6/2020. 
من شأنه التزام جميع الأطراف التعاقدية بإعادة التفاوض والمناقشة حول بنود العقد التي تسبَّت في هذا الإرهاق أو الاختلال العقدي، خصوصًا وأنَّ الأطراف يقفون في مثل هذه العقود على قدم المساواةة). (1).

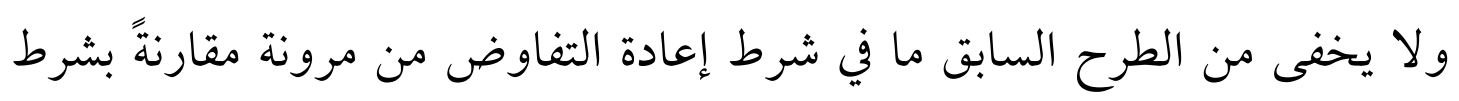

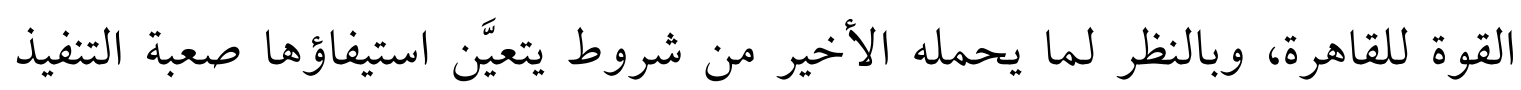

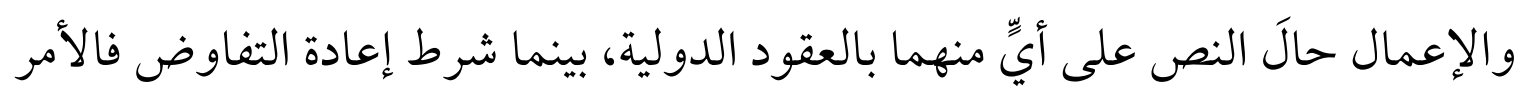

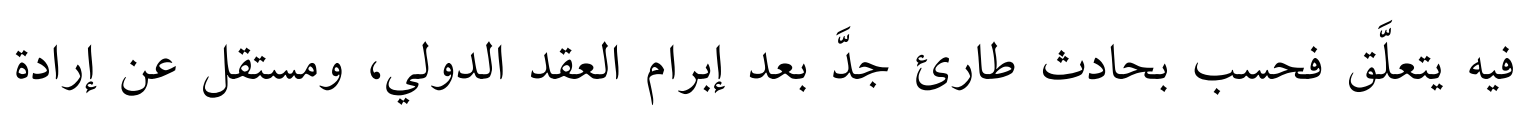
الأطراف، وأدَّى إلى حدوث اختلال بتوازن العقد بدون أن نتحدث عن استحالة التنفيذ المطلقة كما في القوة القاهرة"(r).

\section{ثانيًا: إعادة التفاوض والظروف الطارئة:}

يكمن وجه الشبه بين شرط إعادة التفاوض ونظرية الظروف الطارئة في درجة تأثير

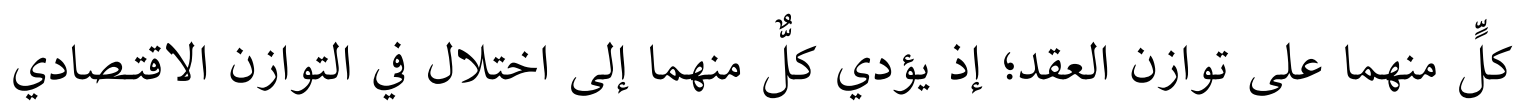

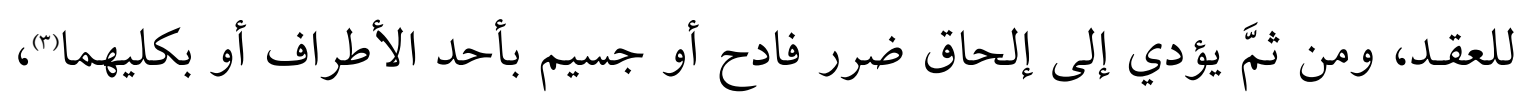
ويُستنَج مما سبق وجود تقارب بين الظروف الطارئة وشرط إعادة التفاوض.

(1) د. أحمد عبد الحميد عشوش، قانون العقد بين ثبات اليقين واعتبارات العدالة، مؤسسة شباب الجامعة،

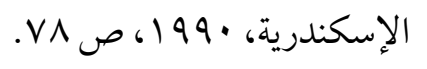

(Y) في هذا التأصيل السابق، راجع كلمة د. سمير أوخليفا، ندوة افتراضية بعنوان الآثار القانونية لفيروس كورونا

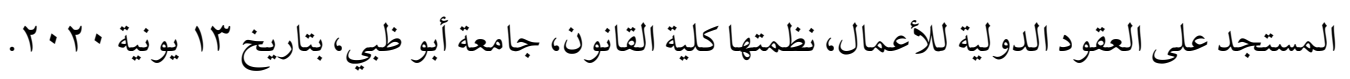

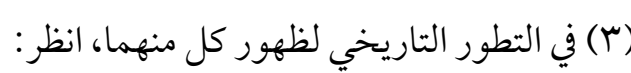

Marcel Fontaine, The evaluation of the Rules on Hardship from the First Study on Hardship Clauses to the Enactment of specific Rules, op, ci., Ch. 1. 


\section{وبالنظر لما بينهما من اختلاف فهي كما يأتي:}

- بالنسبة للظروف الطارئة: فمتى تو افرت الشروط التي مضى بيانها في خصو صها يجوز

للقاضي إمَّا أن ينقص أو يزيد من التزامات أحد الأطراف.

- بالنسبة لشرط إعادة التفاوض: فيكون باتفاق الأطراف؛ نظرًا لكون العقود الدولية

تحتاج إلى مدة أطول لتنفيذها، والظروف التي تعترضها تعيق الاستمرار في تنفيذ

العقد، فيضع الأطراف هذا الشرط لتجنب اللجوء إلى القضاء.

وبناء عليه تختلف نظرية الظروف الطارئة عن الالتزام بإعادة التفاوض في أساسها القانوني؛ ذلك أنَّ تقريرها يتمّ بالاستناد إلى نصِّ قانوني، أمَّا إعادة التفاوض -كما قلنا سابقًا- فأساسه اتفاقيٌّ؛ حيث يندرج في إطار المبدأ الذي يحكم العقود الدولية بصفة عامة، وهو مبدأ المحافظة على العقد وإبقاء العلاقة العقدية مستمرة، ولهذا قلَّما يتفق الأطراف في هذه العقود على إنهاء العقد أو فسخه بسبب تغير الظروف، بل يلجؤون لمثل هذه الحلول الاتفاقية)

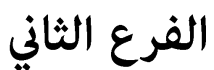

شروط إعادة التفاوض وآثاره ومعايير اختلال توازن عقود الثان

\section{التجارة الدولية في ضوء جائحة كورونا}

إنَّ الحديث عن مدى اتفاق شروط إعادة التفاوض في عقود التجارة الدولية يُعِّزّه البحث عن مدى اتفاق مثل هذه الشروط مع ما أثَّرت به جائحة كورونا على عقود التجارة

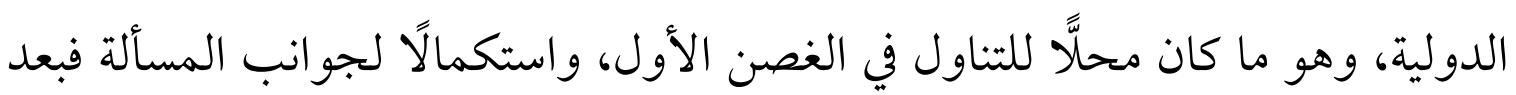

(1) لمزيد من التفاصيل، انظر : أ. حورية جبار، أ. عقيله شيبي، الالتزام بإعادة الثفاوض في العقود الدولية، مرجع

$$
\text { سابق، ص با ا وما بعدها. }
$$


بيان ثمرات هذا الإنزال أُفرِد غصن تالٍ للحديث عن معايير اختلال التوازن العقدي في عموم القول تسليطًا على معطيات فيروس كورونا من زاوية أخرى.

\section{الغصن الأول}

\section{شروط إعمال إعادة التفاوض في عقود التجارة الدولية في ضوء جائحة كورونا}

يمتد نطاق شرط إعادة التفاوض ليشمل من الأحداث ما توافرت فيه تلك الشروط

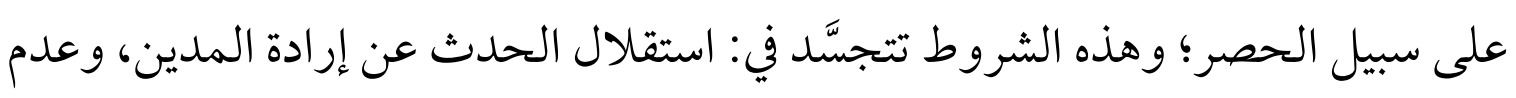
إمكان توقع الحدث، وعدم إمكان دفعه وتجنب نتائجه الضارة"). وبناء عليه فهناك من قسَّم شروط إعادة التفاوض في العقود الدولية إلى نوعين: شروط خاصة بالحادث (عمومية الحادث واستثنائيته، وشرط اختلال توازن العقد)، وشروط خاصة بالمدين: (شرط عدم توقع الحدث، واستقلال الحدث عن إرادة الطرف)(").

وإجمالًا فإذا كان تغيير الظروف الذي كان غير متوقعًا في وقت إبرام العقد، وعلى نحو يجعل أداء الالتزام باهظً التكلفة بالنسبة لطرف لم يوافق على تحمل مخاطره؛ فهنا يجوز لهذا الطرف أن يطلب من الطرف المتعاقد معه إعادة التفاوض بشأن العقد،

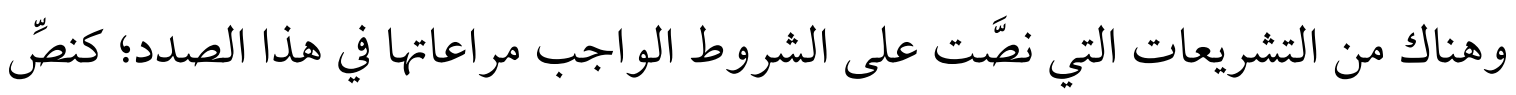
المادة 190 المن القانون المدني الفرنسي، والتي تفترض استيفاء ثلاثة شروط؛ هي:

(1) في شرح هذه الشروط، م. أسيل باقر جاسم، النظام القانوني لشرط إعادة التفاوض، المرجع السابق، ص 119 وما بعدها. (r) لمزيد من التفاصيل، انظر: أ. حورية جبار، أ. عقيله شيبي، الالتزام بإعادة التفاوض في العقود الدولية، مرجع

$$
\text { سابق، ص } 10 \text { وما بعدها. }
$$




$$
\text { - - - مجا يجعل تغيير في الظروف (تغيير غير متوقع في وقت إبرام العقد)؛ }
$$

وإذا تمَّ استيفاء هذه الشروط، يمكن أن يبدأ الطرف في إعادة التفاوض على العقد'. .

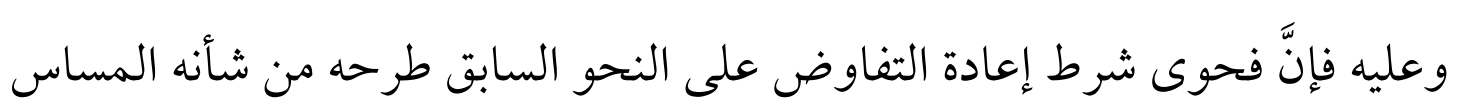
بالقوة الملزمة للعقد، ولقد استتبع هذا المساس أهمية تخصيص شطر من البحث لهذه المسألة على ما سيأتي بيانه.

\section{شر ط إعادة التفاوض و القوة الملزمة للعقد:}

على الرغم من القوة الملزمة للعقد المنصوص عليها في عديد من التشريعات(()، التي

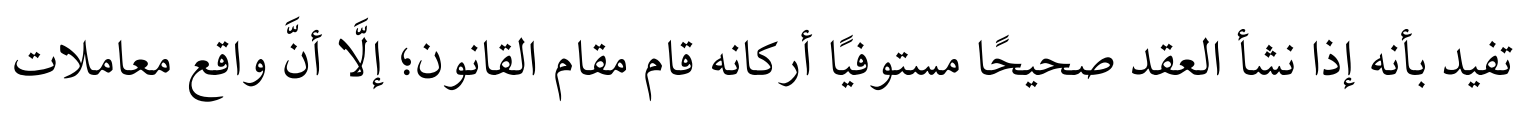
التجارة الدولية سرعان ما أثبت أنَّه يمكن أن يؤدي تبرير الإخفاق في أداء التزاماته إلى إلى إعادة التفاوض على شروط العقد في بعض الحالات التي ينصُّ عليها القانون.

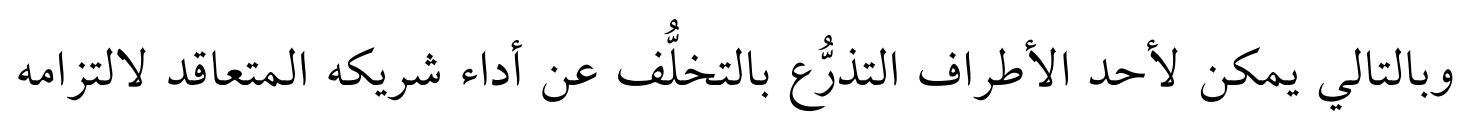
التعاقدي المنصوص عليه بالعقد المبرَمَ بينهما لاستحالة الوفاء به؛ نظرًا لحدوث ظروف معينة تقف بمثابة العقبات التي تواجه المدين ولا يمكنه التغلب عليها، وعلى نحو قد يُمكِّه لاحقًا من التذرع بالقوة القاهرة ليعفي نفسه من كلّ مسؤوليته التعاقدية أو جزء منها، على نحو ما تمَّ بيانه من ناحية، أو قد يُمَحح بإعادة التفاوض على شروط

(1) Olivier Kuhn, Hassan Ben Hamadi, Covid-19 and contract Renegotiation: Q\&A, op, cit., (Y) لمن أراد الاستزادة عن المبدأ انظر: د. محمد على البدوي الأزهري، النظرية العامة للالتزام، مرجع سابق، ص.r. 
العقد بالنظر لعدم القدرة على التنبؤ في ظلّ الظروف التي كانت سائدة وقت إبرام العقد (1).

وطالما تطرَّق الحديث لبيان العلاقة بين شرط إعادة التفاوض و القوة الملزمة للعقد؛ فالإشارة مهمَّة إلى ما بين شرط إعادة التفاوض ومبدأ سلطان الإرادة؛ إذ تخضع العقود الدولية لمبدأ سلطان الإرادة، وهو مبدأ مُستقَر عليه في مجال العقود عمومًا (م)، وله مفاهيم معينة في سياق العقود الدولية(r)، ويعني المبدأ قدرة الإرادة الذاتية على خلق القواعد التي تحكمها، أو قدرة المتعاقدين على خلق قانونهم الخاص(s). و انطلاقًا من مبدأ سلطان الإرادة- يتم وقف تنفيذ العقد مؤقتًا لإعادة التفاوض حول تلك الشروط التي أخلَّت بتنفيذ العقد؛ إذ يستمد الالتزام بإعادة التفاوض في العقود الدولية قوَّته الإلزامية بالدرجة الأولى من إرادة الأطراف تجسيدًا لمبدأ سلطان

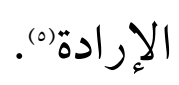

وبذا فإن مبدأ سلطان الإرادة يعتمد على خلق قواعد قانونية وإن كانت فردية؛ على

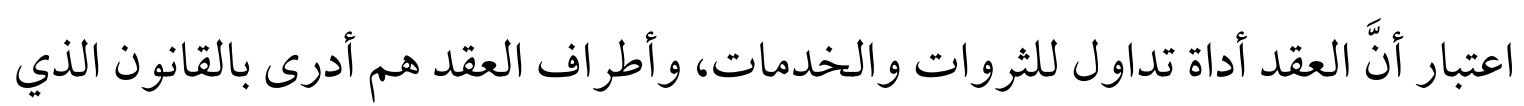

(1) Constance Verroust-Valliot et Serge Pelletier, L'impact du covid-19 sur les contrats de droit privé, op, cit.,

(Y) د. أشرف وفا محمد، الوسيط في القانون الدولي الخاص: المبادئ العامة لثنازع القوانين في القانون المقارن، وقواعد الإسناد في القانون المصري - قواعد الاختصاص القضائي - آثار الأحكام الأجنبية، دار النهضئ

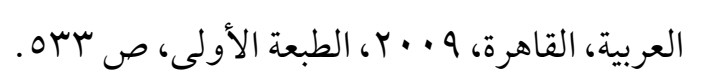

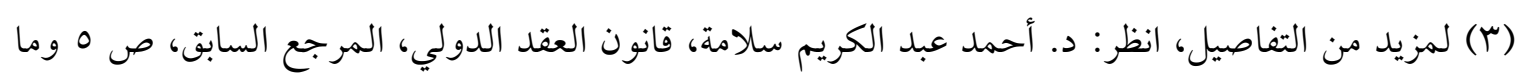
بعدها.

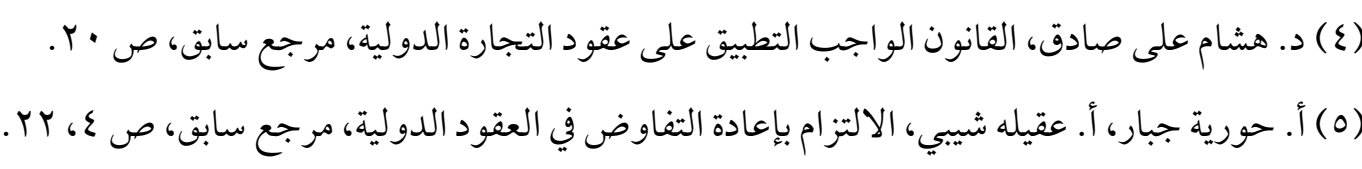


يُعرقل ذلك التداول من عدمه، ولا سيما أنَّ هناك قوانين متقدِّمة لبعض الدول في مجال تنظيم عمليات التجارة، بينما تو جد قوانين للبعض الآخر من الدول لا تزال بدائية؛ كونها لا تصلح إلَّا للمبادلات الزراعية والتجارية المتو اضعة، ومهما وُجِّه لهذا المبدأ من نقد فسيظل قانون الإرادة أو القانون الذي تشير إليه إرادة المتعاقدين هو الوسيلة الخالدة ذات التاريخ (1) والأصل في شأن الجوانب الموضوعية لعقود التجارة الدولية(r)، وسيظل المجال المعتاد للأخذ بقانون إرادة المتعاقدين هو الالتزامات التعاقدية(r). ولقد ترتّبَ على تقديس حرية التعاقد ومبدأ سلطان الإرادة وفقًا لهذه الأفكار أن أصبح من حقِّ المتعاقدين أن يُضمّنِ اعقودهم ما شاءوا من الشروط -بما فيها شرط إعادة التفاوض الذي يجد في عقود التجارة الدولية مجالًا خصبًا لتطبيقه- بل أصبح من حقّ الأطراف في العقود الدولية أن يختاروا قانون الدولة الذي يرونه أكثر تعبيرًا عن مصالحهم المشتركة لينظم الرابطة التعاقدية؛ وبالتالي يترتب على هذا الاختيار الذي يقوم على مطلق سلطان الإرادة أن يندمج القانون المختار في العقد لتصبح أحكامه مجرد شروط تعاقدية ارتضاها المتعاقدون().

(1) في تاريخ هذه القاعدة والدول التي تطبقه، انظر: د. جابر جاد عبد الرحمن، تنازع القوانين، مكتبة النهضة

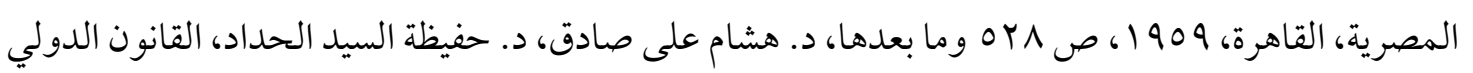

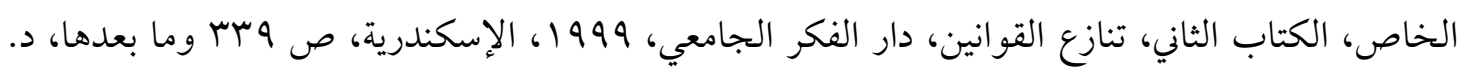

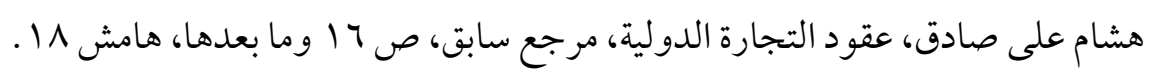

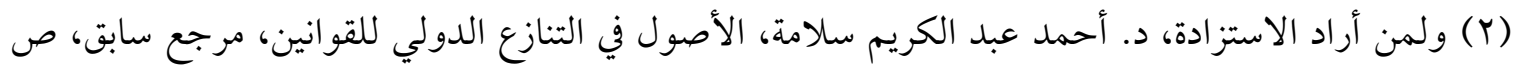

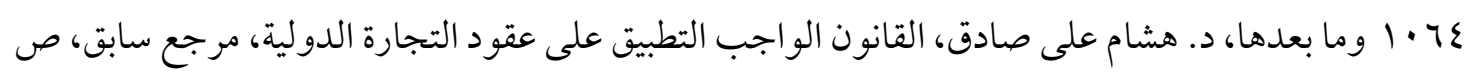

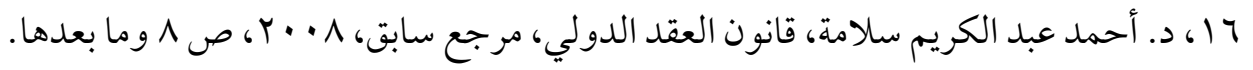

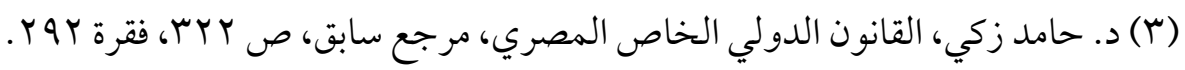

$$
\begin{aligned}
& \text { ( ) ) د. هشام على صادق، القانون الواجب التطبيق على عقو التجارة الدولية، مرجع سابق، ص صـ } 91 .
\end{aligned}
$$


وحريٌّ بالذّّكر أنَّ فقه القانون الدولي الخاص الغالب قد استقَّ على أن تطبيق قانون الإرادة على هذا النحو -كقانون أشارت إليه إرادة المتعاقدين - يقتصر على الجانب الموضوعي للعقد، وبهذه المثابة ينطبق قانون الإرادة على كلّ ما يتعلَّق بتكوين العقد وشروط انعقاده الموضوعية؛ مثل : التراضي و المحل والسبب، كما ينطبق هذا القانون أيضًا- على آثار العقد، سواء تعلقت هذه الآثار بالأشخاص أو بالموضوع، وبصفة خاصَّة على ما يُرتبّه العقد من التزامات متبادلة بين أطرافه، وجزاء مخالفة هذه الالتز امات، وما تثيره هذه المخالفة من مسئولية عقدية'). وبناءً عليه: فإنَّ الالتزامات التعاقدية هي النطاق الطبيعي للأخذ بقانون إرادة المتعاقدين، وأساس تطبيق هذا القانون هو وجوب احترام إرادة المتعاقدين حسبما هو مقرَّر في مبدأ كفاية الإرادة؛ فقانون الإرادة هو القانون الواجب التطبيق في هذا الصدد، سواء أكان أجنبيًّ أم وطنيّا؛ فالمشرع قد حمى الأشخاص بتطبيق قانون جنسيتهم على أحو الهم الشخصية والعائلة، وحمى ثرواتهم بتطبيق قانون المال على أمو الهم، وحمى أرواحهم ومصالحهم بتطبيق القانون المحلي، وعلى المنوال نفسه فقد حمى المشرّع إرادتهم واحترمها عن طريق أخذه بالقانون الذي يختارونه لتنظيم الآثار المترتبة على عقودهم؛ أي التزاماتهم التعاقدية(r).

وهنا تبرز أهمية الإشارة إلى الحاجة إلى صيغة توطّد العلاقة بين "سلطان الإرادة" و "إر ادة السلطان"؛ حيث يتمّ الجمع بين المشروع التعاقدي المشترك بمبادئه الأخلاقية

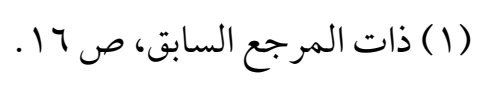

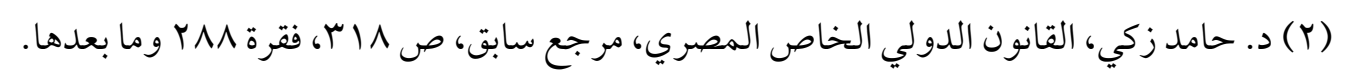


وضوابطه التنظيمية من جهة ودور الدولة الملاذ الأمن للجماعة البشرية في تنظيم تعاملاتها المتنوعة؛ فلابد إذن من مقاربة "حكيمة" تضمن للعلاقة التعاقدية "التوازن"؛ وللوفاء بالعهود و الالتزامات؛ حيث تتضاعف أهمية ذلك في الأزمنة الاستثنائية شديدة القساوة والحساسية التي يتداخل فيها الفكر القانوني مع الاعتبارات الإنسانية و المججتمعية (1)

ولا مراء في أنَّ المعطيات التي أتت به جائحة كورونا بل والالتزامات التي خلَّفتها تتفق في شقِّ كبير منها مع الضو ابط التي يتمٌّ الحديث عنها، بل ربما تحضُّ على الحاجة الته

الآثار المتتبة على توافر شرط إعادة التفاوض:

يلحق بييان مدى انطباق هذه الشروط على جائحة كورونا أهمية الحديث عن الآثار المترتبة على إعمال شرط إعادة التفاوض؛ فمتى تو افرت في الحدث الشروط التي مضى

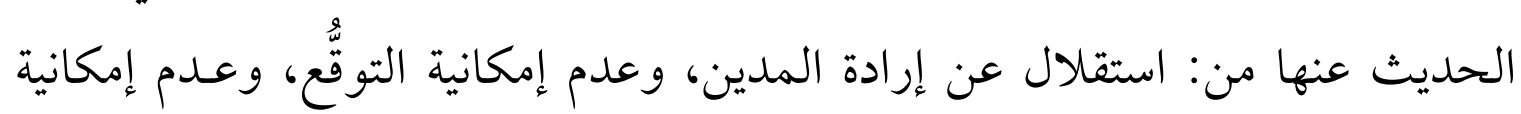

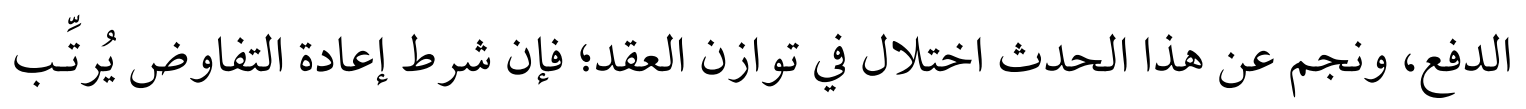
آثاره المتمثلة في: وقف تنفيذ الأطراف التزاماتهم العقديـة، والشروع في إعادة التفاوض في العقد تبعًا للمتغيرات الجديدة؛ بغية التوصل إلى اتفاق جديد حسب قو اعـد محلَّدة

$$
\text { تحكم عملية التفاوض. }
$$

(1) د. محمود المغربي، د. بلال صنديد، التكييف القانوني للجائحة "الكورونية" على ضوء الثوابت الدستورية

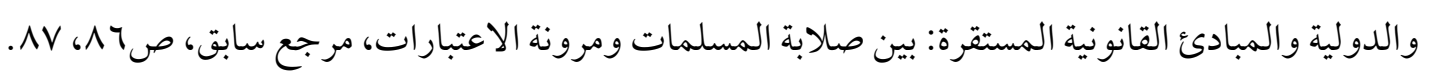

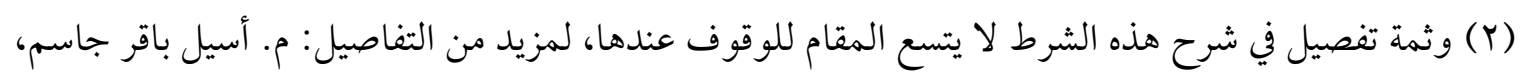

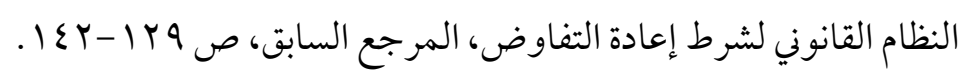




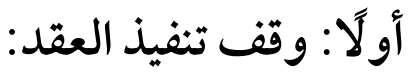

إنَّ الأساس القانوني لنظام وقف تنفيذ العقد -عند إعمال شرط إعادة التفاوض -

يمتثَّل لأكثر من أساس قانوني؛ فهذا الأخير يعتمد في تنظيمه على إرادة الأطر اف؛ أي إنَّ وقف تنفيذ العقد كأثر لشرط إعادة التفاوض يستند كذلك إلى إرادة الأطر اف وبحسب ما اتفقو اعليه من شروط تعاقدية، وفي الأغلب الأعم يتمّ الاتفاق على وقف تنفيذ العقد فترة من الزمن بعد وقوع الحدث لحين إعادة التفاوض في العقد والتوصل إلى اتفاق جديد، وينطبق نظام الوقف بعد وقوع الحدث في الفترة التي تسبق عملية التفاوض، كما ينطبق كذلك أثناء عملية التفاوض ذاتها'(')

وتجدر الإشارة في هذا المقام إلى موقف مبادئ (اليونيدروا) من نظام وقف تنفيذ العقد، والذي تنصُّ المادة (T/ / / / / ) منه على أنَّه: "لا يُخِّول طلبُ إعادة التفاوض، في حدِّ ذاته، الطرفَ الذي اختلَّ التزامه بالحدث الحقَّ في التوقف عن التنفيذ، بل يجب تنظيم ذلك بنص صريح" ل(r). ومفاد النص أعلاه: أنَّ طلب إعادة التفاوض لا يمنح المتعاقد المضرور حقَّ التوقف عن تنفيذ التزاماته مباشرة، بل إن عليه الاستمرار في التنفيذ، إلَّا إذا وجد اتفاق صريح يُخوِّل المضرور حقَّ التوقف الفوري عن تنفيذ الالتزامات وبمجرد وقوع

(1) د. محمود سمير الشرقاوي، الالتزام بالتسليم في عقد البيع الدولي للبضائع، مجلة القانون والاقتصاد، السنة

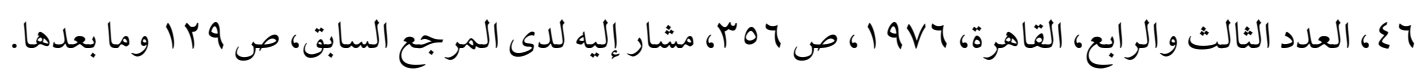

(2) "The request for renegotiation does not in itself entitle the disadvantaged party to withhold performance",

See at, https://www.unidroit.org/instruments/commercial-contracts/unidroit-principles-2010/403-chapter-6performance-section-2-hardship/1057-article-6-2-3-effects-of-hardship , Last visit on 24/7/2020. 
الحدث، كما تشير بعض الشروط النموذجية التي أعدَّهها غرفة التجارة الدولية إلى الأخذ بنظام وقف تنفيذ العقد عند إعادة التفاوض فيه(1). من جانب آخر فإنَّ قضاء التحكيم في ميدان التجارة الدولية يميل إلى الأخذ بنظام وقف تنفيذ العقد حفاظًا عليه أيَّا كانت طبيعة الأحداث التي تُعيق التنفيذ؛ وذلك إيمانًا منهم بخطورة عقود التجارة الدولية وأهميتها وفداحة الخسائر التي تنجم عن إنهاء تلك العقود قبل إتمام تنفيذها)

\section{ثانيًا: الالتزام بإعادة التفاوض:}

إذا وقع الحدث المبرِّ لإعمال شرط إعادة التفاوض؛ فإن الالتزام الرئيس الذي يفرضه هذا الشرط هو إعادة التفاوض في العقد من قبل الأطر اف؛ فإعادة التفاوض هي الخصيصة الأساسية للنظام القانوني للشرط، وهو الأثر المباشر الذي يترتّب على

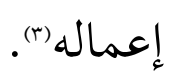

\section{الغصن الثاني}

\section{معايير تقدير اختلال التوازن العقدي وفروضه بالنظر لجائحة كورونا تمهيدٌ وتقسيمٌٌ:}

ثمَّة معيارين أحدهما موضوعيٌّ والآخر شخصيٌّ يُعوَّل عليهما بغرض تقصِّي مقدار اختلال التوازن العقدي، وستقف الدراسة عند كلا المعيارين وما يتصل بهما من أمور

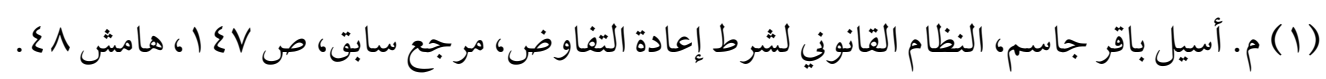

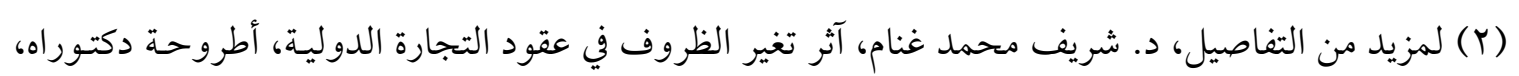

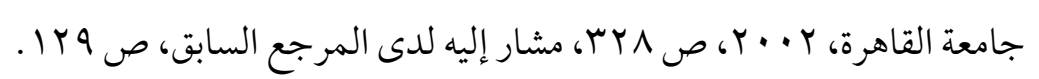

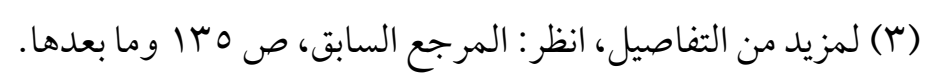


في هذا الغصن، ثمَّ يُنطلق من المعيارين لبيان مدى اعتبار جائحة كورونا حدثًا يؤدِّي إلى اختلال التوازن العقدي من عدمه، واختتامًا بييان فروض شرط إعادة التفاوض من منظور اتفاق الأطراف من عدمه.

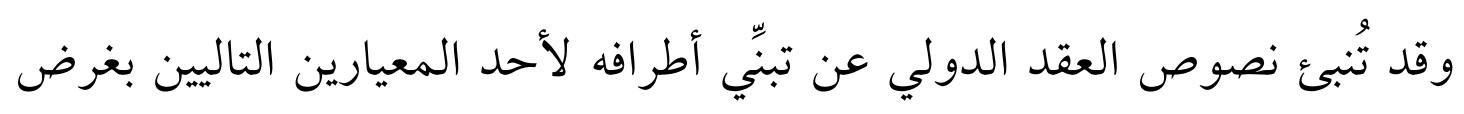

تحديد الاختلال على ما يأتي"):

أولًا: المعيار الموضوعي:

وفيه يتبنَّى المتعاقدون فكرة الاتفاق على قياس الاختلال وفقًا لمعيار الشخص

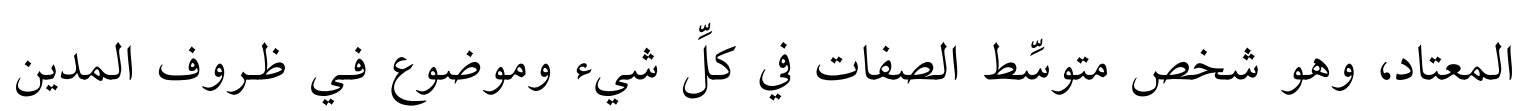

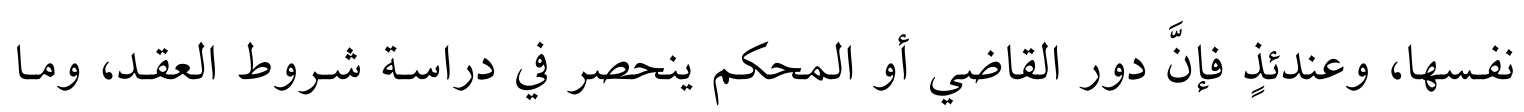

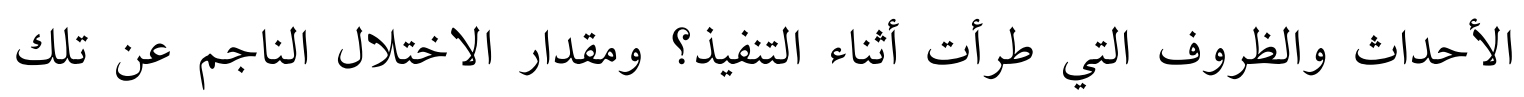
الأحداث وفقًا لما يستطيع أن يتحمله الشخص المعتاد الموضوع في ظروف المدين نفسها. وفي خصوص فيروس كورونا يجب أن تكون إعادة التفاوض على العقد محلَّ طلب

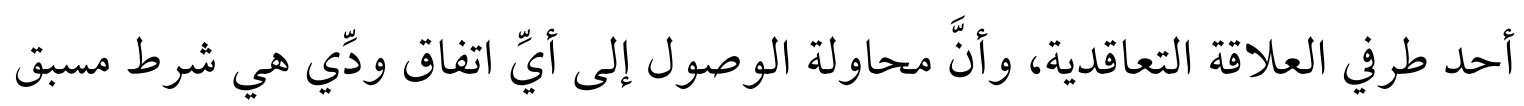

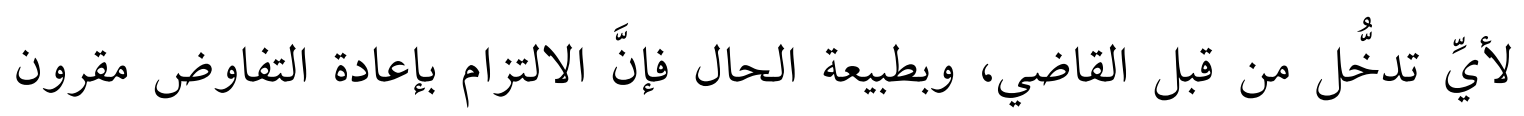

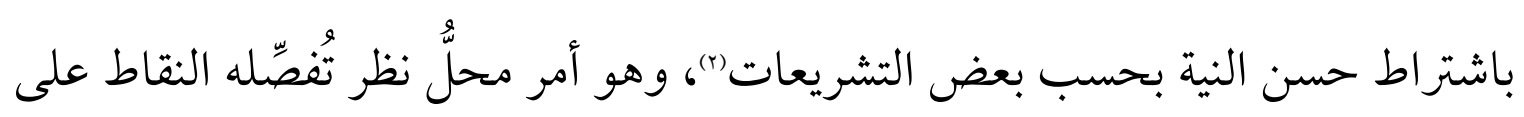
ما يأتي:

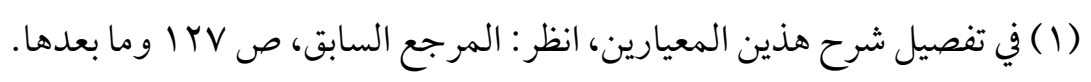

(2) Constance Verroust-Valliot et Serge Pelletier, L'impact du covid-19 sur les contrats de droit privé, op, cit., 


\section{(1) مدى جواز التذرع بحُسن النية، ولأيِّ قانون تخضع:}

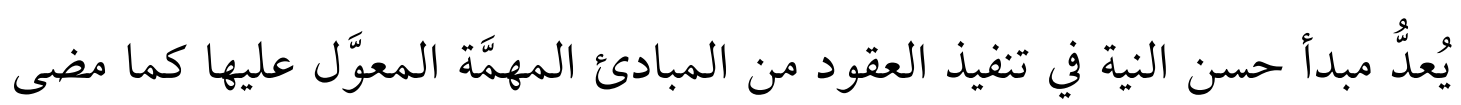

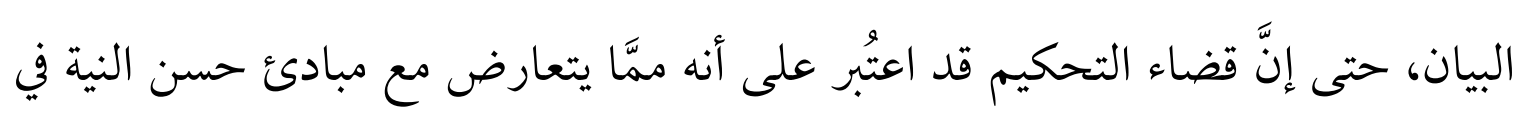

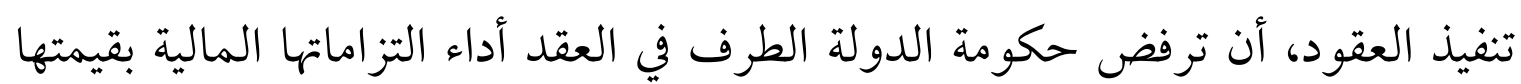

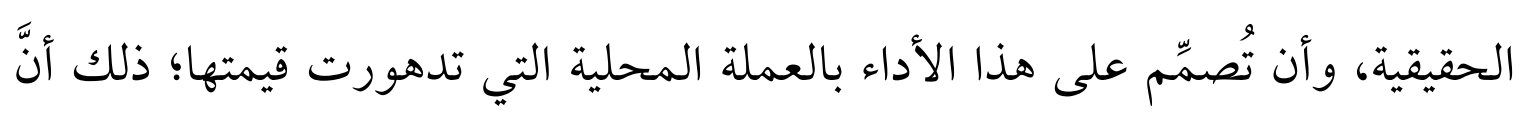

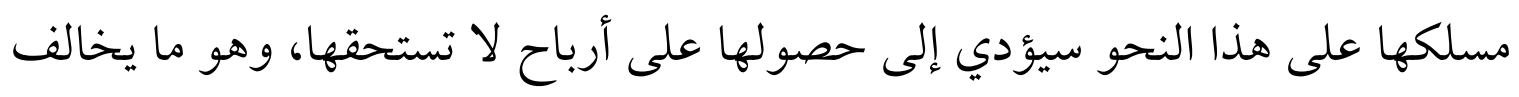
مبادئ حسن النية في تنفيذ العقود"(1).

وهنا يثور التساؤل: هل يمكن لأيِّ من المتعاقدين أن يتذرَّع بحسن نيته ليتفادى تنفيذ

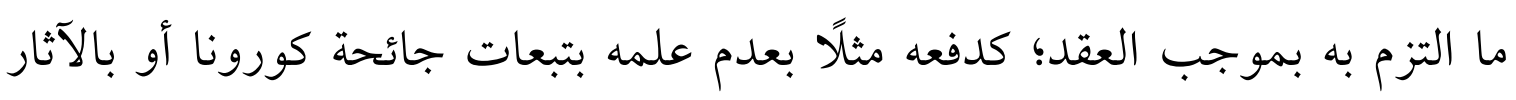
الناجمة عنها؟

ويبدو أن الجواب على التساؤل السابق مرتبط بمدى توقُع حدوث مثل هذه الأوبئة -وتحديدًا جائحة كورونا- من قبل الطرفين، وبشكل عام يخضع مضمون حسن النية في الالتزامات التعاقدية لقانون العقد كغيره من عديد الأمور (r).

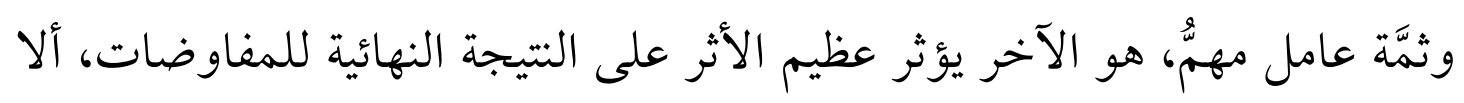

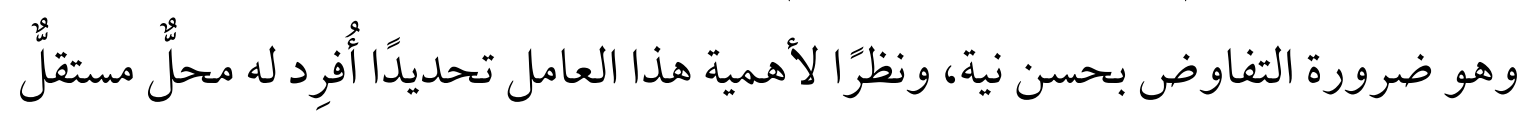
بالدراسة.

\section{(Y) ( أبعاد إعادة تفاوض المتعاقد بحسن نية:}

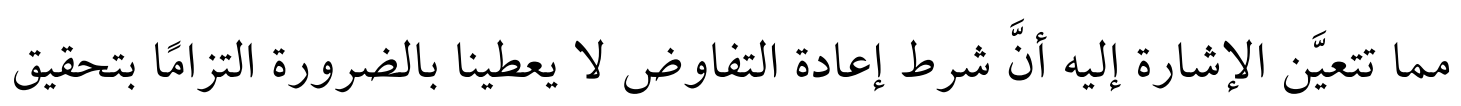

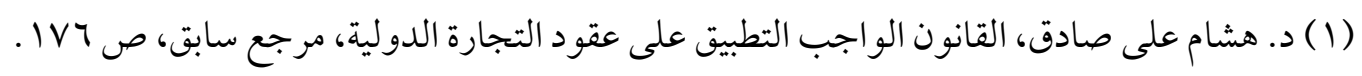

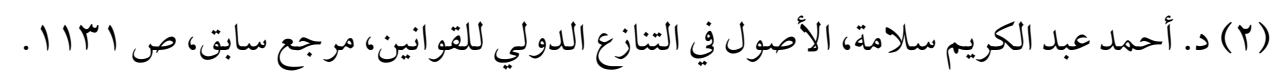


نتيجة بل التزامًا ببذل عناية فحسب، ولكن ما المراد بالتفاوض بحسن نية؟ وهو ما يُجاب عنه بأنَّ التفاوض بحسن نية يعني: القيام بما يلزم أثناء عملية التفاوض من أجل تعديل البند أو البنود التي اختّلت في العقد.

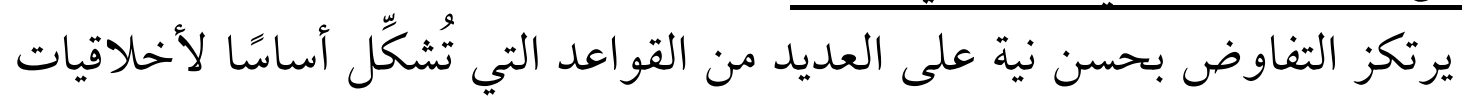

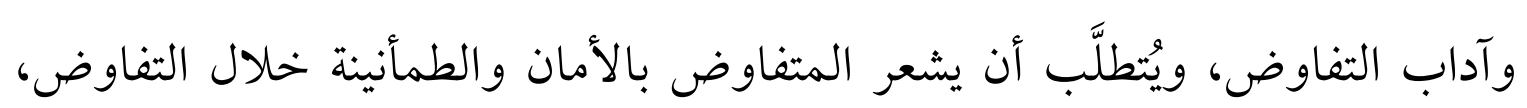
خاصَّةً وأنَّ التفاوض في هذا المجال يتعلق بتنفيذ عقود دولية تتمتَّع بقيمة اقتصادية كبيرة، وقد تحتاج لإنفاق الكثير من الأموال بغرض القيام بدراسات معمَّقة حول الحادث وكيفية مواجهته وتعديل العقد؛ لذا يجب السعي لتجاوز المشاكل التي تعترض التنفيذ؛ وتبعًا لذلك يتعيَّن على أطراف العقد الدولي تنفيذ التزاماتهم بكل حسن نية، وذلك ببذل جهدهم لإزالة الاختلال الناتج عن تغيُّ الظروف، وجعله يتماشى مع الظروف الجديدة حتى في ظلّ غياب شرط إعادة التفاوض (1). ولكن ماذا لو فشل الأطراف أثناء عملية إعادة التفاوض؟ وبعبارة أخرى: ماذا لو سكت العقد عن بيان الموقف إزاء فشل مناقشات إعادة التفاوض (وهو وضع شائع في العقود الدولية)؟ إنَّ هذا التساؤل -أيضًا- يُشَّل في جوهره ارتدادًا للبحث في مدى حسن نية المتعاقد ذاتها من عدمها؛ ففي العقود الدولية قد نجد الحلول مباشرة بنصِّها صر احة مثلًا على إنهاء العقد مباشرة حال فشل إعادة التفاوض، أو يتمّ تنفيذ العقد. وبالبحث في الشروط النموذجية لغرفة التجارة الدولية سنجدها تُقِّر بضرورة استمرار تنفيذ العقد، وعلى الطرف المتضرِّر اللجوء على التحكيم ليطالب بالتعويضِ (1) أ. حورية جبار، أ. عقيله شيبي، الالتزام بإعادة التفاوض في العقود الدولية، مرجع سابق، ص Y. . . 
جرَّاء إعادة تفاوض الطرف المتعاقد بسوء نية، وهذا يُدلِّل مرة أخرى على أنَّ حسن النية

ركيزة أساسية عند تطبيق شرط إعادة التفاوض، وهو ما تنبَّهت له بعض القوانين(1)؛ كالقانون المدني الفرنسي في نصِّه صراحةً في المادة ع • 11 على أنَّه: "يجب التفاوض على العقود بحسن نية"(r)، بل إنَّ حسن النية مطلوب في التفاوض عمومًا (م).

وبطبيعة الحال لم تحد عقود التجارة الدولية المشتملة على شرط إعادة التفاوض

بالصيغة التي مضى بيانها، والتي تمَّ إبرامها قبل جائحة كورونا بمعطياتها التي وُوِفن عندها غير مرَّة هي الأخرى عن اشتراط حسن النية؛ فحسن النية بين أطر اف هذه العقود أمر مطلوب)

(1) في هذا التحليل، ولمزيد من التفاصيل، راجع الندوة الافتراضية بعنوان: الآثار القانونية لفيروس كورونا المستجد على العقود الدولية للأعمال التي نظمتها كلية القانون، جامعة أبو ظبي، كلمة الدكتور سمير أوخليفا، سابقة الإشارة، انظر في ذلك أيضًا، د. أحمد عبد الكريم سلامة، قانون العقد الدولي: مفاوضات العقود الدولية

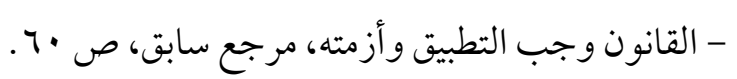

(2) "Les contrats doivent être négociés, formés et exécutés de bonne foi", Constance Verroust-Valliot et Serge Pelletier, L'impact du covid-19 sur les contrats de droit privé, op, cit.,

وعلى خلاف الوضع في إنجلترا؛ إذ لا يعترف القانون الإنجليزي بو اجب عام لحسن النية ينطبق على جميع العقود، وعلى الرغم من ذلك أظهرت المحاكم الإنجليزية بشكل متزايد استعدادها لتطبيق للتعبير عن الشروط التعاقدية التي تتطلب من الأطراف التصرف بحسن نية، وإن يُعزى تحفظ المحاكم الإنجليزية في الاعتراف بالواجب العام في التعامل بحسن نية عمومًا إلى التردد في التدخل في مبادئ حرية العقد واليقين مع صعوبة في

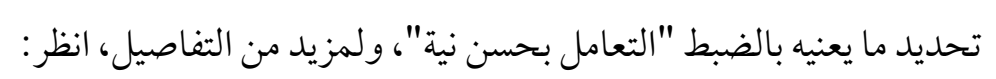

Simon Fawell and Abdul Azeem, COVID-19 and Duties of Good Faith Under English law, Issued by lexology official website, published on 25/6/2020.

See at, https://www.lexology.com/library/detail.aspx?g=d82a34b2-b951-46c0-9904-67691185c9ab , Last Visit on $12 / 7 / 2020$.

$$
\text { (r) د. أحمد عبد الكريم سلامة، قانون العقد الدولي، مرجع سابق، ص • با و ما بعدها. }
$$

(4) For more details, Simon Fawell and Abdul Azeem , COVID-19 and Duties of Good Faith Under English law, op, cit., 
ولمَّا كان حسن النية نقيضه الغش والخداع من قبل الطرف المتعاقد؛ فإنَّ تو افِر هذا في حقّ الطرف مدعاةٌ لوقف عملية التفاوض، و العدول عن العقد المزمع إبر امه، بل ومن حقّ الطرف الآخر المطالبة بالتعويض إذا اقتضى الأمر ذلك، كجزاء الغش في مرحلة التفاوض، ورغم تنوع الجزاءات المترتبة على الغش على نحو ما ذُكر إلا أن التفرقة واجبة بين حالتين بحسب ما ستنتهي إليه إعادة التفاوض؛ ففي الحالة الأولى: إذا أسفرت المفاوضات عن إبرام العقد المنشود: فهنا يتم تطبيق الجزاءات العقدية الخاصة بذلك العقد (العقد النهائي) ، والتي تدخل بدورها في إحدى حالات الغش في مرحلة إبرام العقد، وهو وضع يختلف عن الحالة الثانية: إذا انتهت المفاوضات إلى طريق مسدود، ولم يتو صل الطرفان إلى إبرام العقد ووجود سوء نية من المتعاقد"(.). (r) الوضع حال رفض المتعاقد إعادة التفاوض أو فشله: ليست كلّ الأطر اف التعاقدية تقبل إعادة التفاوض، وحتى على فرض قبولها فليس كلُّ محاو لات إعادة التفاوض تؤدي نتائج؛ إذ قد تفشل محاولات إعادة التفاوض، وهنا يجوز للطرفين الاتفاق على إنهاء العقد في التاريخ و الشروط التي يحددها الطرفان، أو أن يطلبوا من المحكمة -باتفاقهم المتبادل- تعديل العقد، في حالة عدم وجود اتفاق في غضون فترة زمنية معقولة يجوز للمحكمة -بناءً على طلب أحد الأطراف- مراجعة العقد أو إنهاؤه في التاريخ والشروط التي تحددهاי).

(1) لمزيد من التفاصيل، د. هلدير أسعد أحمد، نظرية الغش في العقد، دراسة تحليلية في القانون المدني، دار الكتب

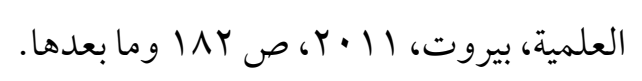

(2) Olivier Kuhn, Hassan Ben Hamadi, Covid-19 and contract Renegotiation: Q\&A, issued by CMS Francis Lefebvre Avocats Law firm, Published on 7/4/2020.

See at, https://cms.law/en/fra/news-information/covid-19-and-contract-renegotiation-q-a , Last visit on $24 / 7 / 2020$. 
ومن المعيار الموضوعي إلى المعيار الشخصي كمعيار آخر يُقََّّر به اختلال التوازن العقدي. ثانيًا: المعيار الشخصي: وفقًا لهذا المعيار يتمّم تقدير الاختلال وفقًا لمدى التغيُر الذي طرأ على الظروف

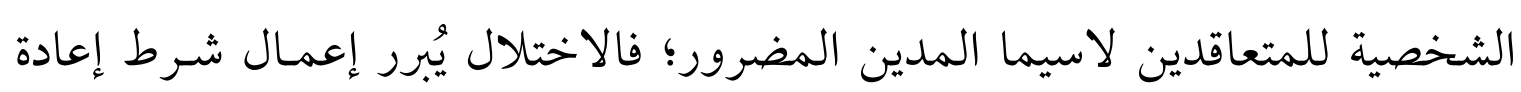
التفاوض متى كان غير عادل بالنسبة إلى المدين، بحيث نجم عنه ضرر شديد جرَّاء

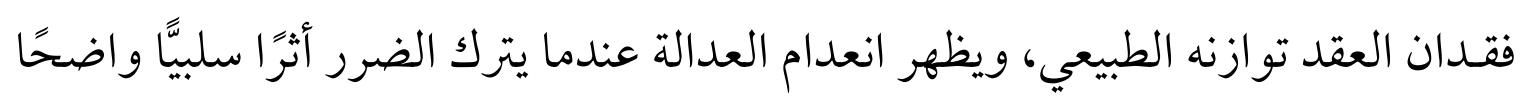
على قدرة المدين على تنفيذ التزامه، حتى وإن لم يكن كذلك بالنسبة إلى مدين آخر

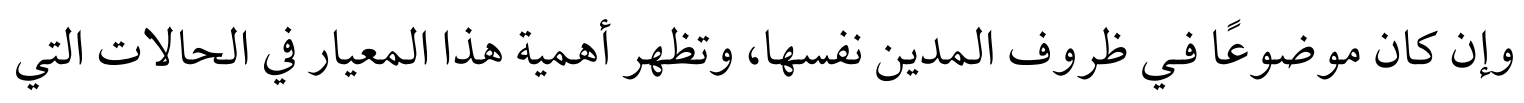

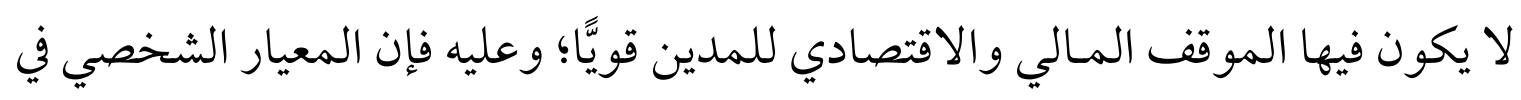
الحالات المذكورة يكون الاختلال كافيًا لإعمال شرط إعادة التفاوض متى أصيب

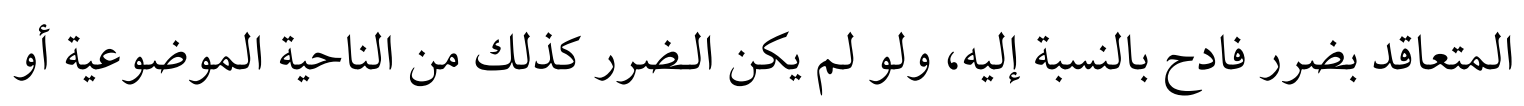

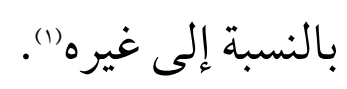
ومن الطبيعي أن يلي عرض المعيارين السابقين الشخصي والموضوعي الوقوف

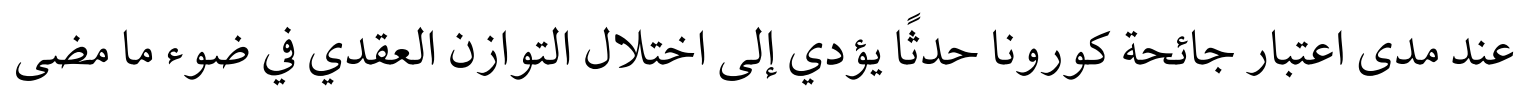
بيانه، وهو ما ستتناوله السطور القادمة. ثالثًا: مدى اعتبار جائحة كورونا حدثًا يؤدي إلى اختلال التوازن العقدي: ما دمنا في إطار الحديث عن شرط إعادة التفاوض في سياق جائحة كورونا؛ فالبحث

(1) م. أسيل باقر جاسم، النظام القانوني لشرط إعادة التفاوض، مرجع سابق، ص IrV . . 
واجب عن مدى درجة تأثير الحدث المبرِّر لإعمال شرط إعادة التفاوض على توازن العقد، لنُحلِّد من خلالها المقصود بالاختلال في حدِّ ذاته وآليات تقديره"(1). إنَّ استقر اء الحالات المشابهة التي حصلت في الماضي يجعل من الممكن التكهُّن بما ستؤول إليه الأمور من اختلال في تنفيذ الالتزامات العقدية الدولية والوطنية، فالاضطر ابات المالية هي نتيجة طبيعية لمثل هذه الجائحة الدولية، حيث ستحاول كثير من الشركات التهرب من تنفيذ التزاماتها العقدية. ويلزم التأكيد على أن الاختلال يُعدُّ مرحلة وسطى بين الاستحالة المطلقـة في التنفيذ التي يؤدي إليها عادةً حدثُ القوة القاهرة، وبين مجرَّد التغيير البسيط أو الطفيف الذي قد يطرأ على اقتصاديات العقد دون أن يجعل التنفيذ مستحيلًا أو حتى مرهقًا بالنسبة لمدين (r) وبشكل عام يحرص المتعاقدون في ميدان التجارة الدولية على اشتراط توفُّر درجـة معيَّنة مـن الخطورة والاضطراب التي تطال اقتصاد العقد في البنود التي ينظمون من خلالها شرط إعـادة التفاوض؛ وعليه فهم يشترطون أن يكون التغير الذي يؤدي إليه الحـدث المبرِّر لإعادة التفاوض جوهريًّا يصاحبه اضطراب واضح في اقتصاد العقد، بحيث يؤدي إلى ضـرر ليس من المنطقي أن يتحمله أحد الأطر اف)(م).

(1) د. ياسر عبد الحميد الإفتيحات، جائحة فيروس كورونا وأثرها على تنفيذ الالتزامات العقدية، مرجع سابق، . v

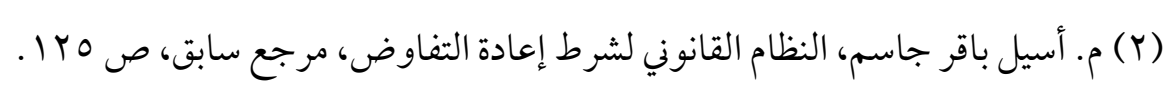

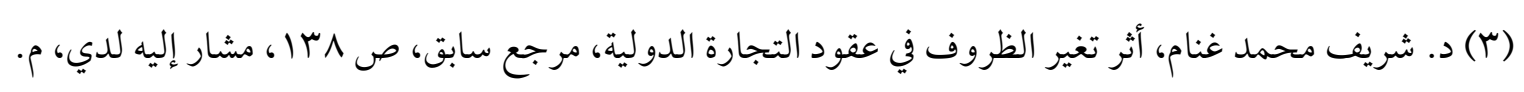

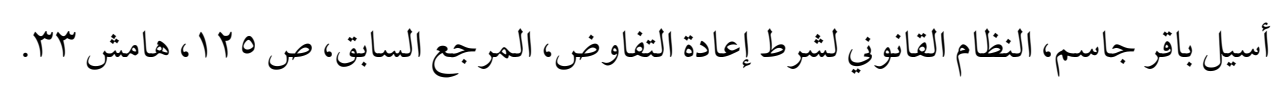


ومن المهم التأكيد على أهمية التمييز بين الاختلال في توازن العقد ومجرد التغيير البسيط والطفيف في توازن الأداءات العقدية وعدم الخلط بينهما، إذ لا يتجاوز الأخير المخاطر العادية والمألوفة؛ فها هو قضاء التحكيم في قضية تتلخص وقائعها في تعاقد شركتين على قيام الأولى بتوريد المشتقَّات النفطية إلى الثانيـة وفقًا للأسعار العالمية (نايمكس)، وبعد مرور فترة من الزمن توقَّتت الشركة المسورّدة عن تنفيذ التزاماتها بدعوى وجود ارتفاع في أسعار البترول، ممَّا يتطلـب التوقف عن تنفيذ التزاماتها، ومن ثمَّ تعديل العقد وفقًا للتغيرات الجديدة في الأسعار، بيد أنَّ هيئة التحكيم التي عُرض أمامها النزاع رفضت ادعاء الشركة الموردة، وقدَّرت أن مجرد ارتفاع أسعار البترول لا يكفي لإعمال شرط إعادة التفاوض الذي يجب لتطبيق الأحكام الخاصة به وجود اختلال كبير وجذري في توازن العقد"). رابعًا: فروض الالتزام بإعادة التفاوض: لََّّا كان الفرض أنَّ العقد الدولي قد أبرِم في سياق توازن مالي معين، لكن حلول جائحة كورونا هو الذي جعل تنفيذ الالتزام يُخلِّف اختلالًا في التوازن المالي أو الاقتصادي بين طرفي العقد من ناحية المكاسب والمنافع، ومن ثمَّ كان سبب لجوء الأطر اف عن إمكانية إعادة التغاوض بغرض إعادة العقد لتوازنه المطلوب. وعليه فالحادث الحاصل وإنْ لم ينظر طرفا العقود الدولية إلى اعتباره من قبيل القوة القاهرة المؤدية إلى استحالة تنفيذ الالتزام التعاقدي استحالةً مطلقة؛ فمن المتصور أن

(1) القضية مشار إليها لدى، د. شريف محمد غنام، أثر تغير الظروف في عقود التجارة الدولية، مرجع سابق، لدى

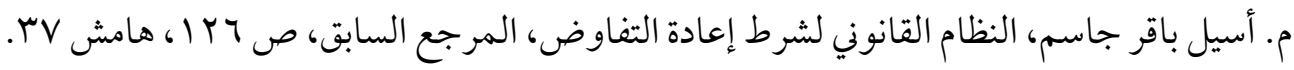


يقوما بإعادة التفاوض بالنظر لما رتَّتَه جائحة كورونا.

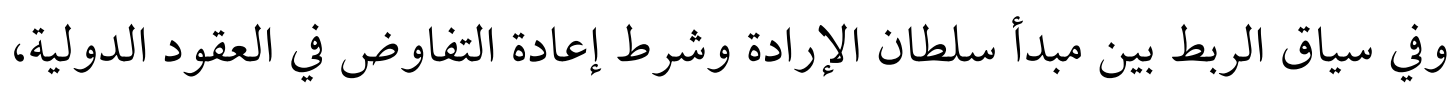

على اعتبار أن نطاق مبدأ كفاية الإرادة أوسع في العلائق ذات العنصر الأجنبي، وعلى ذلك فهي تشجع الإتجار والعلاقات الاقتصادية الدولية")؛ فالوضع إذن ما بين فرضين: الفرض الأول: نصُّ الأطراف على ما يفيد اعتبار الأوبئة (جائحة كورونا أنموذجًا)

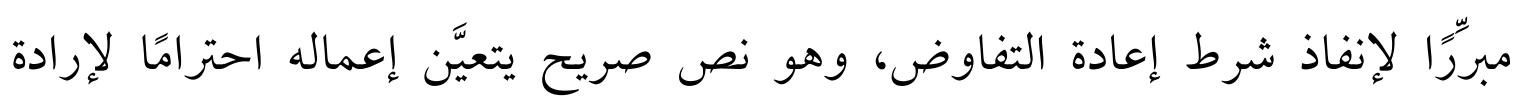
الأطراف، ففي الفرض المطروح لا يوجد مشكلة، وليس هناك مجال للتأويل بالتبعية. وفي هذه الحالة التي يتضمن فيها العقد شرطًا صريحًا يقضي بالالتزام بإعادة

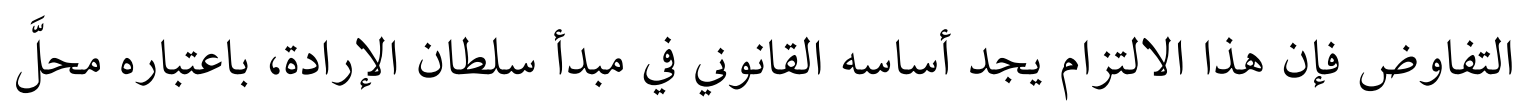
اتفاق بين طرفي العقد من خلال تضمين عقدهم شرط إعادة التفاوض، فهو بمثابة تنظيم اتفاقي للعقد(")، وباعتبار العقد شريعة المتعاقدين نجد بعض الفقه الدولي يذهب إلى أنه

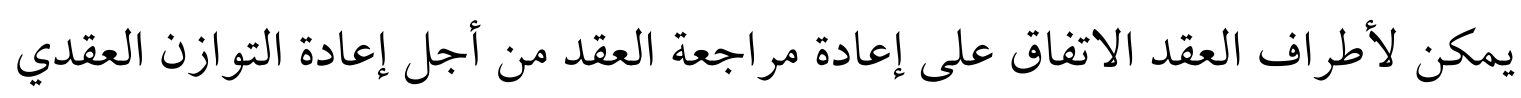
بشكل يتناسب مع الظروف الجديدة"). وتجدر الإشارة إلى أنه إذا كان النص التعاقدي الذي تم التعويل عليه ينص فقط على لقده كلَّ حدث طارئ غير متوقع يجيز لأطراف العقد الدولي إعادة التفاوض؛ فمثل هذه

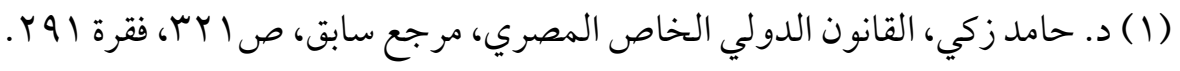

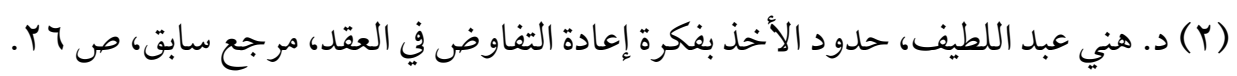

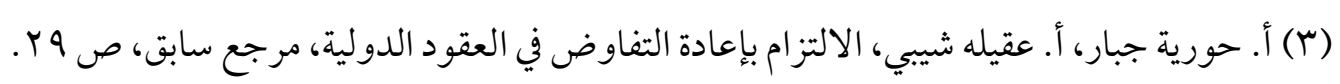


النصوص بحاجة إلى إمعان النظر؛ فالنص وإن عوَّل على الحدث الطارئ في عموم

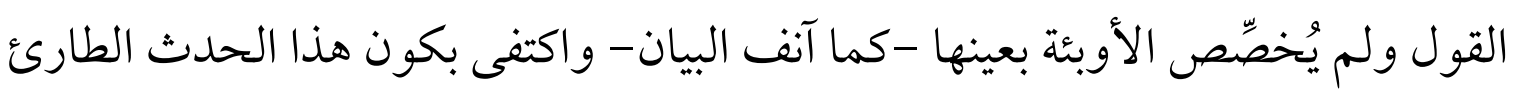

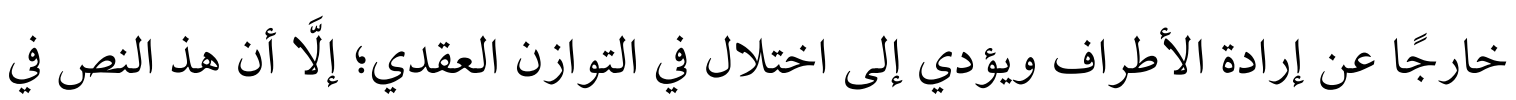

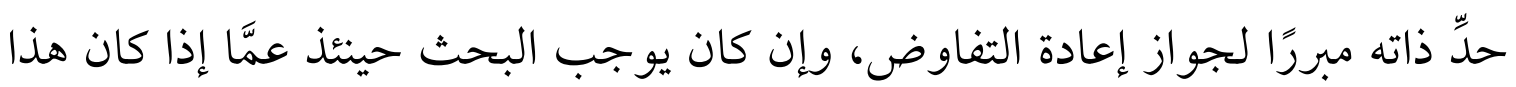

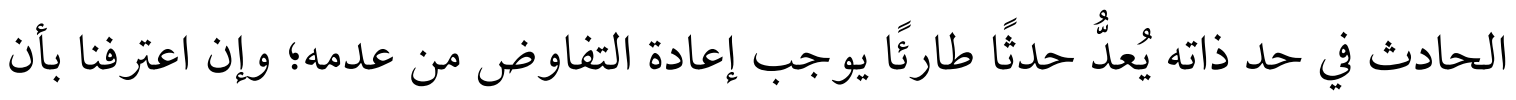

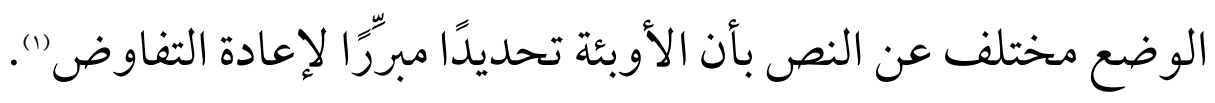
وإجمالًا يرى جانب فقهي أن تحليل الأحداث المخلة بتوازن العقد والمدرجة في شروط إعادة التفاوض لا تخرج عن فرضين اثنين، يميل المتعاقدون في الإطار الأول

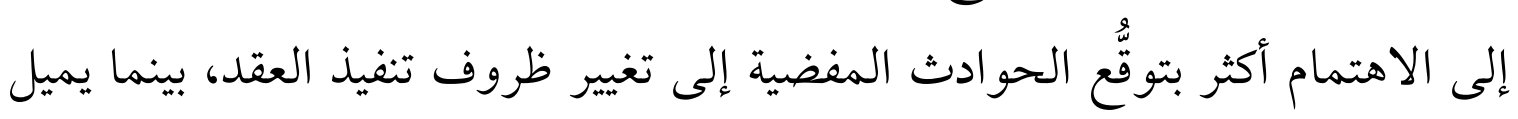

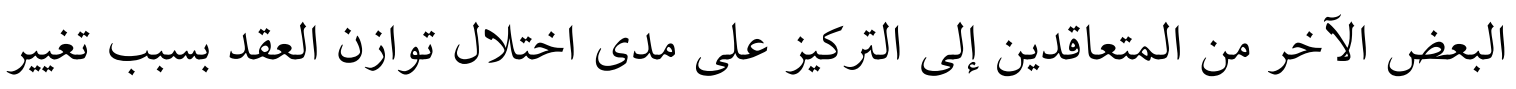
ظروفه (1).

الفرض الثاني: عدم نص الأطراف على ما يفيد اعتبار الأوبئة (جائحة كورونا

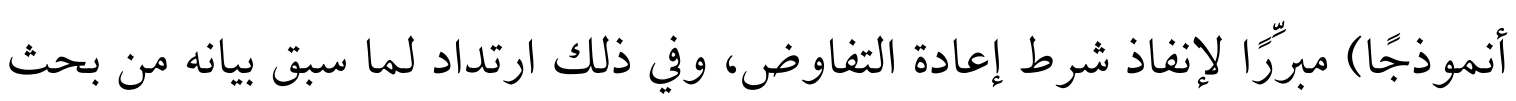
لمدى إمكانية إدراج الأوبئة ضمن موجبات القوة القاهرة أو الظروف الطارئة. وعليه فإذا كان النص العقدي يشير إلى اعتبار الحادث "يعرقل hindering" أو يؤخِّر

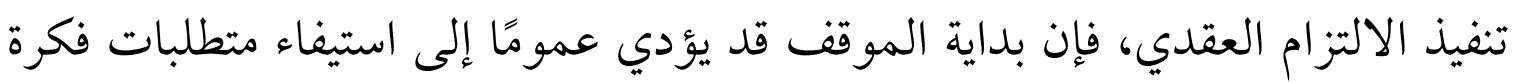

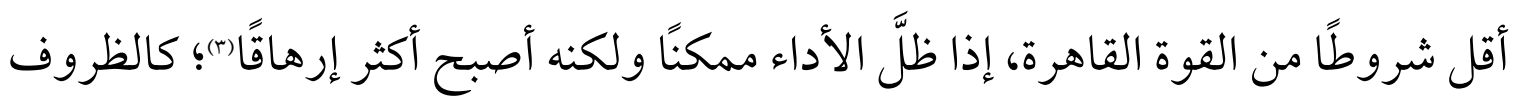

(1) وفي البيان السابق ارتداد إلى أهمية إيلاء الاهتمام بالصياغة العقدية الصحيحة لشرط إعادة التفاوض.

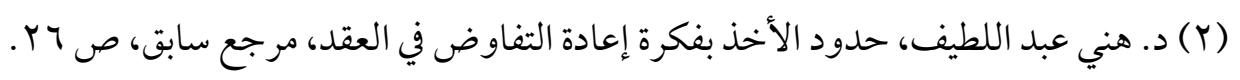

(3) Claudia Galvis, Jose Moran, et al, Coronavirus Outbreak: Global Guide to Force Majeure and International Commercial Contracts, op, cit., 
الطارئة مثلًا.

وبناءُ على الفرض الثاني؛ فثمة سؤال مطروح على مستوى العقود الدولية تحديدًا:

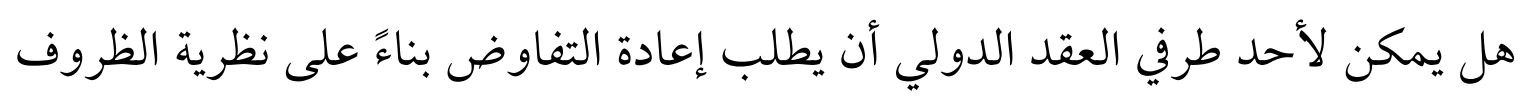

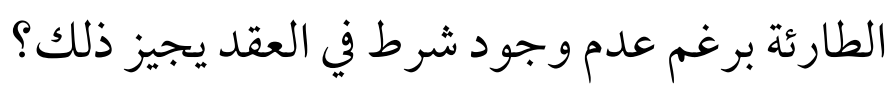

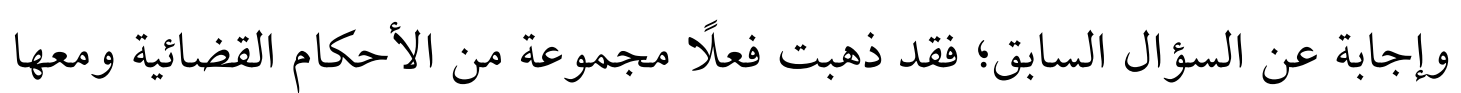
أحكام التحكيم -برغم عدم وجود نص بالعقد الدولي يجيز إعادة التفاوض - إلى اعتبار

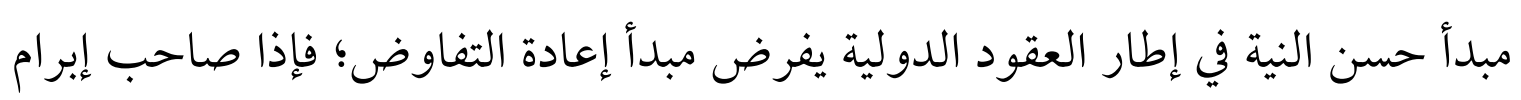

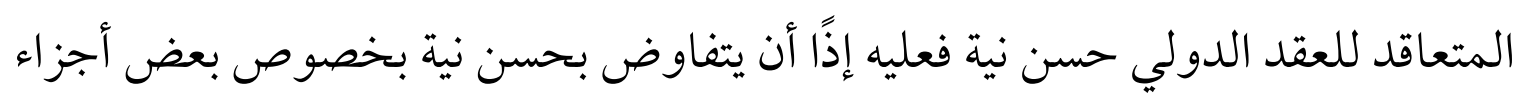

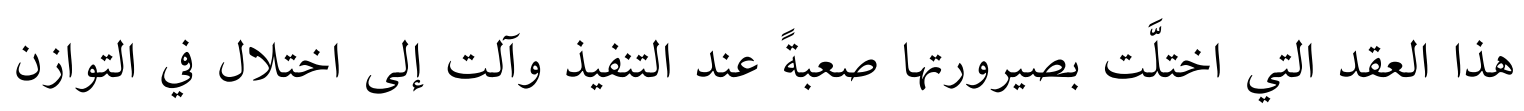
العقدي، وهذا الاتجاه هو ما نميل إليه. 


\section{الخاتمة}

لقد أدر كتْ كافَّة دول العالم بكياناتها وشعوبها صغيرهم وكبيرهم عظيم التأثير الذي

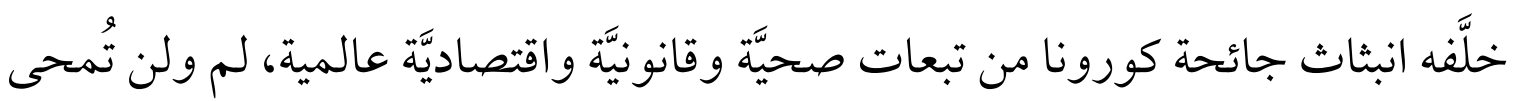
حتمًا من ذاكرة البشرية، على إثر فيروس لائرى بالعين المجرَّدة، ولكنه أضحى شاغل

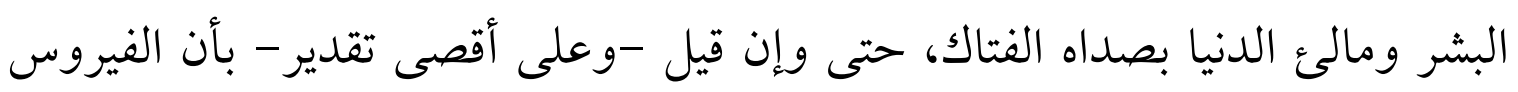

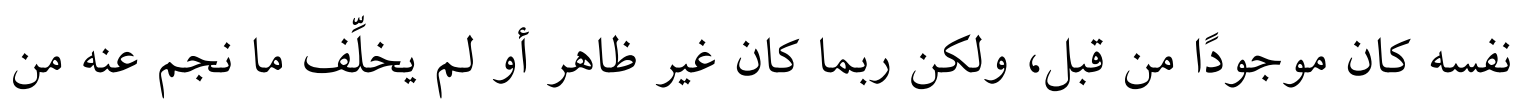
تبعات حالية لا تخفى على القاصي والداني.

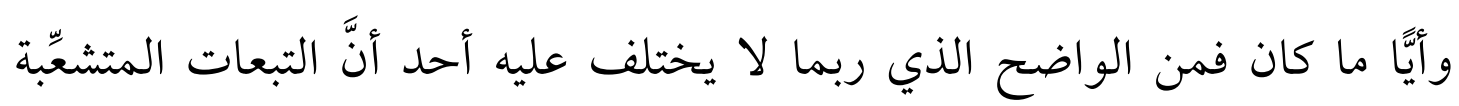
لجائحة كورونا ستظل ترافقنا لفترة زمنية يعلم الله مداها.

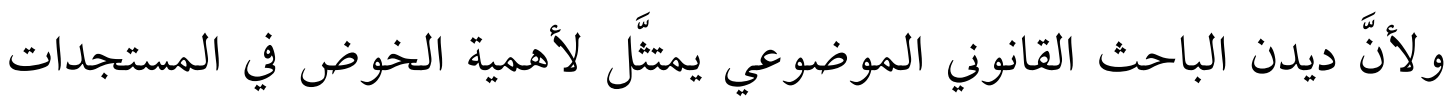

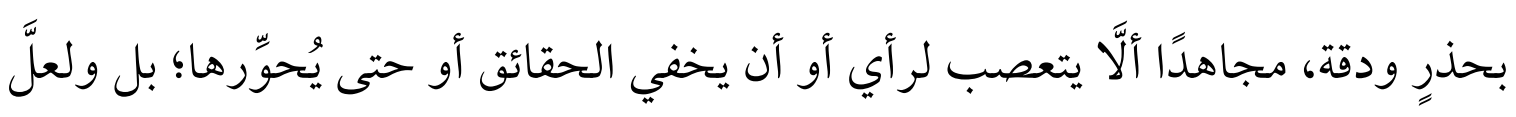

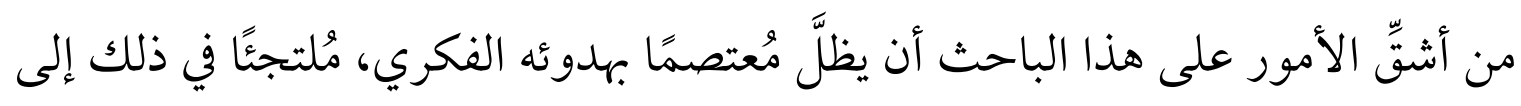

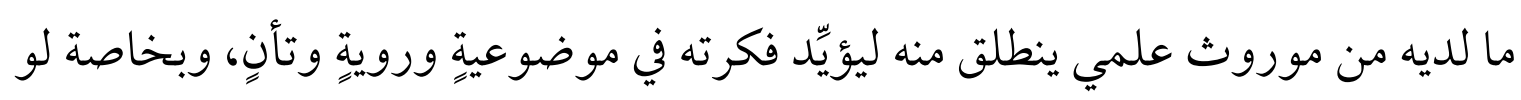

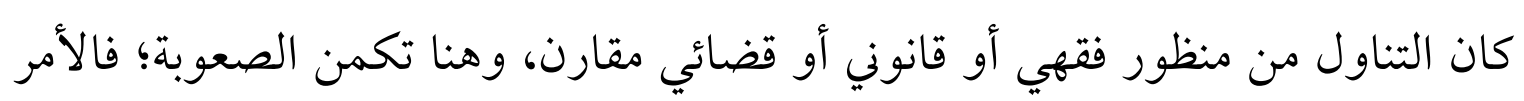

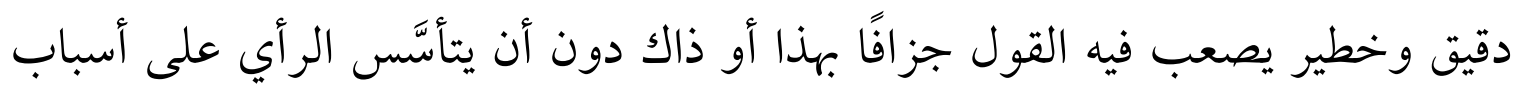
وتوصيفات مقنعة لا تزعزع المسلمات الراسخة والثوابت المتأصلة.

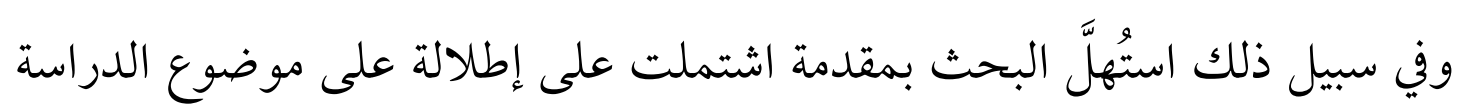

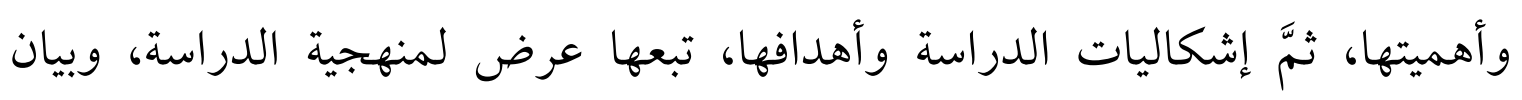

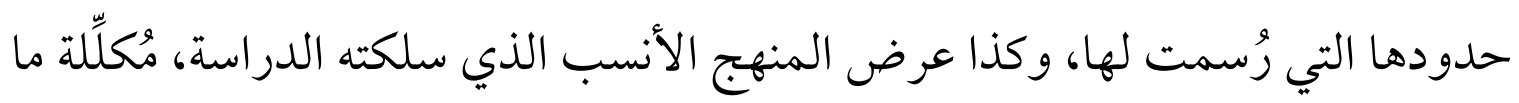
سبق بتوضيح خطتها. 
قُسِّمت الدراسة بعدها إلى: مبحث تمهيديّ؛ وضَّحتُ فيه أهمَّ الإشكاليات الأولية

ذات الصلة بموضوع الدراسة، بين مدى صمود أهم القواعد القانونية المستقرِّة المتعلقة بعقود التجارة الدولية أمام رياح الجائحة، وهو ما أظهر إنَّ الإقرار المطلَق بمبدأ القوة الملزمة للعقد والتطبيق الصارم لمبدأ العقد شريعة المتعاقدين يتنافى في كثير من الحالات مع اعتبارات العدالة؛ تلك الأخيرة التي تقتضي السماح بإيراد استثناءات على المبدأ، استثناءات واضحة محددة وفي أضيق الحدود، لكي لا تفرغ القاعدة من مضمونها؛ فجائحة كورونا قد تسبَّت في خسائر اقتصادية جمَّة، وهو ما عُدِّلت على

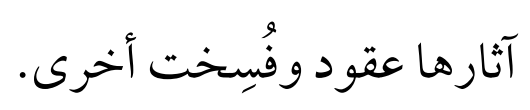

وبحثًا في مدى انطباق مقتضيات نظرية تبديل الأحكام أو النصوص بتبدُّل الظروف؛ فقد أظهر الواقع العملي وجود أعداد هائلة من الظروف المتغيرة المحيطة بمجتمع عقود التجارة الدولية، ومن قبل الجائحة، وفيها تكون الظروف المحيطة بالعقود طويلة الأجل مدعاة لإعمال مقتضيات النظرية المذكورة كردّ فعل لهذه الظروف التي من بينها ما فرضته جائحة كورونا؛ كمبدأ قانوني يُسعف العقد الذي يصبح غير قابل للتطبيق لحدوث تغيير جوهري في الظروف، تعويلًا على فكرتي الإنصاف وحسن النية.

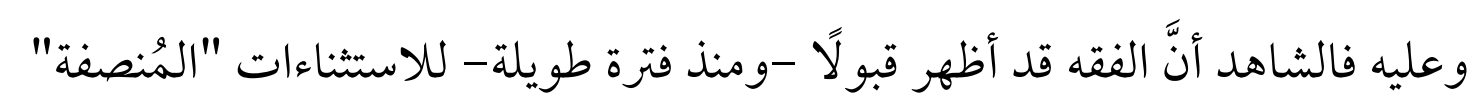
على مبدأ العقد شريعة المتعاقدين في أوجه مختلفة لمبدأي القوة القاهرة والظروف الطارئة وبدرجات متفاوتة، ولقد أنبأت السوابق القضائية عن شروط أربعة يتعيَّن تو افرها لكي يتمّ تطبيق فكرة نظرية تبديل النصوص أو الأحكام الخاصة بالعقد بتغير الظروف، وقد بيَّنت الدر اسة آلياتها. بعد ذلك انشطرت الدراسة إلى مبحثين اثنين، سعى أولهما: لبيان ثمرات تكييف 
جائحة كورونا كقوة قاهرة أو حادث فجائي، وهو شأن استوجب الرجوع إلى أمهات

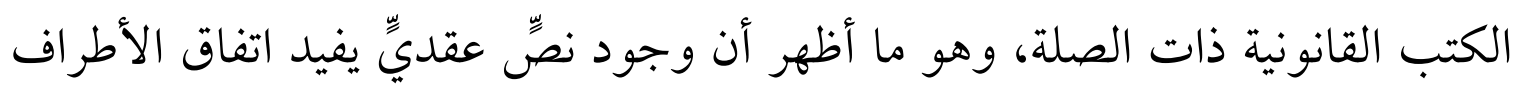
على إضفاء وصف معين يضفيه الأطراف على الأوبئة هي نصوص يتعيَّن تطبيقها؛ كأن

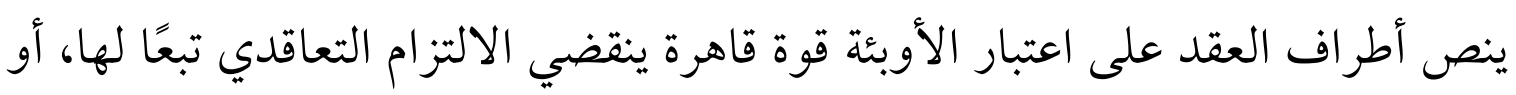
يُنصَّ على أنَّ الأوبئة ظرف طارئ يؤدي وجوده إلى إعادة التوازن المالي للعقد في ظلّ لِّل ما بينهما من اختلاف، أو نص الأطراف على اعتبار الأوبئة مسوغًا لإعادة التفاوض، إلى إلى لئل غير ذلك من صور النصوص واجبة التطبيق، وهو أمر يصون حقوق الأطراف المتعاقدة

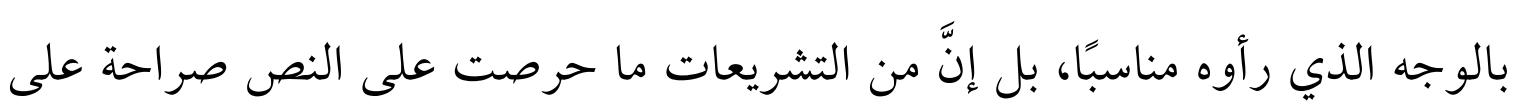
اعتبار الأوبئة من قبيل الظروف الطارئة؛ كالتشريع البولوني.

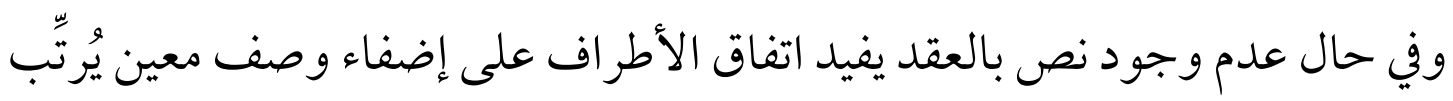

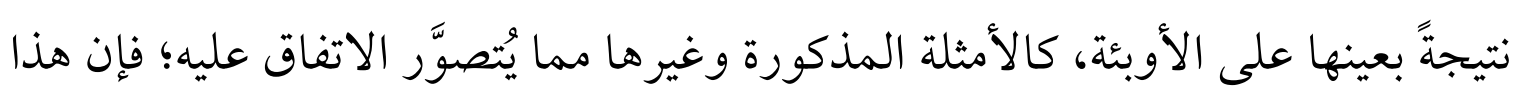
الفرض مرتِبِ للخوض في متن ما أتت به هذه الدراسة من خلال ولوج السبل الموصلة بالجائحة إلى أنسب تكييف لها.

علاوة على الانطلاق لإجمال أبرز مواقف القضاء المقارن من اعتبار جائحة كورونا قوة قاهرة من عدمه؛ كالقضاء الفرنسي والمصري والأمريكي، وكذا القوانين المقارنة من المسألة ذاتها كقانون العقود الإنجليزي ونظيره الصيني، ومن دون إغفال بيان

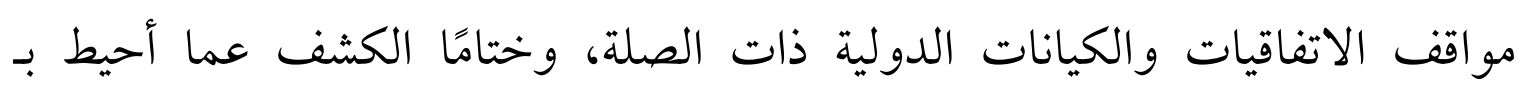
"شهادات القوة القاهرة" التي ملأت الدنيا بصداها كقرينة قد تنقذ المدين المتعاقد؛ بييان طبيعتها القانونية، والدول التي أدخلتها حيِّ التطبيق الفعلي، ومدى إمكانية الاعتداد بها خارج محاكم الدولة الني أصدرتها. 
وعلى الرغم من سعى المبحث الثاني من أجزاء هذه الدراسة إلى وضع جائحة

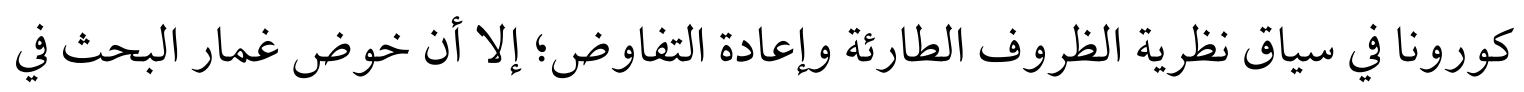
هذا وذاك بالتأصيل الذي أظهره البحث، بل وفي القوة القاهرة من قبلهم أظهر جليًّا أن

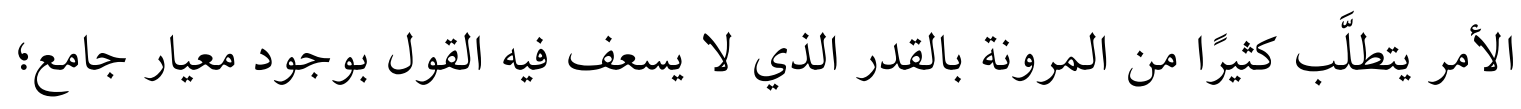

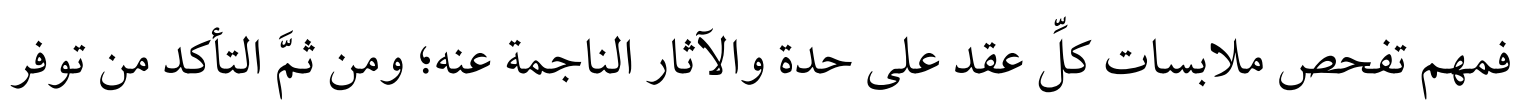
شروط أيِّ منهما من عدمه، وعلى إثره يمكن تحديد ما إذا كانت الجائحة تُعدُّ قوةً قاهرة أو ظرفًا طارئًا، أو حتى غير ذلك.

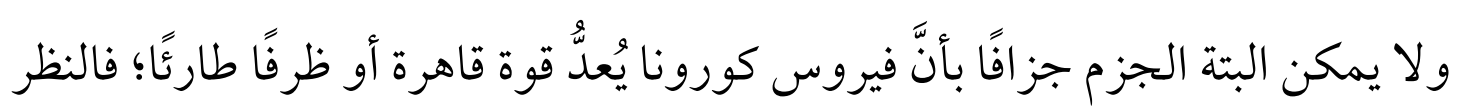

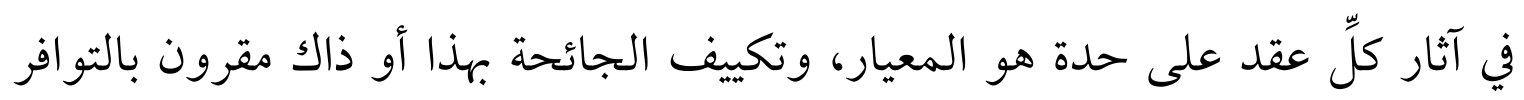
الموضوعي الدقيق لشروط كلٍ منهما.

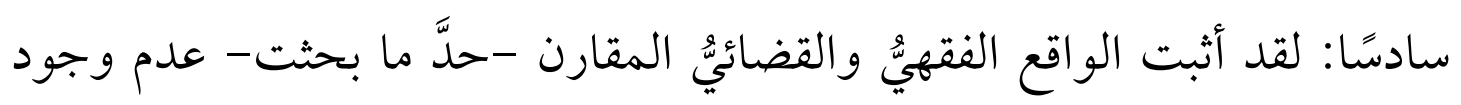
اتفاق كليِّ لجائحة فيروس كورونا مع أيِّ من النظريات القانونية المستقرَّة بصورة جامعة مانعة، وهو شأن يقتضي لزوم الذود لقدرِ لا بأس به من المرونة أثناء إعطاء

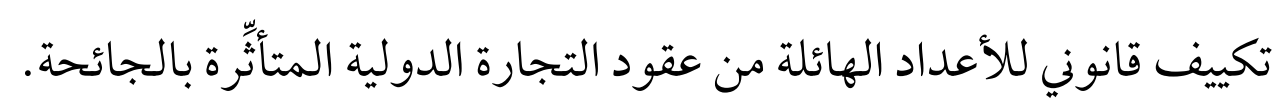

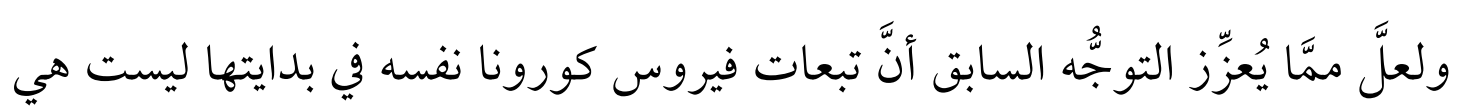

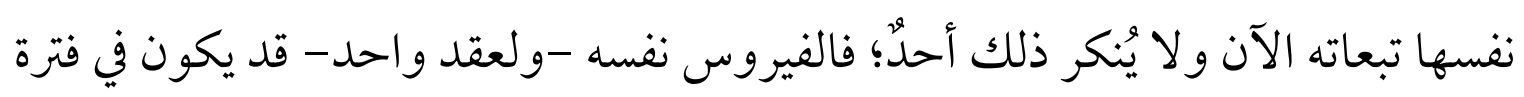
زمنية أقرب لاعتباره قوة قاهرة، وفي فترة زمنية أخرى ظرفًا طارئًا، وقد لا يكون شيئًا من فئن

وبعد أن تمَّ -بفضل الله ومنَّته- الوصول إلى هذه المرحلة من مراحل البحث أُشير إلى أنَّ الدراسة قد خلُصَت إلى بعض النتائج والتوصيات أُجملها فيما يأتي: 


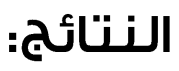

أولًا: إنَّ الإقرار المطلَق بمبدأ القوة الملزمة للعقد والتطبيق الصارم لمبدأ العقد شريعة المتعاقدين قد يتنافى في كثير من الحالات مع اعتبارات العدالة؛ لذا كان مهمَّا في أعقاب جائحة كورونا إعمال "نسبية مبدأ القوة الملزمة للعقد"، وإلَّا فلربما تحوَّلت القوة الملزمة للعقد إلى قيود. ثانيًا: أكَّدت جائحة كورونا على أهمية إجراء موازنة بين مبدأ العقد شريعة المتعاقدين ونظرية تبديل الأحكام أو النصوص بتبدّل الظروف إذعانًا لما أظهره الواقع العملي ثالثًا: صعوبة إخضاع مختلف العقود لأحد القوانين بعينها دون الأخرى؛ لأنَّ لكلٍ منها مبرر اته المعقولة، ومن الأنسب حينئذ البحث في كلّ حالة على حدة؛ وبالتالي يُطبّّق على العقد القانون الأكثر ملائمة، مادام المقصود تحقيق أغراض عملية اقتصادية، وإجمالًا لا يختصٌّ قانون العقد ذاته بتحديد انفساخ العقد لاستحالة تنفيذه فقط، بل وبشروط فسخ العقد بحكم القضاء أو بالاتفاق، وأثار كل من الانفساخ والفسخ. رابعًا: إنَّ إمعان النظر في الطبيعة القانونية لفيروس كورونا والسعي لتكييفه -وبعد الخوض في الاجتهادات فقهية والثوابت القانونية ذات الصلة- يُظهر أنَّ العبرة فيها بالآثار التي أحدثتها جائحة كورونا. خامسًا: إنَّ شرط إعادة التفاوض يأخذ بعض ملامحهه من نظرية القوة القاهرة، ويأخذ الأخرى من نظرية الظروف الطارئة مُكوِّنًا فكرةً مستقلة في حدِّ ذاته، تختلف فيها ثلاثتهم عن بعضهم البعض. سادسًا: إنَّ مدى اعتبار جائحة كورونا مدعاة لإعادة التفاوض من عدمه -وفي ردٍّ 


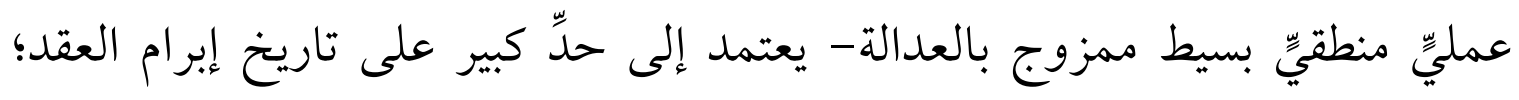

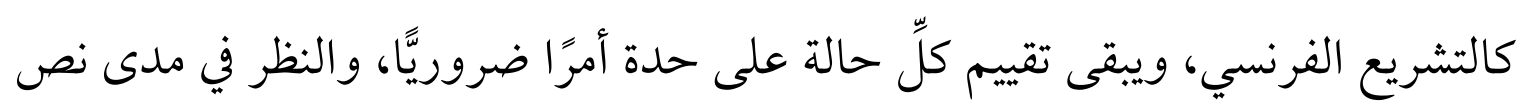
الأطراف على شرط إعادة التفاوض من عدمه.

التوصيات:

أولًا: أهمية إيلاء أطراف عقود التجارة الدوليَّة الاهتمام الكافي بصياغة نصوص عقودهم على النحو الذي يكفل لهم تفادي مغبَّة ما قد يُفرزه الواقع من أحداث غير متوقعه في عموم القول؛ فالعقد التجاري الدولي المحبوك حسن الصياغة يُسعِف أطرافه

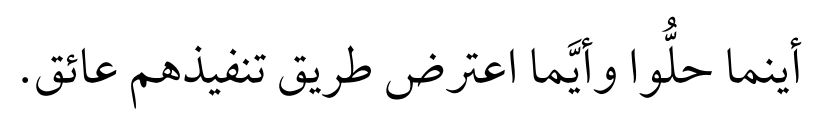

ثانيًا: عبء تكييف جائحة كورونا النهائي يقع على عاتق القضاء، يؤازره في ذلك الفقه بما يعرضه من آراء فقهية مجدية، وعلى القضاء التدقيق من توافر شروط أيِّ من النظريات التي قيل بها كلّ على حدة من عدمه، وهو ما سيصاحبه بطبيعة الحال تفنيد هذا أو ذاك بالحجج المؤيدة.

ثالثًا: تبنِّي الأطراف لشرط إعادة التفاوض في عقدهم الدوليّ ينبغي أن يكون تبنيًا

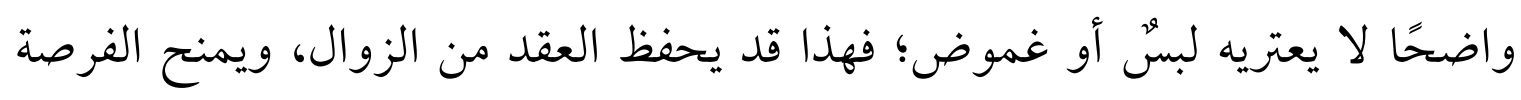

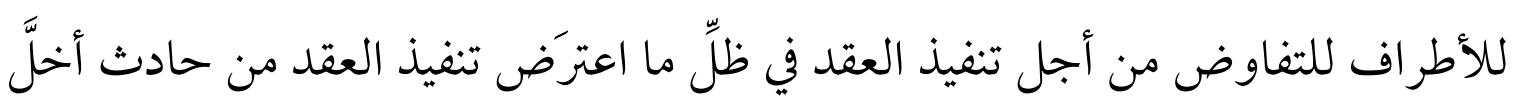
بتوازنه.

رابعًا: لزوم استعانة أطراف عقود التجارة غير المختصين بالممارسين القانونيين المختصين والاستعانة بذوي الاختصاص على النحو الذي يكفل لهم الصياغة الدقيقة؛ فهذا يؤدي إلى تلافي كثير من الإشكاليات والصعوبات التي يُثيرها تحديد ما إذا كان

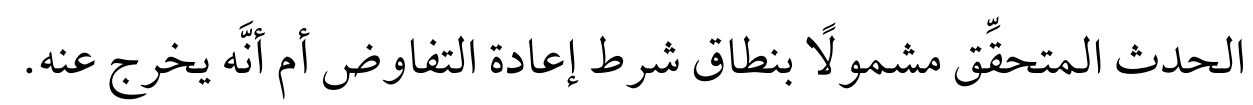


خامسًا: أهمية سعي الممارسين القانونيين لتلمُّس المناهج الصحيحة لصياغة شرط إعادة التفاوض على النحو الذي يكفل لأطرافه تفادي مغبَّة ما قد يطر أ على تنفيذ العقد من حوادث قد تؤدي إلى اختلال التوازن العقدي. سادسًا: لزوم سعي المشرّعين لإيجاد الحلول القانونية الملائمة لأطراف العقود

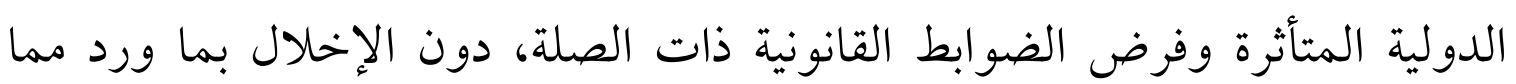
ارتضته الأطر اف التعاقدية مسبقًا. 


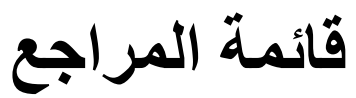 \\ أولاً: قائمة المراجع باللغة العربية$$
\text { (1) - مراجع الشريعة الإسلامية: }
$$

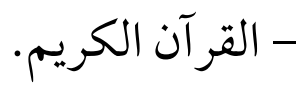$$
\text { - الموقع الإلكتروني الرسمي للشيخ عبد العزيز بن باز، }
$$

https://binbaz.org.sa/audios/2476/561

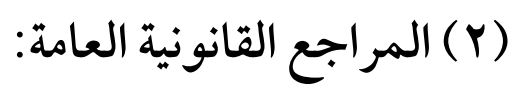

د. أحمد عبد الكريم سلامة،

- الأصول المنهجية لإعداد البحوث العلمية، الطبعة الأولى، حقوق التأليف والنشر محفوظة للمؤلف، 1997.

- الأصول في التنازع الدولي للقوانين، دار النهضة العربية، القاهرة، 1 • ب. - القانون الدولي الخاص، الجنسية والموطن ومعاملة الأجانب والتنازع الدولي للقوانين والمرافعات المدنية الدولية، دار النهضة العربية، القاهرة، الطبعة الأولى، $r \cdot \Lambda$

- نظرية العقد الدولي الطليق بين القانون الدولي الخاص وقانون التجارة الدولية، دار

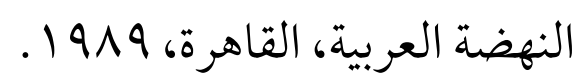

- قانون العقد الدولي: مفاوضات العقود الدولية - القانون وجب التطبيق وأزمته، دار

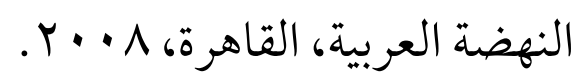
د. أشرف وفا محمد، الوسيط في القانون الدولي الخاص: المبادئ العامة لتنازع القوانين في القانون المقارن، وقواعد الإسناد في القانون المصري - قو اعد الاختصاص القضائي - آثار الأحكام الأجنبية، دار النهضة العربية، الطبعة الأولى، 9 • . r. 
د. حامد زكي، القانون الدولي الخاص المصري، مطبعة نوري، القاهرة، الطبعة الأولى، .1947

د. جابر جاد عبد الرحمن، تنازع القوانين، مكتبة النهضة المصرية، القاهرة، 1909. د. سمير تناغو، النظرية العامة للقانون، منشأة المعارف، الإسكندرية، ع 19V. د. عبد الرزاق السنهوري، الوسيط في شرح القانون المدني الجديد، الجزء الأول، نظرية الالتزام بو جه عام، مصادر الالتزام، الطبعة الثالثة، دار نهضة مصر، الجيزة، Iل إب. د. عكاشة محمد عبد العال مصطفى، - القانون الدولي الخاص في دولة الإمارات العربية المتحدة، الجزء الأول في تنازع القوانين، كلية شرطة دبي، $199 V$. - الوسيط في تنازع القوانين، مطبوعات أكاديمية شرطة دبي، الإمارات العربية المتحدة، .$Y \cdot T$ د. فؤاد عبد المنعم رياض، د. سامية راشد، تنازع القوانين في القانون المصري وفي التشريعات الحديثة، دار النهضة العربية، 1991. د. هشام صادق، د. عكاشة عبد العال، القانون الدولى الخاص، - تنازع القوانين والاختصاص القضائي الدولي، دار المطبوعات الجامعية،

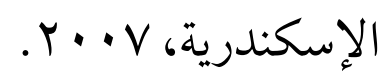
- تنازع القوانين والجنسية ومركز الأجانب، دار المطبوعات الجامعية، الإسكندرية، .$r \cdot 1$.

د. هشام على صادق، القانون الواجب التطبيق على عقود التجارة الدولية، منشأة المعارف، الإسكندرية، 1990.

د. هشام صادق، عقود التجارة الدولية، دار المطبوعات الجامعية، الإسكندرية، V •. . . . rIN 
د. هشام على صادق، د. حفيظة السيد الحداد، القانون الدولي الخاص، الكتاب الثاني، تنازع القوانين، دار الفكر الجامعي، الإسكندرية، 1999. (r) المراجـع القانونية المتخصصة: (r)

د. أبو العلا على أبو العلا النمر، دراسة تحليلية لمبادئ معهد روما "اليونيدروا" المتعلقة بعقود التجارة الدولية، دار الكتب القانونية، المحلة الكبرى، ب + . r. د. أحمد عبد الحميد عشوش، قانون العقد بين ثبات اليقين واعتبارات العدالة، مؤسسة

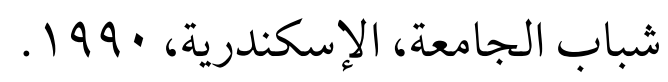
د. خالد منصور إسماعيل، إشكاليات التحكيم في منازعات عقود النفط: دراسة معمقة وفقا للتشريعات الوطنية والاتفاقيات الدولية وأحكام التحكيم الدولية المتعلقة

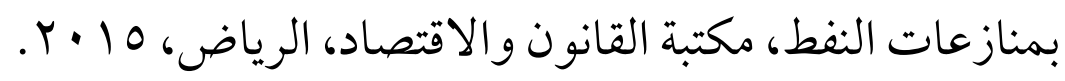
المستشار محمد عزمي البكري، فسخ العقود، دار محمود للنشر والتوزيع، القاهرة، .$r \cdot I V$

د. محمد على البدوي الأزهري، النظرية العامة للالنزام، الجزء الأول، الطبعة الثانية،

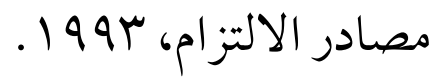
د. هلدير أسعد أحمد، نظرية الغش في العقد، دراسة تحليلية في القانون المدني، دار

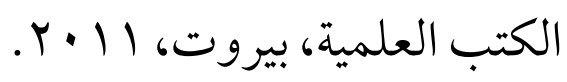

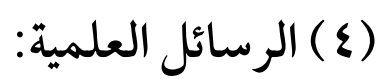

د. هني عبد اللطيف، حدود الأخذ بفكرة إعادة التفاوض في العقد، رسالة لنيل درجة الدكتوراه، كلية الحقوق والعلوم السياسية، جامعة أبي بكر بلقايد تلمسان، الجزائر، 
(0) المقالات:

د. أمينة رضوان، مدى مساهمة فيروس كورونا في إنهاء العلاقة الشغلية، مجلة الباحث كلدر اسات والأبحاث القانونية والقضائية، عدد خاص بكورونا (كوفيد 9 ( )، العدد VIV،

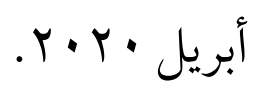

د. أنس فيصل التورة، تأثيرات فيروس كورونا على عقد العمل بين الظروف الطارئة والقوة القاهرة، مجلة كلية القانون الكويتية العالمية، السنة الثامنة، ملحق خاص، العدد

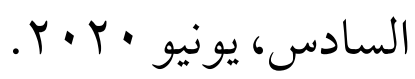
د. محمود المغربي، د. بلال صنديد، التكييف القانوني للجائحة "الكورونية" على ضوء الثوابت الدستورية و الدولية والمبادئ القانونية المستقرة: بين صلابة المسلمات ومرونة الاعتبارات: دراسة مقارنة، مجلة كلية القانون الكويتية العالمية، السنة الثامنة، ملحق

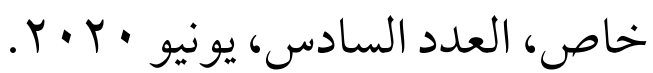
د. ياسر عبد الحميد الإفتيحات، جائحة فيروس كورونا وأثرها على تنفيذ الالتزامات العقدية، مجلة كلية القانون الكويتية العالمية، السنة الثامنة، ملحق خاص، العدد

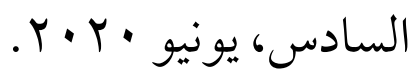

\section{( ) مؤتمـر ات وندوات افتراضية:}

د. جابر محجوب، أثر جائحة كورونا على تنفيذ العقود، الندوة الافتراضية القانونية الأولى بعنوان "جائحة كورونا وانعكاساتها القانونية في القانون الخاص"، الثلاثاء الثاءئي

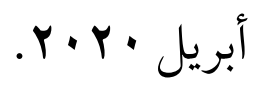

د. سمير أوخليفا، ندوة افتراضية بعنوان الآثار القانونية لفيروس كورونا المستجد على

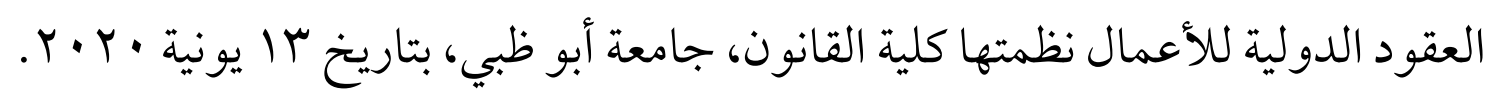


د. عابد فايد بعنوان، أثر جائحة كورونا على تنفيذ العقود، الندوة الافتراضية القانونية الأولى بعنوان "جائحة كورونا وانعكاساتها القانونية في القانون الخاص"، الثلاثاء الثاءئ

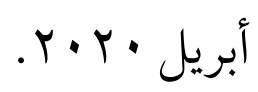

د. محمد عبد الهادي المكنوزي، الندوة الافتراضية بعنوان الآثار القانونية لفيروس كورونا المستجد على العقود الدولية للأعمال، نظمتها كلية القانون، جامعة أبو ظبي،

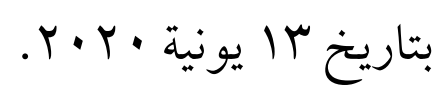

د. مصطفى عبد الجواد حجازي، أثر جائحة فيروس كورونا على عقد العمل، الندوة القانونية الأولى بعنوان "جائحة كورونا وانعكاساتها القانونية في القانون الخاص"،

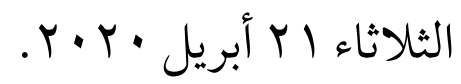

$$
\begin{aligned}
& \text { (أبحاث منشورة على شبكة الإنترنت: (V) }
\end{aligned}
$$

د. إبراهيم أحاطب، فيروس كورونا "كوفيد 9 1" بين القوة القاهرة ونظرية الظروف الطارئة، مقالة منشورة على موقع العلوم القانونية الإلكتروني الرسمي Maroc droit، https://www.marocdroit.com

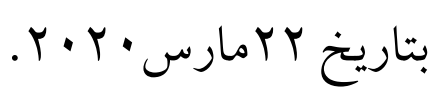

\section{ثانيًا: قائمة المراجع باللغة الإنجليزية:}

Ewan McKendrick, Force Majeure and Frustration of Contract, Second Edition, Informa Law from Routledge, USA, 2013.

Michael Joachim Bonell ,An International Restatement of Contract Law: The UNIDROIT Principles of Intonational Commercial Contracts, Third Edition, Transnational Publishers, USA, 2005.

Sonja Adrienne Kruisinga, (Non-) conformity in the 1980 UN Convention on Contracts for the International Sale of Goods: Aa Uniform Concept, Intersentia, USA, 2014.

Coronavirus: A Guide to Understanding the Virus and What is Known So Far, issued by The Centers for Disease Control's Website, Start publishing company, USA, e-book, 2020. 


$$
\text { (Y) أبحاث باللغة الإنجليزية منشورة على شبكة الإنترنت(1): }
$$

Alessandro Villani, Francesco Amatori, Covid-19: Impact on commercial contracts, Italy, Issued by linklaters Law Firm ,12 March 2020.

https://www.linklaters.com/en/insights/publications/2020/march/novel-coronaviruscommercial-contracts/novel-coronavirus-impact-on-commercial-contracts/italy

Anton A. Ware, Jeffrey Yang et al, What to Do When You Receive a Coronavirus-Related Force Majeure Notice, , Issued by Arnold \& Porter official website, 4/3/2020.

Bae, Kim \& Lee LLC , COVID-19 and Force Majeure in Sales Transactions: South Korea, Issued by lexology official website.

https://www.lexology.com/library/detail.aspx?g=d07462e8-7b46-4b20-9b59-

9855e3bdaeb5

Caterina Benini, The COVID-19 Crisis and Employment Contracts: the Italian Emergency Legislation on Dismissals, Published in The European Association of Private International Law (EAPIL), 11/5/2020.

https://eapil.org/2020/05/11/the-covid-19-crisis-and-employment-contracts-theitalian-emergency-legislation-on-dismissals/

Christian Ule, The Effects of COVID- 19 on International Contracts, Published in Official Legalmondo website, without date.

https://www.legalmondo.com/coronavirus-international-contract-help-desk/?cv=eg

Claudia Galvis, Jose Moran, et al, Coronavirus Outbreak: Global Guide to Force Majeure and International Commercial Contracts, Issued by global compliance news official website, 19/3/2020.

https://globalcompliancenews.com/coronavirus-outbreak-global-guide-to-forcemajeure-and-international-commercial-contracts/

$$
\begin{aligned}
& \text { (1) وحريٌّ بالذكر أنه قد تبدو كثرة الاستعانة بالمقالات المنشورة على الشبكة العنكبوتية، ولقد انبثقت هذه الكثرة }
\end{aligned}
$$

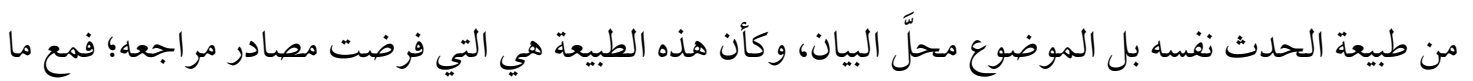

$$
\begin{aligned}
& \text { تطلبته الجائحة من لزوم الامتثال للإجر اءات الصحية الاحترازية -التي في مقدمتها التباعد الاجتماعي وتجنبّ } \\
& \text { التلامس المباشر للأسطح بأنواعها- كان طبيعيًا أن يكون الإنترنت هو البيئة الخصبة الأمثل والملاذ الآمن } \\
& \text { للنشر العلمي، وامتثالًا لضو ابط الأمانة العلمية، ولقد حرصت غاية الحرص على اختيار المقالات من مواقعها } \\
& \text { الرسمية ذات الثقة، وكثير ممَّا أُستعين به من مقالات كان لأساتذة في جامعات عربية وغربية، ووازى ذلك } \\
& \text { الحرص على وضع الروابط الإلكترونية الخاصة بكل مرجع في صيغة أو نظام الارتباط التشعبي hyperlink، } \\
& \text { بحيث يمكن لكلّ من ابتغى الوقوف على المرجع المذكور كاملًا الوصول إليه بضغطة زر واحدة وفي ثوانٍ }
\end{aligned}
$$

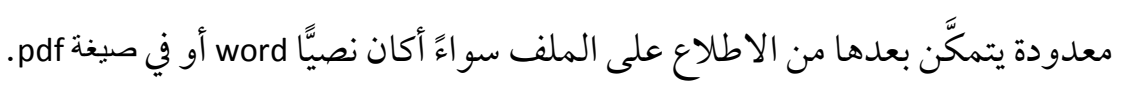


Ekaterina Pannerbakker, Force majeure certificates' issued by the Russian Chamber of Commerce and Industry, Issued by Conflict of Laws. Net official website,17/4/2020. https://conflictoflaws.net/2020/force-majeure-certificates-by-the-russian-chamber-ofcommerce-and-industry/

ICC FORCE MAJEURE CLAUSE (“Clause”), Issued by International Chamber of Commerce, March 2020.

https://iccwbo.org/content/uploads/sites/3/2020/03/icc-forcemajeure-hardshipclauses-march2020.pdf

Kashish Jaitley, Niharika Kuchhal et al, The COVID pandemic: Time to 'ramp-up' India's conflict of law rules in matters of tort?, Issued by Conflict of Laws. Net official website, 14/4/2020.

https://conflictoflaws.net/2020/the-covid-pandemic-time-to-ramp-up-indias-conflict-oflaw-rules-in-matters-of-tort-by-kashish-jaitley-niharika-kuchhal-and-saloni-khanderial

Klaus Peter Berger, Daniel Behn, Force Majeure and Hardship in the Age of Corona: A Historical and Comparative Study, McGill Journal of Dispute Resolution, Forthcoming, published also by SSRN.

Marcel Fontaine, the evaluation of the Rules on Hardship from the First Study on Hardship Clauses to the Enactment of specific Rules, Published in Hardship and Force Majeure in International Commercial Contracts: Dealing with unforeseen events in changing world, Edited by Fabio Bortolotti, Dorothy Ufot, Issued by ICC, 2018.

Matteo M Winkler, Practical Remarks on the Assessment of COVID-19 as Force Majeure in International Contracts, Issued by SIDIBlog Official website, 6/5/2020

http://www.sidiblog.org/2020/05/06/practical-remarks-on-the-assessment-of-covid-19as-force-majeure-in-international-contracts/

Matthew Hendreson, Alam Mendoza, et al ,Coronavirus compensation? Assessing China's Potential Culpability and Avenues of Legal Response, Issued by Henry Jackson Society, April 2020.

https://henryjacksonsociety.org/wp-content/uploads/2020/04/Coronavirus-

Compensation.pdf

Olivier Kuhn, Hassan Ben Hamadi, Covid-19 and contract Renegotiation: Q\&A, issued by CMS Francis Lefebvre Avocats Law firm, 7/4/2020.

https://cms.law/en/fra/news-information/covid-19-and-contract-renegotiation-q-a

Orange Wang, Coronavirus: more than two thirds of China's migrant labourers not yet back at work, issued by south china morning post Newspaper official website, $18 / 2 / 2020$

https://www.scmp.com/economy/chinaeconomy/article/3051175/coronavirus-more-two-thirds-chinas-migrant-labourers-notyet

Philipp Reusch , Laura Kleiner Distribution of risk in connection with coronavirus-related trade disruptions, Issued by reuschlaw Legal Consultants German Law firm, March 2020 https://www.reuschlaw.de/en/news/distribution-of-risk-in-connection-with-coronavirusrelated-trade-disruptions/

Ralf Michaels, Jakob Olbing, Corona and Private International Law: A Regularly Updated Repository of Writings, Cases and Developments, Issued by Conflict of Laws.Net official website, 
https://conflictoflaws.net/2020/corona/?print $=p d f$

Simon Fawell and Abdul Azeem , COVID-19 and Duties of Good Faith Under English law , Issued by lexology official website, 25/6/2020

https://www.lexology.com/library/detail.aspx?g=d82a34b2-b951-46c0-9904-

$67691185 c 9 a b$

Sophia Tang, Coronavirus, force majeure certificate and private international law, Issued by Conflict of Laws. Net official website, 1/3/2020.

https://conflictoflaws.net/2020/coronavirus-force-majeure-certificate-and-privateinternational-law/

Ulrike Glueck, Micheal Munzinger, et al, Does the Coronavirus outbreak constitute Force Majeure, Published by CMS Law Firm, UK, 03/02/2020.

https://cms.law/en/chn/publication/does-the-coronavirus-outbreak-constitute-forcemajeure

Victoria Lee, Mark Lehberg, et al, COVID-19 Contract Issues Reach Beyond Force Majeure, Issued by Law 360 official website, 13 March 2020

https://www.law360.com/articles/1251749/covid-19-contract-issues-reach-beyond-

force-majeure

The coronavirus crisis and the application of the rebus sic stantibus clause in leases for use other than housing, issued by osborne Clarke Law Firm the official website, published on 22 Jun 2020.

https://www.osborneclarke.com/insights/coronavirus-crisis-application-rebus-sic-

stantibus-clause-leases-use-housing/

Under China's lockdown, millions have nowhere to go, issued by Reuters Graphics official website, 14/2/2020.

https://graphics.reuters.com/CHINA-HEALTH-LOCKDOWN/0100B5EF3LJ/index.html

$$
\begin{aligned}
& \text { ثالثأ قائمة المـراجع باللغة الغـرنسية } \\
& \text { أبحاث منشورة على شبكة الإنترنت: }
\end{aligned}
$$

Luc Grynbaum, Force majeure et épidémie de COVID -19: une première décision vient d'être rendue, issued by le club de jurists official website, published on 25/3/2020.

https://www.leclubdesjuristes.com/blog-du-coronavirus/que-dit-le-droit/force-majeureet-epidemie-de-covid-19-les-premieres-decisions-viennent-detre-rendues/

Constance Verroust-Valliot et Serge Pelletier, L'impact du covid-19 sur les contrats de droit privé, Issued by DALLOZ official website, ÉDITION DU 9 JUILLET 2020, Éditions précédentes, published on 09 Juin 2020.

https://www.gide.com/fr/actualites/covid-19-lois-de-police-et-ordonnances-2020.

Face à une pandémie: Assurer la sécurité et la santé au travail, Organisation internationale du Travail, Première edition, 2020.

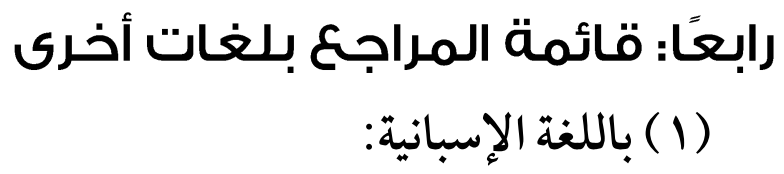

José Antonio Briceño Laborí, El Derecho Internacional Privado ante el COVID-19, issued 
by "Derecho \& Sociedad" es una Asociación, March 2020.

http://www.derysoc.com/especial-nro-3/el-derecho-internacional-privado-ante-elcovid-19/

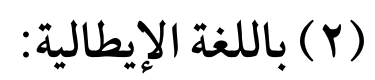

FABRIZIO MARRELLA, LA CINA DEVE RISARCIRE I DANNI TRANSNAZIONALI DA COVID19? ORIZZONTI AD ORIENTE, Issued by SIDIBLOG official website, published on 16/5/2020.

http://www.sidiblog.org/2020/05/17/la-cina-deve-risarcire-i-danni-transnazionali-dacovid-19-orizzonti-ad-oriente/

\section{خامسًا: مواقع إلكترونية متفرقة مفيدة أثرت الدراسة}

$$
\text { - الموقع الرسمي لمنظمة الصحة العالمية }
$$

https://www.who.int/home

$$
\text { - التحديثات الرسمية لمنظمة الصحة العالمية في خصوص فيروس كورونا }
$$

https://covid19.who.int/

$$
\text { - الموقع الرسمي لمحكمة النقض المصرية }
$$

https://www.cc.gov.eg/judgment_single?id=111273720\&ja=72131

- الموقع الرسمي لتنازع القوانين نت: وهو موقع يختص بنشر الأخبار والمقالات

$$
\text { المتعلقة بالقانون الدولي الخاص }
$$

https://conflictoflaws.net

$$
\text { - الموقع الرسمي للجمعية المصرية للقانون الدولي الخاص }
$$

https://eapil.org/

$$
\text { - الموقع الرسمي للمجلس الصيني لتعزيز التجارة الدولية }
$$

http://en.ccpit.org/

$$
\text { - غرفة الصناعة و التجارة الروسية }
$$

https://tpprf.ru/en/

$$
\text { - و كالة أبناء Tass الروسية }
$$

https://tass.ru/

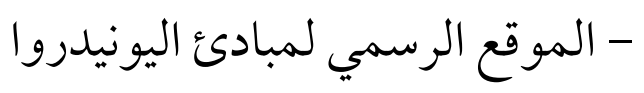

https://www.unidroit.org/ 


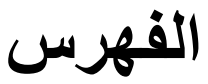

$r \cdots r$

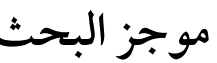

$r \cdots r$. تصدير

$r \cdots v$. المقدمة

مبحث تمهيدي : إشكاليات أوليَّة تتصل بعقود التجارة الدولية في زمن الكورونا ..... 10 المطلب الأول : علاقة جائحة كورونا بالمبادئ القانونية المستقرة في عقود التجارة الدولية $r \cdot 10$

الفرع الأول : أثث جائحة كورونا على مبدأ القوة الملزمة للعقد........................

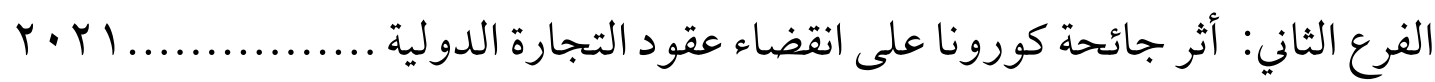
المطلب الثاني : المفردات الموضوعية والزمنية لعقود التجارة الدولية في زمن الكورونا $r \cdot Y \wedge$.

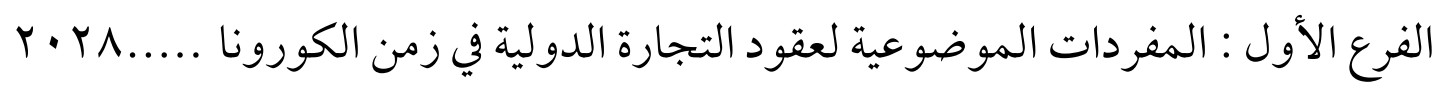
الفرع الثاني : المفردات الزمنية لعقود التجارة الدولية في زمن الكورونا ....................

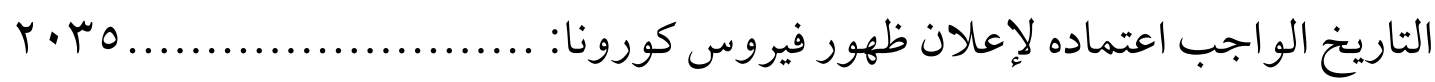

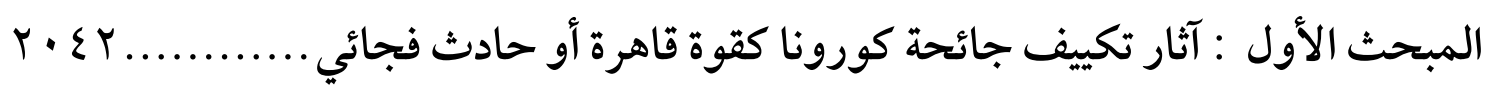
المطلب الأول : جائحة كورونا في سياق القوة القاهرة .......................................

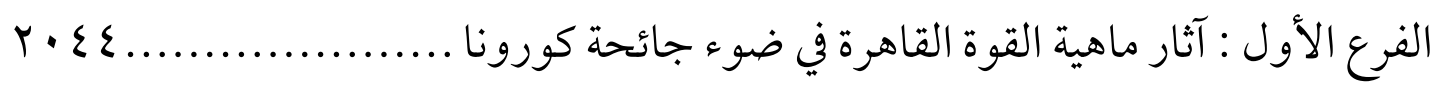
الفرع الثاني : مدى انطباق الشروط التقليدية للقوة القاهرة على جائحة كورونا وآثار

$r \cdot 01$ انطباقها

الغصن الأول : الشروط التقليدية للقوة القاهرة في ضوء جائحة كورونا............

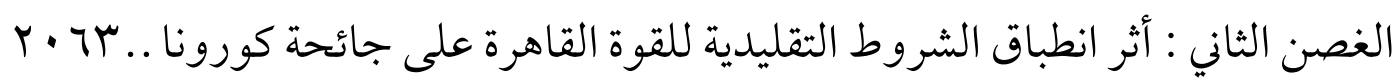

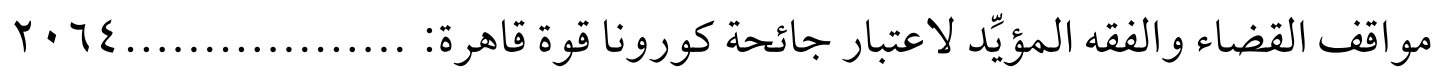
الفرع الثالث : القانون الواجب التطبيق على العقود الدولية في خضم جائحة كورونا 
Y. 70 كقوة قاهرة الغصن الأول : وجود نص عقدي يفيد اتفاق الأطراف على اعتبار الأوبئة أحد أسباب $r .77$. القوة القاهرة الغصن الثاني : عدم وجود نصٍٍ عقدي يفيد اتفاق الأطراف على اعتبار الأوبئة أحد $r \cdot 79$. أسباب القوة القاهرة الغصن الثالث : القانون المحلَّد لمدى اعتبار الحادث قوة قاهرة من عدمه ونطاق تطبيقه

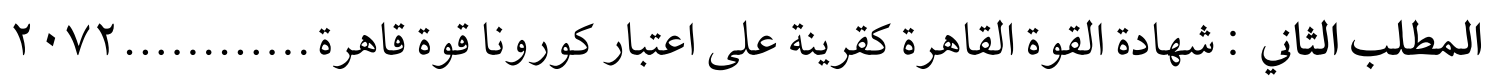

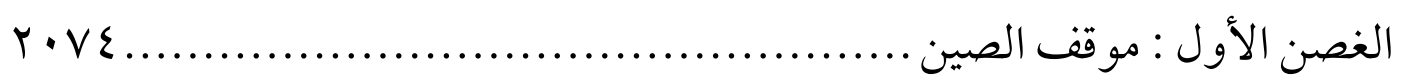

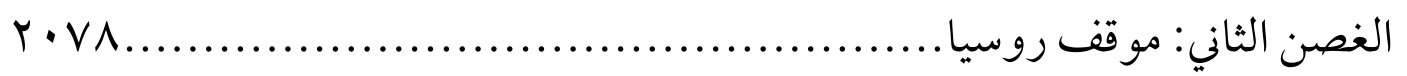
الفرع الثالث : الخطو ات التي يجبب اتخاذها عند استلام إشعار بالقوة القاهرة ....10 • ب

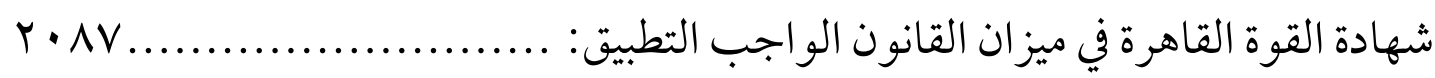
الغصن الرابع: مدى إمكانية الربط بين القوة القاهرة واتفاقية الأمم المتحدة بشأن $r \cdot \Lambda \Lambda$ عقود البيع الدولي للبضائع المطلب الثالث : موقف القضاء والقوانين المقارنة من اعتبار جائحة كورونا قوة قاهرة 4.91

الفرع الأول : موقف القضاء المقارن من اعتبار جائحة كورونا قوة قاهرة ............ .

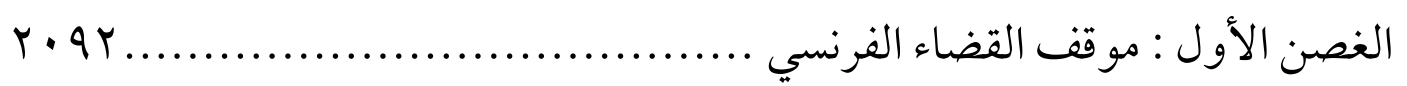

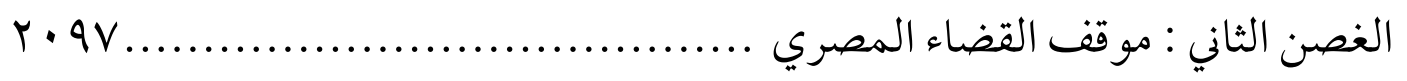

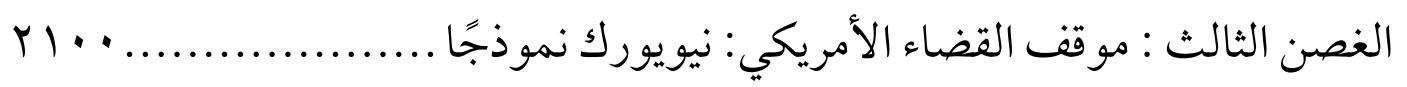

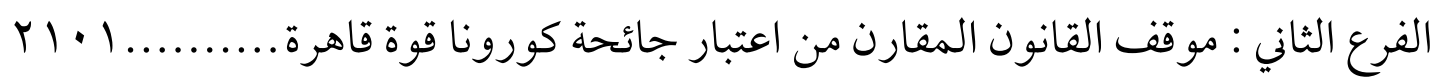
الغصن الأول : موقف قانون العقود الإنجليزي ...................................... • $r \mid \varepsilon$ الغصن الثاني : موقف قانون العقود الصيني . 


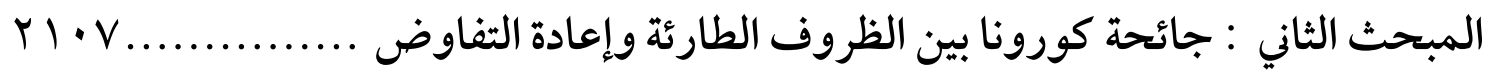

المطلب الأول : آثار تكييف جائحة كورونا كظرف طارئ .....................................

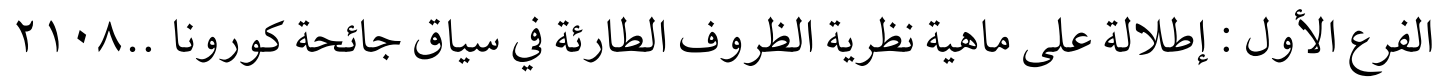
الفرع الثاني : مضمون إنزال شروط نظرية الظروف الطارئة على عقود التجارة الدولية

المتأثرة بجائحة كورونا .................................................................. الفرع الثالث : آثار دور القوانين واجبة التطبيق في ظلّ تكييف جائحة كورونا كظرف طارئ .

الفرع الرابع : الرأي المقترح في اعتبار جائحة كورونا قوةً قاهرةً أم ظرفًا طارئًا ..... بrاي المطلب الثاني : شرط إعادة التفاوض في سياق جائحة كورونا............................

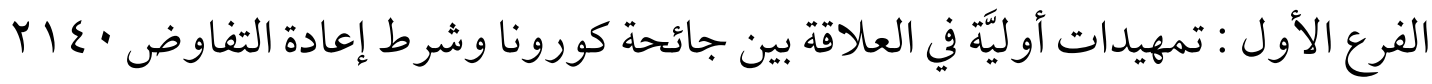
الغصن الأول : التعريف بشرط إعادة التفاوض في عقود التجارة الدولية على خلفيَّة

r) $\varepsilon$ جائحة كورونا الفرع الثاني : شروط إعادة التفاوض و آثاره ومعايير اختلال توازن عقود التجارة الدولية r 107 في ضوء جائحة كورونا . المان. الغصن الأول : شروط إعمال إعادة التفاوض في عقود التجارة الدولية في ضوء جائحة r 107

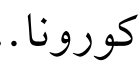
الغصن الثاني : معايير تقدير اختلال التوازن العقدي وفروضه بالنظر لجائحة كورونا

r) $7 \varepsilon$

rIVT

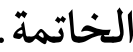

$r \mid \wedge r$ قائمة المراجع ..

r) 94

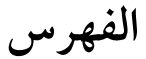

